
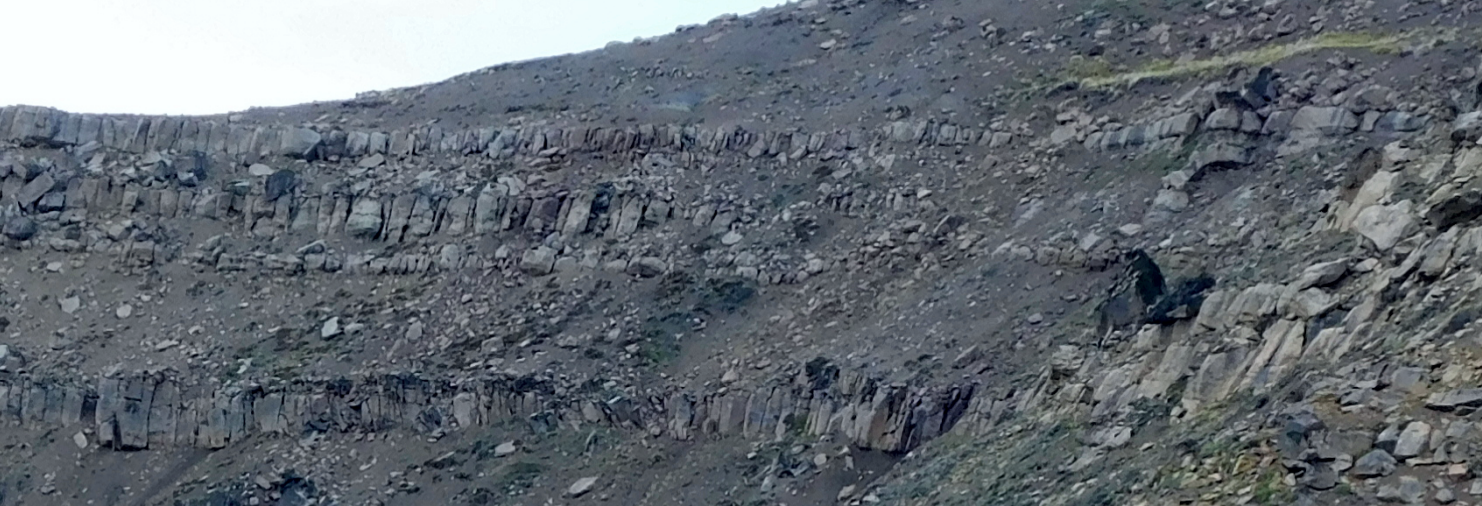

SEDIMENTOLOGIA DE LA FORMACIÓN LA ANITA, RS? CRETACICO SUPERIOR DE LA CUENCA AUSTRAL, ,, 3, PROVINCIA DE SANTA CRUZ, ARGENTINA

Licenciado Damián Moyano Paz 2 . Director: Dr. Augusto N. Varela \%.

Tesis Doctoral

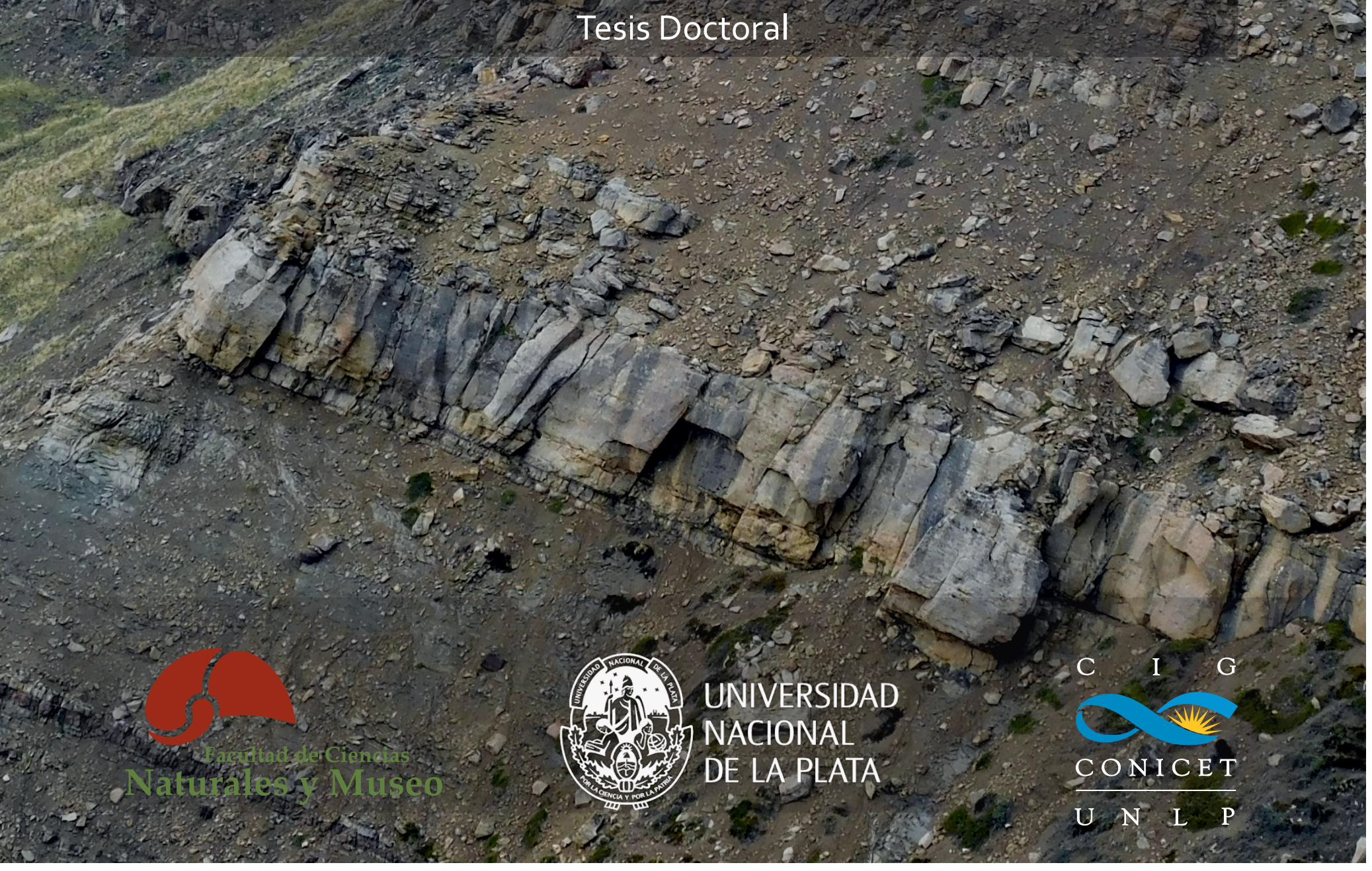




\section{SEDIMENTOLOGÍA DE LA FORMACIÓN LA ANITA, CRETÁCICO SUPERIOR DE LA CUENCA AUSTRAL, PROVINCIA DE SANTA CRUZ, ARGENTINA}

Tesis Doctoral 2020

Licenciado Damián Moyano Paz Director: Dr. Augusto N. Varela

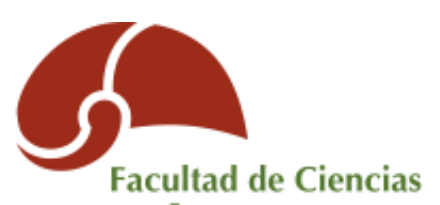

Naturales y Museo

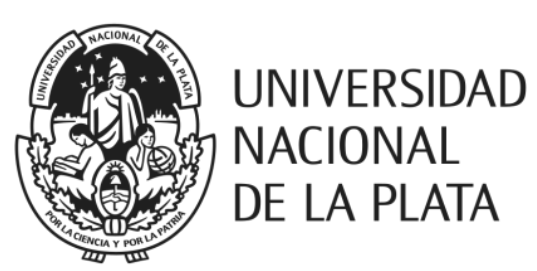

C $\quad$ I $\quad$ G

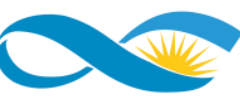

C O N I C E T

U $\quad \mathrm{N} \quad \mathrm{L} \quad \mathrm{P}$ 
A mis familiares, a mis amigos y amigas, quienes siempre estuvieron y siempre van a estar.

Por y para la educación pública, por un sistema científico inclusivo y a disposición de todos y de todas. 


\section{ÍNDICE DE CONTENIDOS}

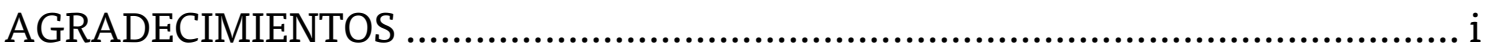

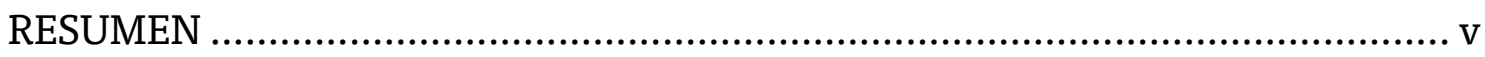

ABSTRACT

CAPÍTULO I - INTRODUCCIÓN: ¿POR QUÉ ESTUDIAR LOS DEPÓSITOS DE LA

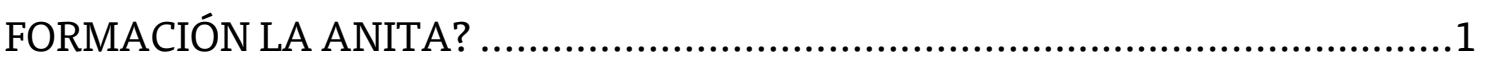

CAPTULO II - MARCO GEOLÓGICO Y ANTECEDENTES DE LA FORMACIÓN LA

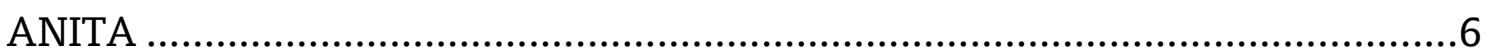

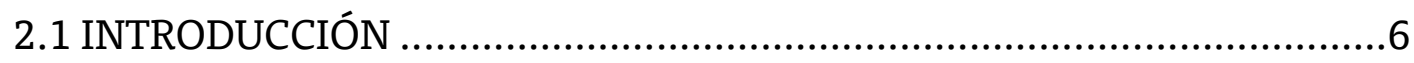

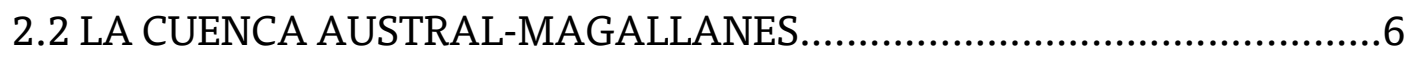

2.2.2 Etapas tectónicas y relleno de la cuenca ...........................................

2.2.3 Ciclos Sedimentarios de la Cuenca Austral-Magallanes .................14

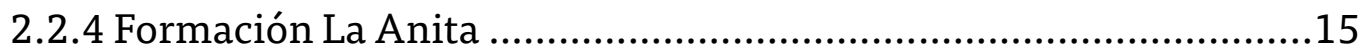

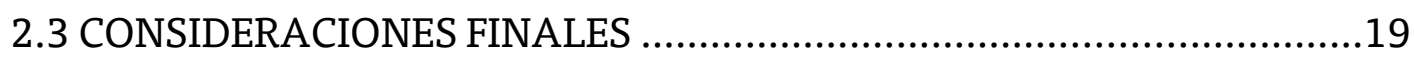

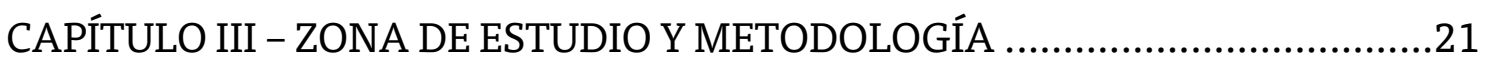

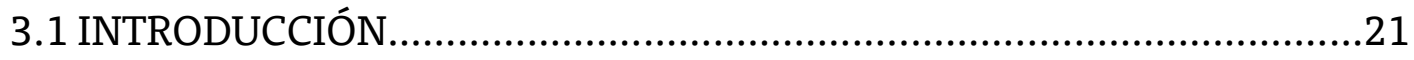

3.2 REGIÓN DEL LAGO ARGENTINO.......................................................21

3.2.1 Afloramientos de la Formación La Anita.......................................25

3.2.1.1 Norte del Lago Argentino........................................................25

3.2.1.2 Sur del Lago Argentino...........................................................26

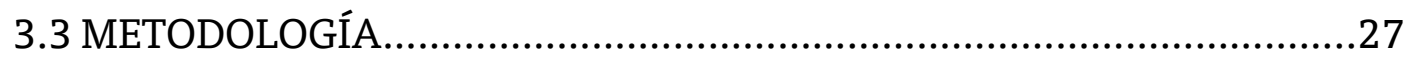

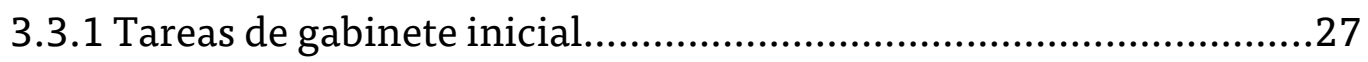

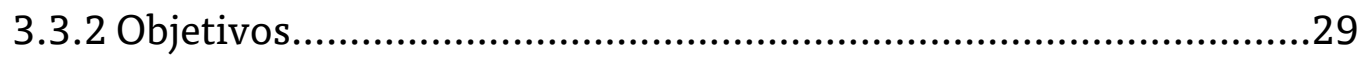

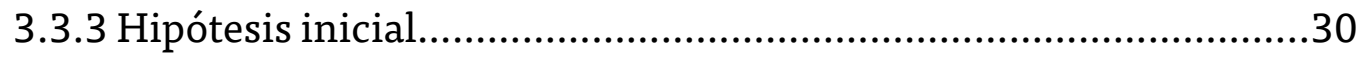

3.3.4 Tareas de campo............................................................................

3.3.4.1 Relevamiento de perfiles sedimentológicos ..............................32 
3.3.4.2 Caracterización bidimensional de litosomas

3.3.4.3 Muestreo litológico..................................................33

3.3.5 Tareas de laboratorio.........................................................33

3.3.5.1 Difracción de Rayos X (DRX) ...........................................33

3.3.5.2 Análisis petrográfico.....................................................37

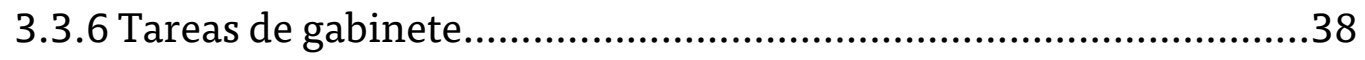

3.3.6.1 Confección de secciones columnares...................................38

3.3.6.2 Análisis de facies y de asociaciones de facies sedimentarias....40

3.3.6.3 Análisis de paleocorrientes.............................................41

3.3.6.4 Análisis arquitectural de cuerpos sedimentarios...................41

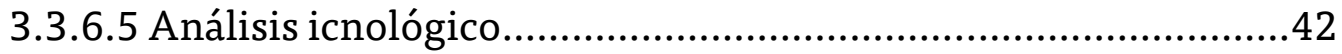

3.3.7 Análisis intelectual de la información...................................42

3.4 CONSIDERACIONES FINALES....................................................44

CAPÍTULO IV- ANÁLISIS DE FACIES SEDIMENTARIAS..............................45

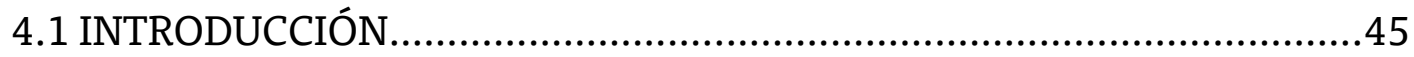

4.1.1 ¿Qué es una facies sedimentaria?..........................................45

4.1.2 ¿Por qué realizar un análisis de facies sedimentarias?............... 45

4.1.3 ¿Cómo se realizó el análisis de facies sedimentarias para el caso de

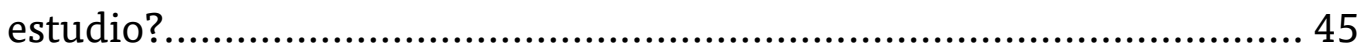

4.2 FACIES SILICOCLASTICAS.........................................................46

4.2.1 Conglomerados......................................................... 46

4.2.1.1 Conglomerados masivos $(\mathrm{Gm})$......................................46

4.2.1.2 Conglomerados con estratificación entrecruzada en artesa

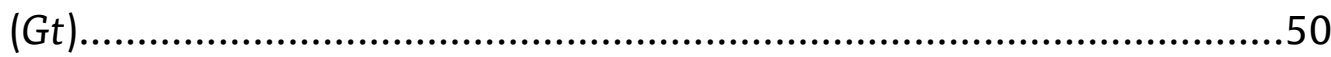

4.2.2 Areniscas conglomerádicas ..............................................50

4.2.2.1 Areniscas conglomerádicas con estratificación entrecruzada en $\operatorname{artesa}(S G t)$....................................................................50 
4.2.3.1 Areniscas con estratificación entrecruzada en artesa (St) ........51

4.2.3.2 Areniscas con estratificación entrecruzada planar ( $S p)$........... 52

4.2.3.3 Areniscas con estratificación entrecruzada monticular (Shcs). .53

4.2.3.4 Areniscas con laminación entrecruzada $(\mathrm{Srl})$........................56

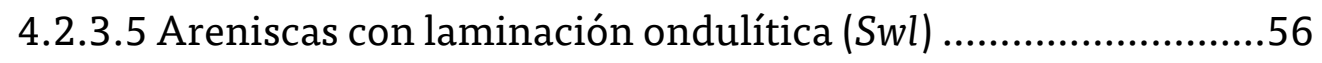

4.2.3.6 Areniscas con laminación horizontal $(S l)$...........................58

4.2.3.7 Areniscas masivas $(\mathrm{Sm})$..................................................60

4.2.3.8 Areniscas masivas bioturbadas $(S m b)$...............................59

4.2.3.9 Areniscas con deformación sinsedimentaria $(S d)$.................60

4.2.4 Depósitos heterolíticos........................................................60

4.2.4.1 Depósitos heterolíticos bioturbados $(\mathrm{Hb})$...........................60

4.2.4.2 Depósitos heterolíticos ondulosos $(\mathrm{Hw})$..............................61

4.2.4.3 Depósitos heterolíticos con laminación flaser $(\mathrm{Hf})$.................61

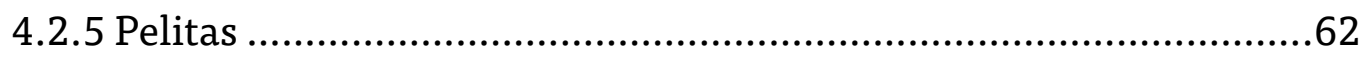

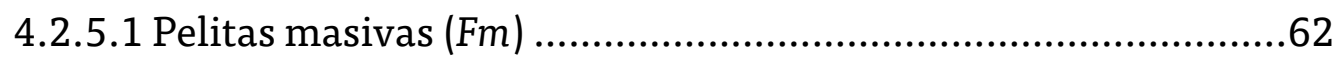

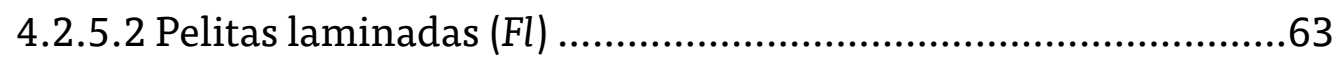

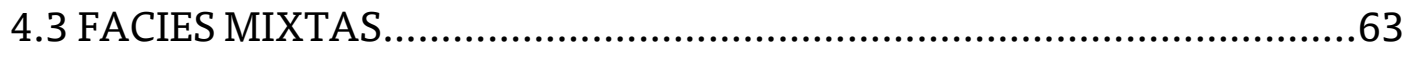

4.3.1 Areniscas bioclásticas .....................................................63

4.3.1.1 Areniscas bioclásticas con estratificación entrecruzada planartangencial (SBtp) ..............................................................63

4.4 CONSIDERACIONES FINALES ...................................................64

CAPÍTULO V - ANÁLISIS DE ASOCIACIONES DE FACIES, PROCESOS DEPOSITACIONALES Y SISTEMAS DE ACUMULACIÓN......................................66

5.1 INTRODUCCIÓN......................................................................66

5.1 .1 ¿Qué es una asociación de facies? ....................................66 
5.1.2 ¿Por qué realizar un análisis de asociaciones de facies?

5.1.3 ¿Cómo se realizó el análisis de asociaciones de facies para el caso de estudio?

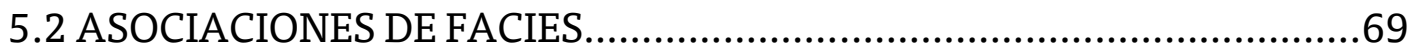

5.2.1 Asociación de Facies 1 (AF1) .................................................69

5.2.2 Asociación de Facies 2 (AF2) ...............................................71

5.2.3 Asociación de Facies 3 (AF3) ................................................74

5.2.4 Asociación de Facies 4 (AF4) ...............................................77

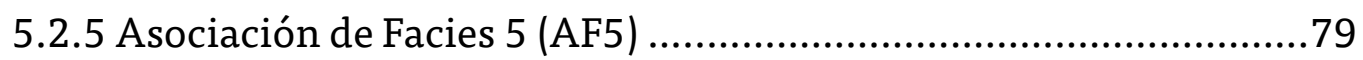

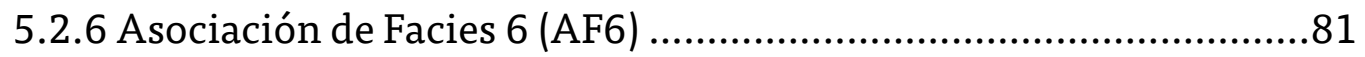

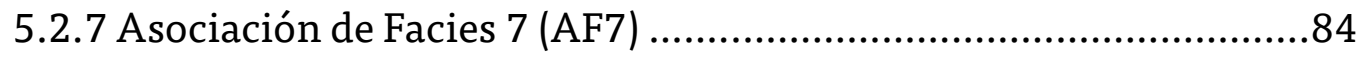

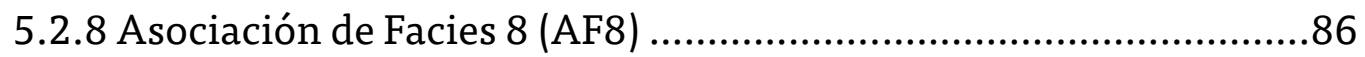

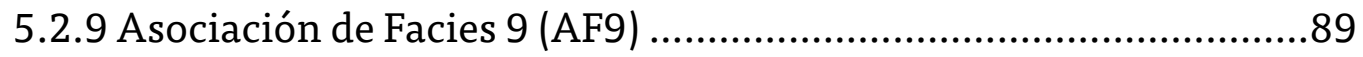

5.3 DISTRIBUCIÓN DE LAS ASOCIACIONES DE FACIES .........................91

5.4 PROCESOS DEPOSITACIONALES Y SISTEMAS DE ACUMULACIÓN.....92

5.4.1 Unidad inferior de la Formación La Anita .................................94

5.4.2 Unidad superior de la Formación La Anita...............................99

5.5 CONSIDERACIONES FINALES ....................................................104

CAPÍTULO VI - ANÁLISIS ICNOLÓGICO Y DE ESTRÉS AMBIENTAL .............106

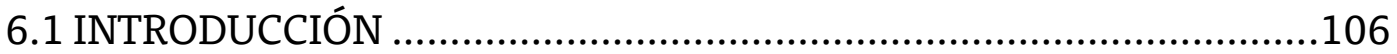

6.1 .1 ¿Qué es la icnología? ................................................106

6.1.2 ¿Por qué realizar un análisis icnológico en estos depósitos?........106

6.1.3 ¿Cómo se realizó el análisis icnológico para el caso de estudio? ..107

6.2 ICNOLOGÍA DE LA FORMACIÓN LA ANITA .107

6.2.1 Icnología de la Asociación de Facies 1 (AF1): Prodelta dominado por olas 
6.2.2 Icnología de la Asociación de Facies 2 (AF2): Frente deltaico distal dominado por olas

6.2.3 Icnología de la Asociación de Facies 3 (AF3): Barras de desembocadura influenciadas por olas

6.2.4 Icnología de la Asociación de Facies 4 (AF4): Canales distributarios terminales

6.2.5 Icnología de la Asociación de Facies 5 (AF5): Canales distributarios.

6.2.6 Icnología de la Asociación de Facies 6 (AF6): Frente deltaico distal fluvio-dominado

6.2.7 Icnología de la Asociación de Facies 7 (AF7): Barras de desembocadura fluvio-dominadas

6.2.8 Icnología de la Asociación de Facies 8 (AF8): Canales distributarios multiepisódicos

6.2.9 Icnología de la Asociación de Facies 9 (AF9): Áreas interdistributarias saturadas en agua 124

6.3 VARIACIONES VERTICALES EN LA INTENSIDAD Y DIVERSIDAD DE LA BIOTURBACIÓN

6.4 CARACTERÍSTICAS ICNOLÓGICAS COMO RESPUESTAS A CONDICIONES DE DOMINIOS DE PROCESOS DE OLEAJE Y FLUVIALES EN SISTEMAS DELTAICOS

6.4.1 Delta dominado por olas, influenciado por procesos fluviales ....133

6.4.2 Delta fluvio-dominado, influenciado por corrientes de marea ....137

6.5 CONSIDERACIONES FINALES …................................................. 140

CAPÍTULO VII - ANÁLISIS COMPOSICIONAL Y DIAGENÉTICO ...................143

7.1 INTRODUCCIÓN

7.1.1 ¿Qué son los análisis composicionales y diagenéticos de sucesiones sedimentarias? 
7.1.3 ¿Cómo se realizó el análisis composicional para el caso de estudio?

7.2 COMPOSICIÓN DE LA FORMACIÓN LA ANITA ..................................145

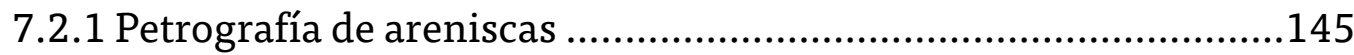

7.2.1.1 Componentes detríticos ........................................................145

7.2.1.2 Areniscas de la Formación La Anita.........................................150

7.2.2 Difracción de rayos X (DRX) ....................................................151

7.3 VARIACIONES COMPOSICIONALES EN LA FORMACIÓN LA

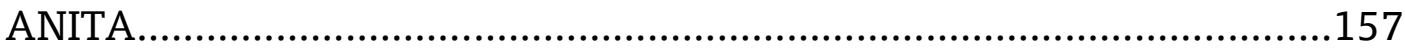

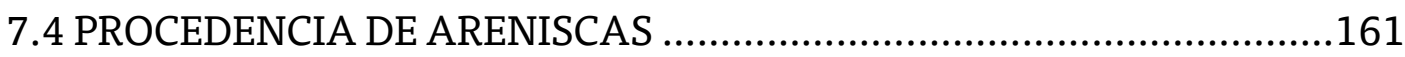

7.5 DIAGÉNESIS DE LA FORMACIÓN LA ANITA ……………………......167

7.5.1 Procesos y productos diagenéticos …………………………......167

7.5.2 Historia diagenética ....................................................................173

7.6 CONSIDERACIONES FINALES …………………...............................

CAPÍTULO VIII - DISCUSIONES: ESQUEMA ESTRATIGRÁFICO SECUENCIAL, FACTORES DE CONTROL E IMPLICANCIAS PALEOGEOGRÁFICA .................180

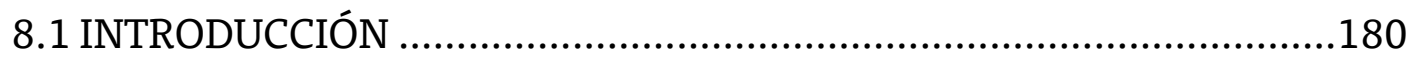

8.1.1 ¿Qué es la estratigrafía secuencial?...........................................180

8.1.2 ¿A qué nos referimos con secuencias, cortejos depositacionales y superficies estratigráficas clave? .....................................................180

8.1.3 ¿Cuáles son los principales factores que actúan sobre la sedimenta-

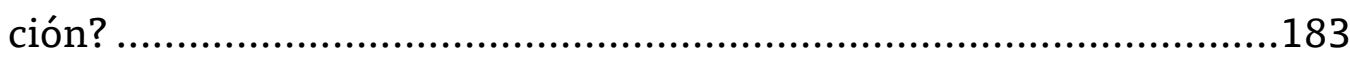

8.1.4 Consideraciones para el caso de la Formación La Anita ...............184

8.2 ESQUEMA ESTRATIGRÁFICO-SECUENCIAL DE LA FORMACIÓN LA

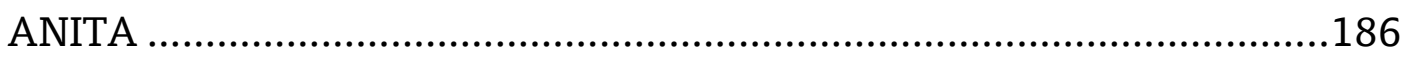

8.2.1 Patrones de apilamiento y tendencias depositacionales ...............186

8.2.2 Superficies estratigráficas clave y cortejos depositacionales de la Formación La Anita ......................................................................... 188 
8.2.3 Discusión sobre la evolución temporal de las secuencias y superficies estratigráficas de la Formación La Anita 193

8.3 FACTORES DE CONTROL ALOCÍCLICLOS EN ELDESARROLLO DE LA FORMACIÓN LA ANITA 196

8.3.1 Incidencia de los factores de control en el desarrollo del límite de secuencia y en la evolución de la Formación La Anita. 196

8.4 EVOLUCIÓN PALEOGEOGRÁFICA 204

CAPÍTULO IX - CONCLUSIONES 208

REFERENCIAS BIBLIOGRÁFICAS. 216

ANEXOS .246 


\section{AGRADECIMIENTOS}

Son difíciles de describir todas las sensaciones, emociones y sentimientos que se viven durante los procesos doctorales. En mi caso personal, creo haber disfrutado al máximo el intenso y extenso camino del doctorado y, ya muy cerca de finalizarlo, considero que he adquirido herramientas y valores que me han formado no solo como profesional sino también como persona. Si bien el objetivo final de doctorarse es de un carácter muy individual, durante todo el proceso me he rodeado de un montón de personas que hicieron que este camino sea más fácil, demostrándome su confianza, apoyo y compañía, y por ello no quiero dejar de nombrarlas y agradecerles.

Gracias a la Universidad Pública, Gratuita y de Calidad. Agradezco a quienes luchan a diario por una educación cada día más inclusiva y al servicio del pueblo. Particularmente gracias a la Facultad de Ciencias Naturales y Museo de la Universidad Nacional de La Plata, la casa de estudios donde me formé y me continúo formando en múltiples aspectos.

A mi familia más cercana. En primer lugar, gracias a mi mamá y a mi papá (Yul) por el apoyo incondicional y la confianza que me brindan a diario en todos mis proyectos. A Barbara, Ceci, Sol, Valentina, Santino, Emmita y Nacho por acompañarme y acompañarme siempre. Esto es por y para ustedes.

A Mari, por habernos encontrado, por acompañarme y apoyarme tanto en este último tramo tan duro de la tesis. Gracias por estar siempre, por sacarme una sonrisa aún en los días más bajos y, por sobre todas las cosas, igracias por tanto amor! 
A Cami, quien vivió gran parte de este proceso muy de cerca dándome siempre todo su apoyo y que, si se pudiera, debería ser coautora de este trabajo de tesis. ¡Gracias por toda la compañía y por los momentos vividos!

A Augusto Varela (Toti), por todo el apoyo y compromiso para con mi formación profesional. Por enseñarme a trabajar de una manera responsable y crítica. Gracias por hacerme sentir un par tuyo, por nunca dejar de lado el factor humano y, por sobre todas las cosas, gracias por tu amistad.

A Daniel Poiré (Flaco), por abrirme las puertas del Centro de Investigaciones Geológicas y por introducirme este desafiante proyecto de tesis. Gracias por toda la confianza, las libertades para decidir y por insistirme siempre en que lo más importante es transitar las cosas con felicidad.

A los jurados de esta tesis, los doctores Gonzalo D. Veiga, José I. Cuitiño y Luis Buatois por el tiempo dedicado a la lectura y revisión crítica del manuscrito. Gracias por todos los comentarios y sugerencias los cuales han enriquecido considerablemente este trabajo.

A mi grupo de amigos/as y compañeros/as del Centro de Investigaciones Geológicas que me acompañaron durante todo este proceso e hicieron entre abrazos, charlas y mates el día a día más fácil. Fundamentalmente gracias a Mari, Jero, Manu I., Cepi, Nanu, Mica, Joaco, Marian y Rodri de la banda del "Viejo Hotel Ostende". A Manu I., Ale, David y al Tonga por todo el aguante y las charlas en la oficina, ¡cómo se los extrañó durante la cuarentena!

A Mercedes Mancino, Rita Irazabal, Rocío Wlasiuk, Andrea García, Nelly, Mabel, Pablo García, Daniel Martire, Luis Vigiani (Pocho) y Germán Kurten, también del Centro de Investigaciones Geológicas, por estar siempre a disposición dando una mano. 
Adrián Prieto, Raúl Cherbukov, Agustina Figueroa y Maximiliano Oses (Pitu) de El Calafate, quienes siempre me han brindado la más cálida hospitalidad y a quienes aprendí a querer muchísimo. Me llevo el mejor de los recuerdos de ustedes, pero lo que más valoro es su amistad.

A Dafne Fraser y Facundo Echeverría de Estancia Anita, a mi querido Firmo Vigil y familia de Estancia Irene por recibirnos siempre con las puertas abiertas. Gracias por la hospitalidad e interés en este trabajo, considero que sin ustedes el trabajo de campo hubiese sido mucho más complicado.

Nuevamente gracias a Cami, que se las bancó todas, a David Tineo (Primo), Andrea Odino (Odi) y Abril Cereceda (Pipi) por todo el aguante y discusiones durante los trabajos de campo. Les agradezco eternamente toda su ayuda y porque con compañía los viajes y el paisaje se disfrutaron mucho más, ¡se llegó a disfrutar hasta del viento!

A Alejandro Gómez Dacal (Alejo) por toda la ayuda con el análisis composicional y diagenético y Gastón Alvarez (Tonga) por facilitarme el microscopio que, durante el ASPO, me permitió completar los estudios composicionales. ¡Gracias por el aguante!

A Sebastián Richiano, quien siempre se brindó al máximo con este proyecto. ¡Gracias por la ayuda con el análisis icnológico, por tu simpleza y por ser como sos!

A Lucía Gómez Peral, Sol Raigemborn, Leandro D’Elia (Negro), Ernesto Schwarz y Gonzalo Veiga, investigadoras e investigadores del CIG por el apoyo, la confianza y por siempre hacerme sentir que las puertas estaban abiertas cuando me surgía alguna duda. 
A mis compañeros y compañeras de las cátedras de Sedimentología y Rocas Sedimentarias por los momentos compartidos en el aula y por ayudarme a crecer como docente. ¡Que ganas de dejar el Zoom y volver a las aulas!

A mis hermanos de la vida Jeronimo Zuazo (Zuazi/Pipi), Nicolás Bozzani (Nichi), Eugenio Mallaviabarrena (Molle), Franco Pellegrini, Juan Pablo De León (Jotita) y Federico Trejo $\left(\mathrm{Pe}^{\prime}\right)$, igracias por hacerme sentir que la distancia no es un impedimento para sentir el cariño de la amistad!

A mis amigos de la facultad Salvador Lamarchina (Salvi), Tobías Muñoz (Tobi), Juan I. Redigonda (Redi), Antonio Lliteras (Ato), Bruno Musolino (Musito) y Gonzalo Fernandez (Gon) por todos los momentos y por entender muy de cerca lo que significó todo este proyecto para mí.

A Néstor Kirchner y a Cristina Fernández de Kirchner por hacer que los y las jóvenes vuelvan a creer en la política como una herramienta de transformación social y por creer que la Educación, la Ciencia y la Tecnología deben formar parte de las políticas de Estado de un país.

A todas las personas mencionadas y a aquellas me esté olvidando de mencionar, pero que crea haberme durante todo este proceso gracias de corazón por creer en mí, y vamos por más (Gallardo, 2015, 2018). 


\section{RESUMEN}

Los sistemas depositacionales costeros del Cretácico de la Cuenca AustralMagallanes son unos de los principales targets para la exploración y explotación de hidrocarburos en reservorios convencionales. A pesar del interés económico existente, el grado de conocimiento en cuanto a las características de estos depósitos y de la dinámica de estos sistemas depositacionales es relativamente escaso en comparación con los sistemas marinos profundos y continentales.

La Cuenca Austral-Magallanes, desde hace aproximadamente $100 \mathrm{Ma}$, corresponde a un sistema de antepaís de retroarco que presenta una elongación norte-sur y se encuentra asociada a la orogénesis de los Andes Patagónicos del Cretácico Temprano-Neogeno. El relleno sedimentario de la Cuenca AustralMagallanes, en la etapa compresiva, se caracteriza por evolucionar desde un estadio de sub-relleno a uno de sobre-relleno. El registro presenta un potente desarrollo de depósitos marinos profundos asociado a sistemas turbidíticos y de talud los cuales han sido el principal foco de estudio en los últimos años. En la región del Lago Argentino, al sudoeste de la provincia de Santa Cruz, esta fase de relleno marino finaliza con la acumulación de una cuña silicoclástica costera progradante pobremente estudiada y que se conoce como Formación La Anita, la cual luego es cubierta por los depósitos continentales del Cretácico Superior.

En este trabajo de tesis se llevó adelante el análisis sedimentológico de detalle de los depósitos conocidos como Formación La Anita los cuales presentan excelentes exposiciones tanto al norte como al sur del Lago Argentino, en los alrededores de la localidad de El Calafate, sudoeste de la provincia de Santa Cruz, Argentina. Con el fin de realizar una completa caracterización de estos depósitos se relevaron 15 perfiles sedimentológicos de 
detalle (escala 1:100) en los que se identificaron los principales tipos litológicos que constituyen a la unidad, las estructuras sedimentarias mecánicas y biogénicas, la geometría de los cuerpos, así como también la jerarquía y naturaleza de las superficies estratigráficas, y tipo de contactos con las unidades infra y suprayacentes. A su vez, se realizó un muestreo con el fin de realizar estudios composicionales y diagenéticos, tanto por petrografía como por difracción de rayos $\mathrm{X}$.

El análisis sedimentológico permitió reconocer un total de 18 facies sedimentarias a partir de las cuales se interpretaron procesos depositacionales. Las facies sedimentarias se agruparon en 9 asociaciones de facies según su distribución lateral y vertical dentro de litosomas con geometrías y características distintivas las cuales reflejan la acumulación en diferentes subambientes sedimentarios. De este modo se definieron asociaciones de: Prodelta dominado por olas (AF1), Frente deltaico distal dominado por olas (AF2), Barras de desembocadura influenciadas por olas (AF3), Canales distributarios terminales (AF4), Canales distributarios (AF5), Frente deltaico distal fluvio-dominad (AF6), Barras de desembocadura fluvio-dominadas (AF7), Canales distributarios multiepisódicos de alta sinuosidad (AF8), y Áreas interdistributarias saturadas en agua (AF9). Estas asociaciones de facies reflejan la influencia mixta de procesos marinos (de oleaje y de mareas) y fluviales actuando activamente durante la depositación de la unidad.

A partir de la distribución espacial de las asociaciones de facies se propone dividir a la Formación La Anita en dos unidades informales. Estas dos unidades se encuentran separadas por una superficie de erosión regional interpretada como un límite de secuencia, y a su vez, esta división también coincide con el cambio en la dominancia relativa de los procesos depositacionales de oleaje y 
fluviales. Se interpretaron 3 sistemas depositacionales responsables de la acumulación de los depósitos de la Formación La Anita. La unidad inferior refleja la acumulación en un sistema deltaico dominado por olas e influenciado por procesos fluviales. Para la unidad superior se interpretaron 2 sistemas de acumulación: el relleno fluvial de un valle inciso en el intervalo más basal de esta unidad, y por encima de este un sistema deltaico fluvio-dominado, influenciado por corrientes de marea.

En análisis detallado del contenido icnológico presente en la Formación La Anita permitió detectar variaciones verticales en cuanto a la diversidad y abundancia de las bioturbaciones sino también realizar la propuesta de un modelo de distribución de condiciones de estrés fisicoquímico en los diferentes sectores de los dos sistemas deltaicos interpretados. Los factores estresantes que operaron en los distintos subambientes y que impactaron sobre la actividad de la fauna bentónica fueron: reducción periódica de la oxigenación, elevada turbidez del agua, recurrencia de eventos de tormenta, flujos rápidos de sedimentos, cambios de salinidad, sedimentación episódica y avulsión de canales.

El estudio petrográfico de las areniscas de la Formación La Anita permitió caracterizarlas en su totalidad como arenitas líticas. No se registran variaciones composicionales verticales significativas en la unidad a partir de los estudios petrográficos y de difracción de rayos X. Sin embargo, en el estudio de la fracción arcilla se observó un aumento en las proporciones de argilominerales del grupo de la esmectita en detrimento de la caolinita en la sección superior con respecto a la unidad inferior. A partir de los análisis de las modas detríticas en combinación con las direcciones de paleoflujo medidas en las estructuras sedimentarias mecánicas se concluyó que las areniscas de la Formación La 
Anita provienen de elevaciones asociadas al Complejo El Quemado y del arco volcánico asociado al Batolito Patagónico. Por su parte, el análisis diagenético realizado en las areniscas de la formación permitió reconocer 9 procesos diagenéticos: compactación física y química, disolución, autigénesis de arcillas, cementación hematítica, revestimiento o coating de arcillas, cementación calcítica, migración de bitumen y piritización. Se concluyo que estos depósitos alcanzaron una etapa de mesodiagénesis temprana durante su soterramiento.

El estudio de los patrones de apilamiento vertical de las diferentes asociaciones de facies y de la identificación de superficies estratigráficas clave permitió la generación de un esquema estratigráfico secuencial para estos depósitos donde se plantea que las dos unidades de la Formación La Anita forman parte de dos secuencias depositacionales sin vinculación genética. Ambas unidades se encuentran limitadas por un límite de secuencia asociado a una superficie erosiva regional que fue impulsada por una rápida caída relativa del nivel del mar. Se interpreta que la unidad inferior de la Formación La Anita como parte de un Cortejo de Mar Alto el cual podría incluir a parte de los depósitos marinos profundos de la Formación Alta Vista. Por su parte, la unidad superior presenta un arreglo más complejo y forma parte de un ciclo relativo del nivel del mar completo. No se reconocen en esta unidad depósitos del Cortejo de Mar Bajo, ya que se interpreta que durante esta etapa en la zona costera hubo un dominio de procesos de erosión y de "by-pass" de sedimentos hacia el centro de la cuenca. Por lo tanto, para los depósitos que constituyen a la unidad superior se interpreta el registro de un Cortejo Transgresivo, para el intervalo caracterizado por el relleno fluvial del valle inciso, el cual está delimitado al tope por una superficie de máxima inundación por encima de la cual se encuentran 
los depósitos del Cortejo de Mar Alto representados por el sistema deltaico fluvio-dominado.

Los cambios en el tipo de sistemas de acumulación, de las dominancias relativas de los procesos depositacionales y de la arquitectura secuencial, son el resultado de variaciones en la relación de la tasa de creación de espacio de acomodación y la tasa de aporte de sedimentos. De este análisis integral se desprenden que estos cambios son la consecuencia de la combinación de controles alocícliclos tectónicos principalmente, y climáticos en menor medida. 


\section{ABSTRACT}

Coastal depositional systems of the Cretaceous of the Austral-Magallanes basin are the main targets for exploration and exploitation of conventional hydrocarbon reservoirs. Despite the existing economic interest, the degree of knowledge regarding the characteristics of these deposits and the dynamic of these depositional systems is relatively low compared to deep marine and continental depositional systems.

The Austral-Magallanes Basin correspond to a retroarc foreland system elongated in a north-south direction and related to the Early CretaceousNeogene Andean orogenesis. The sedimentary infill of the basin, in the compressive phase, is characterized by the evolution of an underfilled stage to an overfilled stage. The sedimentary record shows thick deep marine deposits related to turbiditic and slope systems, which have been the focus of study in the last years. In the Lago Argentino region, southwest of the Santa Cruz province, the marine sedimentation concludes with the accumulation of a poorly studied coastal siliciclastic wedge known as the La Anita Formation which is overlain by the uppermost Cretaceous continental deposits.

In this Thesis, the detailed sedimentological analysis of the La Anita Formation deposits was developed. This unit presents excellent exposures both north and south of the Lago Argentino, in the outskirts of El Calafate town, southwest of the Santa Cruz province. In order to carry out a complete characterization of these deposits, 15 detailed sedimentological logs were measured attending the lithological types that characterize the unit, the mechanic and biogenic sedimentary structures, bodies architecture, as well as 
the nature and hierarchy of the stratigraphic surfaces, and type of contact with the infra and suprajacent units. Also, sampling was done to carry out compositional and diagenetic studies by conventional petrography and by X-ray Diffraction.

The sedimentological analysis of the La Anita Formation allowed the recognition of 18 sedimentary facies from which depositional processes were interpreted. Sedimentary facies were grouped in 9 facies associations according to their lateral and vertical distribution within lithosomes with distinctive geometries and characteristics which reflect accumulation in different sedimentary subenvironments. In this way, facies associations were defined: wave-dominated prodelta (FA1), wave-dominated distal delta front (FA2), waveinfluenced mouth bars (FA3), terminal distributary channels (FA4), distributary channels (FA5), fluvial-dominated distal delta front (FA6), fluvial-dominated mouth bars (FA7), high-sinuosity multi-storey distributary channels (FA8) and, water-logged interdistributary areas (FA9). These associations reflect the mixed influence of marine (wave and tidal) and river processes actively acting during the deposition of the unit.

Based on the spatial distribution of facies associations, it is proposed to divide the La Anita Formation into two informal units. These are bounded by a regional erosion surface interpreted as a sequence boundary, and in turn, this division also coincides with the changes in the relative dominance of wave and fluvial depositional processes. Three depositional systems were interpreted for the accumulation of the La Anita Formation deposits. The lower unit reflects the accumulation in a wave-dominated, fluvial-influenced delta system. For the upper unit, 2 depositional systems were interpreted: the fluvial infill of an 
incised valley in the lowermost interval of this unit, and a fluvial-dominated, tidal-influenced deltaic depositional system.

The detailed ichnological analysis performed in the La Anita Formation deposits allowed detecting vertical variations in terms of the diversity and abundance of bioturbations. According to these variations, it was possible to propose a model for the distribution of physicochemical stressful conditions in different sectors of the two interpreted delta systems. These stresses that operated in the different subenvironments and that impacted directly on the benthic fauna were: periodically reduced oxygenation, elevated water turbidity, wave-energy, rapid sediment influx, salinity fluctuations, episodic sedimentation and channel avulsions.

The petrographic study of the sandstones of the La Anita Formation allowed to classify them all as lithic sandstones. No significant vertical compositional variations were recorded for the unit from both petrographic and X-ray diffraction studies. However, in the clay fraction X-ray diffraction analysis, an increase in the proportions of clay minerals of the smectite group was observed associated to the detriment of kaolinite for the upper unit relative to the lower unit. From the detrital modes analysis, in combination with paleoflow directions measured in the mechanical sedimentary structures, it was concluded that the source of the sandstones of the La Anita Formation was associated with uplifted areas of the El Quemado Complex and the volcanic arc. On the other hand, the diagenetic analysis carried out in the sandstones thin sections of the formation allowed to recognize 9 diagenetic processes: physical and chemical compactation, dissolution, clay autigenesis, hematitic cementations, clay coating, calcitic cementation, bitumen migration and 
pyritization. It is concluded that these deposits reached an early mesodiagenesis stage during their burial.

The vertical stacking patterns of the different facies associations and the identification of key stratigraphic surfaces allowed the generation of a sequence stratigraphic framework for the La Anita Formation deposits. It is stated that the two units of the La Anita Formation are part of two unrelated depositional sequences. These units are separated by a sequence boundary triggered by a rapid relative sea-level fall. The lower unit is interpreted as part of a Highstand Systems Tract which could include part of the deep marine deposits of the Alta Vista Formation. The upper unit show a more complex arrangement and forms part of a complete relative sea-level cycle. Lowstand Systems Tract deposits were recorded within this unit since it is interpreted that during this stage in the coastal zone there was a domain of erosion processes and sediment by-pass directly towards the center of the basin. Therefore, for the upper unit deposits a Transgressive Systems Tract is interpreted for the interval characterized by the fluvial infill of the incised valley which is capped at the top by a maximum flooding surface, followed by the Highstand Systems Tract deposits of the fluvial-dominated delta system.

The changes in the type of depositional systems, relative dominances of the depositional processes and sequence architecture are the result of variations in the relationship between the rate of creation of accommodation space and the rate of sediment supply. This comprehensive analysis shows that these variations are the consequence of the combination of allocyclic tectonic controls, mainly, and climatic controls to a lesser extent. 


\section{Capítulo I \\ INTRODUCCIÓN: ¿POR QUÉ ESTUDIAR LOS DEPÓSITOS DE LA FORMACIÓN LA ANITA?}

La Cuenca Austral, denominada en los últimos tiempos como Cuenca Austral-Magallanes, es una de las cuencas sedimentarias con mayor producción de hidrocarburos de Argentina y Chile. Se ubica en el extremo más austral de la Patagonia, entre los $46^{\circ} 30^{\prime}$ y $55^{\circ}$ de latitud Sur, cubre una superficie de más de $230.000 \mathrm{~km}^{2}$, y su cobertura sedimentaria alcanza los 8.000 metros de potencia (Biddle et al., 1986; Peroni et al., 2002). Los depósitos que constituyen el relleno de la Cuenca Austral-Magallanes son foco de estudio para investigaciones científicas e industriales ya que estos reflejan una compleja y dinámica evolución estratigráfica, paleoambiental, paleoclimática, paleogeográfica y porque en subsuelo desarrollan características petrofísicas de interés para la explotación de gas y petróleo tanto onshore como offshore (Biddle et al., 1986; Robbiano et al., 1996; Cuitiño et al., 2019).

En los últimos años se han producido significativos avances en la caracterización y comprensión de la dinámica de los sistemas continentales y marinos profundos de la Cuenca Austral-Magallanes (Schultz y Hubbard, 2005; Hubbard et al., 2010; Romans et al., 2011; Richiano et al., 2012, 2013, 2015; Varela et al., 2012a, b, 2013, 2018, 2019; Varela, 2015; Malkowski et al., 2015, 2017a, b, 2018; Sickmann et al., 2018; Tettamanti et al., 2018; entre otros). Sin embargo, los depósitos costeros y marinos someros no han recibido la misma atención, especialmente aquellos acumulados durante el Cretácico Tardío. Este hecho representa un faltante en la comprensión de la evolución de la cuenca y en el 
entendimiento de cómo se relacionaban y distribuían los diferentes sistemas de acumulación.

Se denomina Formación La Anita a los depósitos campanianos, dominantemente arenosos, con poca participación de facies conglomerádicas, heterolíticas y pelíticas, que apoyan transicionalmente sobre las sedimentitas marinas profundas de grano fino de la Formación Alta Vista, y que son cubiertas por los Depósitos Continentales del Cretácico Superior (Uppermost Cretaceous Continental Deposits; UCCD; sensu Tettamanti et al., 2018). Los depósitos de la Formación La Anita han sido interpretados en estudios regionales como acumulados en ambientes marinos someros a costeros (Arbe, 1986, 2002; Manassero, 1988; Macellari et al., 1989; Sickmann et al., 2018). Las sedimentitas de la Formación La Anita presentan excelentes exposiciones en la región del Lago Argentino, sudoeste de la provincia de Santa Cruz, y su estudio y entendimiento ofrece la posibilidad de comenzar a llenar ciertos vacíos en la historia evolutiva de la cuenca.

Los ambientes costeros incluyen a varios sistemas depositacionales como los deltas, estuarios, playas y planicies de mareas que coexisten a lo largo de una línea de costa y que pueden evolucionar unos en otros a lo largo del tiempo (Boyd et al., 1992; Dalrymple et al., 1992). Estos sistemas se caracterizan por presentar una compleja interacción entre procesos de oleaje, mareales y fluviales, y comúnmente se clasifican en términos de la dominancia relativa de los mismos (Galloway, 1975; Ainsworth et al., 2011). El accionar mixto de los diferentes procesos depositacionales en distintas jerarquías deja señales impresas en los depósitos, evidenciadas en las estructuras sedimentarias mecánicas y en las características texturales de los depósitos, y su identificación es esencial para su correcta interpretación. Los principales factores que controlan el dominio rela- 
tivo de los procesos fluviales, de oleaje y de marea son: i) el aporte de sedimento, ii) la morfología de la línea de costa y de la cuenca, iii) los cambios relativos del nivel del mar, y iv) el clima, el cual controla la eventualidad de las descargas fluviales y la recurrencia de los eventos de tormenta (Dalrymple et al., 1992; Ainsworth et al., 2008, 2011).

La interacción de los procesos depositacionales que se encuentran operando a lo largo de estas líneas de costa pueden generar condiciones de estrés fisicoquímico sobre la fauna bentónica y esto se refleja directamente en las características icnológicas de los depósitos resultantes (MacEachern et al., 2005; MacEachern y Bann, 2008; Bann et al., 2008; Buatois et al., 2012, 2019; Canale et al., 2015, 2020; Dasgupta et al., 2016; Moyano Paz et al., 2020). Las condiciones de estrés ambiental que actúan sobre los organismos productores de trazas son: i) flujos rápidos cargados en sedimentos, ii) elevada turbidez del agua, iii) reducción periódica de la oxigenación del agua, iv) fluctuaciones en los niveles de salinidad del agua, y v) energía de olas y mareas (MacEachern et al., 2005, Buatois et al., 2012; Dasgupta et al., 2016; Moyano Paz et al., 2020; Canale et al., 2020), y han sido foco de estudios en recientes trabajos y se encuentran enfocados principalmente a sucesiones deltaicas. De esta manera el reconocimiento de estas condiciones estresantes en el medio para los organismos productores de trazas permite realizar consideraciones sobre las reconstrucciones paleoambientales superadoras a las tradicionales.

Los análisis composicionales de sucesiones sedimentarias por petrografía convencional permiten no sólo clasificar a las rocas según diferentes propuestas (Folk et al., 1970; Dott et al., 1964; Pettijohn et al., 1972), sino que también la correcta combinación entre el análisis de componentes detríticos y datos de paleocorrientes constituyen una potente herramienta para la determinación de 
posibles áreas fuentes, reconstrucciones paleogeográficas y análisis de cuencas (Fildani y Hesler, 2005; Varela et al., 2013; Malkowski et al., 2016). A su vez, también se pueden reconocer y ordenar cronológicamente los procesos diagenéticos a los que estuvieron expuestos los depósitos y dar indicios de la calidad y tipo de hidrocarburos que pueden llegar a alojar. Por su parte, los estudios por difracción de rayos $\mathrm{X}$ pueden complementar y resaltar variaciones composicionales significantes en las sucesiones sedimentarias y también reflejar cambios en las condiciones paleoclimáticas que no siempre se detectan en estudios petrográficos (Gómez-Peral et al., 2011; Varela et al., 2013, 2018; Richiano et al., 2015).

La instalación de la estratigrafía secuencial como una herramienta consolidada para el análisis de secuencias sedimentarias y la subdivisión de estas en cortejos depositacionales, los cuales involucran a sistemas depositacionales contemporáneos, provee los medios para interpretar variaciones en las tasas de aporte de sedimentos y de generación de espacio de acomodación, y su relación con los factores externos (alocícliclos) que se encontraban controlando la sedimentación. Así cómo también, permite realizar correlaciones críticas entre depósitos marinos y continentales y llevar a cabo reconstrucciones paleogeográficas (Posamentier et al., 1988; Bhattacharya, 1993). Los sistemas depositacionales costeros son extremadamente sensibles no solo a los factores alócicliclos sino también a los autocíclicos (Catuneanu, 2006; Bhattacharya, 2006) y la correcta implementación de un análisis de secuencias puede permitir realizar correlaciones no solo otras unidades aflorantes, sino también con depósitos del subsuelo, representando un gran desafío para el caso de la Cuenca AustralMagallanes donde gran parte de la cobertura sedimentaria mesozoica se encuentra en subsuelo. 
Dentro de este marco, el objetivo principal de este trabajo de tesis es el de reconstruir los paleoambientes sedimentarios bajo los cuales se acumularon los depósitos de la Formación La Anita, mientras que los objetivos específicos son: i) determinar y comprender la magnitud en la que actuaron los diferentes procesos depositacionales durante la acumulación de estos depósitos y su relación con la generación de condiciones de estrés fisicoquímico, ii) establecer consideraciones paleoclimáticas y de áreas fuentes de material detrítico, así como también el grado de diagénesis alcanzado durante el soterramiento, iii) determinar el rol de los diferentes factores de control en la evolución de estos depósitos, y iv) establecer relaciones con las unidades supra e infrayacentes, para determinar la posible relación lateral/depositacional y determinar un esquema paleogeográfico para ese momento del Cretácico en la Cuenca Austral-Magallanes. 


\section{Capítulo II \\ MARCO GEOLÓGICO Y ANTECEDENTES DE LA FORMACIÓN LA ANITA}

\subsection{INTRODUCCIÓN}

En este capítulo se presenta el marco geológico y el contexto estratigráfico en el cual se encuentra enmarcada la unidad estudiada en este trabajo de tesis. Para el desarrollo de este capítulo se realizó una exhaustiva recopilación bibliográfica de trabajos regionales y detallados, tanto de la Cuenca Austral-Magallanes como de la Formación La Anita en particular. El objetivo de este capítulo es introducir a la ubicación, evolución tectónica, compartimentalización y estratigrafía de la Cuenca Austral-Magallanes, y finalmente se presentan los antecedentes sobre la Formación La Anita.

\subsection{LA CUENCA AUSTRAL-MAGALLANES}

La Cuenca Austral, también conocida como Cuenca Austral-Magallanes, se ubica en el borde suroccidental de la placa Sudamericana, entre los $46^{\circ} 30^{\prime}$ y $55^{\circ}$ de latitud sur (Fig. 2.1a). Abarca gran parte de la provincia argentina de Santa Cruz y de la Isla Grande de Tierra del Fuego, Antártida e Islas del Atlántico Sur, así como también a la provincia chilena de Magallanes. La cuenca presenta una característica forma de "L", pasando de un rumbo norte-sur a uno esteoeste. Se encuentra delimitada al oeste y al sur por la Cordillera Patagónica Austral y por los Andes Fueguinos respectivamente, por el Macizo del Deseado al norte y por el Alto del Río Chico y la Cuenca de Malvinas al este (Figs. 2.1a; Rodríguez y Miller, 2005). 


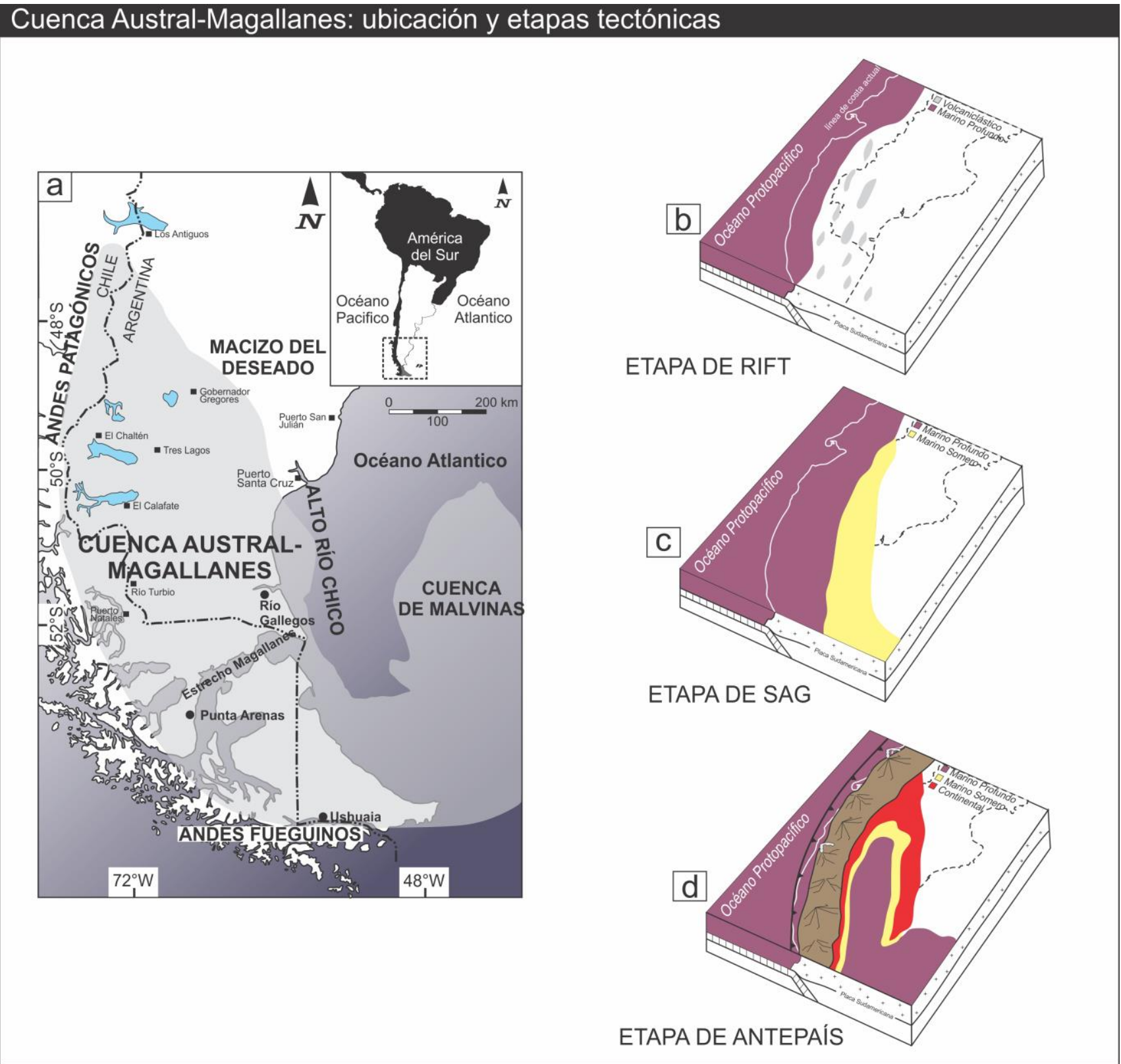

Figura 2.1. a) Ubicación y límites de la Cuenca Austral-Magallanes (modificado de Moyano Paz et al., 2020). Representación de los tres estadios tectónicos de la cuenca, b) rift, c) subsidencia termal (SAG), y d) antepaís.

Los depósitos que conforman el relleno sedimentario de la Cuenca Austral-Magallanes se registran desde el Jurásico Tardío al Cenozoico y se extienden por regiones conocidas como la Cordillera Patagónica Austral, la Cordillera Fueguina, la Patagonia Austral Extraandina y también por la Plataforma Continental Argentina (Russo y Flores, 1972; Riccardi y Rolleri, 1980; Russo et al., 1980; Cuitiño et al., 2019). La cuenca presenta un relleno que en su depocentro alcanza los 8.000 metros de espesor compuesto casi 
exclusivamente por componentes silicoclásticos con limitada productividad carbonática (Peroni et al., 2002).

La Cuenca Austral-Magallanes es foco de estudio para investigaciones científicas e industriales porque registra una compleja evolución paleoambiental, climática y paleogeográfica, por el abundante contenido paleontológico que ha sido descubierto en ella y también porque es una de las cuencas productoras de petróleo y gas más importante de Argentina y Chile tanto onshore como offshore (Biddle et al., 1986; Robbiano et al., 1996; Cuitiño et al., 2019). La evolución estratigráfica de la cuenca, así como también la maduración, migración y entrampamiento de hidrocarburos, presenta una estrecha relación con los esfuerzos tectónicos que ocurrían a lo largo del borde occidental de la placa Sudamericana (Fig. 2.1b, c, d y 2.2; Biddle et al., 1986).

\subsubsection{Etapas tectónicas y relleno de la cuenca}

La evolución tectono-estratigráfica de la Cuenca Austral-Magallanes, en la región del Lago Argentino, se encuentra relacionada a la evolución geotectónica de los Andes Patagónico-Fueguinos. La historia evolutiva de la cuenca se divide en tres etapas tectónicas principales: i) una etapa extensional, o de rift (Fig. 2.1b), ii) una etapa de subsidencia termal (Fig. 2.1c), y iii) una etapa compresiva, o de antepaís (Fig. 2.1d; Biddle et al., 1986; Robbiano et al., 1996; Ramos, 2002; Kraemer et al., 2002; Peroni et al., 2002; Rodriguez y Miller, 2005, Varela et al., 2012; Ghiglione et al., 2014; Malkowski et al., 2017; Cuitiño et al., 2019).

El estadio de rift tuvo lugar durante el Jurásico Tardío al Cretácico Temprano ( 170 Ma) y se encuentra asociado a la fragmentación de Gondwana y al comienzo de la apertura del Océano Atlántico (Pankhurst et al., 2000). 
Durante esta etapa extensional se generaron fallas normales que dieron origen a un sistema regional de grábenes y hemigrábenes con una orientación norte-sur (Uliana et al., 1989). El relleno sedimentario correspondiente a este estadio se encuentra caracterizado por una secuencia de syn-rift conocida como Complejo El Quemado en Argentina y como Formación Tobífera en Chile (Fig. 2.2; Féraud et al., 1999; Pankhurst et al., 2000; Poiré y Franzese, 2010). Este complejo está compuesto principalmente por secuencias volcano-sedimentarias continentales, donde se reconocen dacitas y andesitas, que intercalan con ignimbritas y con sedimentitas silicoclásticas (Ramos et al., 1982, Kraemer y Riccardi, 1997). La depositación del Complejo El Quemado fue coetánea con la extensión y ocurrió dentro de los grábenes y hemigrábenes (Uliana et al., 1989). Durante esta etapa, el sector suroccidental de la cuenca, sobre el margen continental Pacífico, estuvo caracterizado por la generación de corteza oceánica, lo que llevó a la apertura de la denominada Cuenca Marginal de Rocas Verdes (Dalziel, 1981, Calderón et al., 2016). Por encima de los depósitos del Complejo El Quemado apoyan las sedimentitas silicoclásticas de la Formación Springhill que representan el inicio de la sedimentación marina en los grábenes y hemigrábenes previamente formados (Fig. 2.2; Biddle et al., 1986; Schwarz et al., 2011; Richiano et al., 2016; Cuitiño et al., 2019). La Formación Springhill representa el reservorio convencional más importante de la Cuenca Austral y fue el foco de estudios petroleros durante varias décadas. Esta unidad muestra un arreglo transgresivo con depósitos acumulados en planicies costeras hacia la base y depósitos estuarinos y marino someros hacia el tope conformando una secuencia transgresiva (Biddle et al., 1986; Arbe y Fernandez Bell Fano, 2002; Schwarz et al., 2011; Richiano et al., 2016). 


\section{Cuadro estratigráfico de la Cuenca Austral-Magallanes}

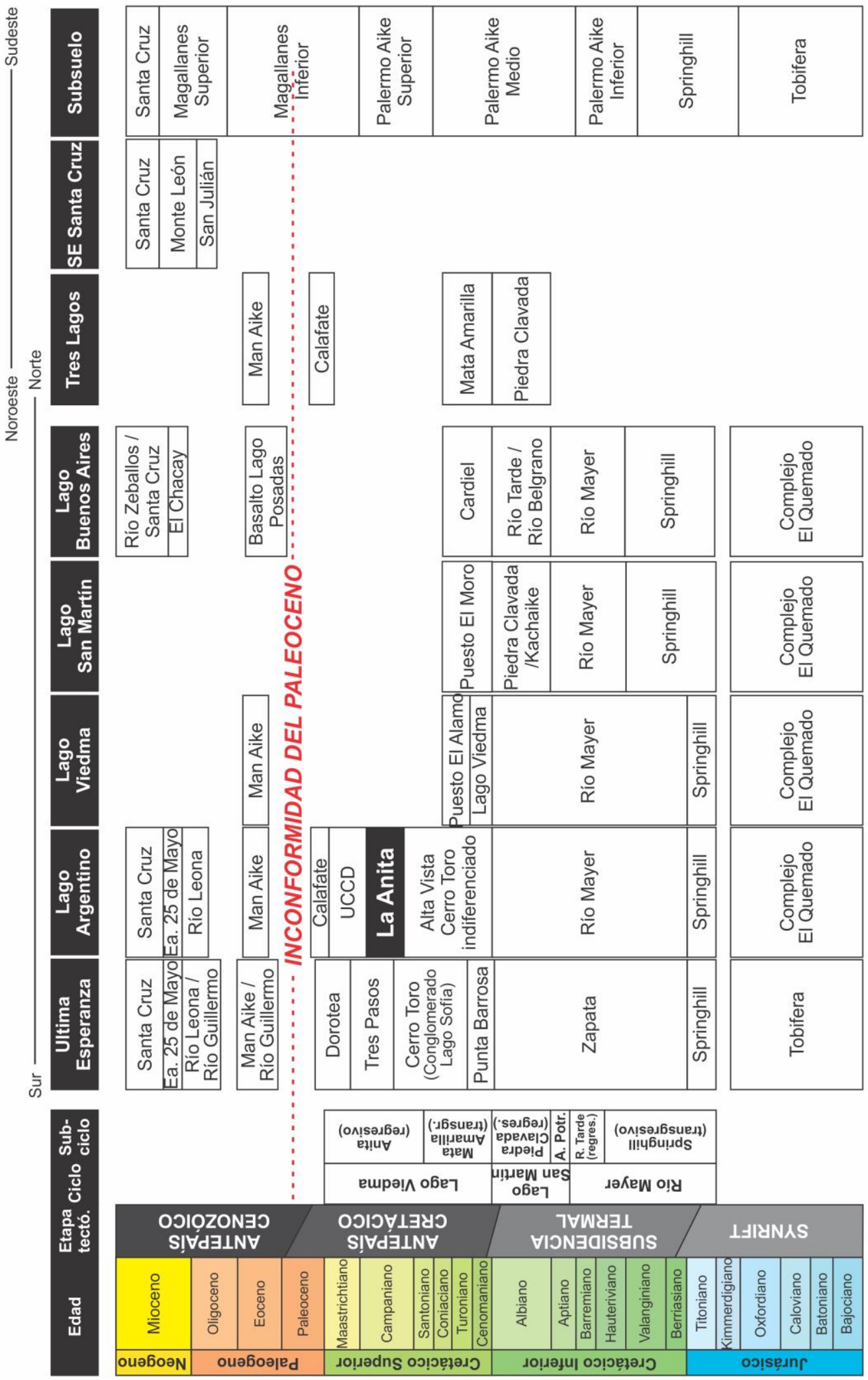

Figura 2.2. Esquema estratigráfico integral del sector centro-norte de la Cuenca Austral Magallanes (modificado de Cuitiño et al., 2019). 
Durante el Berriasiano - Albiano, la transgresión asociada a la depositación de la Formación Springhill continuó, favoreciendo la depositación de las pelitas negras, marinas profundas, de la Formación Río Mayer (Fig. 2.2; Richiano et al., 2012). La depositación de la Formación Río Mayer representa el estadio de subsidencia termal (sag) posterior al proceso de rifting. Esta unidad alcanza espesores de hasta $1.000 \mathrm{~m}$ en la región del Lago Argentino y sus depósitos muestran un arreglo transgresivo-regresivo (Richiano et al., 2012). La sección basal fue acumulada en un ambiente marino de plataforma externa, la sección media también se acumuló en un ambiente marino de plataforma externa, pero muestra una influencia deltaica distal, y la sección superior se acumuló en un ambiente de prodelta el cual se encontraba asociado al desarrollo del sistema deltaico de la Formación Piedra Clavada (Fig. 2.2; Richiano, 2012; 2015).

Durante el límite Albiano - Cenomaniano ( 100 Ma) hubo un importante cambio en el régimen tectónico de la cuenca, evolucionando desde uno extensional hacia un tipo de régimen compresivo, producto del cambio en la convergencia de las placas. Este cambio produjo la obducción de las ofiolitas y el cierre de la Cuenca Marginal de Rocas Verdes (Calderón et al., 2016), la generación de una faja plegada y corrida, y el desarrollo de una cuenca de antepaís asociada hacia el este (Ramos et al., 1982). Durante el comienzo del desarrollo del sistema de antepaís, la Cuenca Austral-Magallanes se encontraba compartimentalizada en dos principales depocentros separados por el Alto de Piedra Clavada (Marinelli 1998; Varela et al., 2019): i) un depocentro principal, denominado foredeep con un eje central de orientación norte-sur que se extendía desde El Chaltén (Argentina) hasta la región de la Última Esperanza 
(Chile), y ii) uno menor denominado Cardiel - Tres Lagos con una orientación sureste-noroeste (Varela et al., 2019).

El depocentro principal presenta un relleno regresivo y una clara asimetría de subsidencia a lo largo de su eje (Cuitiño et al., 2019). Esta asimetría se observa en la distribución de los sistemas depositacionales, con la instalación de sistemas marinos profundos hacia el sur y sistemas continentales al norte (Varela et al., 2019). El inicio de la etapa de antepaís en el depocentro principal se encuentra caracterizada, de sur a norte, por: i) los depósitos de abanicos submarinos no confinados de la Formación Punta Barrosa los cuales se desarrollaron hasta el Turoniano (Fig. 2.2; Fildani et al., 2003, 2009; Malkowski et al., 2017a, b; Daniels et al., 2019); ii) por los depósitos marinos someros de la Formación Lago Viedma (Fig. 2.2; Malkowski et al., 2016, 2017a, b), y iii) por los depósitos estuarinos y continentales de la Formación Puesto El Moro (Fig. 2.2; Varela et al., 2019). Por su parte, en el depocentro de Cardiel - Tres Lagos, el inicio de la etapa de antepaís se caracteriza por la acumulación de los depósitos estuarinos y continentales de la Formación Mata Amarilla (Varela et al., 2011, 2012a, b, 2013, 2018, 2019; Varela, 2015).

La progresiva convergencia los Andes y el desarrollo de la faja plegada y corrida Patagónica provocó que el depocentro de foredeep se desplazara hacia el este y que se produzca un estrechamiento del depocentro (Fosdick et al., 2011; Romans et al., 2011; Cuitiño et al., 2019). Esto tuvo su repercusión en los sistemas sedimentarios principalmente desde el Coniaciano Tardío al Campaniano donde se registra una espesa secuencia turbidítica que caracteriza a la Formación Cerro Toro y se extiende tanto en Argentina como en Chile (Fig. 2.2; Arbe y Hechem, 1984; Hubbard et al., 2008; Romans et al., 2011; Ghighlione et al., 2014; Malkowski et al., 2017, 2018). Estos depósitos 
turbidíticos son cubiertos por una alternancia de pelitas y areniscas que representan un sistema de talud progradacional y depósitos de plataforma externa que se conoce como Formación Alta Vista en Argentina y Formación Tres Pasos en Chile (Fig. 2.2; Macellari et al., 1989; Schultz and Hubbard, 2005; Hubbard et al., 2010; Ghighlione et al., 2014; Sickmann et al., 2018). Este sistema de talud se encuentra genéticamente relacionado con los depósitos de plataforma, marinos marginales y deltaicos del Campaniano y Maastrichtiano, conocidos como Formación Dorotea en Chile (Fig. 2.2; Schwartz y Graham, 2015; Gutiérrez et al., 2017; Bauer et al., 2020), así también como con los depósitos deltaicos de la sección inferior de la Formación La Anita en Argentina (Fig. 2.2; Manassero, 1988; Macellari et al., 1989; Moyano Paz et al., 2018, 2020). El intervalo más superior del Campaniano al Maastrichtiano se caracteriza por una rápida transición de facies desde deltaicas a fluviales en la región del Lago Argentino correspondientes a la sección superior de la Formación La Anita (sensu Moyano Paz et al., 2018) y los Depósitos Continentales del Cretácico Superior (UCCD por sus siglas en inglés; sensu Tettamanti et al., 2018), donde se incluyen a unidades estratigráficas conocidas como las formaciones Cerro Fortaleza, La Irene, y Chorrillo (Fig. 2.2; Sickmann et al., 2018; Tettamanti et al., 2018). La última unidad que conforma el relleno cretácico de la Cuenca Austral-Magallanes en la región del Lago Argentino se conoce como Formación Calafate y se corresponde a un evento transgresivo de edad maastrichtiana (Odino Barreto et al., 2018; Fig. 2.2).

El tope del relleno cretácico de la etapa de antepaís de la cuenca coincide con una superficie de inconformidad erosiva y de no depositación la cual ha sido registrada por encima de las formaciones Dorotea (Schwartz y Graham, 2015), Calafate (Marenssi et al., 2004; Odino Barreto et al., 2018), Cerro 
Fortaleza y también en subsuelo (Varela, 2011). Esta inconformidad abarca un lapso de por lo menos 20 ma (Fosdick et al., 2015; Gutiérrez et al., 2017; George et al., 2019) y por encima de ella se desarrolla una espesa y compleja sucesión sedimentaria que involucra depósitos continentales, marinos someros y marinos profundos (Cuitiño et al., 2019 y referencias allí incluidas). La estratigrafía de la Cuenca Austral-Austral en su etapa de antepaís durante el Cenozoico se encuentra resumida en la Figura 2.2 pero no será tratada ni discutida a lo largo de este trabajo de tesis.

\subsubsection{Ciclos Sedimentarios de la Cuenca Austral-Magallanes}

Arbe $(1986,2002)$ dividió al relleno sedimentario del Jurásico - Cretácico de la región del Lago Argentino y Lago San Martín en lo que llamó diferentes "ciclos tectono-sedimentarios", los cuales se encontraban limitados por superficies de discontinuidad. Arbe (2002), definió entonces para el relleno de la cuenca 3 ciclos que denominó: Ciclo Río Mayer (Titoniano - Aptiano temprano), Ciclo Lago San Martin (Aptiano temprano - Turoniano temprano) y Ciclo Lago Viedma (Turoniano temprano - Maastrichtiano).

Estos ciclos son el producto sedimentario de eventos tectónicos y se encuentran divididos por subciclos o secuencias depositacionales de tercer orden las cuales se caracterizan por presentar un patrón de apilamiento (stacking pattern) equivalente al que desarrollan las parasecuencias de los diferentes cortejos sedimentarios (systems tract; Arbe, 2002). Durante este capítulo se desarrollarán las principales características de la Formación La Anita, la cual forma parte del Subciclo Regresivo Anita del Ciclo Lago Viedma (Fig. 2.2). 


\subsubsection{Formación La Anita}

Leanza (1972) y Furque (1973) fueron los primeros en elevar al rango formacional a los depósitos marinos marginales de edad campaniana que Feruglio (1938) y posteriormente Feruglio (1949) denominaban “Estratos de La Anita" o "Areniscas de la Anita", las cuales suprayacen a las pelitas negras de la Formación Alta Vista y son cubiertas por los depósitos continentales de la Formación Chorrillo (Furque, 1973). La localidad tipo de la Formación La Anita se encuentra en las barrancas que se ubican al sur de su estancia homónima al sur del Lago Argentino, donde sus afloramientos conforman una franja continua, de aproximadamente 30 kilómetros, con una orientación suroestenoreste hasta desaparecer hacia la base del Cerro Calafate, a partir de donde continúa su desarrollo en el subsuelo constituyendo uno de los principales reservorios convencionales (ver Capítulo 3; Varela, 2011; Cevallos, comunicación personal). Hacia el norte, entre el Lago Argentino y el Lago Viedma, la unidad se presenta tanto como afloramientos continuos como irregulares con una orientación norte-sur. Litológicamente la Formación La Anita se compone principalmente de areniscas grises y amarillentas, y en menor medida conglomerados, areniscas conglomerádicas, depósitos heterolíticos y pelitas (Feruglio, 1938, 1949; Leanza, 1972, Furque, 1973; Manassero, 1988; Arbe y Hechem, 1984; Arbe, 1989; Macellari et al., 1989; Arbe, 2002; Moyano Paz et al., 2018, 2020).

Durante las décadas de los 70' y de los 80' existió una tendencia a dividir a estos depósitos en miembros formales (Furque, 1973; Arbe y Hechem, 1984; Arbe, 1989; Macellari et al., 1989), los cuales fueron continuamente modificados. Los trabajos más recientes que involucran a los depósitos de la Formación La Anita no utilizan una división formal (Sickmann et al., 2018, 
2019) o proponen una división informal para esta unidad (Moyano Paz et al., 2018, 2020; este trabajo).

En su trabajo, Furque (1973) reconoció dos miembros dentro de la Formación La Anita: un miembro inferior que denominó El Barco y un miembro superior que denominó Cachorro. El Miembro El Barco fue descripto por este autor en el borde septentrional del Lago Argentino, así como también al sur del mismo en las barrancas de las estancias Anita y Chorrillo Malo (Furque, 1973). Litológicamente el Miembro El Barco fue descripto por este autor como un conjunto de areniscas finas a gruesas y conglomerádicas amarrillentas y grisáceas. Por su parte, el Miembro Cachorro fue también reconocido por Furque (1973) tanto al norte como al sur del Lago Argentino y litológicamente se compone por areniscas finas a medianas que intercalan con conglomerados y presenta una coloración amarilla a verdosa (Furque, 1973). A pesar de esta primera subdivisión de la unidad en miembros formales, el autor destaca la necesidad de realizar trabajos de mayor detalle en estos depósitos.

Arbe y Hechem (1984) realizan un primer análisis de facies sedimentarias para las unidades del Cretácico Superior de la cuenca. En este trabajo los autores siguen la línea planteada por Furque (1973) pero incorporan dos miembros más quedando la unidad compuesta por los miembros: El Barco, Cachorro, La Asunción y La Irene. Estos autores llamaron Miembro La Asunción a las areniscas amarillentas que afloran a lo largo del Río Leona y son cubiertas por la Formación Cerro Fortaleza. Por otra parte, el Miembro La Irene corresponde según estos autores a "un cuerpo sedimentario que aflora en ambas márgenes del Lago Argentino" y que su sección tipo se encuentra en las barrancas de la estancia Irene, por encima de los depósitos de la Formación Cerro Fortaleza (Arbe y Hechem, 1984). Uno de los principales problemas que surgió de esta 
nueva división de los depósitos de la Formación La Anita fueron los siguientes: i) no se plantea una localidad donde afloren los cuatro miembros y pueda verse su relación estratigráfica, y ii) entre el Miembro La Asunción y La Irene se desarrolla una unidad de 350 metros de espesor denominada Formación Cerro Fortaleza, la cual es descripta por los mismos autores en su trabajo. Estas controversias llevaron por ejemplo a que el Miembro La Irene sea rápidamente elevado al rango formacional (Macellari et al., 1989) y que varios de los autores de los trabajos que se realizaron en los últimos años no utilicen esta división de miembros formales (Cereceda, 2016; Sickmann et al., 2018, 2019; Tettamanti et al., 2018; Moyano Paz et al., 2018, 2020).

En este trabajo de tesis se considera como Formación La Anita a los depósitos predominantemente arenosos que afloran en la región del Lago Argentino, los cuales gradan sobre los depósitos finos de la Formación Alta Vista y que son cubiertos por los Depósitos Continentales del Cretácico Superior (Fig. 2.3a y b; Tettamanti et al., 2018; Moyano Paz et al., 2018, 2020; Cuitiño et al., 2019). Los depósitos de la Formación La Anita pueden ser divididos en dos unidades informales: una inferior y otra superior a partir de características texturales, dominancia de procesos depositacionales y distribución de asociaciones de facies (sensu Moyano Paz et al., 2018; Fig. 2.3), las cuales en parte podrían coincidir con los miembros propuestos por Furque (1973), pero como no se conocen detalles de las características de estos miembros y para evitar confusiones se evita usar estos nombres. La unidad inferior de la Formación La Anita grada desde los depósitos pelíticos de la Formación Alta Vista y consiste en una sucesión dominantemente arenosa de coloración gris la cual es limitada al tope por una superficie de erosión regional (Fig. 2.3a y b). Por su parte la unidad superior se ubica por encima de esta superficie de erosión 
regional, consiste también en una sucesión dominantemente arenosa, pero de tamaño de grano más grueso que la inferior, y es cubierta por las unidades que Tettamanti et al. (2018) unificó como los Depósitos Continentales del Cretácico Superior (UCCD; Fig. 2.3a y b).
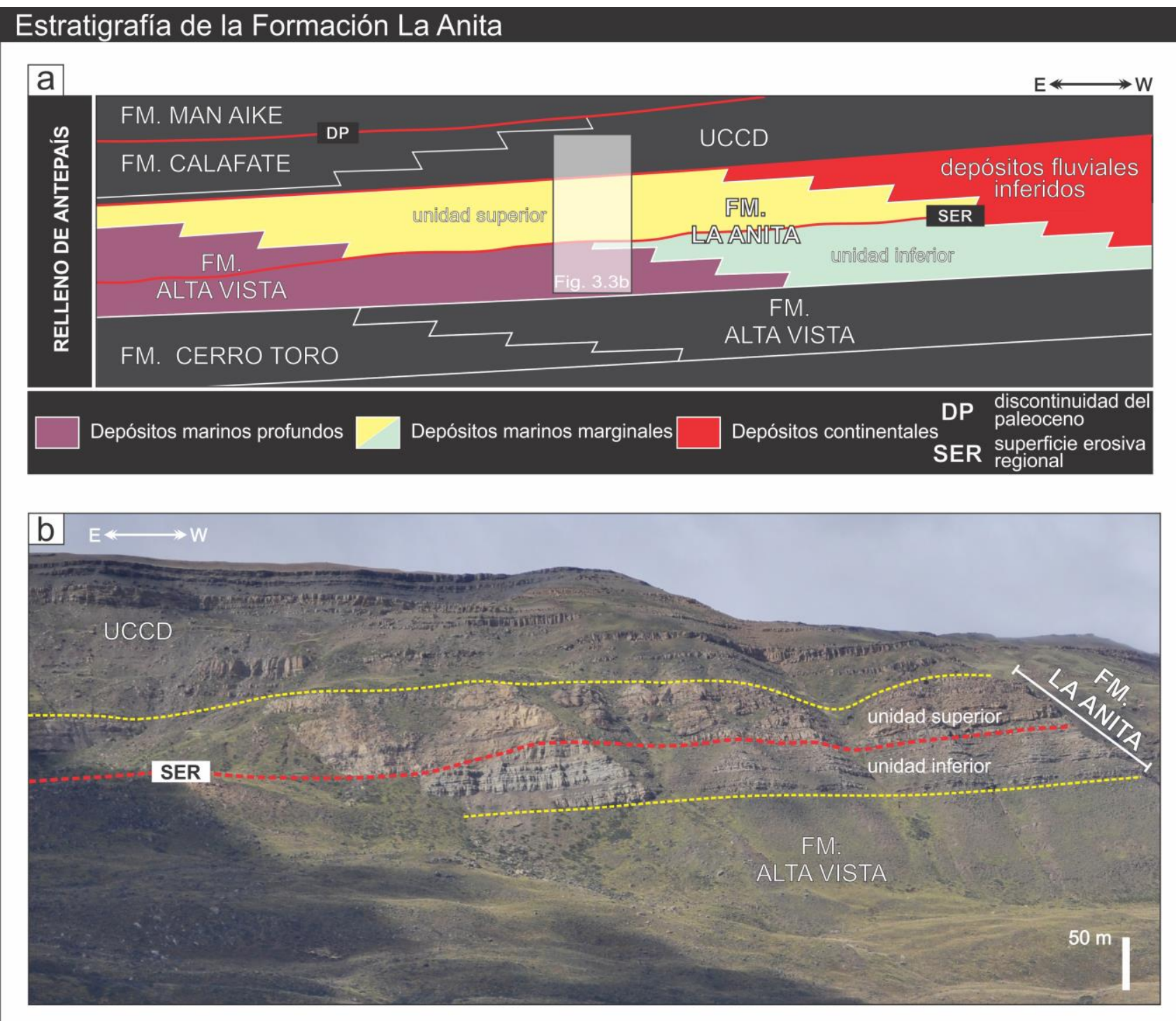

Figura 2.3. a) Ubicación estratigráfica de la Formación La Anita y de sus unidades supra e infrayacentes. b) Vista E-W de las barrancas de Estancia Anita con las unidades que allí afloran, ubicación de la superficie erosiva regional (SER) que separa a las dos secciones informales de la Formación La Anita.

Los primeros estudios estratigráficos en la cuenca proponen una edad campaniana - maastrichtiana para los depósitos de la Formación La Anita a partir de la presencia de ammonites, bivalvos y gastrópodos (Feruglio, 1944, 1949; Leanza, 1967, 1969; Furque, 1973; Riccardi y Rolleri, 1980; Riccardi, 
1983; Kraemer y Riccardi, 1997), así como también por estudios palinológicos (Santamarina et al., 2020). Recientemente y a través de edades de máxima depositación obtenidas a partir de circones detríticos se propuso una edad coniaciana-santoniana $(86 \pm 1 \mathrm{Ma})$ para los depósitos de la unidad inferior (Ghiglione et al., en prensa) y una edad campaniana ( $83 \pm 2-80 \pm 3 \mathrm{Ma}$ ) para los depósitos de la unidad superior (Sickmann et al., 2018, 2019; Ghiglione et al., en prensa).

\subsection{CONSIDERACIONES FINALES}

La revisión de antecedentes de la Cuenca Austral-Magallanes y de la Formación La Anita en particular permitió no solo entender la historia evolutiva de la cuenca, sino también en qué contexto geotectónico se produjo la acumulación de los depósitos de la Formación La Anita; así como también definir los límites estratigráficos de la formación. Dicha unidad se depositó durante el lapso Coniciano - Campaniano en un ambiente marino marginal. Una detallada caracterización de los depósitos de la Formación La Anita es clave para comprender la relación espacial y temporal con los depósitos de las unidades infra y suprayacentes y es algo que se desarrollará a lo largo de este trabajo de tesis. Según los diferentes trabajos mencionados en este capítulo los afloramientos de la Formación La Anita se encuentran distribuidos en lo que se conoce como la región del Lago Argentino, con exposiciones tanto al norte como al sur del mismo (Feruglio, 1944, Leanza, 1972; Furque, 1973; Arbe y Hechem, 1984; Macellari et al., 1989; Kraemer y Riccardi, 1997; Sickmann et al., 2018; Moyano Paz et al., 2018, 2020; Santamarina et al., 2020). Al norte del Lago Argentino los afloramientos se pierden en las márgenes del Río Leona mientras que al sur del lago lo hacen en la base del Cerro Calafate, continuando su desarrollo en el subsuelo donde conforma uno de los reservorios 
convencionales más importantes de lo que se conoce como Palermo Aike Superior (Fig. 2.2). A pesar de la importancia económica de esta unidad, son muy escasos los trabajos de detalle que caractericen variabilidades internas dentro de esta unidad. En el siguiente capítulo de este trabajo de tesis se introducirá con detalle a la región del Lago Argentino, así como también a la metodología implementada para el desarrollo de este trabajo. 


\section{Capítulo III \\ ZONA DE ESTUDIO Y METODOLOGÍA}

\subsection{INTRODUCCIÓN}

El trabajo de campo del presente trabajo de tesis se llevó a cabo en la región del Lago Argentino la cual se encuentra localizada en el sudoeste de la provincia de Santa Cruz (Fig. 3.1). La zona fue elegida porque es en la única región de la cuenca donde afloran las sedimentitas que constituyen a la Formación La Anita antes de continuar su extensión en el subsuelo (Fig. 3.1). Para alcanzar los objetivos de este trabajo, en esta región se implementó una metodología clásica para el análisis de sucesiones sedimentarias y también metodologías particulares para resolver problemáticas particulares como las relaciones organismo-sustrato.

En el presente capítulo de este trabajo de tesis se realiza una introducción a la región del Lago Argentino y se describen con detalle las metodologías que se utilizaron.

\subsection{REGIÓN DEL LAGO ARGENTINO}

Se denomina región del Lago Argentino al sector ubicado al sudoeste de la provincia de Santa Cruz que abarca la zona entre los $49^{\circ} 40^{\prime}$ y $50^{\circ} 40^{\prime}$ de latitud sur y los $72^{\circ} 4^{\prime}$ y $72^{\circ} 58^{\prime}$ de longitud oeste, que va desde el límite fronterizo con Chile hasta la margen sur del Lago Viedma (Figs. 3.1 y 3.2). Este sector se conoce como región del Lago Argentino (sensu Moyano Paz et al., 2018; Cuitiño et al., 2019) debido a que dicho lago se encuentra ubicado en una posición casi central de la región y la divide en dos sectores, norte y sur, los cuales se describirán por separado en este capítulo. La zona de estudio es 
recorrida en dirección norte-sur por la Ruta Nacional 40 y por seis Rutas Provinciales (21, 69 y 19 al norte del lago, y 11, 15 y 60 al sur) en dirección esteoeste que conectan la Ruta 40 con la zona andina (Fig. 3.2). El único asentamiento urbano dentro de esta región es la localidad de El Calafate, sin embargo, hay numerosas estancias rurales (Fig. 3.2).

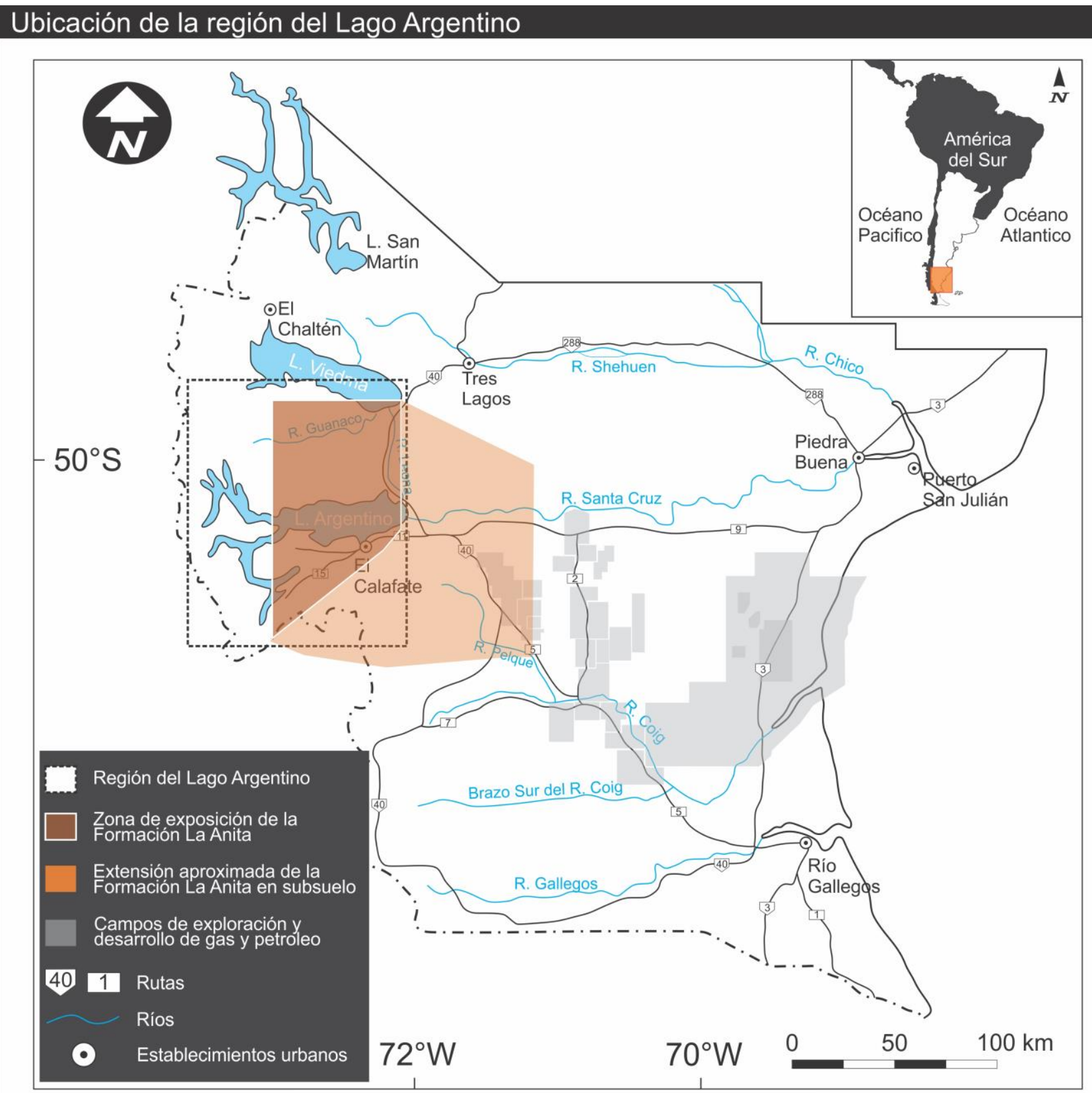

Figura 3.1. Mapa del sur de la provincia de Santa Cruz, Argentina, donde se presenta la ubicación de la región del Lago Argentino y la zona de exposición de la Formación La Anita y su aproximada extensión en el subsuelo (Varela, 2011; Moyano Paz et al., 2018, 2020). 
Esta región se sitúa dentro de la provincia geológica conocida como los Andes Patagónicos Australes y la Faja Plegada y Corrida de la Patagonia (Riccardi y Rolleri, 1980; Ghiglione et al., 2009) y es una zona clave dentro de la cuenca porque se encuentran expuestos los depósitos de la etapa de synrift, los depósitos de la etapa de subsidencia termal, los depósitos del antepais del Cretácico y parte de la sucesión del antepaís del Cenozoico (Fig. 3.3a).

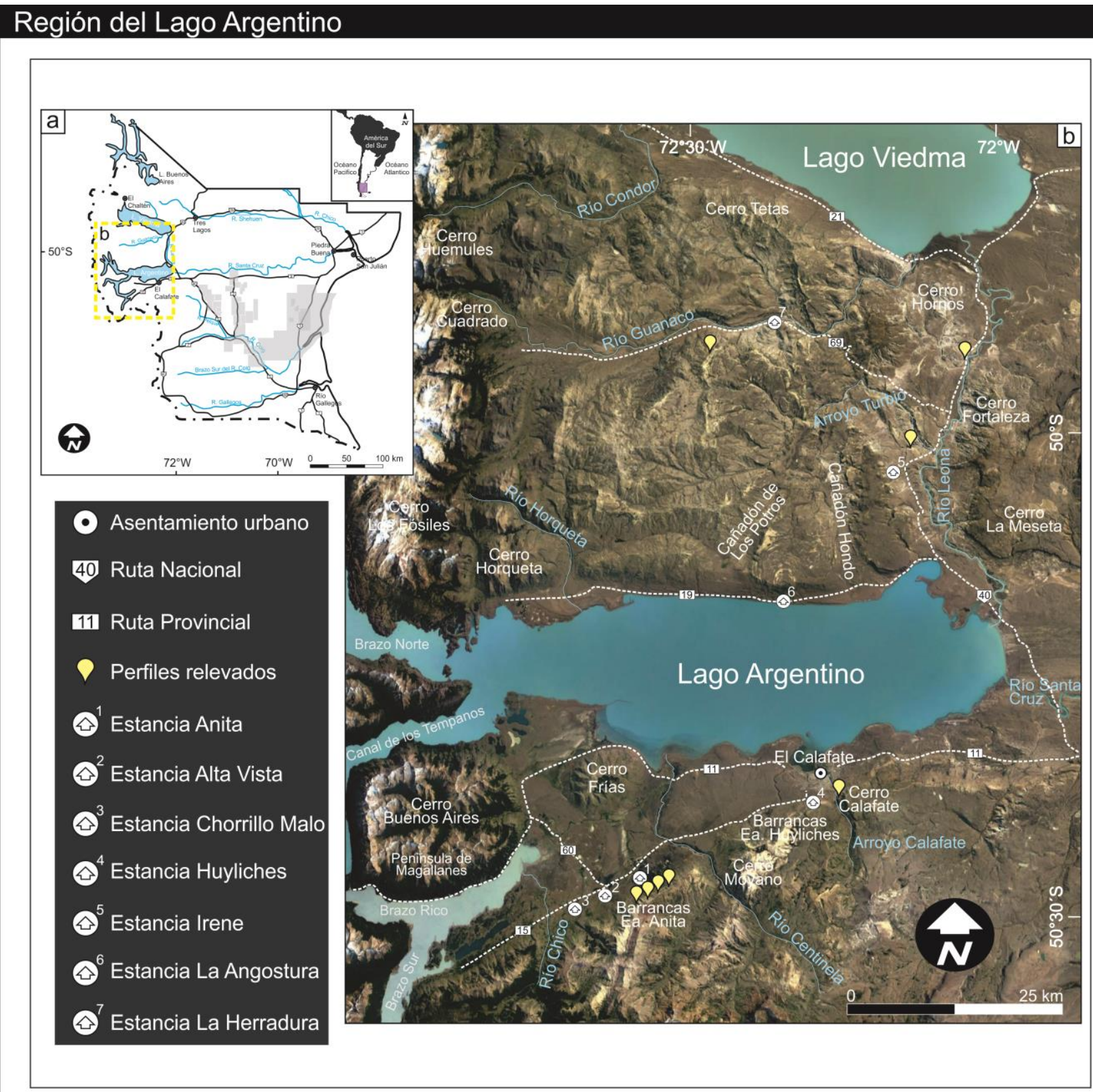

Figura 3.2. a) Ubicación de la región del Lago Argentino. b) Imagen satelital tomada de Google Earth ${ }^{\circledR}$ de la región del Lago Argentino, donde se pueden observar rasgos fisiográficos más destacados de la región, así como también las principales rutas y asentamientos urbanos. 


\section{Contexto geológico de la región del Lago Argentino}
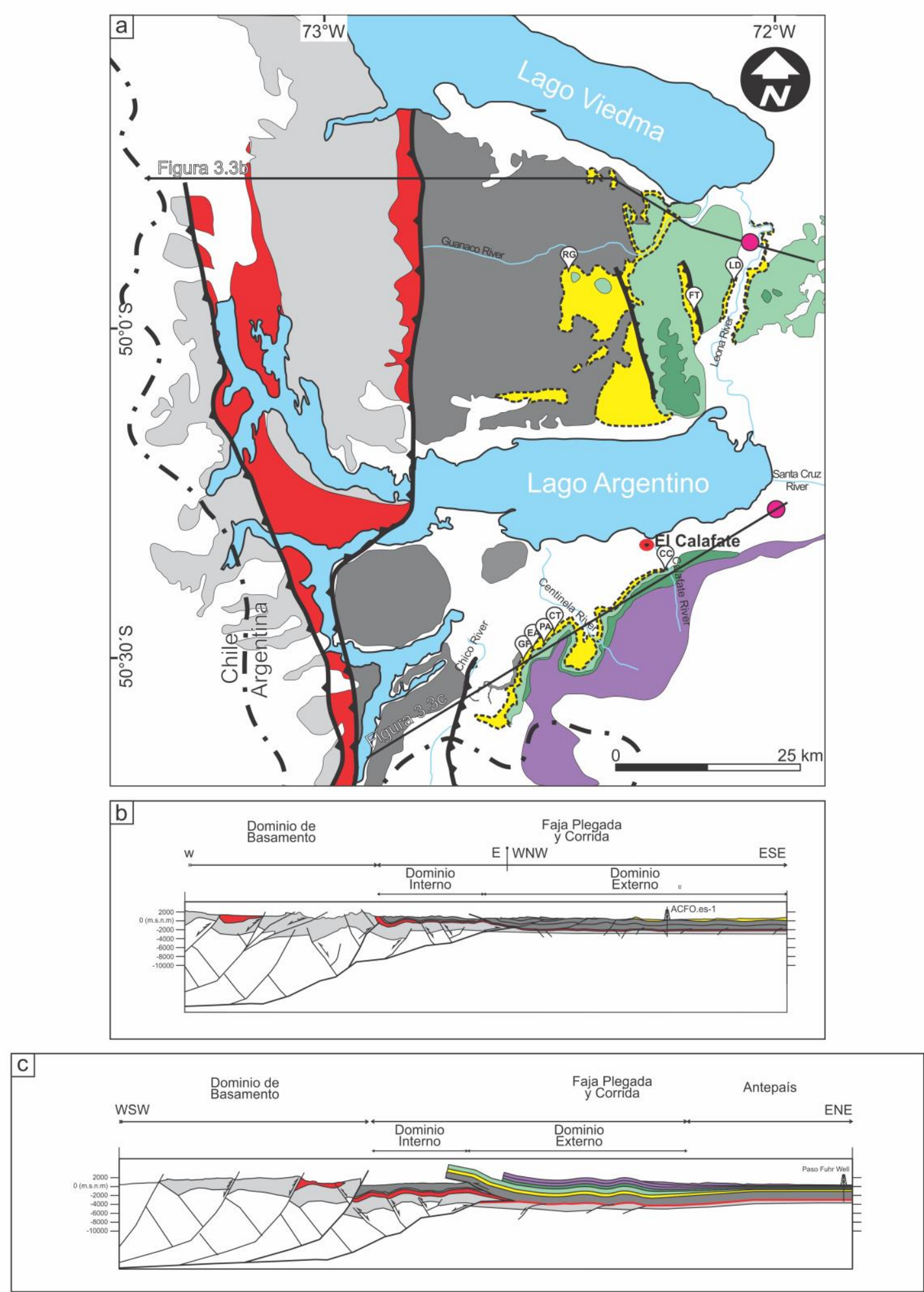

Formación La Anita

Formaciones Cerro Toro/ Alta Vista sin diferenciar Formación Río Mayer

Complejo El Quemado
Pozo exploratorio

Unidades cenozoicas no diferenciadas

Formaciones Calafate/ Man Aike sin diferenciar UCCD
- Asentamiento urbano

Perfil relevado

Limite internacional

Falla inversa 
Figura 3.3 (página anterior). a) Mapa geológico de la región del Lago Argentino (modificado Ghiglione et al., 2014). b y c) Cortes estructurales.

Estructuralmente, la zona de estudio comprende parte de la faja plegada y corrida generada durante el estadio de antepaís de la cuenca y expone de manera casi continua todo el registro sedimentario de la zona. Esta morfoestructura consiste en una faja plegada con abundantes plegamientos y pocos fallamientos generados a partir de estructuras invertidas (Ghiglione et al., 2014) y se encuentra dominada principalmente por la inversión tectónica positiva parcial de las estructuras generadas en el estadio de rift durante el Jurásico (Kraemer, 1998; Ghiglione et al., 2009, 2014; Fosdick et al., 2011; Giacosa et al., 2012). De acuerdo a los estilos de deformación, Ghiglione et al. (2009) dividió a la región del Lago Argentino en tres dominios: i) un dominio cristalino, también llamado dominio de basamento, que consiste en una estructura de piel gruesa que es la responsable de la exposición del basamento en el flanco occidental de los Andes Patagónico-Fueguinos, ii) un dominio interno, con estructuras de piel gruesa con de orientación norte-sur y una vergencia hacia el este, y iii) un dominio externo, con estructuras de piel fina que también muestran una vergencia hacia el este (Ghiglione et al., 2014 Fig. $3.3 \mathrm{~b}$ у c).

\subsubsection{Afloramientos de la Formación La Anita}

Los depósitos de la Formación La Anita afloran exclusivamente en la región del Lago Argentino, y se encuentran distribuidos tanto al norte como al sur del lago (Figs. 3.2 y 3.3). A continuación, se describirán estas dos subregiones dentro de la zona de estudio.

\subsubsection{Norte del Lago Argentino}


Este sector se localiza entre los $40^{\circ} 40^{\prime}$ y $50^{\circ} 10^{\prime}$ de latitud sur y los $72^{\circ} 4^{\prime}$ y $72^{\circ} 58^{\prime}$ de longitud oeste, y que coincide aproximadamente con la margen sur del Lago Viedma al norte, la margen norte del Lago Argentino al sur, el límite fronterizo con Chile al oeste, mientras que el límite oriental coincide con el Río Leona. En este sector, los depósitos de la Formación La Anita se encuentran expuestos en la zona central y oriental (Fig. 3.3a) mayormente dentro del dominio interno (sensu Ghiglione et al., 2014), con una orientación dominantemente norte-sur coronando las barrancas que se encuentran detrás de la estancia La Angostura y a lo largo del Cañadón Hondo, así como también en la margen sur del Río Guanaco, cerca de la estancia La Herradura y en la margen sur del Lago Viedma en la parte superior del Cerro Teta (Figs 3.2 y 3.3a). Sin embargo, también hay exposiciones de la unidad dentro del denominado dominio externo (sensu Ghiglione et al., 2014), los cuales son más acotados espacialmente y se encuentran a lo largo del curso del Río Leona tanto en la base del Cerro Fortaleza, en la zona del parador abandonado Luz Divina y en las cercanías de la estancia La Asunción (Figs. 3.2 y 3.3a). También hay afloramientos en las barrancas del Arroyo Turbio y en la zona de desembocadura del Río Guanaco en el Lago Viedma.

\subsubsection{Sur del Lago Argentino}

El sector sur de la zona de estudio se ubica entre los $50^{\circ} 20^{\prime}$ y $50^{\circ} 40^{\prime}$ de latitud sur y $\operatorname{los} 72^{\circ} 4^{\prime}$ y $72^{\circ} 58$, de longitud oeste. En este sector los afloramientos de la Formación La Anita se presentan conformando una franja continua de aproximadamente unos $30 \mathrm{~km}$ con una orientación sudoestenoreste que se extienden desde las barrancas ubicadas al sur de las estancias Alta Vista y Anita, continuando por las barrancas de la estancia Huyliches hasta desaparecer hacia la base del Cerro Calafate (Figs. 3.2 y 3.3a). En este sector, las 
exposiciones de la Formación La Anita se encuentran restringidas a la zona de dominio externo.

\subsection{METODOLOGÍA}

El desarrollo del presente trabajo de tesis se encuentra guiado por las etapas que comprende el método científico donde como primera medida se definió una hipótesis de trabajo y una serie de objetivos con la intención de resolver problemáticas específicas, las cuales han sido mencionadas en el Capítulo 1 (Fig. 3.4). La identificación de la problemática y la formulación de una hipótesis de trabajo surgió a partir de una primera instancia de recopilación de antecedentes y de observaciones iniciales realizadas en afloramientos, las cuales permitieron establecer los objetivos de esta tesis (Fig. 3.4). Luego se procedió a la etapa de recopilación bibliográfica no sólo de la unidad de interés sino también de la problemática en particular. Posteriormente, se recolectaron datos de campo y de laboratorio los cuales se integraron y se analizaron en conjunto para la etapa final de análisis intelectual (Fig. 3.4).

\subsubsection{Tareas de gabinete inicial}

Las primeras tareas realizadas consistieron en una recopilación y minuciosa lectura de información bibliográfica disponible sobre la geología regional de la cuenca, de las unidades que conforman el relleno de esta durante su estadio de antepaís, y se hizo especial énfasis en los trabajos que analizan la distribución espacial y las características de los depósitos de la Formación La Anita. Durante esta instancia se pudo constatar el grado de conocimiento incipiente que existía hasta el momento sobre estos depósitos y la disparidad que presenta con otras unidades consideradas claves para la industria petrolera, como por ejemplo las formaciones Springhill, Río Mayer y Mata Amarilla. Sobre la base de 
Flujo metodológico

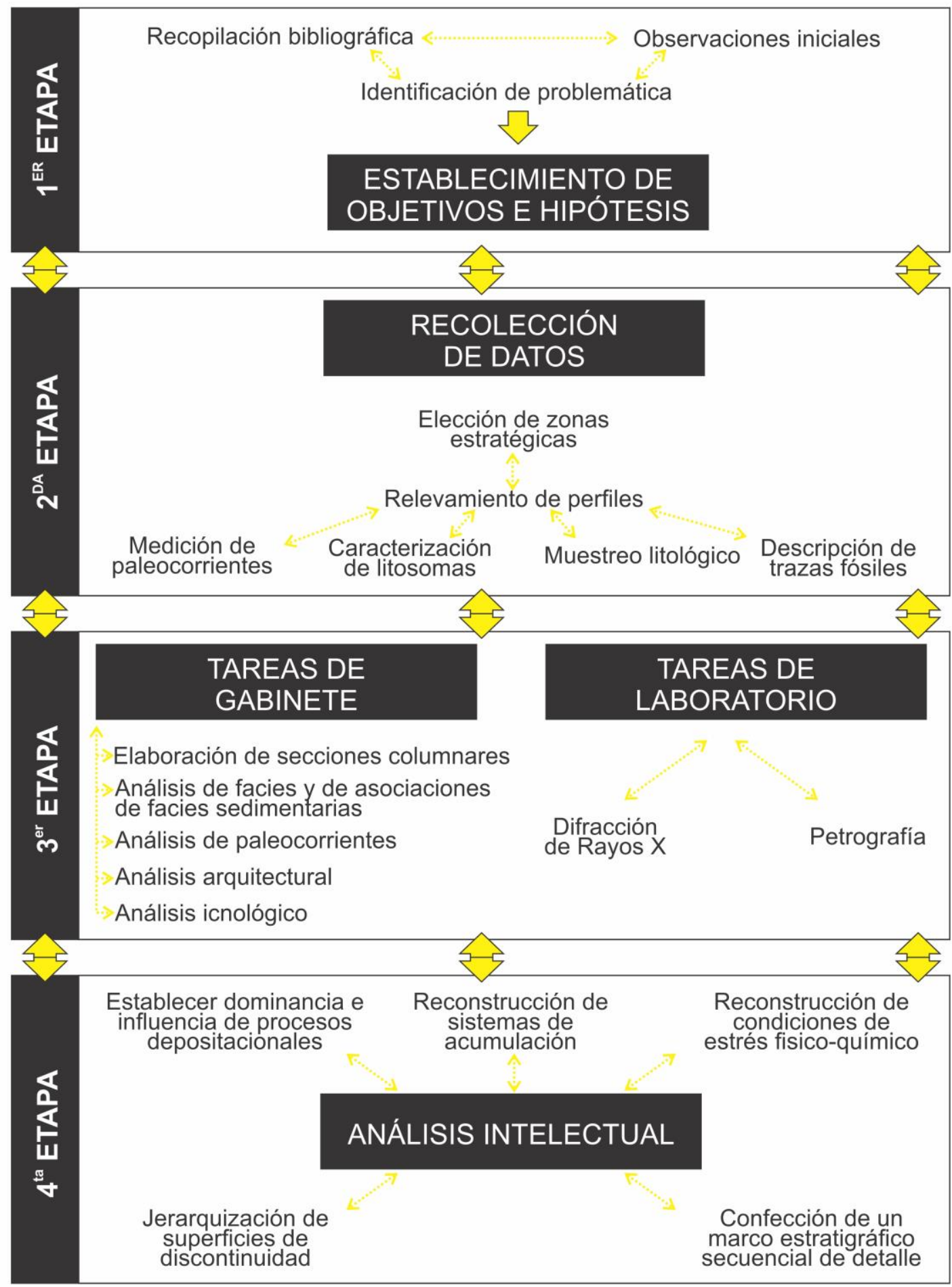

Figura 3.4. Flujo metodológico utilizado para el desarrollo del presente trabajo de tesis.

la información reunida se discutieron los enfoques y criterios que los diferentes autores utilizaron para el estudio de la unidad de interés. En este punto, se hizo notoria la falta de detalle en las caracterizaciones sedimentológicas y 
estratigráficas de la Formación La Anita estando las mismas enmarcadas en trabajos de índole regional.

Un aspecto fundamental en esta etapa inicial de gabinete fue la lectura y estudio de trabajos bibliográficos sedimentológicos específicos con el fin de obtener conocimientos y herramientas teóricas para la caracterización de estos depósitos, y poder discriminar entre los diferentes elementos que conforman los diferentes sistemas sedimentarios marinos someros, marinos marginales y continentales.

Por otro lado, durante esta etapa, se realizó una recopilación de imágenes satelitales a través de Google Earth ${ }^{\circ}$, imágenes satelitales LANDSAT-ETM+ y Aster, además de la información cartográfica de las hojas geológicas Calafate 5172-I (Nullo et al., 2006) y El Chaltén 4972-III (Giacosa et al., 2013) del Servicio Geológico Minero Argentino (SEGEMAR). Los antecedentes bibliográficos sumados a la información de las imágenes satelitales y de la cartografía permitieron conocer la ubicación y extensión de los afloramientos de los depósitos de la Formación La Anita. Así como también, las características topográficas de la región del Lago Argentino, las cuales sirvieron para conocer facilidades, accesos a los diferentes afloramientos, y en base a esto definir las mejores localidades para el levantamiento de perfiles sedimentológicos y diferentes actividades de campo.

\subsubsection{Objetivos}

El objetivo principal de este trabajo de tesis es contribuir con una caracterización sedimentológica de detalle y un análisis estratigráfico de los depósitos campanianos de la Formación La Anita, acumulados en la etapa de antepaís de la Cuenca Austral. Con el objetivo principal de reconstruir 
detalladamente los paleoambientes sedimentarios en los cuales estos depósitos fueron acumulados, se plantearon una serie de objetivos específicos que a continuación se detallan y que son tratados a lo largo de los siguientes capítulos de este trabajo de tesis.

1) Determinar y comprender la magnitud en la que actuaron los diferentes procesos depositacionales durante la acumulación de estos depósitos y su relación con la generación de condiciones de estrés fisicoquímico para la fauna bentónica.

2) Establecer consideraciones paleoclimáticas y de áreas fuentes, así como también el grado de diagénesis alcanzado durante el soterramiento.

3) Determinar el rol de los factores de control en la evolución de los depósitos de la Formación La Anita.

4) Establecer relaciones con las unidades supra e infrayacentes a la unidad de interés para establecer su posible relación lateral/depositacional y determinar un esquema paleogeográfico para ese momento del Cretácico Tardío en la Cuenca Austral-Magallanes.

\subsubsection{Hipótesis inicial}

Luego de la primera etapa de análisis de antecedentes bibliográficos y de la realización de una primera campaña de reconocimiento se definieron algunas problemáticas existentes que conforman los objetivos principales de este trabajo de tesis, y en este marco distintas hipótesis fueron formuladas, testeadas, refutadas y reformuladas en los casos necesarios.

La hipótesis fundamental de trabajo propone que los depósitos de la Formación La Anita fueron acumulados en un ambiente marino marginal. Los ambientes marinos marginales muestran interacción entre diferentes procesos depositacionales (acción de oleaje, mareal y descargas fluviales), los cuales actúan con diferente intensidad (Ainsworth et al., 2008, 2011, 2019). La 
hipótesis fundamental de este trabajo hace énfasis en que la acción de estos procesos debe encontrarse reflejada en estos depósitos y que la dominancia relativa de los diferentes procesos pudo variar en el tiempo. A su vez se propone que, en estos ambientes, se crean condiciones de estrés fisicoquímico en el medio que dificultan o inhiben la colonización del sustrato por parte de fauna bentónica y esto debería reflejarse en la abundancia y diversidad de estructuras biogénicas presentes en estos depósitos (MacEachern et al., 2005; Buatois et al., 2012; Dasgupta et al., 2016; Canale et al., 2020). Otra de las hipótesis que se proponen en este trabajo de tesis es que la superficie que separa a la unidad inferior y unidad superior de la Formación La Anita representa un límite de secuencia de escala regional y se relacionaría con un significativo evento de caída relativa del nivel del mar que podría vincularse con momentos de quietud y de levantamiento tectónico durante el Campaniano.

\subsubsection{Tareas de campo}

A partir de las tareas iniciales de gabinete se eligieron zonas estratégicas para la obtención de datos de afloramiento de la unidad de interés. De esta manera, se trabajó en dos sectores ubicados al sur del Lago Argentino, en las barrancas de la estancia Anita y en la localidad del Cerro Calafate donde se relevó un perfil sedimentológico de detalle (Figs. 3.2 y 3.3). Por otra parte, en el norte del Lago Argentino el trabajo de campo se realizó en 3 localidades diferentes: en las barrancas ubicadas a lo largo del Río Guanaco, en el Arroyo Turbio y en la zona del parador abandonado de Luz Divina (Figs. 3.2 y 3.3). Durante el periodo de abril de 2016 y marzo de 2018, se realizaron diferentes viajes de campo donde se realizó la descripción detallada de los depósitos aflorantes de la Formación La Anita. Estas actividades incluyeron el relevamiento de ocho perfiles sedimentológicos de detalle, en los cuales se 
realizaron tareas de reconocimiento, descripción y muestreo de los distintos elementos litológicos presentes.

\subsubsection{Relevamiento de perfiles sedimentológicos}

En las localidades seleccionadas se relevaron ocho perfiles sedimentológicos de detalle a escala 1:100, tres ubicados al norte del Lago Argentino (RG = Río Guanaco; FT = Filo del Turbio; LD = Luz Divina) y seis al sur del mismo $(\mathrm{GF}=$ Galpón de Freile; $\mathrm{EA}=$ Estancia Anita; $\mathrm{PA}=$ Paredón; $\mathrm{CT}=$ Campo Tropilla; $C C=$ Cerro Calafate; Fig. 3.3a). Para realizar una completa caracterización de la unidad de interés se trabajó en localidades con un buen control estratigráfico, donde preferentemente se encuentren expuestos los contactos con las unidades infra y suprayacentes. Las posiciones iniciales y finales de cada perfil fueron localizadas satelitalmente mediante un GPS (Garmin eTrex 20).

Los espesores de las diferentes capas que componen la sucesión de interés fueron medidos con cinta métrica. La descripción detallada de la unidad consistió en, para cada una de estas capas, describir el tamaño de grano, su selección y textura, identificar y medir estructuras sedimentarias primarias, identificación de estructuras biogénicas constatando la distribución de las mismas y la intensidad de las bioturbaciones, y en la medición de orientaciones de paleocorrientes en estructuras mecánicas indicadoras de flujo tales como estratificaciones entrecruzadas, laminaciones entrecruzadas y óndulas de corriente.

\subsubsection{Caracterización bidimensional de litosomas}

Se realizó un análisis de la geometría y de las dimensiones de los diferentes cuerpos sedimentarios (litosomas). Este análisis se realizó a partir de 
la geometría y jerarquización de las superficies que limitan cada litosoma y de la determinación de relaciones laterales y verticales de las facies que los constituyen. El relevamiento de esta información se realizó a partir de la confección de perfiles sedimentológicos de alta resolución con espaciamientos de aproximadamente 50 metros para constatar la variabilidad vertical y lateral de facies y también de la obtención de fotografías para la confección de fotomosaicos y su posterior análisis en gabinete.

\subsubsection{Muestreo litológico}

Paralelamente durante el relevamiento de los perfiles sedimentológicos se realizó un muestreo en las diferentes litologías presentes para posteriormente realizar análisis composicionales y de procedencia de cada uno de los perfiles relevados mediante análisis petrográficos y de Difracción de Rayos X.

\subsubsection{Tareas de laboratorio}

Las muestras obtenidas durante las tareas de campo fueron enviadas al Laboratorio de Rayos X y al Taller de Cortes del Centro de Investigaciones Geológicas y (CIG - CONICET - UNLP) para realizar análisis composicionales que a continuación se describen.

\subsubsection{Difracción de rayos X (DRX)}

Con el objetivo de reconocer y describir la composición mineralógica de los depósitos de la Formación La Anita, así como para identificar los minerales de arcilla y su abundancia relativa, se le realizaron análisis de difracción de rayos X (DRX) a 81 muestras litológicas que fueron obtenidas en los perfiles RG, GF, EA, CT y CC las cuales fueron seleccionadas previamente para que sean representativas de estos perfiles. Este análisis se realizó en el Laboratorio de 
Rayos X del CIG el cual está equipado con un difractómetro de Rayos X marca PANalytical modelo X'Pert Pro de óptica pera-alineada de alta resolución y tubos de Rayos X metal-cerámico con ánodo de Cobre $(\mathrm{Cu})$.

El primer paso al realizar estos análisis consiste en desagregar y pulverizar las muestras en un mortero de ágata hasta obtener un polvo impalpable que se coloca en un porta-muestra en forma pareja. Este portamuestra se coloca en el difractómetro y se somete a un haz de Rayos X de longitud de onda conocida (2Ө) con ángulos de incidencia desde los 4 a los 37 grados. Una vez terminado el escaneo, se obtiene una primera lectura del análisis conocida como roca total.

El siguiente paso consiste en colocar el polvo de la muestra en un vaso con agua destilada. Esta solución es agitada y dejada en reposo por unos 20 minutos con el fin de que se produzca la decantación de las partículas más gruesas y de esta manera concentrar las fracciones menores a los $2 \mu$. Pasados estos 20 minutos, con una pipeta se muestrean algunos mililitros de esta solución y se colocan sobre la superficie de dos porta-objetos de vidrio en los que se deja secar el material hasta obtener una película muy fina de sedimento. Uno de estos porta-objetos es llevado al difractómetro de Rayos X y sometido a un haz de longitud $2 \theta$, y se produce el escaneo entre los 2 y los 32 grados. Esta segunda lectura corresponde a la de las fracciones finas (arcillas) denominada normal.

El mismo porta-objeto que se utiliza para la muestra normal es colocada en un secador expuesta a vapores de una solución de etilenglicol durante al menos 24 horas con el objetivo de provocar la hidratación de arcillas expansivas. Luego de esta hidratación, se coloca en el difractómetro y se realiza 
un escaneo con entre los 2 y los 27 grados $\theta$. Esta tercera lectura corresponde a la de las fracciones finas denominada glicolada.

Por último, el segundo porta-objeto se somete a un proceso de calentamiento en una mufla a $550^{\circ} \mathrm{C}$ durante un lapso de 2 horas con el objetivo de generar el colapso de las estructuras cristalinas de las arcillas expansivas y de la caolinita. Se coloca el porta-objeto en el difractómetro y se produce el escaneo entre los 3 y los 15 grados. Esta cuarta lectura corresponde a la de las fracciones finas denominada calcinada.

Todos los resultados que se obtuvieron fueron procesados y graficados en el software Origin ${ }^{\circledR}$ donde se generaron diagramas de roca total y de la fracción arcilla, estos últimos incluyen las lecturas de los análisis normales, glicolados y calcinados de manera combinada.

La identificación de las especies minerales se realizó a partir de la interpretación de los diferentes picos de los difractogramas, que se encuentran expresados en unidades angulares $2 \theta$, siendo $\theta$ el ángulo de refracción. Mediante la fórmula de Bragg los valores angulares obtenidos mediante la refracción de los rayos se convierten en datos espaciales que representan el espaciamiento entre los planos de las estructuras cristalinas y son medidos en Ángstroms (Á; Brindley, 1961; Brindley y Brown, 1980). Cada especie mineral presenta un patrón de refracciones y de espaciamientos característicos definidos por el uso de patrones estándar ya establecidos.

Una vez reconocida la composición mineralógica de cada muestra se realizó la semi-cuantificación de cada una de las especies minerales en forma gráfica. Por un lado, se graficaron los resultados obtenidos de los análisis de 
roca y total, y por otro lado los de la fracción arcilla. Según la abundancia de estas especies minerales se definieron 6 clases diferentes.

$$
\begin{aligned}
\text { I. } & \text { Traza }=\leq 1 \% \\
\text { II. } & \text { Muy Escaso }=1-5 \% \\
\text { III. } & \text { Escaso }=5-15 \% \\
\text { IV. } & \text { Moderada }=15-25 \% \\
\text { V. } & \text { Abundante }=25-50 \% \\
\text { VI. } & \text { Muy Abundante }=\geq 50 \%
\end{aligned}
$$

Para establecer el grado de abundancia en los diagramas de roca total, se utilizó la altura de los picos principales de cada mineral, los cuales reflejan la intensidad de refracción. Por otro lado, la semi-cuantificación de los argilominerales se realizó sobre los difractogramas de las muestras naturales. Para estos casos se utilizó el método del área de los picos de las diferentes especies minerales (Biscaye, 1965). Debido a que las respuestas de estos minerales dependen de la forma de la partícula, estas áreas no reflejan directamente la abundancia, motivo por el cual se realizaron las siguientes correcciones siguiendo la metodología propuesta por Moore y Reynolds (1989):

- Illita: se considera al área correspondiente al pico 001 (10 Á) como unidad entera.

- Como el pico de máxima intensidad de la caolinita (001) y el pico 002 de la clorita se localizan ambos en $7 \AA$, las proporciones relativas de ambas especies se realizan en: el pico 002 de la caolinita $(3,57 \AA ̊)$ y en el pico 004 de la clorita (3.53 ̊́; Lluch y Spalletti, 1976). El área de ambos picos debe ser dividida por 2 .

- Esmectita: el área del pico 001 de la esmectita, que se encuentra entre los 12 y 17 Á debe ser dividido por 4 . 
- La semi-cuantificación de las capas de los interestratificados illita/esmectita (IS) se calculó a partir de las refracciones ubicadas entre los 10 y 12 Á. Esta área debe ser dividida por 1,5.

Todos los resultados fueron plasmados en tablas Excel ${ }^{\circ}$ y recalculados a valores porcentuales. Estos valores porcentuales fueron representados paralelamente a los perfiles sedimentológicos con el objetivo de reflejar variaciones verticales en la composición y su relación con las diferentes facies sedimentarias.

\subsubsection{Análisis petrográfico}

Se prepararon un total de 27 secciones delgadas en el Taller de Cortes del CIG a partir de muestras litológicas de areniscas, areniscas-conglomerádicas y, en menor medida, fangolitas. Estos cortes delgados fueron analizados en un microscopio petrográfico Nikon Eclipse E200 el cual cuenta con una cámara Leica ${ }^{\circledR}$ DFC290 HD incorporada. Durante el análisis petrográfico se describieron los elementos que constituyen el esqueleto, la matriz y el cemento. También se determinó el grado de selección (Harrell, 1984), redondez-circularidad (Powers, 1953), y tipo de contactos entre clastos (Taylor, 1950).

Para el estudio de las psamitas se llevó adelante un análisis estadístico de modas detríticas en 27 cortes delgados siguiendo la metodología de GazziDickinson (Ingersoll et al., 1989). Este análisis se realizó con un contador Swift ${ }^{\circ}$ que se encuentra conectado al microscopio y con el cual se llevó a cabo el recuento de 300 puntos por sección delgada con el espaciamiento mayor o igual al tamaño de grano máximo de cada muestra. Luego de realizado el recuento, estas muestras fueron clasificadas utilizando los diagramas ternarios de Folk et al. (1970) y Dott (1964) modificado por Pettijohn et al. (1972). También se 
utilizaron los diagramas de Dickinson et al. (1983) y Dickinson (1988) para trabajar sobre la procedencia de estas sedimentitas.

Por otro lado, también se hizo hincapié en la descripción, clasificación y relaciones entre elementos como cementos, venas, porosidades, relaciones entre clastos, los cuales permitieron estudiar la evolución diagenética de las secciones estudiadas.

\subsubsection{Tareas de gabinete}

Esta segunda etapa de tareas de gabinete comprendió el procesamiento y análisis de la información obtenida durante las tareas de campo y de laboratorio.

\subsubsection{Confección de secciones columnares}

Toda la información del relevamiento de los perfiles sedimentológicos en los afloramientos fue digitalizada en 8 secciones verticales (perfiles Selley) de detalle con la utilización del software CorelDRAW ${ }^{\bullet}$ (Figs. 3.5 y 3.6). Estos perfiles fueron graficados en escala 1:100 y 1:400 con el fin de favorecer la visualización, comprensión y posterior análisis de estas secciones. En estos gráficos se volcó toda la información textural, de los espesores y color de las capas, las estructuras mecánicas y biogénicas, los tipos de contactos entre las capas y presencia de contenido fosilífero. 


\section{Perfiles sedimentológicos}

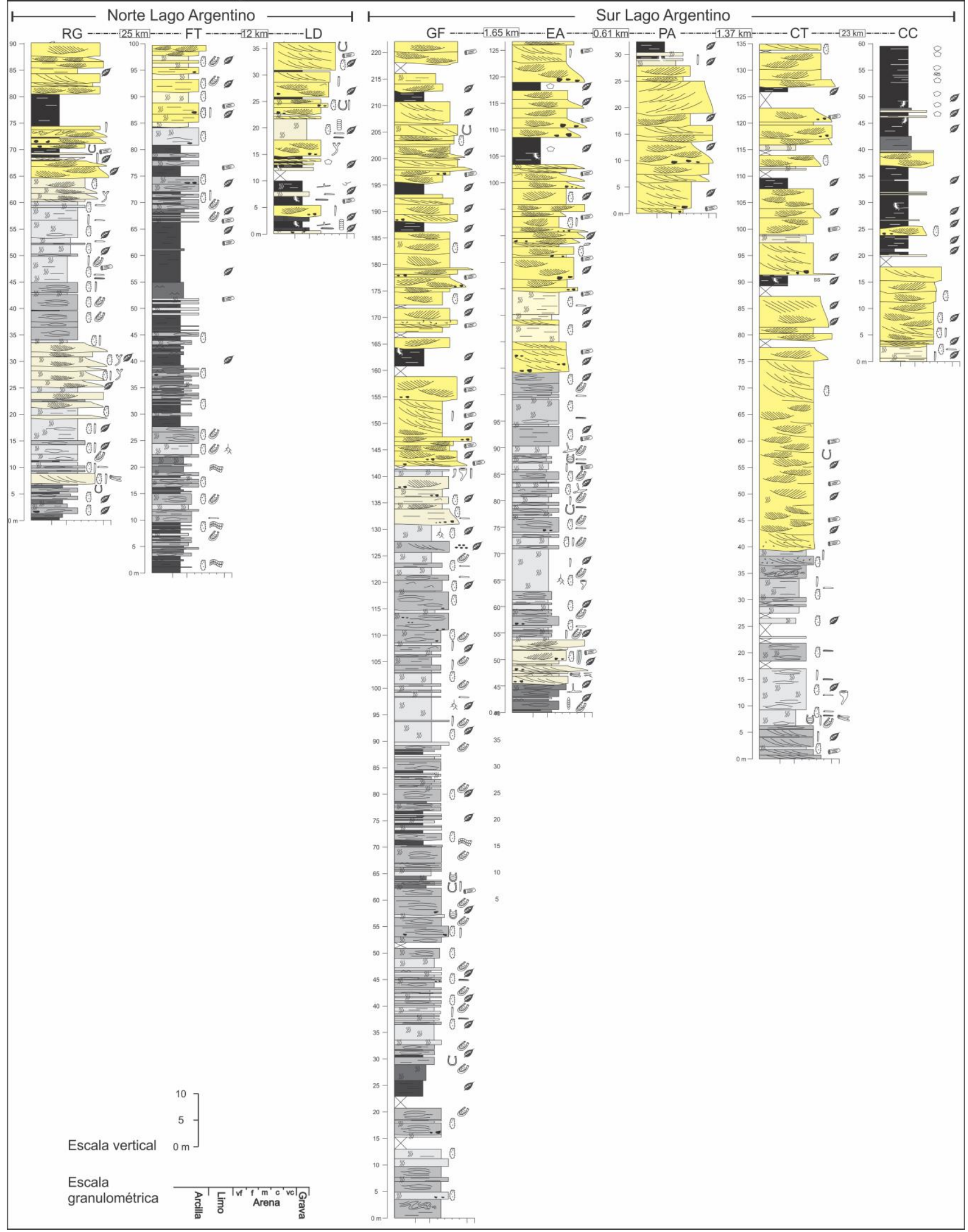

Figura 3.5. Perfiles sedimentológicos relevados en la Formación La Anita. Para ver la ubicación detallada de cada uno de los perfiles ver Figura 3.3 . 


\begin{tabular}{|c|c|c|c|c|c|c|}
\hline$\overline{-}$ & Laminación horizontal & b' & Bioclastos & () & Diplocraterion isp. ()ㅛ & Rhizocorallium isp. \\
\hline 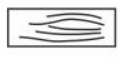 & Estrat. entrecruzada monticular & ss & Slickensides & 晋 & Fugichnia & Rizolitos \\
\hline serey & Estrat. entrecruzada en artesa & 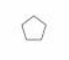 & Agregados angulares & $\bar{z}$ & Gordia isp. & Rosselia isp. \\
\hline$M$ & Estrat. entrecruzada tangencial & 0 & Agregados subangulares & 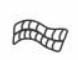 & Gyrochorte isp. & Schaubcylindrichnus isp. \\
\hline Nin & Estrat. entrecruzada planar & $\checkmark$ & Ostracodos & $\varnothing$ & Lockeia isp. & Siphonichnus isp. \\
\hline 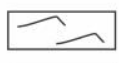 & Laminación entrecruzada & 8 & Material carbonoso & $\therefore$ & Macaronichnus isp. & Skolithos isp. \\
\hline 角 & Óndulas simétricas & $\Rightarrow$ & Troncos & : & Ophiomorpha isp. $\Omega$ & Thalassinoides isp. \\
\hline 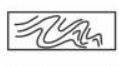 & Deformación sinsedimentaria & U & Arenicolites isp. & $\rightleftarrows$ & Palaeophycus isp. కి & Teichichnus isp. \\
\hline \$\$S $\$ \$$ & Bioturbación & 众 & Chondrites isp. & 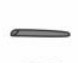 & Planolites isp. & \\
\hline$\cdots$ & Intraclastos pelíticos & $\int$ & Cylindrichnus isp. & y & Psilonichnus isp. & \\
\hline
\end{tabular}

Figura 3.6. Referencias de los perfiles sedimentológicos de la Figura 3.5.

3.3.6.2 Análisis de facies y de asociaciones de facies sedimentarias

Se procedió a la definición de facies sedimentarias a partir de rasgos descriptivos como lo son la litología, textura y estructuras sedimentarias, tanto mecánicas como biogénicas con el fin de comprender los procesos sedimentarios que ocurrieron durante la acumulación de estos depósitos. Se confeccionó un código apropiado para la denominación de cada una de estas facies siguiendo los criterios propuestos por Miall (1977, 1978, 1996). Este código de facies consta de letras mayúsculas que hacen referencia a la litología y una o más letras minúsculas que describen las estructuras sedimentarias presentes (Tabla 4.1). El análisis de facies sedimentarias se desarrolla en detalle en el Capítulo 4. Con posterioridad al análisis de facies se realizó el análisis del ordenamiento espacial de facies con el fin de determinar facies que se encuentren genéticamente relacionadas y así definir asociaciones de facies. El análisis de las asociaciones de facies que permitió realizar las interpretaciones paleoambientales para los depósitos de la Formación La Anita se presenta en el Capítulo 5. 


\subsubsection{Análisis de paleocorrientes}

Con el objetivo de realizar un análisis estadístico de paleodirecciones de flujo (paleocorrientes), se midieron estructuras sedimentarias direccionales con la utilización de una brújula tipo Brunton ${ }^{\circledR}$. Todos los datos de paleocorrientes fueron ajustados de acuerdo a la declinación magnética de la fecha y hora en la cual fueron relevados. Para llevar a cabo el análisis de los datos se confeccionaron tablas Excel $^{\circledR}$ con los valores angulares corregidos, discriminando por nivel donde se obtuvieron los datos y por asociación de facies correspondiente. Posteriormente estos datos fueron volcados en el software Stereonet ${ }^{\bullet}$ donde se generaron diagramas de rosas para visualizar las direcciones preferenciales de paleocorrientes de los diferentes intervalos. Los resultados del análisis de paleocorrientes se presentan y discuten en el Capítulo 5.

\subsubsection{Análisis arquitectural de cuerpos sedimentarios}

Se confeccionaron fotomosaicos de variadas dimensiones en los afloramientos donde se resaltan las mejores características de las distintas asociaciones de facies para el análisis 2D de cuerpos sedimentarios. Estos fotomosaicos fueron realizados a partir del software Kolor Autopano Giga siguiendo los criterios de Wizevich (1991), Olsen et al. (1995) y Bridge et al. (2000), sobre los cuales se mapearon superficies de diferente jerarquía. A partir de esto, se definieron cuerpos sedimentarios a partir de las diferentes asociaciones de facies con la incorporación de datos geométricos, jerarquización de superficies de discontinuidad y distribución espacial de las facies que los constituyen. Los resultados del análisis arquitectural se presentan en el Capítulo 5. 


\subsubsection{Análisis icnológico}

Se llevó a cabo la descripción, caracterización, distribución, abundancia y tipo de estructuras biogénicas (trazas fósiles) presentes en las diferentes capas de la unidad de interés (Figs. 3.5 y 3.6). De este modo, con la ayuda de fotografías tomadas durante el trabajo de campo, se completaron las descripciones de las formas y dimensiones de las diferentes trazas fósiles. Con el objetivo de registrar las variaciones verticales y laterales en la intensidad de la bioturbación se estableció el Índice de Bioturbación (IB) para cada capa y también para cada asociación de facies siguiendo los criterios de Taylor y Goldring (1993). Las características icnológicas de cada asociación de facies en combinación con los procesos depositacionales físicos dominantes se utilizaron en conjunto para establecer condiciones de estrés fisicoquímico. Los resultados obtenidos a partir de este análisis se presentan y discuten en detalle en el Capítulo 6.

\subsubsection{Análisis intelectual de la información}

Durante esta etapa se combinó toda la información obtenida a partir del análisis de facies, de asociaciones de facies, paleocorrientes, arquitectural e icnológico, se analizó también la distribución espacial de las diferentes asociaciones de facies y su patrón vertical de apilamiento (stacking pattern).

A partir del análisis del arreglo vertical y lateral de las asociaciones de facies se discriminaron intervalos característicos, los cuales permitieron la reconstrucción de los sistemas de acumulación, así como también la dinámica y evolución de los mismos. Los sistemas que se reconstruyeron fueron representados en esquemas tridimensionales para mostrar, de una forma simplificada, los atributos de estos. A partir del análisis de facies se determinó 
que los depósitos de la unidad de interés evidencian que los procesos marinos (olas y mareas) y fluviales estuvieron activos, pero en diferentes proporciones durante la acumulación. De esta manera, y siguiendo el criterio propuesto por Ainsworth et al. (2008) se establecieron cuáles fueron los procesos dominantes y subordinados durante la acumulación de diferentes capas. Los procesos dominantes y subordinados que constituyen la mayor proporción de un intervalo estratigráfico son considerados como los procesos dominantes y subordinados que se encontraban activos durante la acumulación (Ainsworth et al., 2008, 2011). Con el objetivo de reconstruir las condiciones de estrés fisicoquímico del medio sobre la fauna bentónica se realizó un análisis de las relaciones organismo-sustrato a partir de la integración de las reconstrucciones paleoambientales y de la dominancia relativa de los procesos depositacionales para estos ambientes con el análisis icnológico.

A partir de una jerarquización de superficies estratigráficas y del análisis del patrón de apilamiento que muestran los sistemas de acumulación identificados para la Formación La Anita y su relación con las unidades infra y suprayacentes se confeccionó un esquema estratigráfico-secuencial para estos depósitos. Los intervalos comprendidos entre diferentes superficies estratigráficas clave se vincularon a distintas condiciones de aporte de sedimentos y de tasa de acomodación. De este modo, se interpretaron los cortejos depositacionales (systems tracts) y se elaboraron modelos para relacionar a la instalación y evolución de los sistemas depositacionales con factores de control alocíclicos. A su vez, con el estudio de la distribución no sólo espacial, sino también temporal, de los depósitos de la unidad de interés y su relación con otras unidades sincrónicas se realizaron consideraciones 
paleogeográficas para comprender la distribución de los diferentes sistemas de acumulación para el Cretácico tardío de la cuenca.

\subsection{CONSIDERACIONES FINALES}

En este capítulo se realizó una breve descripción de la zona de la Cuenca Austral-Magallanes donde afloran las sedimentitas de la Formación La Anita, conocida como "región del Lago Argentino", y se detallaron las metodologías implementadas para el desarrollo de este trabajo de tesis doctoral.

La integración del conocimiento no solo geográfico, sino también geológico, de la región del Lago Argentino con las metodologías implementadas durante las instancias de gabinete inicial, tareas de campo y laboratorio, y las instancias finales de procesamiento y análisis intelectual de la información obtenida permitió llegar a conclusiones y consideraciones sedimentológicas, icnológicas y estratigráfico-secuenciales de estos depósitos. Los resultados que se presentan en los siguientes capítulos y los modelos generados, constituyen una importante base para la correlación con los reservorios del Cretácico Superior del subsuelo y también sirven como modelos predictivos de proyectos de exploración y desarrollo de hidrocarburos en la cuenca. 


\section{Capítulo IV \\ ANÁLISIS DE FACIES SEDIMENTARIAS}

\subsection{INTRODUCCIÓN}

\subsection{1 ¿Qué es una facies sedimentaria?}

El termino facies proviene del latín y hace referencia al "aspecto o apariencia de algo". Una facies sedimentaria es por ende un cuerpo de roca caracterizado por una combinación particular de litología, textura y estructuras sedimentarias físicas y biogénicas que le otorgan un aspecto (facies) el cual difiere de las capas que se encuentran por debajo, por encima y lateralmente (Walker, 1992). La subdivisión de una sucesión sedimentaria en facies debe realizarse en base a una descripción cuidadosa, detalla y objetiva de los depósitos (Middleton, 1978).

\subsection{2 ¿Por qué realizar un análisis de facies sedimentarias?}

La combinación de las características litológicas, texturales y estructuras sedimentarias que definen una facies brindan valiosa información ya que reflejan procesos sedimentarios particulares (Reading y Levell, 1996). El análisis de facies por ende se basa en la interpretación de los atributos de facies y de sucesiones de facies en términos de los procesos sedimentarios responsables de su génesis (Reading y Levell, 1996; Dalrymple, 2010).

4.1.3 ¿Cómo se realizó el análisis de facies sedimentarias para el caso de estudio?

La detallada descripción de los depósitos de la Formación La Anita en los ocho perfiles relevados permitió el reconocimiento de las características litológicas y de estructuras sedimentarias. Posteriormente, a través del análisis pe- 
trográfico de las areniscas se ajustaron las características texturales y se pudieron definir un total de 18 facies sedimentarias (Tabla 4.1). En base a la naturaleza de los componentes de estas facies se diferenciaron facies silicoclásticas y facies mixtas. Las facies silicoclásticas se integran principalmente por componentes terrígenos extracuencales y representan casi la totalidad de las facies reconocidas en la Formación La Anita (17 de un total de 18; 94,4\%). Se ha reconocido una sola facies mixta, la cual se conforma por una mezcla entre componentes silicoclasticos extracuencales y bioclastos carbonáticos en una relación 75 - 25 respectivamente.

Para la nomenclatura de las facies se siguió el código propuesto por (Miall (1977, 1978 y 1996) donde se utilizaron letras mayúsculas para describir las litologías (G, facies conglomerádicas; SG, facies areno-conglomerádicas; S, facies arenosas; $\mathrm{F}$, facies pelíticas; $\mathrm{H}$, facies heterolíticas; $\mathrm{SB}$, facies de areniscas bioclásticas) y letras minúsculas para hacer referencia a las estructuras sedimentarias.

\subsection{FACIES SILICOCLÁSTICAS}

\subsubsection{Conglomerados}

\subsubsection{Conglomerados masivos (Gm)}

Descripción: Esta facies se compone de ortoconglomerados de grano fino y sabulitas clasto sostén cuyo esqueleto se compone principalmente de cristaloclastos de cuarzo y líticos volcánicos. La facies se caracteriza por presentar un aspecto masivo (Fig. 4.1a) y suele portar intraclastos pelíticos. La facies $\mathbf{G m}$ suele presentarse hacia las bases de cuerpos lenticulares, en espesores de hasta 0,2 m. Comúnmente presenta restos vegetales como fragmentos de troncos y hojas. 
Interpretación: La facies $\mathbf{G m}$ se interpreta como un depósito de carga de fondo, generado por corrientes subácueas unidireccionales con una alta concentración de sedimentos (Collinson et al., 2006; Miall, 1978). Debido al contexto en al cual se presenta esta facies (ver facies Gt, SGt y St; ver Capítulo 5), se interpreta que corresponden a depósitos residuales o "lags" basales correspondientes a reactivaciones dentro de un canal o barra (Miall, 1978). 


\begin{tabular}{|c|c|c|c|c|c|}
\hline FS & LITOLOGÍA & $\begin{array}{l}\text { ESTRUCTURA } \\
\text { SEDIMENTARIA }\end{array}$ & SELECCIÓN & RESTOS FÓSILES & $\begin{array}{l}\text { PROCESO } \\
\text { SEDIMENTARIO }\end{array}$ \\
\hline $\mathrm{Gm}$ & $\begin{array}{l}\text { Conglomerados finos } \\
\text { y sabulitas }\end{array}$ & $\begin{array}{l}\text { Masiva, intraclastos } \\
\text { pelitícos }\end{array}$ & Pobre & $\begin{array}{l}\text { Fragmentos de } \\
\text { troncos y hojas }\end{array}$ & $\begin{array}{l}\text { Depósitos residuales. } \\
\text { Reactivación de canales } \\
\text { o barras }\end{array}$ \\
\hline Gt & $\begin{array}{l}\text { Conglomerados finos } \\
\text { y sabulitas }\end{array}$ & $\begin{array}{l}\text { Estratificación } \\
\text { entrecruzada en artesa, } \\
\text { intraclastos pelíticos }\end{array}$ & Moderada - Pobre & $\begin{array}{l}\text { Fragmentos de } \\
\text { troncos y hojas }\end{array}$ & $\begin{array}{l}\text { Migración de dunas } \\
\text { gravosas tridimensionales }\end{array}$ \\
\hline SGt & $\begin{array}{l}\text { Areniscas- } \\
\text { conglomerádicas }\end{array}$ & $\begin{array}{l}\text { Estratificación } \\
\text { entrecruzada en artesa, } \\
\text { intraclastos pelíticos } \\
\text { arreglo granodecreciente }\end{array}$ & Pobre & $\begin{array}{l}\text { Cortinas de fitodetritos, } \\
\text { fragmentos de troncos } \\
\text { y hojas }\end{array}$ & $\begin{array}{l}\text { Migración de dunas } \\
\text { tridimensionales } \\
\text { areno-gravosas }\end{array}$ \\
\hline St & $\begin{array}{l}\text { Areniscas finas } \\
\text { a muy gruesas }\end{array}$ & $\begin{array}{l}\text { Estratificación } \\
\text { entrecruzada en artesa y } \\
\text { planar-tangencial, arreglo } \\
\text { granodecreciente } \\
\text { intraclastos pelíticos }\end{array}$ & Buena - Pobre & $\begin{array}{l}\text { Cortinas de fitodetritos, } \\
\text { fragmentos de troncos } \\
\text { y hojas }\end{array}$ & $\begin{array}{l}\text { Migración de dunas } \\
\text { arenosas tridimensionales }\end{array}$ \\
\hline Sp & $\begin{array}{l}\text { Areniscas finas } \\
\text { a gruesas }\end{array}$ & $\begin{array}{l}\text { Estratificación } \\
\text { entrecruzada } \\
\text { planar, arreglos } \\
\text { granodecrecientes, } \\
\text { intraclastos pelíticos }\end{array}$ & Moderada - Pobre & $\begin{array}{l}\text { Cortinas de fitodetritos, } \\
\text { fragmentos de } \\
\text { troncos y hojas }\end{array}$ & $\begin{array}{l}\text { Migración de dunas } \\
\text { arenosas bidimensionales }\end{array}$ \\
\hline Shcs & $\begin{array}{l}\text { Areniscas muy } \\
\text { finas a finas }\end{array}$ & $\begin{array}{l}\text { Estratificación } \\
\text { entrecruzada monticular }\end{array}$ & Buena & $\begin{array}{l}\text { Cortina de fitodetritos, } \\
\text { fragmentos de hojas }\end{array}$ & $\begin{array}{l}\text { Agradación y migración de } \\
\text { hummocks durante eventos } \\
\text { de tormenta }\end{array}$ \\
\hline Srl & $\begin{array}{l}\text { Areniscas finas } \\
\text { a medianas }\end{array}$ & $\begin{array}{l}\text { Laminación entrecruzada } \\
\text { planar-tangencial }\end{array}$ & Buena & $\begin{array}{l}\text { Cortinas de } \\
\text { fitodetritos }\end{array}$ & $\begin{array}{l}\text { Migración de óndulas } \\
\text { asimétricas de corriente }\end{array}$ \\
\hline Swl & $\begin{array}{l}\text { Areniscas fangosas, } \\
\text { areniscas muy finas }\end{array}$ & Laminación ondulítica & Buena - Moderada & Fragmentos de hojas & $\begin{array}{l}\text { Agradación de óndulas } \\
\text { simétricas }\end{array}$ \\
\hline SI & $\begin{array}{l}\text { Areniscas muy } \\
\text { finasa gruesas }\end{array}$ & $\begin{array}{l}\text { Laminación horizontal, } \\
\text { intraclastos pelíticos }\end{array}$ & Moderada - Pobre & $\begin{array}{l}\text { Fragmentos de } \\
\text { troncos y hojas }\end{array}$ & $\begin{array}{l}\text { Capa plana de } \\
\text { alto régimen }\end{array}$ \\
\hline Sm & $\begin{array}{l}\text { Areniscas finas } \\
\text { a gruesas }\end{array}$ & $\begin{array}{l}\text { Masiva, intraclastos } \\
\text { pelíticos }\end{array}$ & Moderada - Pobre & - & $\begin{array}{l}\text { Rápida desaceleración } \\
\text { flujos unidireccionales } \\
\text { concentrados en sedimentos }\end{array}$ \\
\hline Smb & $\begin{array}{l}\text { Areniscas fangosas } \\
\text { areniscas finas a } \\
\text { muy finas }\end{array}$ & Masiva & Pobre & Fragmentos de hojas & $\begin{array}{l}\text { Retrabajo del sustrato } \\
\text { por organismos }\end{array}$ \\
\hline $\mathrm{Sd}$ & $\begin{array}{l}\text { Areniscas finas } \\
\text { a medianas }\end{array}$ & $\begin{array}{l}\text { Laminación } \\
\text { convoluta }\end{array}$ & Buena - Moderada & - & $\begin{array}{l}\text { Deformación plástica } \\
\text { de sustrato parcialmente } \\
\text { licuado }\end{array}$ \\
\hline $\mathrm{Hb}$ & Heterolítica & Masiva & Moderada - Pobre & Fragmentos de hojas & $\begin{array}{l}\text { Retrabajo del sustrado } \\
\text { por organismos }\end{array}$ \\
\hline $\mathrm{Hw}$ & Heterolítica & Laminación wavy & Moderada - Pobre & - & $\begin{array}{l}\text { Agradación de óndulas } \\
\text { simétricas y decantación } \\
\text { de sedimento en suspensión }\end{array}$ \\
\hline $\mathrm{Hf}$ & Heterolítica & Laminación flaser & Moderada - Pobre & - & $\begin{array}{l}\text { Migración de óndulas } \\
\text { asimétricas, decantación } \\
\text { de sedimento en suspensión }\end{array}$ \\
\hline $\mathrm{Fm}$ & Fangolitas & $\begin{array}{l}\text { Masiva, rizolitos, } \\
\text { slickensides }\end{array}$ & Buena & $\begin{array}{l}\text { Fragmentos de hojas } \\
\text { y troncos }\end{array}$ & $\begin{array}{l}\text { Decantación de sedimento } \\
\text { en suspensión, frecuente } \\
\text { sobreimposición de rasgos } \\
\text { pedogenéticos }\end{array}$ \\
\hline $\mathrm{FI}$ & $\begin{array}{l}\text { Fangolitas, } \\
\text { limolitas }\end{array}$ & $\begin{array}{l}\text { Laminación } \\
\text { horizontal }\end{array}$ & Buena & $\begin{array}{l}\text { Fragmentos de } \\
\text { hojas }\end{array}$ & $\begin{array}{l}\text { Decantación de sedimento } \\
\text { en suspensión }\end{array}$ \\
\hline SBtp & $\begin{array}{l}\text { Areniscas finas } \\
\text { a gruesas bioclásticas }\end{array}$ & $\begin{array}{l}\text { Estratificación } \\
\text { entrecruzada } \\
\text { planar-tangencial }\end{array}$ & Pobre & Ostreidos inarticulados & $\begin{array}{l}\text { Migración de dunas } \\
\text { tridimensionales }\end{array}$ \\
\hline
\end{tabular}




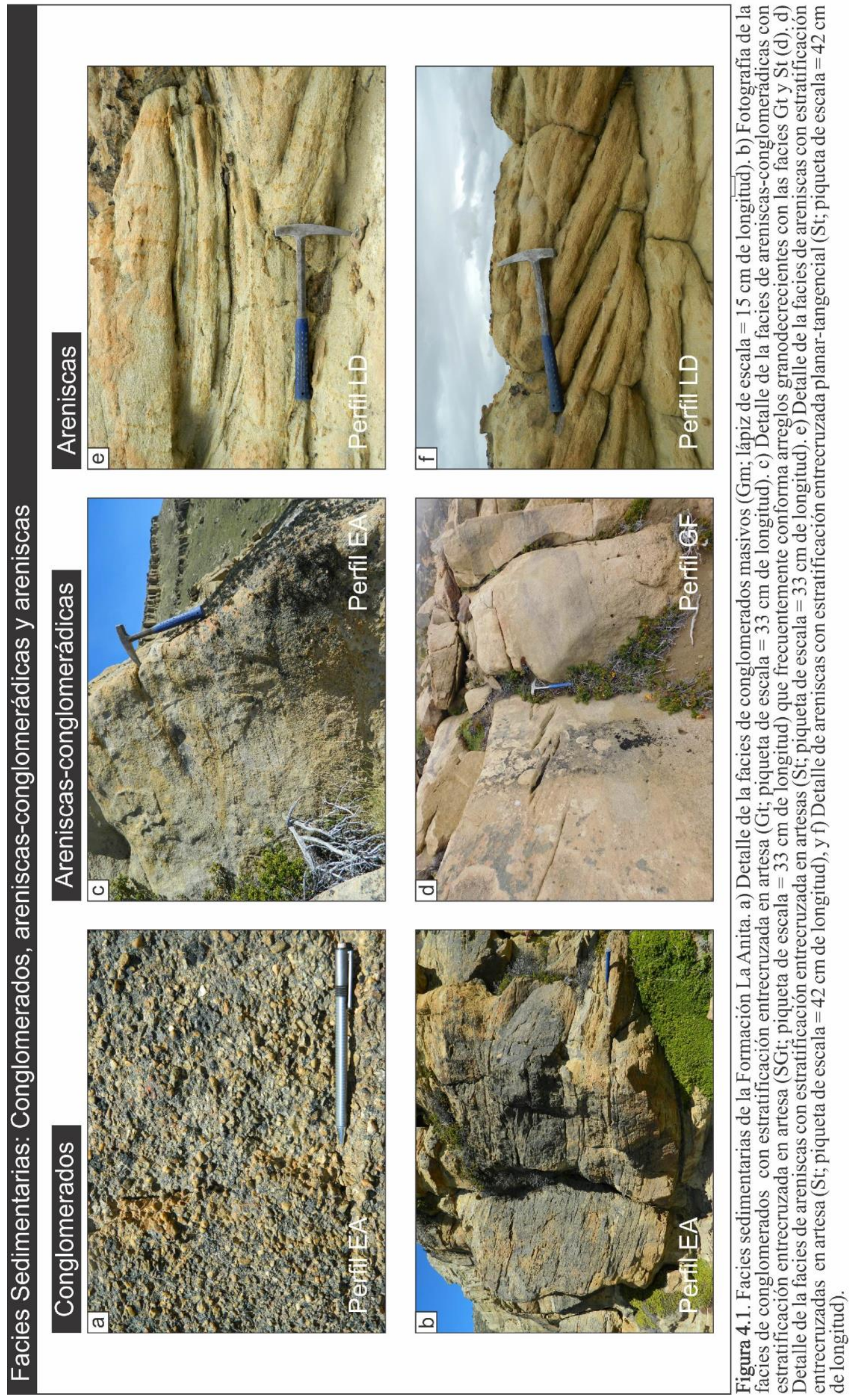




\subsubsection{Conglomerados con estratificación entrecruzada en artesa (Gt)}

Descripción: Esta facies se compone de sabulitas y conglomerados de grano fino, moderadamente bien seleccionados con textura clasto sostén. La facies presenta una escasa matriz de arena mediana a gruesa. Los clastos de esta facies son subredondeados y corresponden principalmente a cristaloclastos de cuarzo y líticos volcánicos. La facies Gt se caracteriza por presentar una estratificación entrecruzada en artesa, conformando sets de entre 0,4 y 0,6 $\mathrm{m}$ de espesor y arreglos granodecrecientes con transición a las facies SGt y St (Fig. 4.1b). La facies Gt se encuentra presente en litosomas de geometría lenticular y frecuentemente acompañada de restos de troncos y hojas. La facies Gt típicamente carece de rasgos de bioturbación $(\mathrm{IB}=0-1)$, reconociéndose solo excavaciones aisladas asociadas a Ophiomorpha isp.

Interpretación: Esta facies se interpreta como un depósito de carga de fondo, generado por la migración de formas de lecho gravosas complejas (dunas tridimensionales), las cuales se generan a partir de corrientes unidireccionales, diluidas, tractivas y turbulentas (Collinson y Thompson, 1989; Leeder, 1999; Collinson et al., 2006; Bridge y Demicco, 2008).

\subsubsection{Areniscas conglomerádicas}

4.2.2.1 Areniscas conglomerádicas con estratificación entrecruzada en artesa $(\mathbf{S G} \mathbf{t})$

Descripción: Esta facies se compone de areniscas medianas a gruesas que se encuentran intercalando con láminas psefíticas, de tamaño sábulo a grava fina. Las areniscas presentan una textura clasto sostén y una moderada selección. Esta facies se caracteriza por presentar una estratificación entrecruzada en artesa en sets de hasta $0,7 \mathrm{~m}$ de potencia (Fig. 4.1c) y suele portar intraclastos 
pelíticos hacia la base de los cuerpos. Se encuentra asociada a las facies $\mathbf{G m}, \mathbf{G t}$ y St conformando tanto arreglos granocrecientes como decrecientes (Fig. 4.1d). Esta facies se encuentra presente en cuerpos lenticulares y está acompañada de restos de hojas y troncos, estos últimos suelen presentar Teredolites isp. Comúnmente carece de rasgos de bioturbación preservando solo algunas estructuras biogénicas aisladas de Arenicolites isp., Ophiomorpha isp., Schaubcylindrichnus coronus y Psilonichnus isp.

Interpretación: Esta facies se interpreta como un depósito de carga de fondo, generado por la migración de dunas tridimensionales areno-gravosas (Collinson y Thompson, 2006; Bridge y Demicco, 2008), las cuales son originadas a partir de flujos subácueos unidireccionales diluidos, tractivos y turbulentos.

\subsubsection{Areniscas}

\subsubsection{Areniscas con estratificación entrecruzada en artesa (St)}

Descripción: Esta facies se compone de areniscas medianas a muy gruesas, con moderada selección y textura clasto sostén. Presentan clastos de cuarzo de tamaño grava dispersos y ocasionalmente suelen presentar intraclastos pelíticos hacia la base de los sets. Esta facies se caracteriza por presentar una estratificación entrecruzada en artesa, planar-tangencial y sigmoidal de pequeña a mediana escala conformando sets entre 0,15 y $1 \mathrm{~m}$ de espesor (Fig. 4.1e y f) que suelen presentar arreglos granodecrecientes y granocrecientes. Frecuentemente presenta importantes acumulaciones de fitodetritos en los senos de las artesas y en los foresets sin mostrar ningún tipo de ciclicidad en su distribución. Los sets se disponen conformando cosets de hasta $5 \mathrm{~m}$ de potencia los cuales se encuentran dentro de cuerpos de geometrías lenticulares y cuneiformes. Esta facies 
ocasionalmente presenta excavaciones biogénicas de Arenicolites isp., Diplocraterion isp., Gordia isp., Lockeia isp., Macaronichnus isp., Ophiomorpha isp., Psilonichnus isp., Schaubcylindrichnus isp., Skolithos isp. y Siphonichnus isp. También son comunes los restos de troncos y de hojas fragmentadas.

Interpretación: Esta facies se interpreta como un depósito generado por la migración de dunas arenosas de crestas sinuosas y discontinuas (tridimensionales; Collinson et al., 2006) generadas a partir de un flujo subácueo unidireccional, diluido, tractivo y turbulento en condiciones de bajo régimen de flujo, pero con la energía necesaria y la profundidad suficiente para generar estas formas de lecho en vez de óndulas o dunas con crestas rectas y continuas (bidimensionales; Collinson y Thompson, 1989; Leeder, 1999; Collinson et al., 2006). El amplio rango granulométrico que presenta esta facies se debe a que el tamaño de grano está relacionado con la profundidad del agua y la velocidad del agente de transporte (Southard y Boguchwal, 1990), mientras que las diferencias entre los tamaños de los sets se deben principalmente a: 1) la relación que existía entre las tasas de sedimentación y de migración de las dunas; 2) las variaciones en las escalas de las dunas producto a cambios en la columna de agua; 3) cambios en la tasa de migración y cambios en la geometría de cada duna mientras migran (Allen, 1982; Paola y Borgmanm 1991; Bridge, 1997; Leclair y Bridge, 2001; Bridge y Demicco, 2008).

\subsubsection{Areniscas con estratificación entrecruzada planar (Sp)}

Descripción: Esta facies se compone de areniscas medianas a gruesas, moderada a pobremente seleccionadas, con textura clasto sostén, que internamente presentan una estratificación entrecruzada planar (Fig. 4.2a). Esta facies se encuentra en cuerpos de geometrías lenticulares y cuneiformes, y se presenta en espesores que varían entre los 0,2 y $1 \mathrm{~m}$. La facies se dispone conformando 
sets en los que son comunes los arreglos granodecrecientes, la presencia de intraclastos peliticos hacia las bases y la presencia de material vegetal como impresiones y restos de troncos y hojas. Al igual que en la facies $\mathbf{S t}$, suele presentar acumulaciones de fitodetritos en los foresets de las estructuras. En ocasiones, la estratificación entrecruzada se encuentra perturbada por rasgos de bioturbación correspondientes a los ichnogéneros Arenicolites isp., Ophiomorpha isp. y Skolithos isp.

Interpretación: Esta facies se interpreta como un depósito de carga de fondo el cual es originado a partir de la migración de dunas arenosas de crestas rectas y continuas (bidimensionales; Collinson et al., 2006; Bridge y Demicco, 2008). Estas formas de lecho se generan a partir de flujos unidireccionales, turbulentos, diluidos y en bajo régimen de flujo (Collinson y Thompson, 1989; Leeder, 1999). El motivo por el cual estos depósitos se presentan con diferentes tamaños de grano se basa en que esta característica depende tanto de la velocidad que presente el agente de transporte, así como también de la profundidad de la columna de agua al momento de la depositación del sedimento (Southard y Boguchwal, 1990).

\subsubsection{Areniscas con estratificación entrecruzada monticular (Shcs)}

Descripción: Esta facies se compone de areniscas muy finas a finas, rara vez medianas, de buena selección y textura clasto sostén, las cuales se caracterizan por presentar una estratificación entrecruzada monticular (hummocky crossstratification; HCS; Fig. 4.2b). Internamente esta estructura se compone de láminas levemente inclinadas y se disponen tanto de manera cóncava (swales) como convexa (hummocks) hacia arriba. Se presentan en capas individuales cuyos espesores varían entre 0,1 y $0,5 \mathrm{~m}$, pero frecuentemente se presentan conformando cuerpos amalgamados los cuales pueden alcanzar los 2,3 $\mathrm{m}$ de espe- 
sor. Esta facies frecuentemente se encuentra intensamente retrabajada por organismos generando pasajes transicionales hacia la facies $\mathbf{S m b}$. Las estructuras biogénicas que se han identificado dentro de esta facies se corresponden a los icnogéneros Diplocraterion isp., Ophiomorpha isp., Rhizocorallium isp., Rossellia isp. y Skolithos isp. Esta facies porta una gran cantidad de fitodetritos entre los granos de arena.

Interpretación: Esta facies se interpreta como un depósito generado a partir de la acción de flujos subácueos unidireccionales y oscilatorios combinados, con mayor participación de movimientos oscilatorios (Arnott y Southard, 1990; Dumas y Arnott, 2006), provocando la migración de óndulas simétricas y asimétriscas (Myrow y Southard, 1991), así como también la generación de formas de lecho monticulares (hummocks). Si la componente unidireccional fuera más fuerte que la oscilatoria favorecería la formación y migración de dunas en vez de los hummocks (Dumas, 2004). Los flujos combinados son comunes durante episodios de tormenta en sistemas marinos someros, donde se favorece la formación de grandes olas, junto con fuertes corrientes unidireccionales en simultaneo, provocando así la remoción de arena de las zonas más someras (shoreface) transportándola hacia aguas más profundas (Grant y Madsen, 1979; Snedden et al., 1988; Eide et al., 2015). Estos hummocks se desarrollan y preservan donde la tasa de sedimentación es lo suficientemente alta, en aguas que sean lo suficientemente someras como para que los orbitales de las olas sean grandes (>1 m) y rápidos (>50 cm/s), pero lo suficientemente profundas como para mantener olas simétricas y corrientes unidireccionales lentas $(<10 \mathrm{~cm} / \mathrm{s}$; Dumas y Arnott, 2006). 


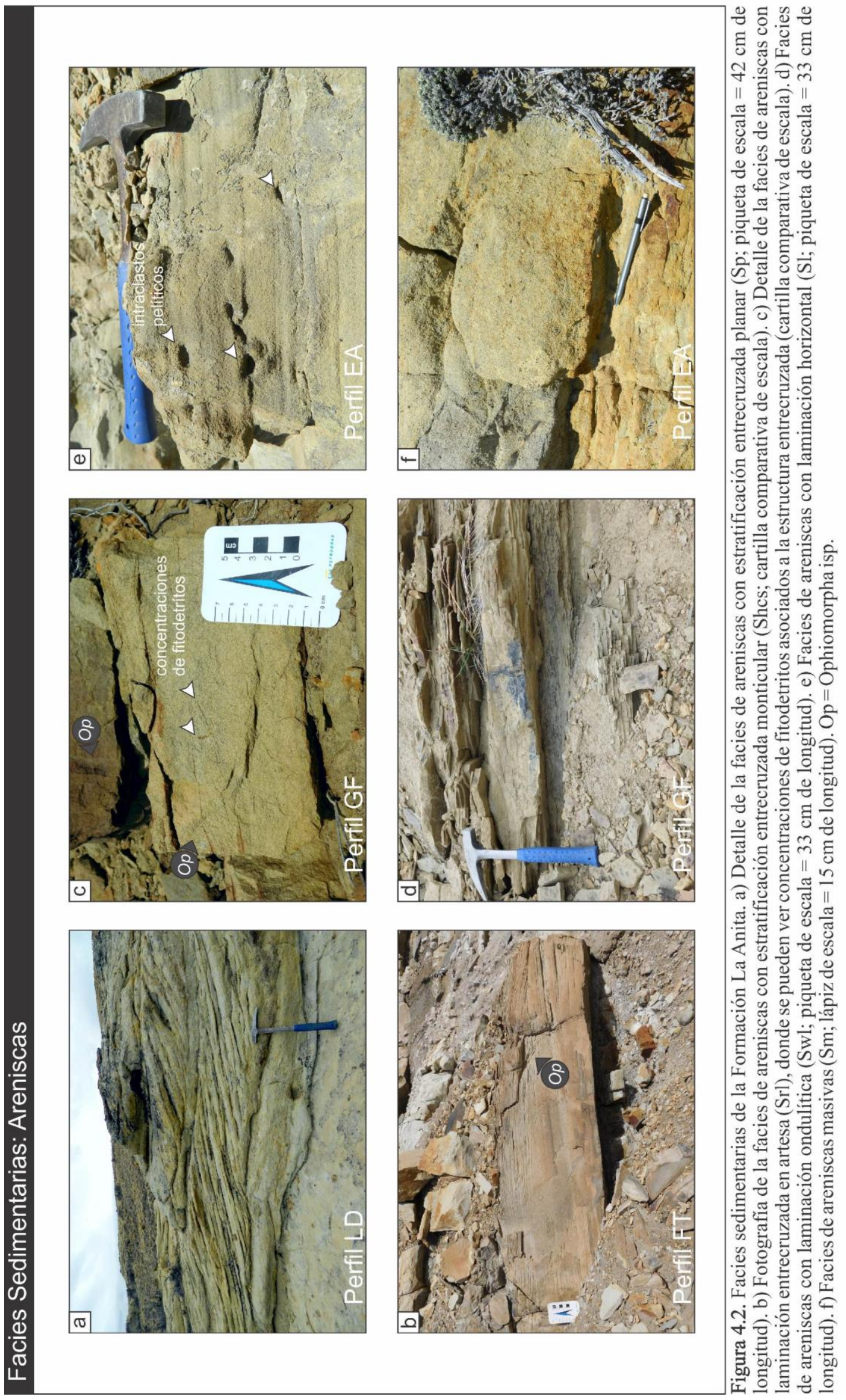




\subsubsection{Areniscas con laminación entrecruzada (Srl)}

Descripción: Esta facies se compone de areniscas finas a medianas bien seleccionadas las cuales se caracterizan por presentar laminaciones entrecruzadas planar-tangencial y sigmoidal con escalonamientos subcríticos (Fig. 4.2c). Estas laminaciones se disponen conformando sets de entre 0,1 a 0,3 m de potencia los cuales se agrupan en cosets de hasta $0,7 \mathrm{~m}$ de espesor. Frecuentemente la facies Srl presenta acumulaciones de fitodetritos en los foresets entrecruzados (Fig. 4.2c). Esta facies se encuentra dentro de litosomas de geometrías tabulares y lenticulares. En ocasiones particulares se han observado, asociado a esta facies, estructuras biogénicas de Ophiomorpha isp.

Interpretación: Esta facies se interpreta como un depósito de carga de fondo generado por la migración de óndulas asimétricas con crestas sinuosas y discontinuas (tridimensionales), las cuales se generan a partir de corrientes subácueas, unidireccionales y turbulentas, en condición de bajo régimen de flujo (Collinson et al., 2006; Bridge y Demicco, 2008). El escalonamiento subcrítico se debe a que la tasa de acumulación era baja en relación con la tasa de migración de las óndulas (Collinson et al., 2006).

\subsubsection{Areniscas con laminación ondulítica (Swl)}

Descripción: Esta facies se integra por areniscas fangosas, y areniscas muy finas a finas las cuales se caracterizan por presentar laminaciones horizontales a subhorizontales con óndulas simétricas (Fig. 4.2d). Estas óndulas presentan crestas angulosas y una altura comprendida entre los 0,5 y 2 centímetros. Esta facies alcanza espesores de hasta 0,3 $\mathrm{m}$ y se encuentra relacionada a cuerpos de geometrías tabulares. 

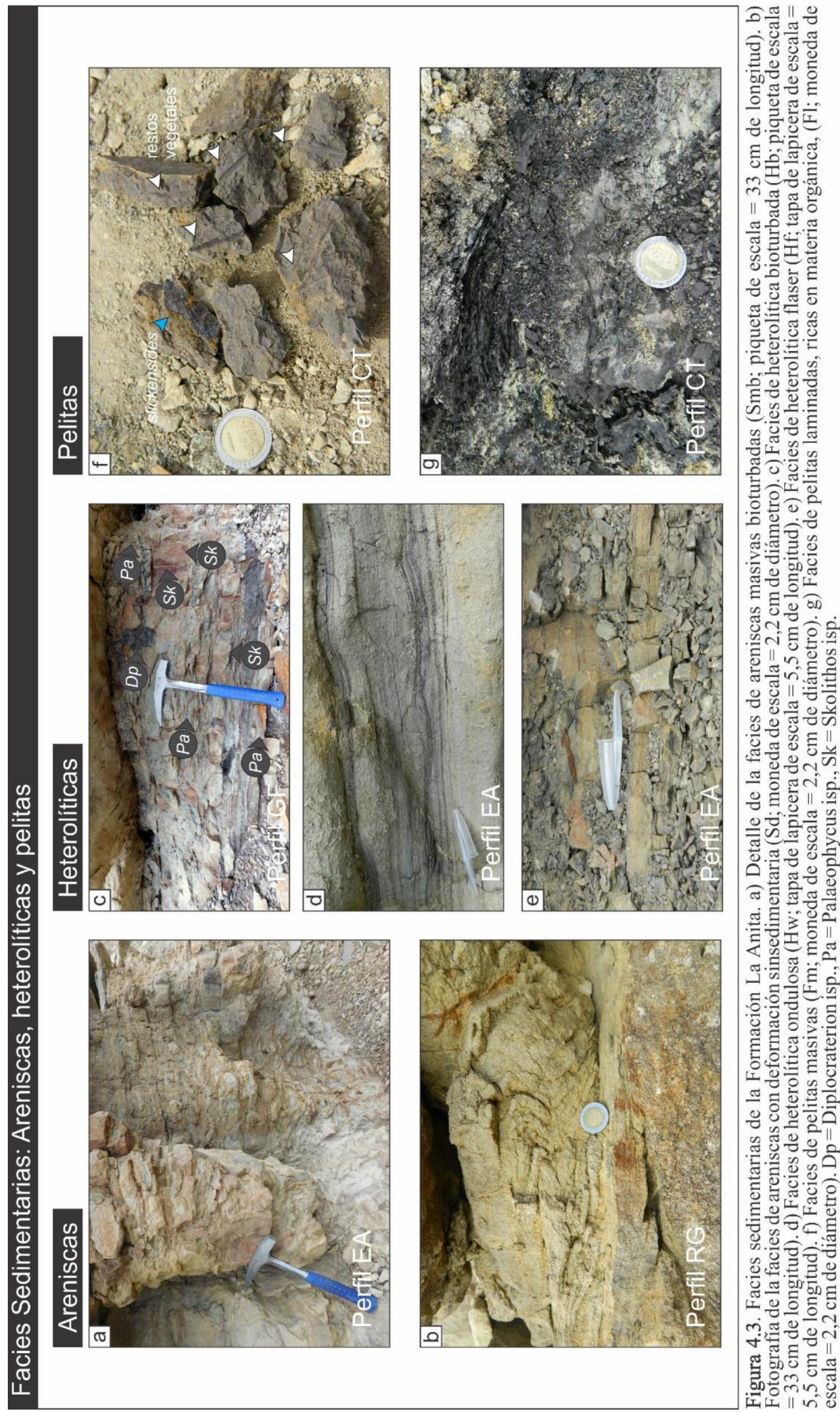
Interpretación: Esta facies se interpreta como un depósito generado por la migración y acreción de óndulas de oleaje de crestas rectas y continuas (Collinson et al., 2006) generadas a partir de movimientos oscilatorios de olas.

\subsubsection{Areniscas con laminación horizontal (Sl)}

Descripción: Esta facies se compone de areniscas finas a gruesas clasto soportadas, que varían entre moderadamente bien a pobremente seleccionadas las cuales se caracterizan por mostrar una laminación horizontal a entrecruzada de muy bajo ángulo $\left(<5^{\circ} ;\right.$ Fig. $\left.4.2 \mathrm{e}\right)$. Esta facies se encuentra en cuerpos arenosos de geometrías tabulares y lenticulares con bases irregulares acompañadas de intraclastos pelíticos, y presenta espesores comprendidos entre los 0,05 y 1,2 metros. La facies suele presentar rasgos de lineación parting, arreglos internos granodecrecientes, abundantes fragmenteos vegetales como hojas y troncos, así también como algunas estructuras biogénicas aisladas de Diplocraterion isp., Ophiomorpha isp., Rhizocorallium isp., Palaeophycus isp., Rosselia isp. y Skolithos isp.

Interpretación: Esta facies se interpreta como un depósito de fondo en fase de capa plana de alto régimen originada a partir de flujos subácueos unidireccionales, diluidos y turbulentos (Collinson y Thompson, 1989; Leeder, 1999; Miall, 2006). Las diferentes laminas que constituyen a la laminación representan oscilaciones en la energía del flujo quedando definidas por una leve diferencia granulométrica entre las láminas (Collinson et al., 2006).

\subsubsection{Areniscas masivas $(\mathbf{S m})$}

Descripción: Esta facies se compone de areniscas finas a muy gruesas pobremente seleccionadas que presentan un aspecto masivo y suelen mostrar clastos de cuarzo tamaño grava dispersos, así como también intraclastos pelíticos 
(Fig. 4.3f). Esta facies se presenta en espesores comprendidos entre los 0,05 y 1 m y se encuentra contenida dentro de cuerpos de geometría tabular. La presencia de estructuras biogénicas dentro de esta facies no es común, sin embargo se han reconocido algunas trazas de Ophiomorpha isp. y Rhizocorallium isp.

Interpretación: Esta facies se interpreta como un depósito generado a partir de la rápida desaceleración de flujos gravitatorios concentrados en sedimentos (Miall, 1978; Collinson y Thompson, 1989, Collinson et al., 2006). Los clastos de tamaño grava dispersos dentro de esta facies, sugiere que los flujos perdieron rápidamente su capacidad de transporte y que carecían de turbulencia suficiente como para ordenar los clastos dentro de la columna de agua por lo que se interpreta que la masividad de estos depósitos es primaria y no producto de la bioturbación.

\subsubsection{Areniscas masivas bioturbadas $(\mathbf{S m b})$}

Descripción: Se incluyen dentro de esta facies a las areniscas fangosas y areniscas finas a medianas que se caracterizan por presentar un aspecto masivo y una gran cantidad de estructuras biogénicas (Fig. 4.3a), a tal punto que el reconocimiento de los diferentes icnogéneros resulta difícil, sin embargo se han reconocido Chondrites isp., Cylindrichnus isp., Ophiomorpha isp., Palaeophycus isp., Rhizocorallium isp., Rosselia isp., Schaubcylindrichnus isp., Skolithos isp. y Teichichnus isp. Esta facies se dispone conformando cuerpos tabulares de espesores que varían entre los 0,1 y 2 metros.

Interpretación: Esta facies se interpreta como depósitos cuya estructura primaria ha sido completamente obliterada por la acción de fauna bentónica (Buatois y Mángano, 2011). Debido a esto no es posible realizar una interpretación de las características del flujo que originó estos depósitos más allá de infe- 
rir un transporte tractivo. Sin embargo, estas capas altamente bioturbadas sugieren acumulación en una configuración marina con condiciones de fisicoquímica adecuadas para la colonización del sustrato por la fauna bentónica, con una tasa de acumulación relativamente lenta (Collinson et al., 2006; MacEachern et al., 2005, 2007, 2010, Buatois y Mángano, 2011; Moyano Paz et al., 2020).

\subsubsection{Areniscas con deformación sinsedimentaria $(\mathbf{S d})$}

Descripción: Esta facies comprende a areniscas finas a medianas con textura clasto sostén las cuales se caracterizan por presentar laminaciones convolutas y pliegues de deformación de diferente intensidad y escala (Fig. 4.3b). Esta facies se presenta en espesores de entre 0,15 y 1,5 m, asociada a cuerpos de geometría tabular.

Interpretación: Esta facies se interpreta como un depósito que sufrió un proceso de deformación plástica cuando el sedimento se encontraba parcialmente licuado, es decir, presentaba una gran cantidad de fluidos en el espacio poral. La rápida depositación de sedimento sobre estos depósitos licuados generó suficiente presión como para provocar el escape de fluidos producto de una sobrecarga (Collinson et al., 2006).

\subsubsection{Depósitos heterolíticos}

\subsubsection{Depósitos heterolíticos bioturbados $(\mathbf{H b})$}

Descripción: Esta facies se compone de areniscas finas a muy finas y fangolitas que presentan un aspecto masivo debido a la homogeneización por bioturbación entre las dos fracciones granulométricas, sin embargo, aún es posible reconocer láminas arenosas y fangosas en forma discreta (Fig. 4.3c). Esta facies presenta una gran cantidad de estructuras biogénicas, reconociéndose Diplocraterion isp., Gyrochorte isp., Palaeophycus isp., Planolites isp., Skolithos isp. y Tei- 
chichnus isp. Se encuentra en cuerpos tabulares y presenta espesores de hasta 0,5 metros.

Interpretación: Esta facies se interpreta como un depósito cuya estructura primaria resultó obliterada por la intensa actividad de la fauna bentónica, la cual logró la colonización del sustrato gracias a condiciones favorables de oxigenación, salinidad, turbidez de agua y energía (Collinson et al., 2006; MacEachern et al., 2005, 2007, 2010; Bann et al., 2008; Buatois y Mángano, 2011; Moyano Paz et al., 2020).

\subsubsection{Depósitos heterolíticos ondulosos $(\mathbf{H w})$}

Descripción: Esta facies se compone de intervalos heterolíticos caracterizados por la alternancia bien marcada entre areniscas muy finas a finas y fangolitas (Fig. 4.3d). Las capas arenosas se caracterizan por presentar óndulas simétricas a levemente asimétricas con crestas agudas, las cuales presentan un carácter agradante generando una laminación ondulítica (Fig. 4.3d). Las láminas de arena con óndulas son cubiertas por niveles de fangolitas grises a negras masivas las cuales presentan abundante contenido de fitodetritos. La alternancia bien marcada entre los niveles de arena y pelita en proporciones similares de abundancia conforman interestratificados arena-pelita.

Interpretación: Esta facies se interpreta como un depósito generado por la alternancia de procesos tractivos y de decantación. A partir de flujos oscilatorios tractivos en un medio subácueo se generaron las óndulas simétricas (Collinson et al., 2006). Estas corrientes son interrumpidas por periodos de menor energía donde tiene lugar la decantación del sedimento fino el cual se transporta en suspensión (Bridge y Demicco, 2008).

4.2.4.3 Depósitos heterolíticos con laminación flaser (Hf) 
Descripción: Esta facies se compone de areniscas finas a muy finas que presentan una laminación la cual puede ser entrecruzada u horizontal y se caracterizan por alternar con pequeñas láminas de fangolitas discontinuas (Fig. 4.3e). Esta alternancia bien marcada entre estos niveles de arena y las láminas de pelita conforman un interestratificado arena-pelita con un predominio de la fracción granulométrica más gruesa.

Interpretación: Se interpreta a esta facies como un depósito generado a partir de un flujo subácueo, unidireccional, diluido, en condición de bajo régimen de flujo el cual era capaz de generar y causar la migración de óndulas asimétricas tridimensionales (Collinson et al., 2006). Sin embargo, este flujo eventualmente se encontraba interrumpido por momentos de menor energía, donde se producía la decantación de sedimentos finos que se encontraban siendo transportados en suspensión (Collinson et al., 2006; Bridge y Demicco, 2008).

\subsubsection{Pelitas}

\subsubsection{Pelitas masivas $(\mathbf{F m})$}

Descripción: Esta facies se compone de fangolitas negras a grisáceas y verdes que se caracterizan por presentar un aspecto masivo (Fig. 4.3f). Esta facies se presenta en espesores que varían entre los 0,1 y los $6 \mathrm{~m}$, en cuerpos tabulares de gran continuidad lateral. Asociado a estas sedimentitas de grano fino suelen reconocerse abundantes restos de hojas y troncos, superficies de fricción o "slickensides", desarrollo de estructuras en bloque, así como también rizolitos y excavaciones biogénicas de Palaeophycus isp., Planolites isp. y Gyrochorte isp.

Interpretación: Esta facies se interpreta como un depósito que se generó a partir de la decantación de la carga en suspensión (Collinson et al., 2006). El aspecto masivo de esta facies puede tener diferentes génesis: 1) debido a un proce- 
so de decantación muy homogéneo y posiblemente rápido, 2) por una falta de granos de forma plana, lo cual puede estar asociado a la floculación de partículas coloidales, ó 3) por la destrucción de láminas preexistentes producto del trabajo biogénico o procesos pedogenéticos (Potter et al., 1980; Collinson et al., 2006). Los niveles que contienen rizolitos, "slickensides" y estructuras en bloque evidencian que estos depósitos sufrieron exposición subaérea y estuvieron sometidos a procesos pedogenéticos (Retallack, 2001).

\subsubsection{Pelitas laminadas $(\mathbf{F l})$}

Descripción: Esta facies se compone de fangolitas grises y negras, y limolitas grisáceas que se caracterizan por presentar una laminación horizontal bien definida (Fig. 4.3g). Se disponen conformando cuerpos tabulares de gran continuidad lateral. Presenta abundantes restos e impresiones de briznas vegetales que suelen constituir potentes niveles carbonosos. Dentro de esta facies se han registrado escasas y aisladas excavaciones de Planolites isp.

Interpretación: Esta facies se interpreta como un depósito generado por la decantación subácuea de sedimentos finos los cuales fueron transportados como carga en suspensión (Collinson et al., 2006). La laminación interna se genera por fluctuaciones en la tasa de sedimento que es transportado en suspensión resultando en una decantación rítmica (Potter et al., 1980).

\subsection{FACIES MIXTAS}

\subsubsection{Areniscas bioclásticas}

4.3.1.1 Areniscas bioclásticas con estratificación entrecruzada planartangencial (SBtp)

Descripción: Esta facies incluye a las areniscas medianas a muy gruesas pobremente seleccionadas, con textura clasto sostén, las cuales se caracterizan 
por presentar bioclastos de ostreidos desarticulados de hasta $4 \mathrm{~cm}$ de longitud con bajo grado de fragmentación los cuales se disponen conformando una estratificación entrecruzada (Fig. 4.4a y b). Los sets entrecruzados presentan espesores comprendidos entre los 0,2 y 0,6 m, y suelen presentar bases irregulares.

Interpretación: Esta facies se interpreta como un depósito de carga de fondo, generado a partir de la migración de dunas tridimensionales las cuales se originan por una corriente unidireccional, turbulenta y diluida en condición de bajo régimen de flujo (Collinson y Thompson, 1989; Leeder, 1999; Collinson et al., 2006). El grado de transporte que sufrieron los bioclastos fue relativamente bajo debido al bajo grado de fragmentación que presentan, representando una fauna paraautóctona.

\section{Facies Sedimentarias: Areniscas bioclásticas}
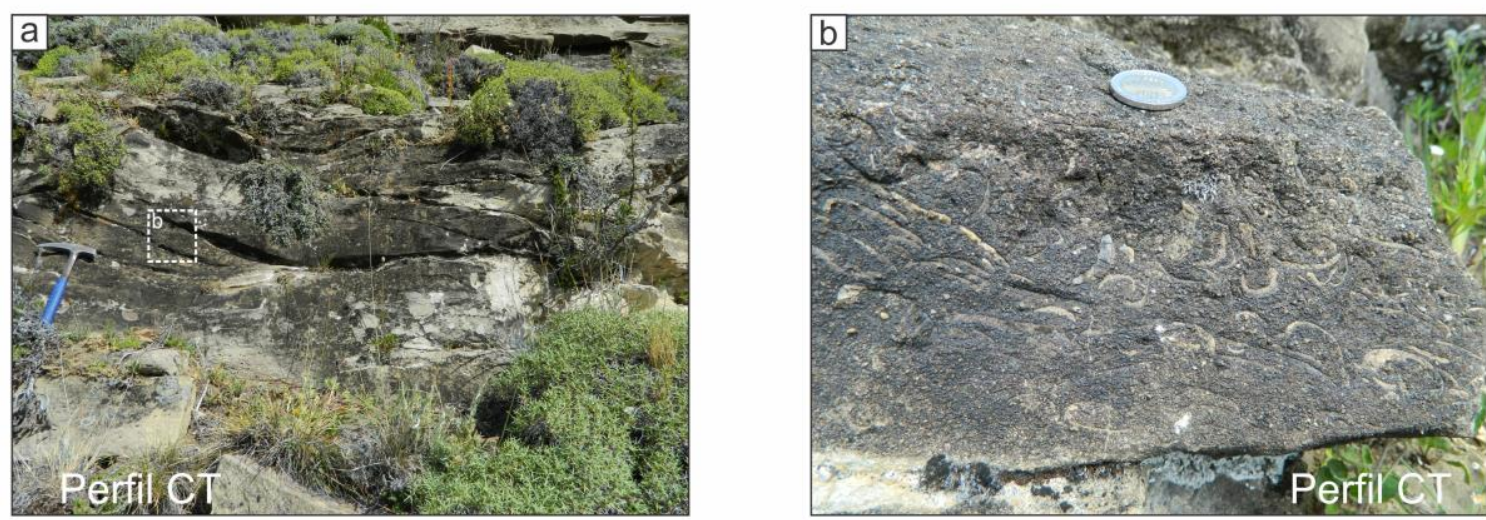

Figura 4.4. Facies sedimentarias de la Formación La Anita. a) Facies de areniscas bioclásticas con estratificación entrecruzada planar-tangencial (SBtp; piqueta de escala $=33 \mathrm{~cm}$ de longitud). b) Detalle de la facies SBtp mostrando la mezcla de componentes bioclásticos y terrígenos (moneda de escala $=2,2 \mathrm{~cm}$ de diámetro).

\subsection{CONSIDERACIONES FINALES}

El análisis de facies sedimentarias realizado en la sucesión estudiada permitió reconocer 18 facies sedimentarias diferentes las cuales reflejan procesos de erosión y transporte de componentes extra e intracuencales hasta su acumulación. El transporte y la acumulación tuvo lugar bajo condiciones subácueas, 
aunque algunos depósitos luego de su acumulación muestran evidencias de exposición subaérea (por ejemplo, la facies Fm; Ratallack, 2001).

Composicionalmente se reconocieron componentes extracuencales representados por cuarzo, feldespato y líticos, y componentes intracuencales representados por intraclastos pelíticos y bioclastos. En función de los componentes presentes en los diferentes litosomas se diferenciaron entre facies silicoclásticas y facies mixtas. Las facies silicoclásticas representan el grupo de facies mayoritario y las más abundantes dentro de la sucesión estudiada (Anexo 1) lo que sugiere que estos depósitos se acumularon durante condiciones de alta disponibilidad de aporte de materiales terrígenos. A su vez, dentro de las facies silicoclásticas, las más abundantes en la unidad estudiada son las facies arenosas lo que podría indicar alta disponibilidad de clastos de esta granulometría y condiciones de energía favorables para su transporte y acumulación.

En cuanto a los procesos sedimentarios que actuaron durante la acumulación de los sedimentos de la Formación La Anita, el análisis de facies refleja que existió una dominancia de depositación por procesos tractivos por encima de la acumulación por decantación de sedimentos finos transportados por suspensión. A su vez, las facies reconocidas para la Formación La Anita reflejan que existió depositación tanto por corrientes unidireccionales, como oscilatorias y también por corrientes combinadas, la dominancia de estos procesos se tratará con detalle en el Capítulo 5. 


\section{Capítulo V \\ ANALLISIS DE ASOCLACIONES DE FACIES, PROCESOS DEPOSITACIONALES Y SISTEMAS DE ACUMULACIÓN}

\subsection{INTRODUCCIÓN}

\subsection{1 ¿Qué es una asociación de facies?}

Las asociaciones de facies son definidas como un conjunto de facies sedimentarias genéticamente relacionadas y que por lo tanto tienen un significado ambiental (Collinson, 1969). A diferencia de las facies sedimentarias, que reflejan procesos sedimentarios los cuales no sugieren un ambiente depositacional particular, las asociaciones de facies representan el conjunto de procesos físicos, químicos y biológicos que ocurren en un subambiente sedimentario particular (Dalrymple, 2010).

\subsection{2 ¿Por qué realizar un análisis de asociaciones de facies?}

Debido a que cada asociación de facies tiene un significado ambiental, el análisis de éstas permite entender las combinaciones de procesos sedimentarios que ocurren en los diferentes subambientes que componen a un sistema de acumulación determinado (Walker, 2006). Otro aspecto interesante que surge a partir de este estudio es el del análisis de sucesiones de asociaciones de facies. El concepto de sucesión implica que las asociaciones de facies pueden variar progresivamente tanto vertical como lateralmente con una tendencia determinada y permitir que sean analizadas de una forma descriptiva, y definir por ejemplo sucesiones granocrecientes, y también interpretativamente definiendo por ejemplo sucesiones somerizantes (Walker, 2006; Dalrymple, 2010). La manera en la que se apilan las asociaciones de facies, es decir las sucesiones de asocia- 
ciones de facies, permiten comprender de una forma más precisa la evolución de los diferentes sistemas de acumulación (Dalrymple, 2010).

5.1.3 ¿Cómo se realizó el análisis de asociaciones de facies para el caso de estudio?

Para realizar el análisis de asociaciones de facies se realizaron descripciones y mediciones de campo y también a partir de fotomosaicos. De esta manera se describieron la geometría y dimensión de los diferentes litosomas que constituyen a la Formación La Anita y también la jerarquía de las superficies tanto internas como limitantes de estos litosomas. Una vez que se definieron los diferentes cuerpos sedimentarios (unidades sedimentarias) se describió en detalle la relación de las diferentes facies sedimentarias que los componen, las direcciones de paleocorrientes y las características icnológicas que presentaban (esto último será tratado en detalle en el Capítulo 6 de este trabajo de tesis). De esta manera se definieron un total de 9 asociaciones de facies (Tabla 5.1) las cuales se describen e interpretan en detalle a continuación. La manera en la que se disponen las diferentes asociaciones de facies del caso de estudio permitió interpretar 3 sistemas de acumulación diferentes para la Formación La Anita. 


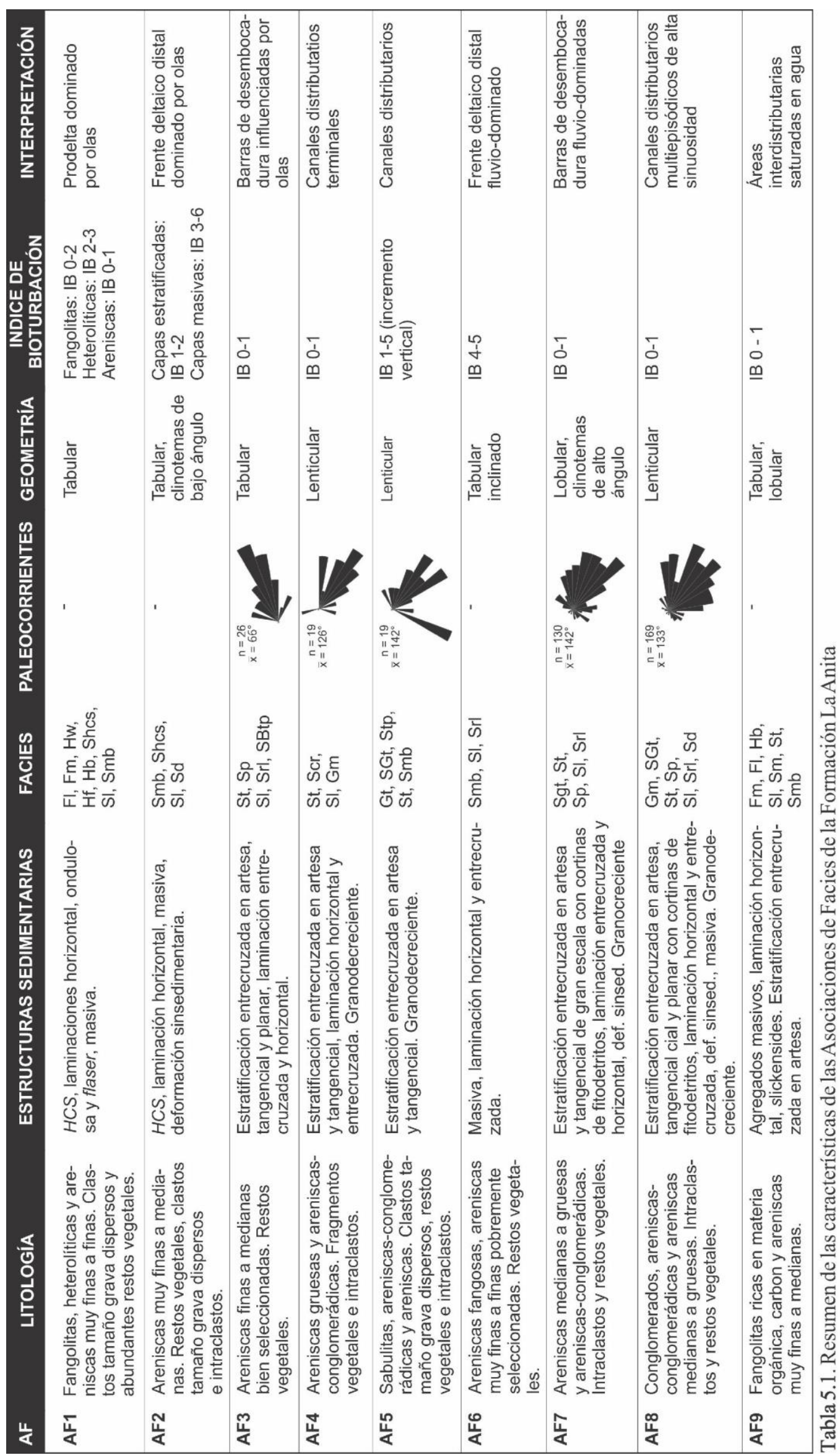




\subsection{ASOCIACIONES DE FACIES}

\subsubsection{Asociación de Facies 1 (AF1):}

Descripción: La AF1 grada vertical y transicionalmente desde los depósitos marinos profundos de plataforma externa y talud dominantemente de grano fino de la Formación Alta Vista y es cubierta por las areniscas de la AF2. También ha sido registrada cubriendo a las sedimentitas de la AF2 a través de superficies de inundación. La AF1 conforma cuerpos tabulares de hasta $5 \mathrm{~m}$ de espesor y al menos $400 \mathrm{~m}$ de continuidad lateral (Fig. 5.1a). Esta asociación de facies consiste en intercalaciones de fangolitas negras, depósitos heterolíticos y areniscas muy finas a finas y conforman arreglos granocrecientes (Fig. 5.1a). Las facies de grano fino consisten principalmente en fangolitas laminadas o masivas (Fly $F m$, Fig. 5.1b), los depósitos heterolíticos se presentan tanto con laminaciones de tipo ondulosa, flaser, o masivas ( $H w, H f$ y $H b$; Fig. 5.1c). Las areniscas de esta asociación se caracterizan por presentar estratificación entrecruzada monticular (HCS; Shcs, Fig. 5.1c) y laminación paralela ( $\boldsymbol{S}$ ) las cuales suelen contener clastos de cuarzo tamaño grava dispersos. Los depósitos arenosos de esta asociación de facies rara vez se presentan masivos $(\boldsymbol{S} m b)$. Las capas que conforman a la AF1 presentan una baja abundancia y también una baja diversidad de estructuras biogénicas (IB 0-3; Tabla 5.1), reconociéndose Arenicolites isp., Diplocraterion isp., Gyrochorte isp., Ophiomorpha isp., Palaeophycus isp., Planolites isp., Rhizocorallium isp. y Skolithos isp. Los depósitos de esta asociación también se caracterizan por presentar abundantes restos vegetales como fitodetritos, fragmentos de hojas y troncos (Fig. 5.1e).

Interpretación: La AF1 refleja la alternancia entre depositación por decantación de carga en suspensión del sedimento de grano fino durante condiciones de buen tiempo, o durante la fase final de eventos de tormenta, y la depositación 


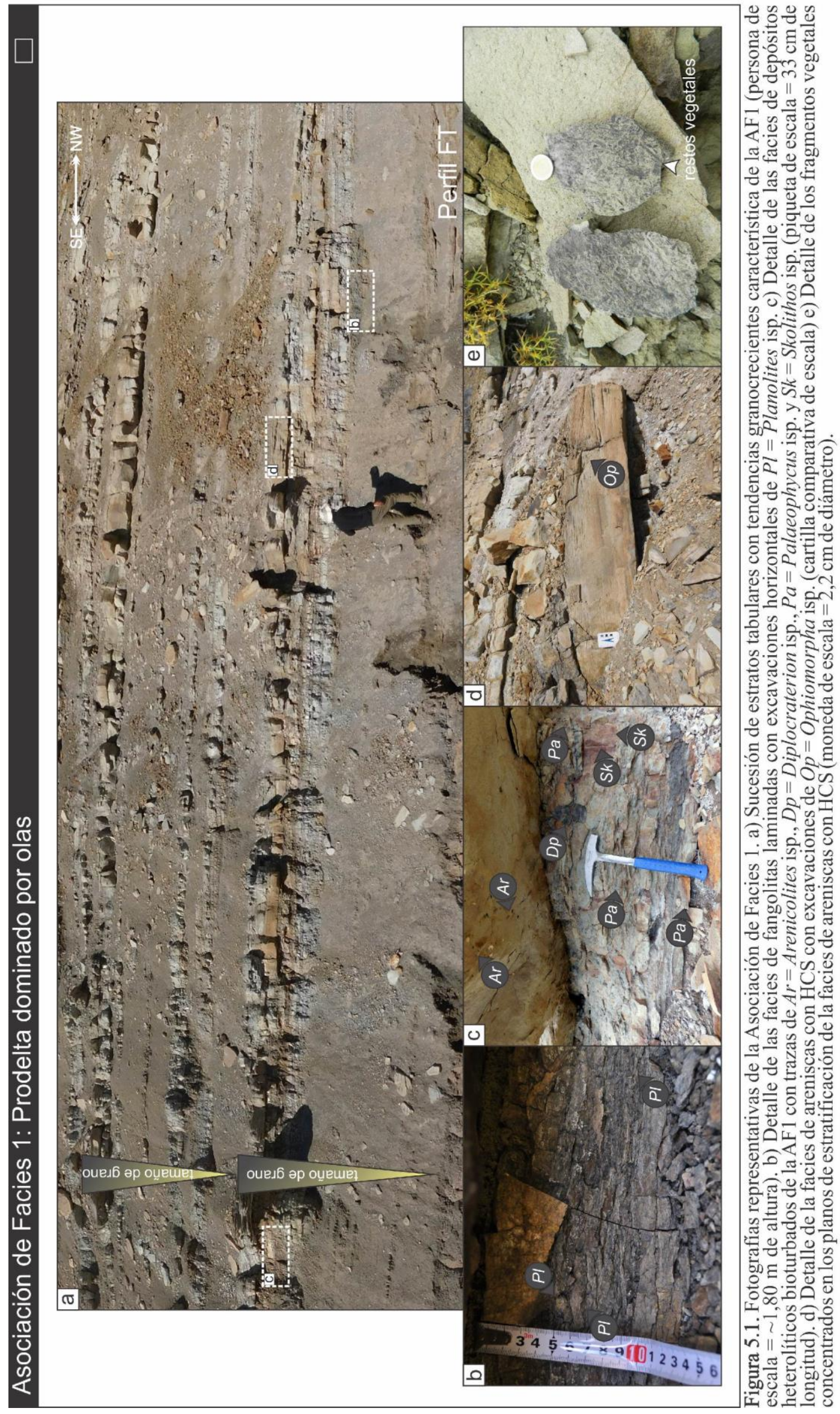


de sedimentos de grano más grueso a partir de la combinación de flujos unidireccionales y oscilatorios durante eventos de tormenta. La baja abundancia de estructuras biogénicas sugiere que esta asociación de facies se depositó en un ambiente marino marginal (MacEachern et al., 2005). La baja abundancia de trazas fósiles, así como también la presencia de clastos de tamaño grava dispersos en las facies arenosas y la presencia de abundantes restos vegetales, así como también la presencia de facies heterolíticas con laminación tipo flaser podrían asociarse a descargas fluviales cercanas (Bhattacharya, 2006; Bann et al., 2008). La AF1 sugiere la acumulación en una profundidad de offshore-transition, entre los niveles de base de acción de olas de tormenta y de buen tiempo (Dott y Bourgeois, 1982; Myrow y Southard, 1996; Dumas y Arnott, 2006; Eide et al., 2015). Sin embargo, debido a la posible presencia de corrientes fluviales activas durante la depositación, la AF1 se interpreta como la depositación en un subambiente de prodelta dominado por olas (Asquith, 1970, 1974; Bhattacharya, 2006, 2010; Bhattacharya y MacEachern, 2009; Moyano Paz et al., 2018, 2020).

\subsubsection{Asociación de Facies 2 (AF2):}

Descripción: La AF2 grada de forma transicional desde los depósitos de la AF1 o desde los depósitos marinos profundos de grano fino de la Formación Alta Vista. También ha sido registrada por encima de las AF3 y AF4 a través de superficies de inundación. La AF2 grada verticalmente hacia las sedimentitas que conforman la AF3 o también se ha observado que es incidida por los cuerpos de geometría canalizada de las AF4 y AF5. La AF2 se dispone conformando clinotemas de bajo ángulo $\left(\sim 4^{\circ}-7^{\circ}\right)$ de hasta $15 \mathrm{~m}$ de potencia las cuales se encuentran compuestas por areniscas muy finas a medianas dispuestas en arreglos grano y estratocrecientes (Fig. 5.2a). En algunos casos, estos cuerpos se 
presentan amalgamados conformando sucesiones de hasta $45 \mathrm{~m}$ de espesor y cientos de metros de continuidad lateral (Fig. 5.2a). Esta asociación de facies consiste en una intercalación de areniscas masivas con un alto índice de bioturbación (IB 4-6; $S m b$ y facies de areniscas con HCS y laminación horizontal o de bajo ángulo las cuales presentan una menor intensidad de bioturbación (IB 1-3; Shcs y $S$; Fig. 5.2a, b y c). La presencia de clastos de cuarzo tamaño grava dispersos en las capas arenosas de esta asociación de facies es común. Las capas que preservan las estructuras mecánicas comúnmente conforman cuerpos arenosos amalgamados que alcanzan los $10 \mathrm{~m}$ de potencia e internamente presentan superficies erosivas acompañadas de intraclastos pelíticos y estructuras de deformación sinsedimentaria $(\boldsymbol{S} \boldsymbol{d})$. En esta asociación de facies se han registrado trazas de escape y Chondrites isp., Cylindrichnus isp., Diplocraterion isp., Ophiomorpha isp., Palaeophycus isp., Rhizocorallium isp., Rossellia isp., Schaubcylindrichnusisp. y Skolithos isp. Dentro de los depósitos que conforman a la AF2 son abundantes los restos vegetales en forma de fitodetrítos, fragmentos de hojas y de troncos (Fig. 5.2d).

Interpretación: La presencia de facies arenosas con HCS y laminación horizontal reflejan depositación tractiva a partir de flujos combinados formados durante eventos de tormenta (Myrow y Southard, 1996; Dumas y Arnott, 2006), mientras que, por otro lado, las areniscas masivas son el resultado del retrabajo por organismos de estas capas de tormenta durante condiciones de buen tiempo (Bann et al., 2008; Buatois y Mángano, 2011). Los cuerpos amalgamados de capas generadas por tormenta podrían indicar una alta periodicidad de flujos de relajación generados después de los eventos de tormenta, los cuales erosionan las formas de lecho que se generan durante condiciones de buen tiempo (Dott y Bourgeos, 1982; Isla et al., 2018; Schwarz et al., 2020). La presencia de clastos 


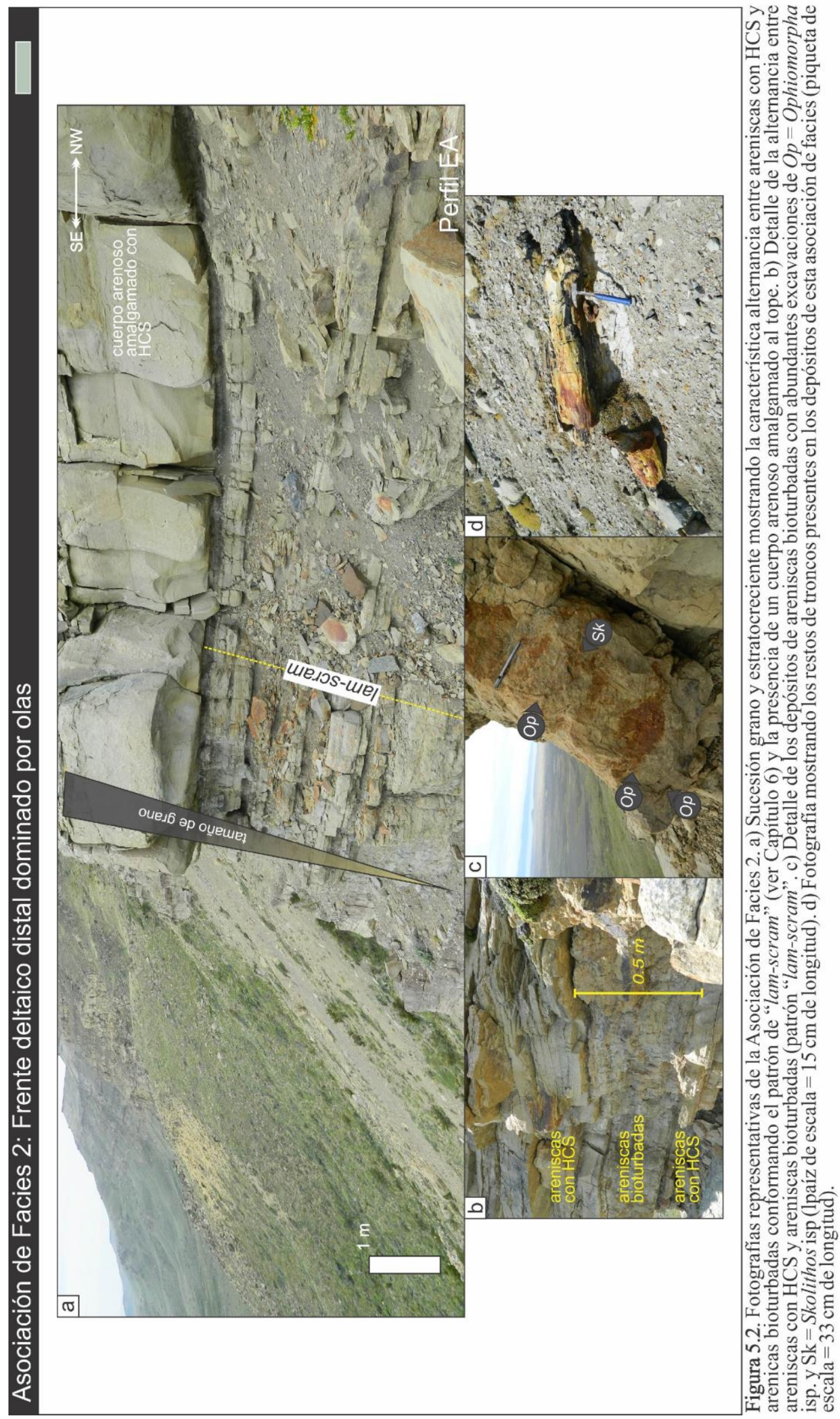


de cuarzo tamaño grava y los abundantes restos vegetales que se han registrado en estos depósitos sugieren la presencia de una cercana desembocadura de un río y la influencia de procesos fluviales durante la acumulación de estos depósitos (Bhattacharya, 2006; Bann et al., 2008; Moyano Paz et al., 2018). La AF2 refleja la depositación en una zona por encima del nivel de base de olas de buen tiempo y por debajo el nivel de olas de $\operatorname{surf}($ Clifton, 2006), la cual se encontraba influenciada por corrientes fluviales y se interpreta como la sedimentación en un subambiente de frente deltaico distal dominado por olas (Bhattacharya y Giosan, 2003; Bhattacharya, 2006, 2010; Moyano Paz et al., 2018, 2020).

\subsubsection{Asociación de Facies 3 (AF3):}

Descripción: La AF3 consiste en cuerpos levemente inclinados $\left(3^{\circ}-5^{\circ}\right)$ de geometría tabular los cuales gradan vertical y lateralmente desde los depósitos del frente deltaico distal dominado por olas (AF2) y son truncados al tope por incisiones de los cuerpos canalizados de las AF4 y AF5 o por los depósitos de la AF2 a través de superficies de inundación (Fig. 5.3a). Los cuerpos de la AF3 llegan a alcanzar $5 \mathrm{~m}$ de potencia y presentan varias decenas de metros de continuidad lateral. Internamente se encuentran compuestos por areniscas finas a medianas y por areniscas bioclásticas de color gris que se presentan con buena selección, con escasa a nula presencia de matriz pelítica y suelen presentar arreglos granocrecientes. Estas areniscas se encuentran caracterizadas por presentar sets de estratificación entrecruzada tangencial, en artesa y planar, de hasta 0,4 m de espesor ( $\boldsymbol{S t}, \boldsymbol{S} \boldsymbol{p}$, y $\boldsymbol{S} \boldsymbol{G} t \boldsymbol{p}$, Fig. 5.3a). Sin embargo, dentro de la AF3 también se han registrado facies de areniscas con laminaciones entrecruzadas y horizontales, estas últimas suelen presentar lineación parting (Srly $\boldsymbol{S}$; Fig. 5.3b, c y d). Las estructuras entrecruzadas de esta asociación de facies se encuentran orientadas principalmente hacia el noreste y presentan muy poca dispersión 
(Tabla $5.1 ; n=26, \bar{x}=66^{\circ}$ ). Un rasgo distintivo de esta asociación es que se presenta sin rasgos de bioturbación o con excavaciones muy aisladas (IB 0-1) de Diplocraterion isp., Gordia isp., Lockeia isp., Macaronichnus isp. y Ophiomorpha isp. ubicadas hacia los topes de los cuerpos. Las facies que componen a esta asociación están acompañadas de abundantes restos vegetales tales como fitodetritos, fragmentos de hojas y troncos, así como también clastos de cuarzo tamaño grava dispersos.

Interpretación: La AF3 refleja la acumulación de sedimentos a partir de corrientes tractivas unidireccionales que permitieron la migración de dunas y óndulas tridimensionales (Southard y Boguchal, 1990; Bridge y Demicco, 2008). La baja abundancia de estructuras orgánicas marinas en esta asociación indica altas condiciones de energía y probablemente de agua salobre, mientras que la presencia de material vegetal sumado a los clastos de tamaño grava dispersos podrían sugerir la cercanía a la desembocadura de un río (Bhattacharya, 2006; Bann et al., 2008; Moyano Paz et al., 2018). La AF3 se interpreta como depósitos de barras de desembocadura desarrolladas en un subambiente de frente deltaico proximal (Bhattacharya y Giosan, 2003, Bhattacharya, 2006, Enge et al., 2010; Moyano Paz et al., 2018). Si bien en esta asociación de facies no hay evidencias directas de acción de oleaje que se puedan reflejar en las estructuras mecánicas, la influencia de los procesos de oleaje se infiere por la ausencia de sedimento fino en la matriz de estos depósitos arenosos lo cual podría asociarse al movimiento oscilatorio de las olas de alta frecuencia y por lo tanto se interpreta como un frente deltaico distal influenciado por olas (Plint, 2010; Ainsworth et al., 2016; Moyano Paz et al., 2018). Esto se sustenta además por la asociación con los depósitos del frente deltaico distal dominado por olas de la AF2. 


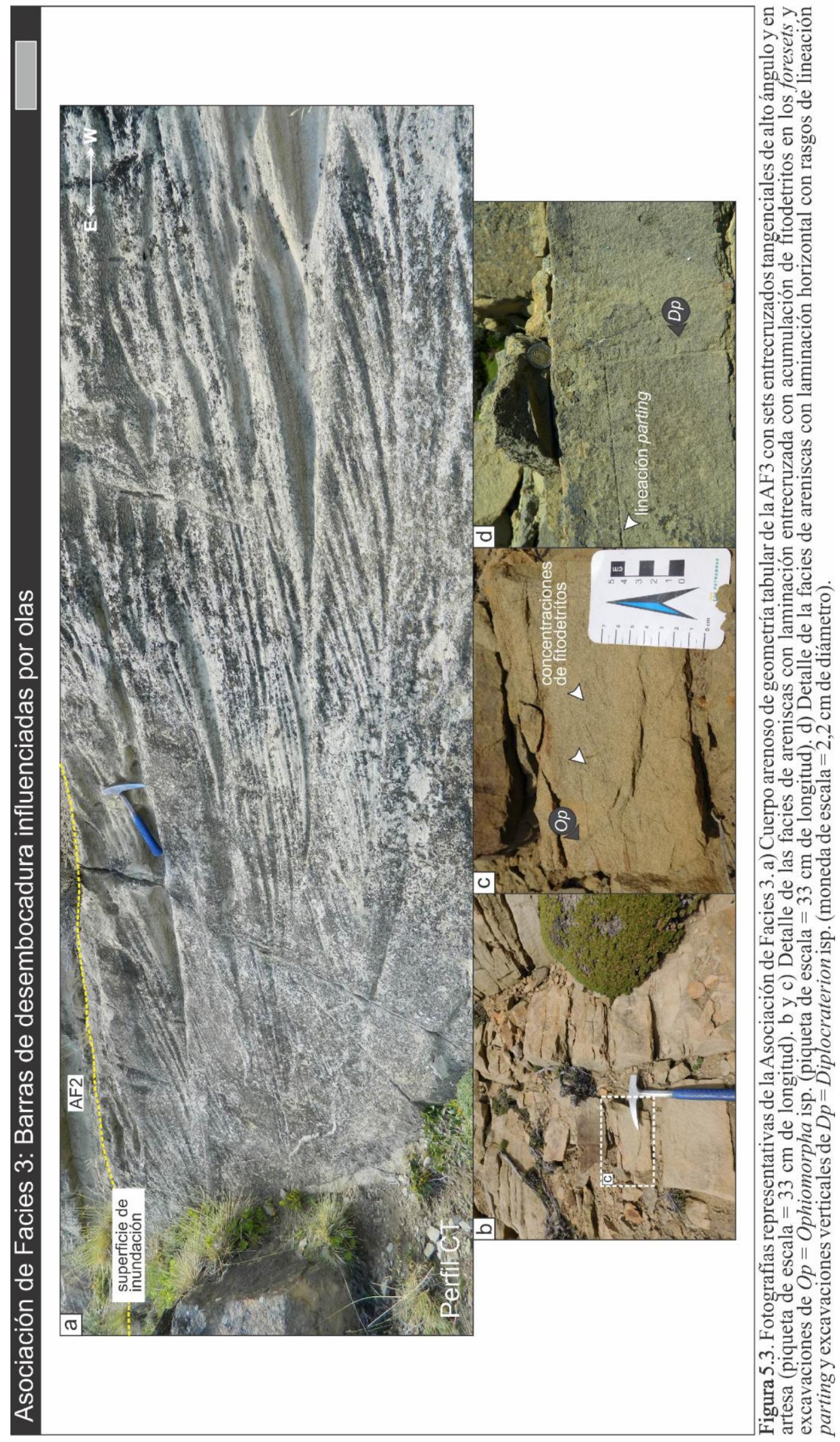




\subsubsection{Asociación de Facies 4 (AF4):}

Descripción: La AF4 se dispone por encima de los depósitos de las AF2 y AF3 a través de superficies erosivas y es cubierta por incisiones generadas por los cuerpos de geometría canalizada de la AF5 o por los depósitos de la AF2 mediante superficies de inundación. La AF4 consiste en cuerpos arenosos lenticulares no amalgamados de hasta 6 metros de espesor y 20 metros máximo de continuidad lateral, los cuales presentan bases irregulares cóncavas hacia arriba (Fig. 5.4a). Estos cuerpos se encuentran compuestos por areniscas medianas a gruesas y areniscas-conglomerádicas pobremente seleccionadas que se disponen conformando arreglos granodecrecientes (Fig. 5.3b), y se caracterizan por presentar estratificaciones entrecruzadas en artesa y tangencial (St, Fig. 5.3c), las cuales pasan verticalmente a facies con laminación entrecruzada y laminación horizontal ( $\boldsymbol{S} r$ y $\boldsymbol{S} I$ ). Hacia la base de estos cuerpos son comunes los intraclastos pelíticos y la concentración de los clastos más gruesos ( $G m$, Fig. 5.3b y d). Internamente estos cuerpos no disponen de superficies de menor jerarquía. Las paleocorrientes medidas en las estructuras entrecruzadas se orientan dominantemente hacia el sudeste (Tabla $5.1 ; n=19, \bar{x}=126^{\circ}$ ). La AF4 típicamente carece de rasgos de bioturbación o presenta algunas estructuras biogénicas aisladas, las cuales se encuentran principalmente hacia el techo de los cuerpos, y se corresponden a Ophiomorpha isp., Schaubcylindrichnus coronus y Siphonichnus isp. Esta asociación contiene abundantes restos vegetales, tales como fragmentos de hojas y de leños (Fig. 5.3e).

Interpretación: La AF4 refleja la depositación por corrientes unidireccionales tractivas. La naturaleza erosiva de sus bases, los arreglos granodecrecientes, la pobre selección, estructuras asociadas a la migración de dunas, la ausencia de superficies internas y la presencia de un lagde grano grueso hacia la base de los 


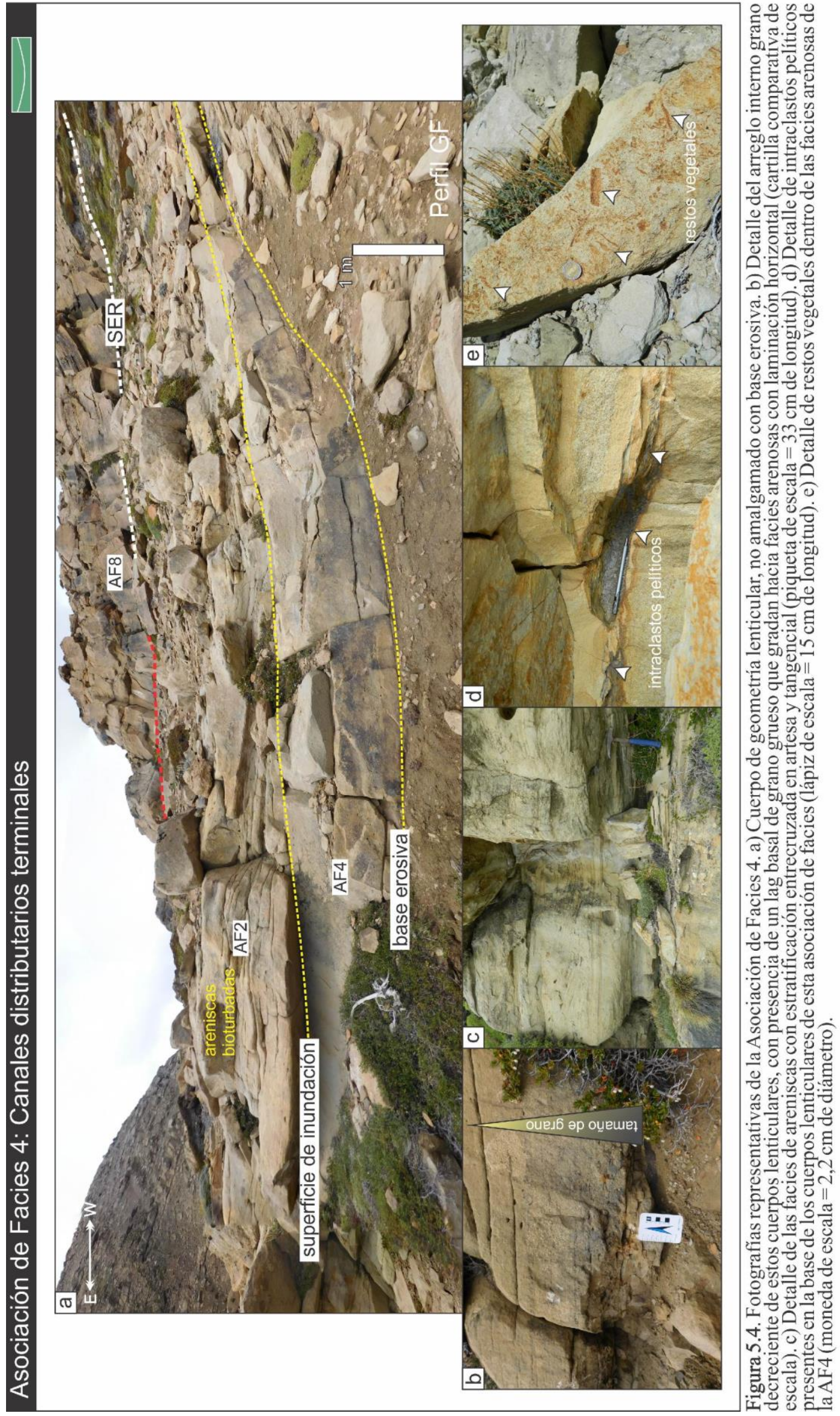


cuerpos indica que la AF4 es el producto de la depósitación dentro de canales monoepisódicos (Bhattacharya, 2006; Olariu y Bhattacharya, 2006; Moyano Paz et al., 2018). Debido a la estrecha relación de estos canales no amalgamados con los depósitos de frente deltaico y la presencia de una suite empobrecida trazas fósiles marinas es que se los interpreta como canales distributarios terminales (Olariu y Bhattacharya, 2006).

\subsubsection{Asociación de Facies 5 (AF5):}

Descripción: La AF5 incide sobre los depósitos de la AF4, hacia los cuales también grada lateralmente, y también se presenta erosionando a los depósitos de la AF2. Es cubierta por los depósitos de la AF2 mediante una superficie de inundación. La AF5 consiste en cuerpos lenticulares que se amalgaman alcanzando una potencia de hasta 7 metros (Fig. 5.5). Los cuerpos individuales (storeys) desarrollan un espesor de hasta 1,5 $\mathrm{m}$ y decenas de metros de continuidad lateral, sus bases presentan un aspecto irregular. Internamente, estos cuerpos se componen de conglomerados de grano fino, areniscas-conglomerádicas y areniscas de grano mediano a grueso que se disponen conformando arreglos grano decrecientes (Fig. 5.5). Esta asociación se caracteriza por presentar el desarrollo de estratificaciones entrecruzadas tangenciales y en artesa $(\boldsymbol{G} t, \boldsymbol{S} G \boldsymbol{t}$ y $\boldsymbol{S} t$, Fig. 5.5) hacia la base de los cuerpos las cuales gradan verticalmente a areniscas masivas ubicadas en los topes de los cuerpos ( $\boldsymbol{S m b}$; Fig. 5.5). El índice de bioturbación para esta asociación incrementa gradualmente desde la base al techo de cada cuerpo (IB 1-5; Fig. 5.5) y se han reconocido excavaciones aisladas de $O p$ hiomorpha isp., Psilonichnus isp. y Skolithos isp. Dentro de estos depósitos, pero especialmente hacia la base de los cuerpos, son abundantes los restos vegetales como fragmentos de hojas y troncos. 


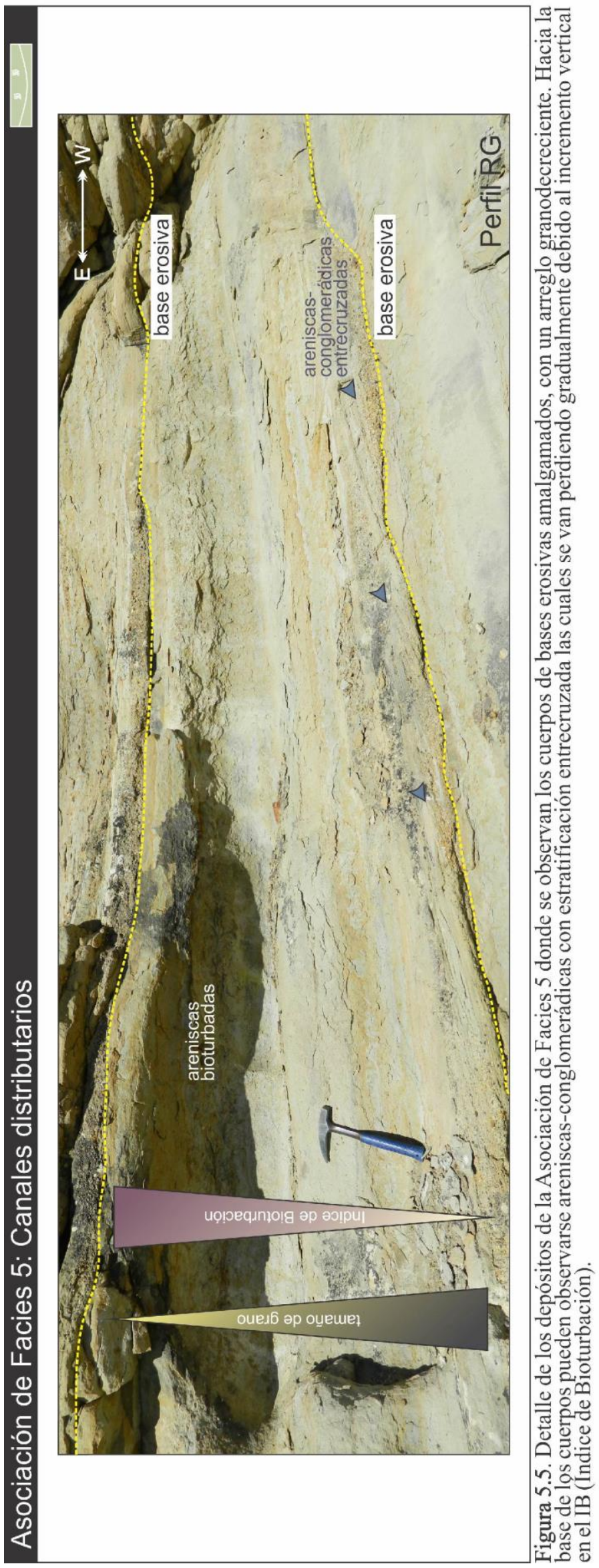


Interpretación: La naturaleza erosiva de las bases de los cuerpos, las tendencias grano decrecientes y la presencia de estructuras tractivas asociadas a migración de dunas 3D sugieren la depositación dentro de cuerpos canalizados. El aumento gradual en el IB podría reflejar el progresivo abandono de estos canales (Buatois y Mángano, 2011). La baja diversidad de estructuras biogénicas caracteriza una asociación empobrecida de trazas que sugiere un estresante para la fauna bentónica (Beynon y Pemberton, 1992; MacEachern et al., 2005; MacEachern y Gingras, 2007; Bann et al., 2008; Buatois y Mángano, 2011; Moyano Paz et al., 2020; ver Capitulo 6). La presencia de Psilonichnus isp. sugiere condiciones de agua dulce mientras que la presencia de Ophiomorpha isp. indicaría la instalación eventual de condiciones de agua salobre debido a la influencia de procesos marinos durante momentos de baja descarga fluvial (Gingras et al., 2011). La amalgamación de estos cuerpos canalizados, la relación vertical y lateral con los canales distributarios terminales (AF4) y la presencia de trazas asociadas a condiciones de agua dulce sugieren una posición más proximal para los estos canales los cuales se interpretan como canales distributarios (Bhattacharya, 2006, 2010; Bhattacharya y Olariu, 2006).

\subsubsection{Asociación de Facies 6 (AF6):}

Descripción: La AF6 se encuentra por encima de los depósitos de frente deltaico distal dominado por olas (AF2) a través de una superficie erosiva regional (SER) o de las de las sedimentitas de las AF7 y AF8 a través de superficies de inundación. La AF6 consiste en cuerpos arenosos tabulares de hasta 0,8 m de espesor los cuales se encuentran levemente inclinados hacia el sudeste $\left(6^{\circ}-8^{\circ}\right.$; Fig. 5.6a) y se amalgaman hasta alcanzar los $10 \mathrm{~m}$ de potencia. Los depósitos de la AF6 gradan vertical y lateralmente hacia los depósitos de barras de desembocadura fluvio-dominadas de grano más grueso de la AF7 (Fig. 5.6b). Los cuerpos 


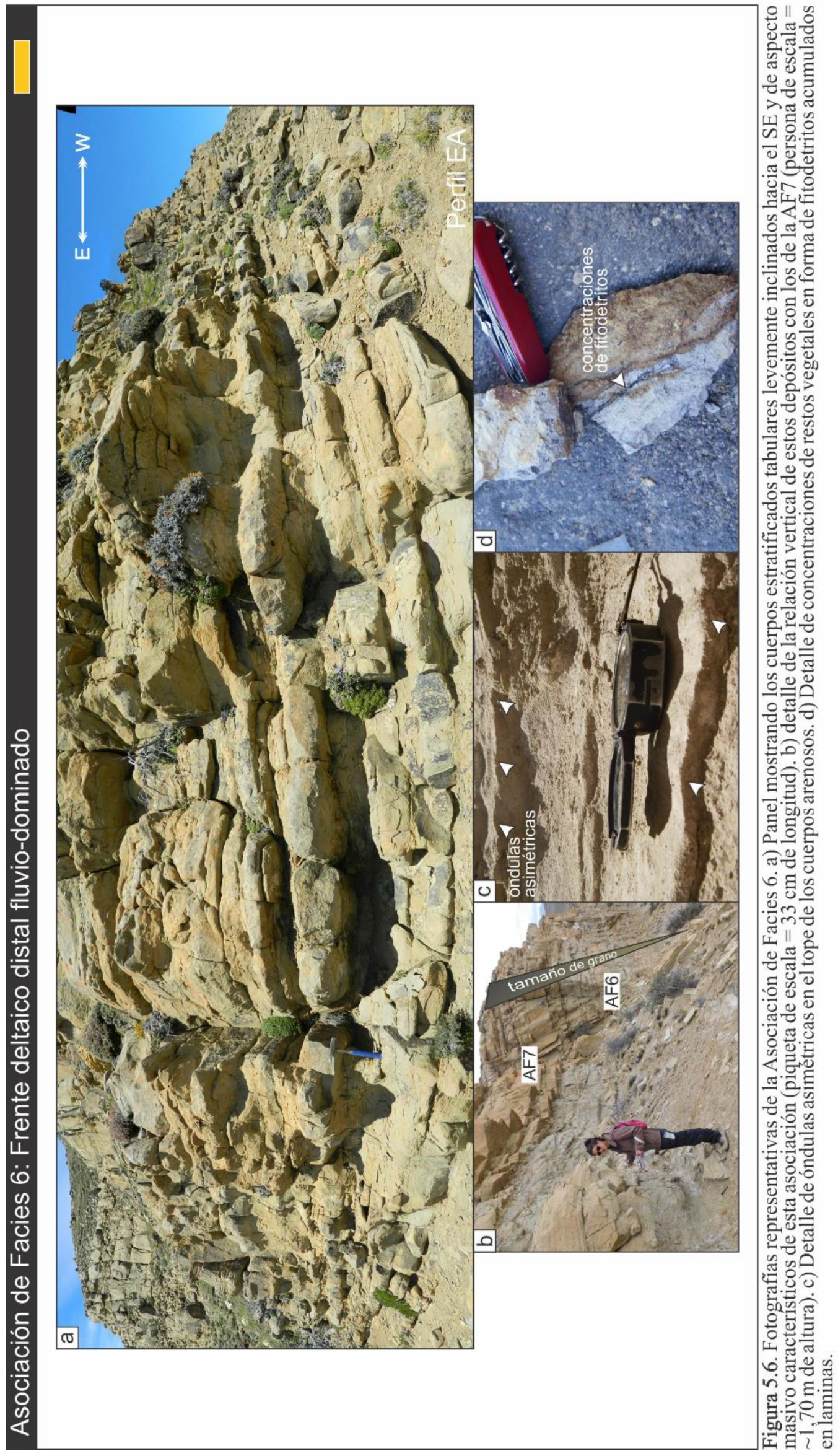


tabulares de la AF6 se componen de areniscas muy finas a finas con mala selección debido al alto contenido de matriz fina y se presentan típicamente de una forma masiva, preservando en la mayoría de los casos la estratificación ( $\mathbf{S m b}$; Fig. 5.6a y b). Sin embargo, facies de areniscas con laminación horizontal, con laminación entrecruzada y preservación de óndulas asimétricas también fueron registradas dentro de esta asociación ( $\boldsymbol{S} 1$ y $\boldsymbol{S} r$; Fig. 5.6b y c). La AF6 se caracteriza por presentar alta abundancia (IB 4-5) y baja diversidad de estas trazas fósiles reconociéndose solo Ophiomorpha nodosa y Palaeophycus isp. Dentro de los depósitos de esta asociación es común encontrar abundantes fragmentos de hojas y troncos, así como también altas concentraciones de fitodetritos conformando laminaciones (Fig. 5.6d).

Interpretación: La baja diversidad de estructuras orgánicas sugiere la depositación en un ambiente marino marginal sometido a condiciones de estrés (MacEachern et al., 2005; Moyano Paz et al., 2020). El aspecto masivo, principalmente en los sectores inferiores de las capas, se interpreta como la depositación episódica producto de flujos gravitatorios de sedimentos (Collinson et al., 2006; Bridge y Demicco, 2008). Estas corrientes episódicas cargadas en sedimentos podrían representar el registro de corrientes turbidíticas generadas por el colapso de las barras de desembocadura de la AF7, o por corrientes de densidad asociadas a descargas hiperpícnicas (Mulder y Syvitski, 1995; Bhattacharya, 2006; Ponce et al., 2007; Enge et al., 2010; Li et al., 2011; Kurcinka et al., 2018; Moyano Paz et al., 2018, 2020). El aspecto masivo observado en los topes de estas capas podría interpretarse como producto del retrabajo del substrato por la fauna bentónica y refleja una baja periodicidad de estos eventos depositacionales (Enge et al., 2010; Moyano Paz et al., 2020). Por lo previamente mencionado, se interpreta a los depósitos de la AF6 como el producto de la depositación en un 
subambiente de frente deltaico distal dominado por procesos fluviales (Bhattacharya, 2006, 2010; Enge et al., 2010; Kurcinka et al., 2018; Moyano Paz et al., 2018).

\subsubsection{Asociación de Facies 7 (AF7):}

Descripción: La AF7 grada verticalmente desde las sedimentitas del frente deltaico distal fluvio-dominado (AF6; Fig. 5.6b) y es incidida por los cuerpos canalizados de la AF8, o cubierta por los depósitos de grano fino de las áreas interdistributarias de la AF9. La AF7 consiste en clinotemas amalgamadas de alto ángulo $\left(8^{\circ}-15^{\circ}\right)$ las cuales se encuentran inclinando hacia el sudeste y desarrollan sucesiones de hasta 30 metros de potencia y varios cientos de metros de continuidad lateral, con sets de hasta 1,5 m de espesor (Fig. 5.7a, b y c). Cada una de estos clinotemas presentan espesores comprendidos entre los 5 y $7 \mathrm{~m}$ y se encuentran compuestos por areniscas medianas y gruesas, y por areniscas conglomerádicas, ambas litologías presentan una pobre selección, abundante contenido de matriz fina y se disponen en arreglos tanto granocrecientes como granodecrecientes (Fig. 5.7c). Internamente se caracterizan por presentar estratificaciones entrecruzadas de gran escala ( $\boldsymbol{S} G \boldsymbol{t}, \boldsymbol{S t}$ y $\boldsymbol{S} \boldsymbol{p}$, Fig $5.7 \mathrm{c}$ y d) y de forma subordinada laminaciones horizontales y entrecruzadas, con preservación de óndulas asimétricas ( $\boldsymbol{S l}$ y $\boldsymbol{S} r$ ). Los valores de paleocorrientes obtenidos en las estructuras entrecruzadas indican una alta dispersión, pero una dirección preferencial hacia el sudeste (Tabla 5.1; $\mathrm{n}=130, \overline{\mathrm{x}}=142^{\circ}$ ). Las partes más basales de estos clinotemas presentan abundantes intraclastos pelíticos y restos vegetales tales como fragmentos de hojas y troncos. Es muy común la acumulación de cortinas de fitodetritos en los foresets de las estructuras entrecruzadas, aunque estas cortinas orgánicas no presentan ningún tipo de ciclicidad en su espacia- 
miento. La AF7 suele carecer de rasgos de bioturbación (IB 0-1), sin embargo, se

han reconocido estructuras de Ophiomorpha isp. y Lockeia isp.

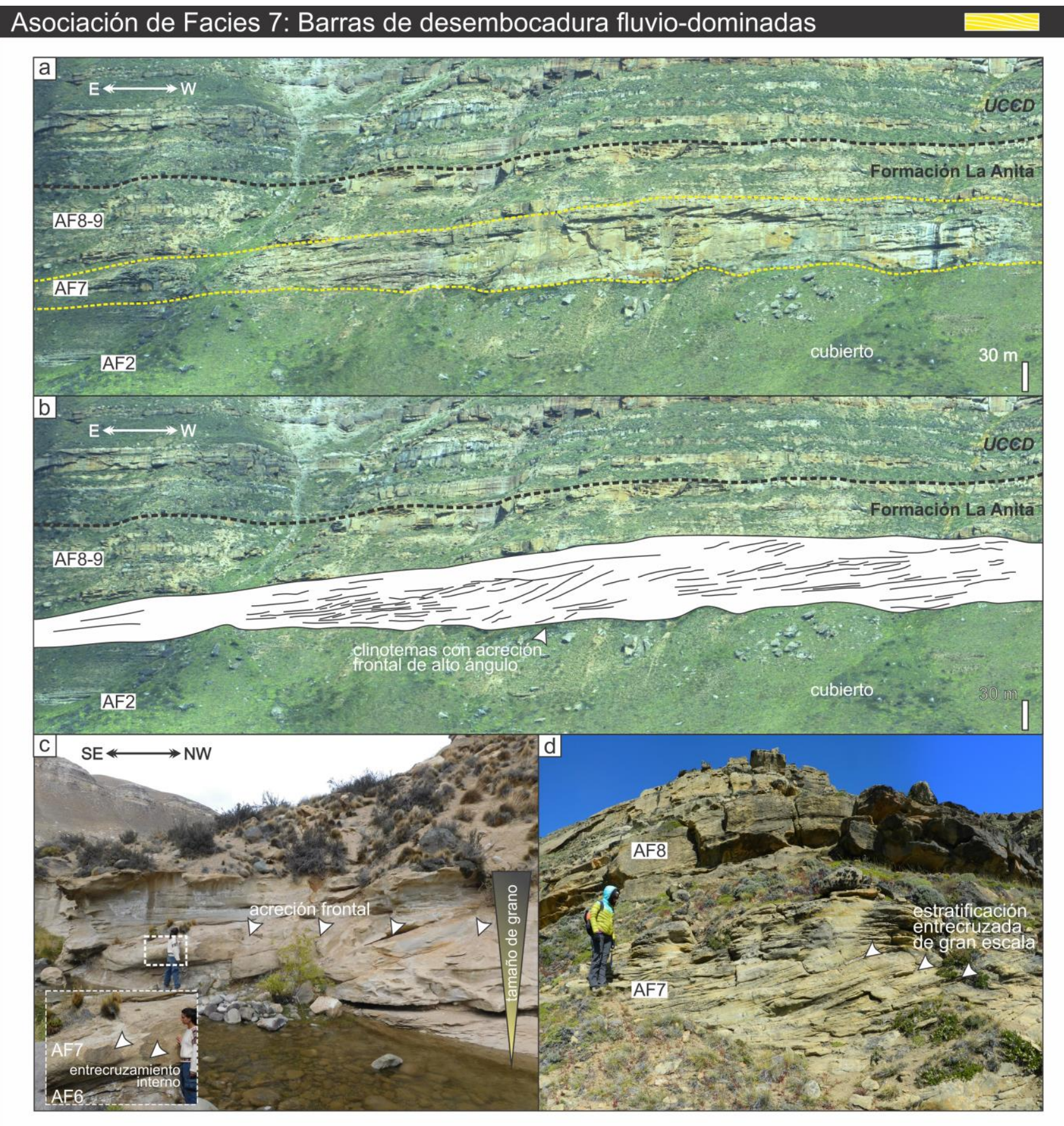

Figura 5.7 (página siguiente). Fotografías representativas de la Asociación de Facies 7. a y b) Paneles de afloramientos donde se observan los clinotemas de alto ángulo con acreción frontal inclinando hacia el sudeste. c) Detalle de la acreción frontal de los clinotemas y la presencia de estructuras entrecruzadas internas con la misma orientación de los clinotemas. d) Detalle de las estructuras entrecruzadas tangenciales de gran escala de esta asociación. Persona de escala en c y d = $\sim 1,70 \mathrm{~m}$ de altura.

Interpretación: La coincidencia en la dirección de inclinación de los clinotemas y de las estructuras tractivas internas indica acreción frontal de los clino- 
temas. Debido al desarrollo de clinotemas con acreción frontal que presenta la AF7, sumado a la presencia de estructuras asociadas a la migración de dunas y óndulas por corrientes unidireccionales, la pobre selección de los depósitos y la baja abundancia y diversidad de estructuras biogénicas, se interpreta a la AF7 como depósitos de barras de desembocadura desarrolladas en un subambiente de frente deltaico proximal fluvio-dominado (Bhattacharya, 2006; Olariu et al., 2010; Enge et al., 2010; Kurcinka et al., 2018; Moyano Paz et al., 2018). Esta interpretación también se encuentra soportada por la relación vertical que existe entre esta asociación y los subyacentes depósitos de frente deltaico distal fluviodominados (AF6) y los suprayacentes canales distributarios de la AF8.

\subsubsection{Asociación de Facies 8 (AF8):}

Descripción: La AF8 consiste en cuerpos lenticulares amalgamados con bases cóncavas hacia arriba y con capacidad erosiva (Fig. 5.8a y b) que inciden por sobre los depósitos del frente deltaico proximal fluvio-dominado (AF7) y por encima de las sedimentitas del frente deltaico distal dominado por olas (AF2) o de los canales distributarios terminales (AF5) a través de la superficie erosiva regional (SER). La AF8 se presenta en asociación con los depósitos de grano fino de las áreas interdistributarias de la AF9 conformando intercalaciones verticales. Los cuerpos individuales (storeys) alcanzan los $10 \mathrm{~m}$ de espesor, se encuentran separados unos de otros a través de superficies erosivas, y se caracterizan por presentar superficies internas de $2 \mathrm{~m}$ de altura y $30 \mathrm{~m}$ de extensión lateral que se disponen de forma inclinada $\left(20^{\circ}-35^{\circ}\right)$ tanto hacia el noreste como hacia el sudeste (Fig. 5.8b). Internamente, estos storeys se encuentran rellenos por areniscas gruesas pobremente seleccionadas y por areniscas-conglomerádicas que comúnmente se presentan conformando estratificaciones entrecruzadas en artesas, planar-tangencial y planar $(S t, S p$ y $S G t)$ y arreglos granodecrecientes 
(Fig. 5.8c). También son comunes facies de areniscas con deformación sinsedimentaria, laminación horizontal y laminación entrecruzada con preservación de óndulas asimétricas ( $\boldsymbol{S d}, \boldsymbol{S l}, \boldsymbol{S r})$. Las bases erosivas de los storeys están cubiertas por facies de conglomerados masivos $(\mathrm{Gm})$ con abundantes intraclastos pelíticos y abundantes fragmentos de troncos y hojas. Dentro de esta asociación es común la presencia de fitodetritos acumulados como cortinas en los foresets y toeset de las estructuras entrecruzadas, pero sin presentar una ciclicidad en su espaciamiento (Fig. 5.8d). Los datos de paleocorrientes obtenidos en las estructuras entrecruzadas indican una alta dispersión, pero una dirección preferencial hacia el sudeste (Tabla 5.1; $\left.\mathrm{n}=169, \overline{\mathrm{x}}=133^{\circ}\right)$. La AF8 típicamente carece de estructuras orgánicas (IB 0-1), sin embargo, se han encontrado excavaciones aisladas de Arenicolites isp., Ophiomorpha isp. y Psilonichnus isp., así como también perforaciones en restos de troncos asociadas a Teredolitesisp.

Interpretación: El desarrollo de bases erosivas, seguidas de depósitos dominantemente arenosos con tendencias granodecrecientes y estructuras asociadas a corrientes unidireccionales sugieren la depositación dentro de cuerpos canalizados. Las estructuras internas inclinadas de gran escala se interpretan como superficies de acreción lateral e indican alta sinuosidad de estos canales (Miall, 1985). Estos rasgos, sumados a las variaciones verticales de escala de las estructuras sedimentarias desde dunas a óndulas y la amalgamación de los diferentes storeys, sugieren que la acumulación de la AF8 ocurrió dentro de canales distributarios multiepisódicos de alta sinuosidad (Bhattacharya, 2006, 2010; Olariu y Bhattacharya, 2006; Moyano Paz et al., 2018). Los fitodetritos acumulados en los foresets y toesets de las estructuras entrecruzadas se interpretan como parte del transporte tractivo que culmina las tendencias granodecrecientes de los sets 
(Arregui et al., 2019). Si bien no hay una evidencia clara de estructuras mecáni-

cas asociadas a procesos marinos, la presencia de estructuras biogénicas mari-

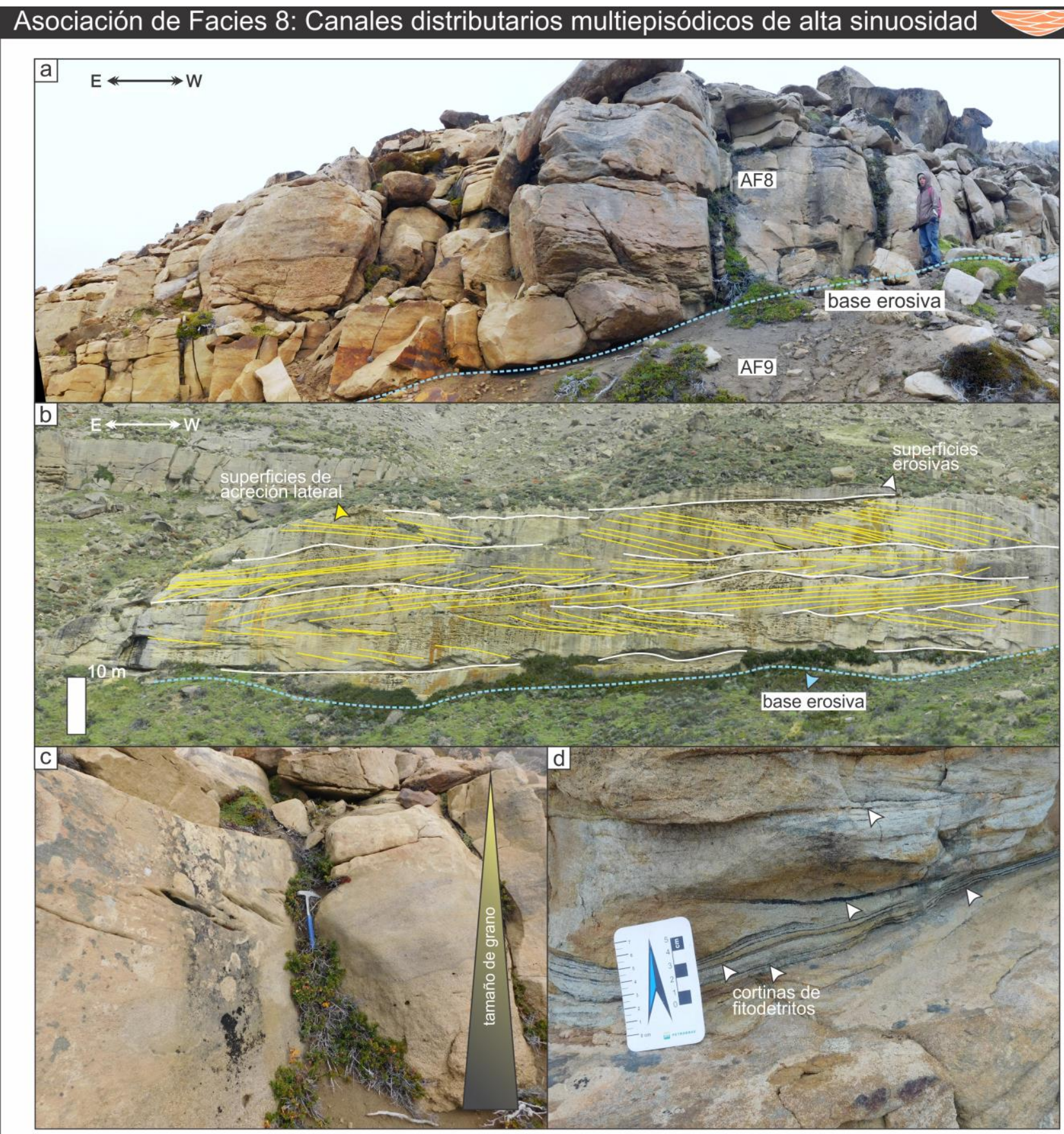

Figura 5.8. Fotografías representativas de la Asociación de Facies 8. a) Detalle de la geometría lenticular canalizada, con base erosiva de los cuerpos de la AF8 (persona de escala $=\sim 1,70 \mathrm{~m}$ de altura). b) Panel de afloramiento mostrando los cuerpos lenticulares amalgamados con superficies internas de acreción lateral y limitados entre ellos por superficies erosivas. c) Detalle de la tendencia granodecreciente de los cuerpos lenticulares con estratificación entrecruzada en artesa (piqueta de escala $=33 \mathrm{~cm}$ de longitud). d) Detalle de las cortinas de fitodetritos en los toesets de las estructuras entrecruzadas sin presentar un espaciamiento cíclico. 
nas es indicativa de influencia de procesos marinos en estos canales, durante momentos de baja descarga fluvial, cómo por ejemplo corrientes mareales las cuales podrían generar un pequeño retardo en las corrientes fluviales favoreciendo la instalación de aguas salobres. La asociación vertical que esta asociación muestra con los depósitos de las áreas interdistributarias de la AF9 apoya la interpretación de la AF8 como canales distributarios multiepisódicos de alta sinuosidad desarrollados en un subambiente en una planicie deltaica.

\subsubsection{Asociación de Facies 9 (AF9):}

Descripción: La AF9 se presenta en asociación vertical con los depósitos de los canales distributarios multiepisódicos de la AF8, y consiste en cuerpos tabulares con espesores comprendidos entre 1 y $17 \mathrm{~m}$ y varios cientos de metros de continuidad lateral. La AF9 se compone de fangolitas negras carbonosas y carbón, con intercalaciones subordinadas de limolitas, areniscas muy finas y depósitos heterolíticos (Fig. 5.9a). Estos depósitos se caracterizan por presentar laminación paralela o tener un aspecto masivo $(F l, F m, H b, S l, S m y ~ S m b)$ y es común que presenten desarrollo de rasgos pedogenéticos tales como slickensides, agregados (peds) angulares y subangulares, y abundantes rizolitos. Estos cuerpos tabulares de grano fino que caracterizan a la AF9 se encuentran eventualmente interrumpidos por cuerpos arenosos lenticulares con bases planas y topes convexos, los cuales se encuentran compuestos por areniscas finas a medianas con estratificación entrecruzada en artesa y laminación horizontal (Sty SI; Fig. 5.9b). La intensidad de bioturbación de las capas que constituyen a la AF9 es baja (IB 1-3), sin embargo, localmente pueden aparecer niveles intensamente retrabajados por organismos (IB 4). Para esta asociación, además de los rizolitos, se han reconocido Ophiomorpha isp., Palaeophycus isp., Planolites isp., Thalassinoidesisp. y Teichichnusisp. 


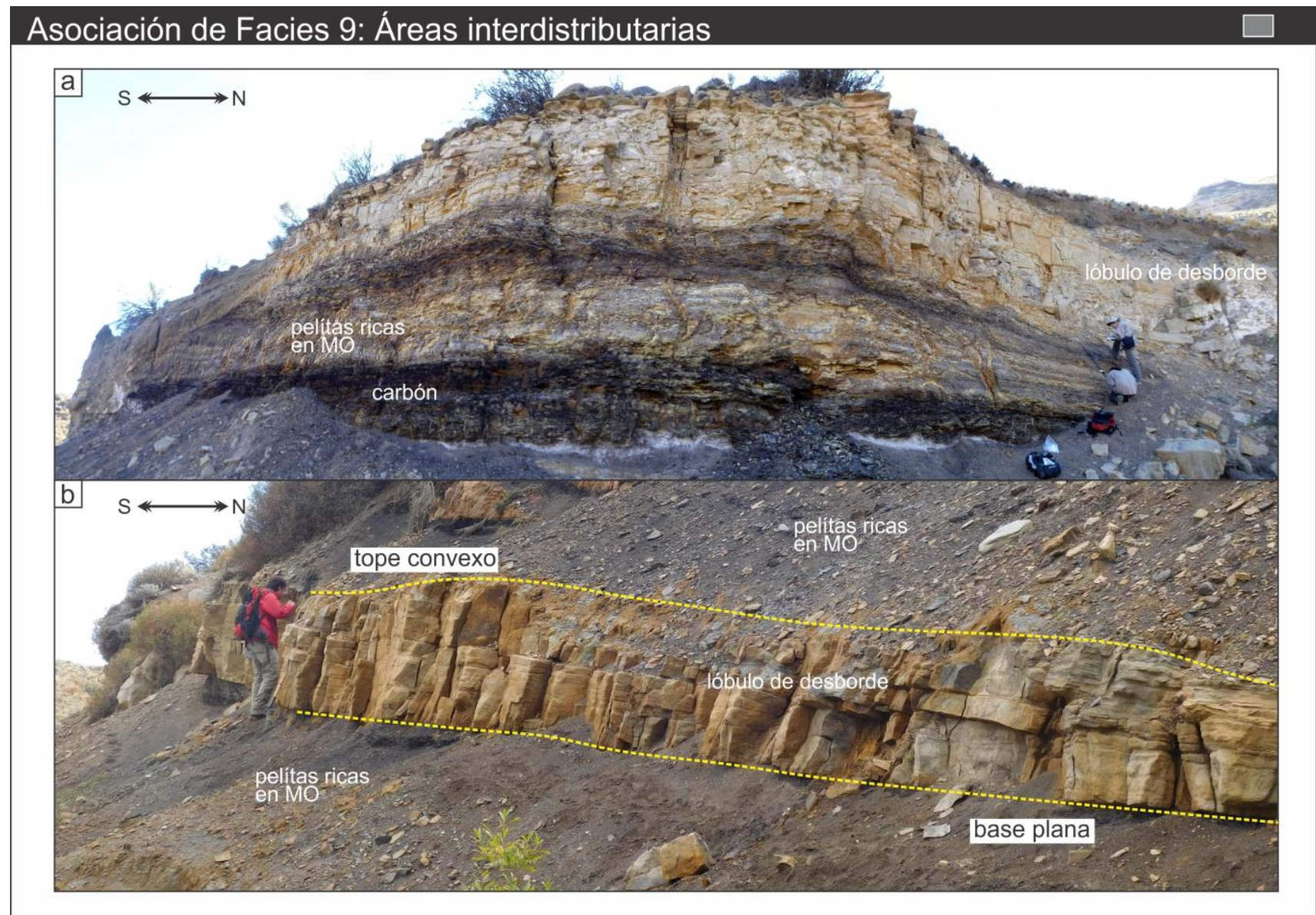

Figura 5.9 (página siguiente). Fotografías de afloramientos representativas de la Asociación de Facies 9. a) Panel donde se puede observar la geometría tabular de los depósitos de pelitas ricas en materia orgánica (MO) y de las acumulaciones de carbón. b) Panel donde se resalta la geometría lobular de uno de los cuerpos arenosos con base plana y tope convexo de la AF9 intercalando con los depósitos finos ricos en materia orgánica.

Interpretación: La dominancia de sedimentos de grano fino dentro de la AF9 sugiere condiciones de baja energía durante su acumulación que favoreció la decantación de la carga en suspensión (Collinson et al., 2006). La presencia de rasgos pedogenéticos y de materia orgánica poco descompuesta indican el desarrolló de suelos en ambientes saturados/anegados en agua los cuales se encontraban sometidos a condiciones reductoras y se corresponderían a Histosoles (Everett, 1983; Retallack, 2001; Varela et al., 2018). Se interpreta a los depósitos de la AF9 como la acumulación en áreas interdistributarias saturadas en agua las cuales se inundaban frecuentemente producto del desborde de los canales distributarios (AF8) aportando principalmente sedimentos de grano fino durante etapas de altas descargas (Bhattacharya, 2006; Fielding, 2010). Los cuerpos 
arenosos de geometría lobular que reflejan depositación a partir de corrientes unidireccionales tractivas son interpretados como como depósitos de lóbulos de desbordamiento (Mjøs et al., 1993; Pérez-Arlucea y Smith, 1999; Varela, 2015). La presencia de estructuras biogénicas marinas es indicativa de que, por momentos, condiciones de agua salobre eran instaladas en estas áreas interdistributarias (MacEachern et al., 2005; Gugliotta et al., 2015; Moyano Paz et al., 2020).

\subsection{DISTRIBUCIÓN DE LAS ASOCIACIONES DE FACIES}

La correlación de las secciones estratigráficas relevadas al sur del Lago Argentino se llevo a cabo mediante la identificación y seguimiento de una superficie estratigráfica clave interpretada como una superficie de inundación marina (Fig. 5.10; ver Capítulo 8). Este nivel de correlación permitió reconocer rasgos en estas secciones que fueron a su vez identificados al norte del Lago Argentino (Fig. 5.11) y se detallan a continuación.

Como se ha mencionado anteriormente, los depósitos de la Formación La Anita pueden dividirse informalmente en dos unidades, una inferior y otra superior (Figs. 5.10, 5.11 y 5.12). Esta discriminación se basa en la diferencia de color que presentan estas dos secciones y por la presencia de la superficie de erosión regional (SER) de bajo ángulo que las limita y que incide $\sim 50 \mathrm{~m}$ en la sección inferior (Figs. 5.10, 5.11 y 5.12a). Esta división estratigráfica también representa cambios en la distribución espacial de las asociaciones de facies interpretadas para la unidad como así también implica la variación de los roles relativos de los diferentes procesos depositacionales (olas, mareas y fluviales; Fig. 5.120b). La unidad inferior de la Formación La Anita grada verticalmente desde las sedimentitas de grano fino asociadas a la depositación en un ambiente de plataforma externa a talud de la Formación Alta Vista (Malkowski et al., 
2017a y b; Fig. 5.12a), consiste en una sucesión dominantemente arenosa que incluye a las AF1, AF2, AF3, AF4 y AF5, y es truncada en el tope por la SER (Figs. $5.10,5.11$ y 5.12). Por su parte, la unidad superior está limitada en su base por la SER y consiste en una sucesión dominantemente arenosa de color amarillento que abarca a las AF6, AF7, AF8 y AF9 y es cubierta por los depósitos de las formaciones Cerro Fortaleza y La Irene las cuales forman parte de los Depósitos Continentales del Cretácico Superior (UCCD sensu Tettamanti et al., 2018; Figs. $5.10,5.11$ y 5.12$)$

\subsection{PROCESOS DEPOSITACIONALES Y SISTEMAS DE ACUMULACIÓN}

Las asociaciones de facies que constituyen los depósitos de la Formación La Anita reflejan que tanto procesos marinos como fluviales se encontraban actuando con diferente intensidad durante su acumulación. En este trabajo de tesis se seguirán las ideas propuestas por Ainsworth et al. (2008) quienes establecieron criterios para definir dominancia e influencia de los diferentes procesos depositacionales dentro de asociaciones de facies para sistemas costeros de influencia mixta. Estos autores proponen que las estructuras sedimentarias más comunes definen al proceso dominante dentro de una asociación de facies y que los procesos secundarios que generan características subordinadas dentro de estos depósitos se dice que han influenciado la depositación (Fig. 5.12b). Este criterio también es considerado válido para el análisis de unidades depositacionales donde los procesos dominantes y subordinados que constituyan la mayor proporción de la unidad estratigráfica son considerados como los procesos que dominaron y que influyeron durante la depositación de la unidad (Ainsworth et al., 2008, 2011). 


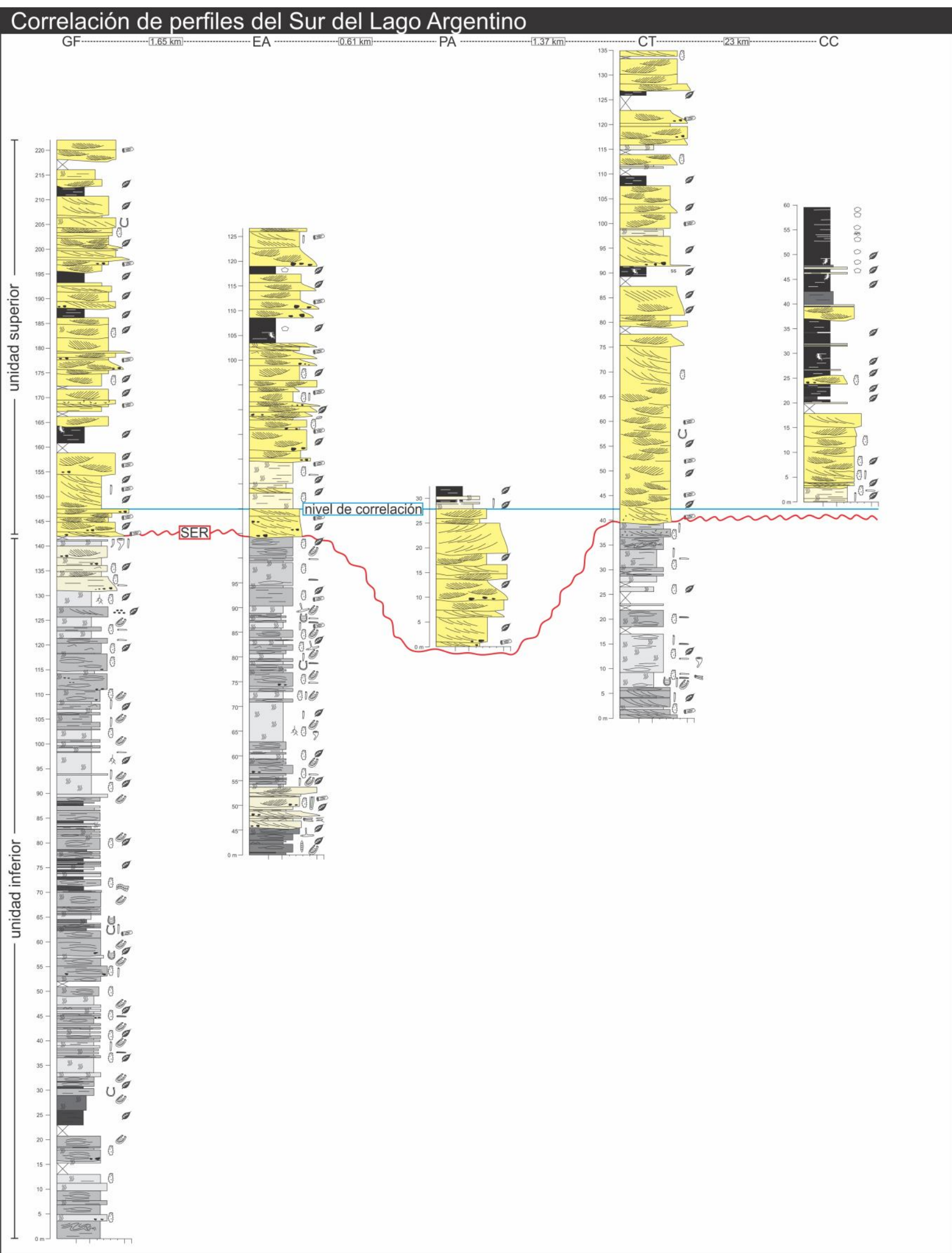

Figura 5.10. Panel de correlación de los perfiles sedimentológicos del Sur del Lago Argentino, división en unidad inferior y superior, y expresión de la superficie de correlación y SER (superficie de erosión regional). 


\section{Correlación de perfiles del Norte del Lago Argentino}

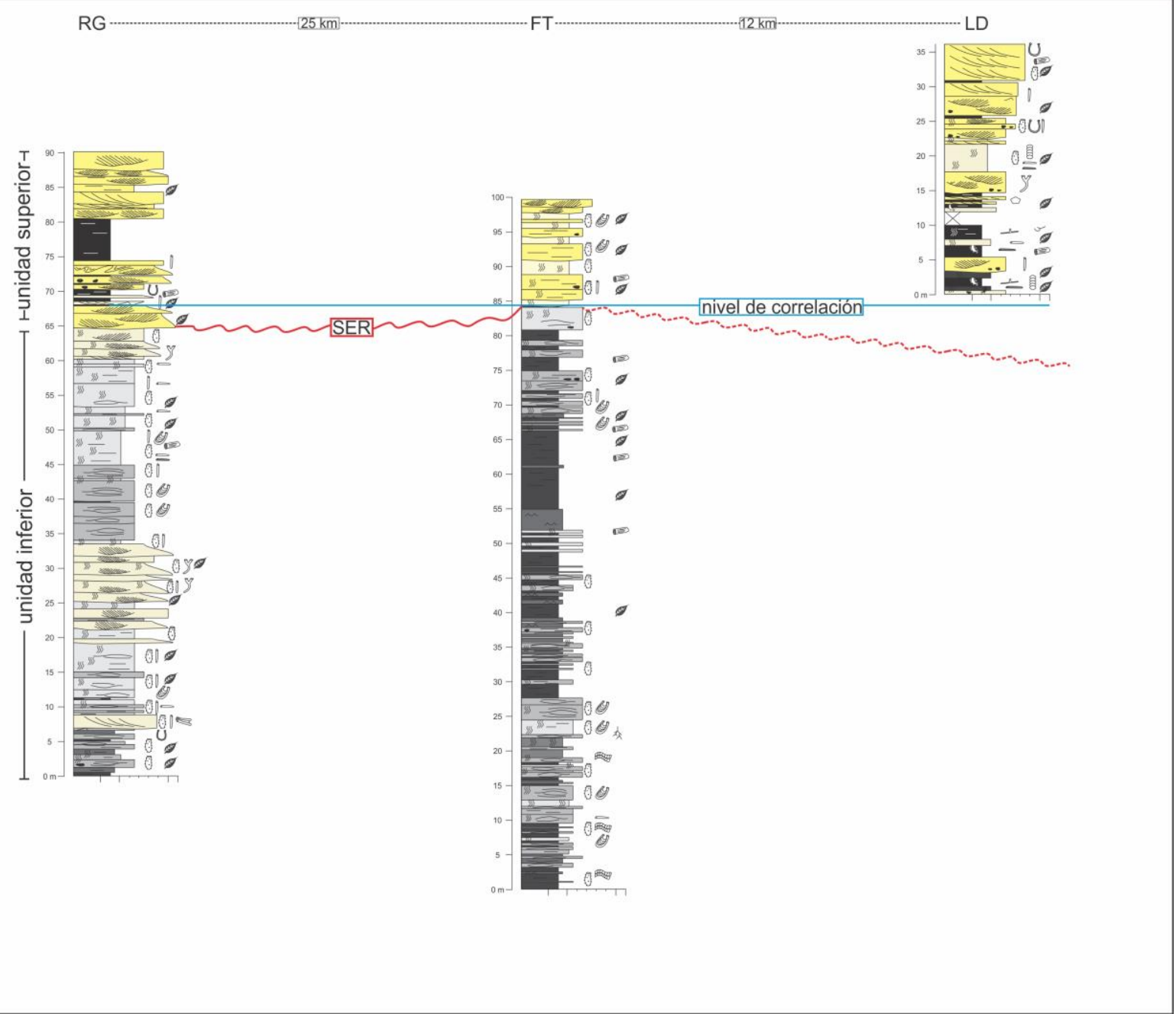

Figura 5.11. Panel de correlación de los perfiles sedimentológicos del Norte del Lago Argentino, división en unidad inferior y superior, y expresión de la superficie de correlación y SER (superficie de erosión regional).

\subsubsection{Unidad inferior de la Formación La Anita}

Como se expuso anteriormente, esta unidad grada verticalmente desde los depósitos de grano fino de la Formación Alta vista y consiste en una sucesión dominantemente arenosa de color gris compuesta por las AF1, AF2, AF3, AF4 y AF5 la cual se encuentra limitada al tope por la SER (Figs. 5.12 y 5.13). El apilamiento vertical de las asociaciones de facies de esta unidad refleja un patrón principalmente agradante a progradante, sin embargo, las tendencias granocrecientes de cada asociación de facies y de la unidad en general sugieren un sistema depositacional progradante (Fig. 5.13). 


\section{División en unidades y dominancia de procesos depositacionales}
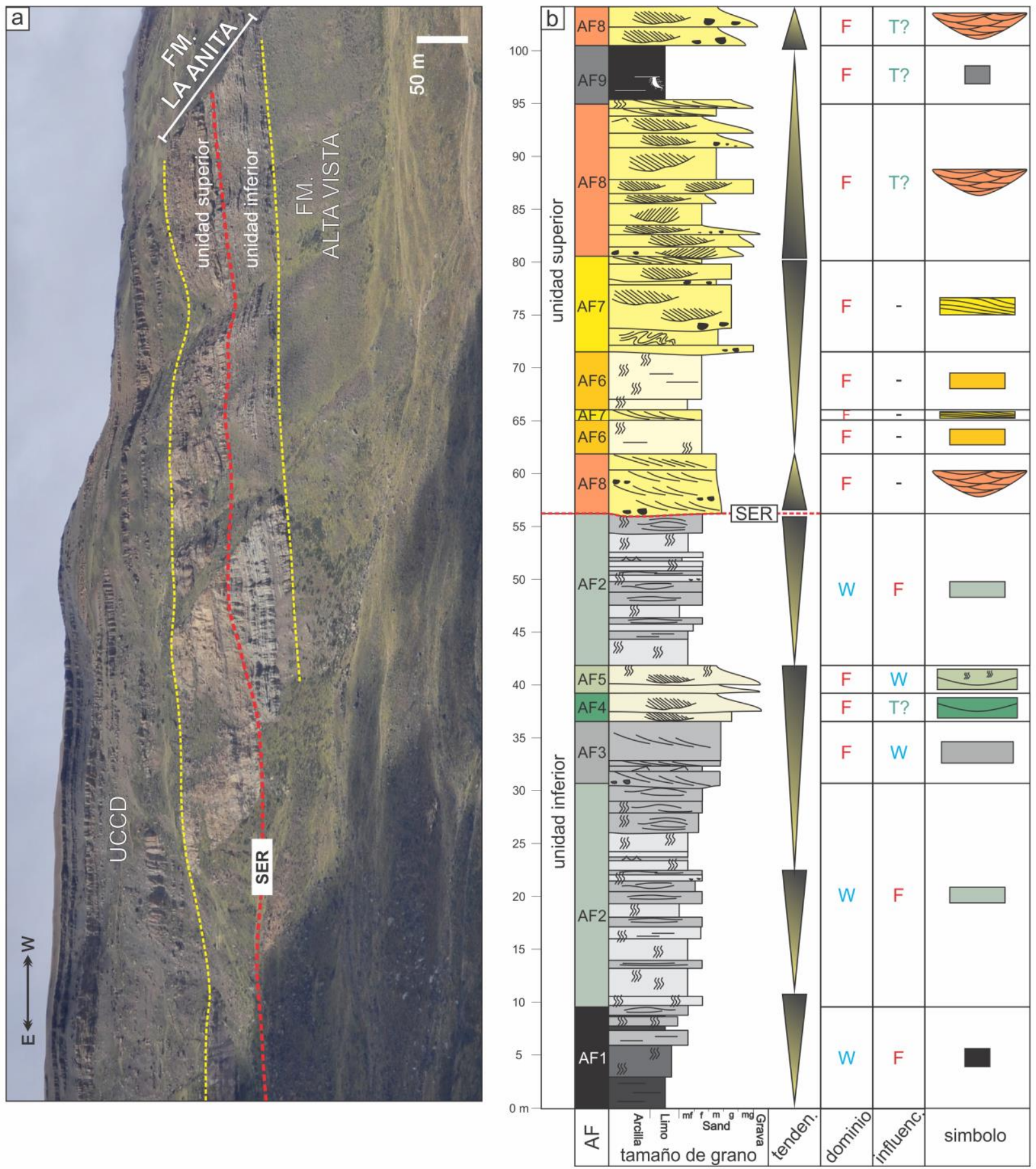

Figura 5.12. a) Panel de las barrancas de la Estancia Anita donde se pueden observar las unidades estratigráficas del Cretácico Superior de la cuenca. La unidad inferior de la Formación La Anita presenta estratos de coloración grisácea y clinoformas de bajo ángulo. La unidad superior presenta una coloración amarillenta y se separa de la unidad inferior a través de la SER (superficie de erosión regional). b) Sección esquemática donde se puede ver la relación vertical entre las AFs de cada una de las unidades y la dominancia e influencia de los procesos depositacionales. $\mathrm{W}=\mathrm{Olas}($ Waves); $\mathrm{F}=$ Fluvial; $\mathrm{T}=$ Mareas (Tides), así como también los símbolos con los que se representa a cada asociación de facies.

La abundancia de estructuras entrecruzadas monticulares (HCS; Shcs) y de otras estructuras generadas por procesos de oleaje como laminación paralela o 
con laminaciones asociadas a la agradación de óndulas simétricas ( $\boldsymbol{S}$ Iy $\boldsymbol{S} w \boldsymbol{W}$ ) en los depósitos de prodelta y frente deltaico distal de las AF1 y AF2, respectivamente, sugieren una depositación bajo una fuerte influencia de procesos de oleaje, tanto bajo condiciones de buen tiempo como de tormenta (Fig. 5.12b). Sin embargo, rasgos como el abundante contenido de restos vegetales, la presencia de clastos de tamaño grava dispersos y las condiciones de estrés fisicoquímico que reflejan las estructuras orgánicas (ver Capítulo 6) que han sido registradas dentro de estas asociaciones, son considerados como producto de los efectos de descargas fluviales activas en la zona costera (Fig. 5.12b).

Los depósitos de barras de desembocadura de la AF3 no son muy abundantes (Fig. 5.13). Estos gradan desde las capas asociadas a procesos de oleaje de buen tiempo y de tormenta de la AF2 y se encuentran cubiertos por incisiones canalizadas de la AF4 o por las sedimentitas de frente deltaico distal dominado por olas de la AF2 (Fig. 5.13). Las barras de desembocadura se generan cuando un flujo turbulento que está siendo transportado por canales distributarios alcanza un cuerpo de agua permanente y se expande perdiendo competencia y genera estos depósitos (Wright, 1977). Entonces, las barras de desembocadura son por definición generadas por procesos fluviales, sin embargo, la presencia de depósitos de frente deltaico distal dominado por olas por debajo, y eventualmente por encima de estas barras, en conjunto con la ausencia de matriz, sugieren que estas barras de desembocadura se desarrollaron en un contexto con alta influencia de acción de oleaje (Fig. 5.12b; Plint et al., 2010; Ainsworth et al., 2016). La escasa proporción de depósitos de barra de desembocadura en esta unidad (Fig. 5.13) podría encontrarse asociada a la alta recurrencia de eventos de tormenta, los cuales se encuentran muy bien evidenciados en los depósitos de prodelta y de frente deltaico distal, y esto se debe a que, durante las tormen- 
tas, grandes cantidades de arenas son transportadas desde zonas de aguas someras en dirección mar adentro (Dumas y Arnott, 2006).

Los depósitos de canales terminales y distributarios de las AF4 y AF5 sugieren fuertemente que los procesos que más influyeron durante su acumulación fueron los fluviales. Sin embargo, la presencia de estructuras orgánicas marinas dentro de estos depósitos evidencia que condiciones de agua salobre ocurrían dentro de estos canales, posiblemente durante momentos de baja descarga fluvial, y esto podría deberse a la influencia de procesos marinos (Fig. 5.12b). Las direcciones de paleocorrientes medidas en las estructuras entrecruzadas de estas asociaciones canalizadas muestran una dirección predominante hacia el sudeste con una mayor dispersión de direcciones en los canales distributarios (AF5) que en los canales terminales (AF4) cuya dispersión es considerablemente menor (Tabla 5.1). Esta mayor dispersión en la AF5 podría también estar asociada a la incidencia de procesos marinos, por más que no se haya registrado bidireccionalidad en la dirección de migración de las formas de lecho. Las estructuras entrecruzadas de las barras de desembocadura (AF3) se orientan de manera oblicua, casi perpendicular, a la de los canales terminales y distributarios. Esta relación oblicua de direcciones de paleocorrientes sugiere una incidencia oblicua del tren de olas en dirección a la costa, lo cual representaría una evidencia adicional para interpretar influencia de acción de oleaje en estas barras de desembocaduras (Tabla 5.1; Figs. 5.12b y 5.13; Ainsworth et al., 2016).

Se interpreta que el sistema de acumulación que acumuló los depósitos de la unidad inferior de la Formación La Anita fue un sistema deltaico dominado por olas, influenciado por procesos fluviales (Fig. 5.14; Ainsworth et al., 2008, 2011; Moyano Paz et al., 2018, 2020). Si bien el sistema era alimentado por canales distributarios fluviales, la redistribución del sedimento dentro del sistema 


\section{Panel de distribución espacial de las AFs}
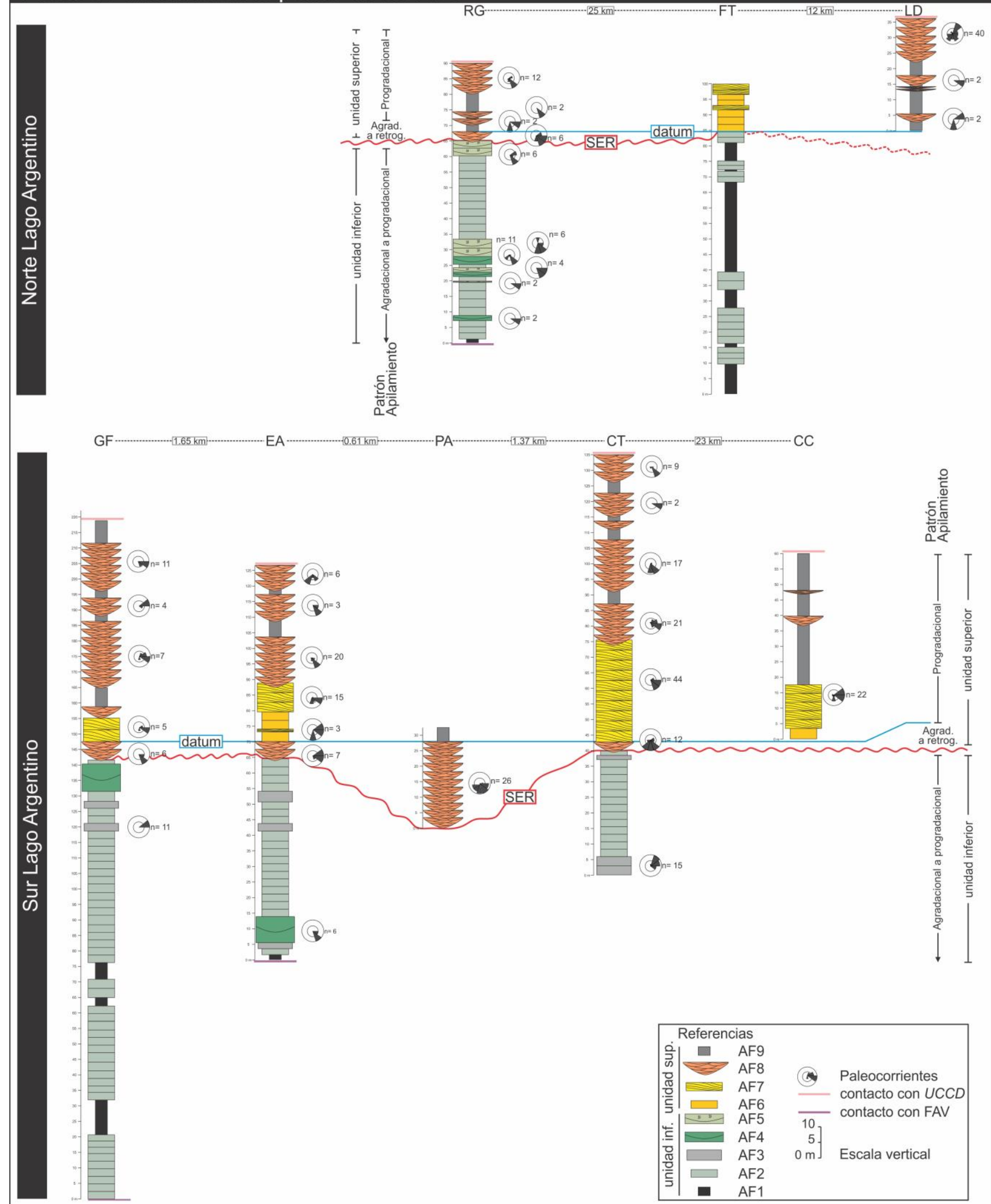

Figura 5.13. Paneles de correlación este-oeste donde se pueden observar las relaciones y distribuciones verticales y laterales de las asociaciones de facies, así como también los patrones de apilamiento para las unidades depositacionales de la Formación La Anita. 
se encontraba dominado por la acción de las olas. La acción de las olas de buen tiempo y de tormenta se encuentran muy bien representadas en el prodelta (AF1), frente deltaico distal (AF2) y barras de desembocadura (AF3). Aunque los procesos fluviales no aparecen como dominantes durante la depositación de la unidad inferior, representan un rasgo clave para diferenciar entre un delta dominado por olas y un sistema de shoreface-plataforma dominado por olas sin influencia fluvial (Ainsworth et al., 2011). La incidencia oblicua del tren de olas hacia la línea de costa produce la deflección de las barras de desembocadura y provoca que la migración de estas sea en una dirección paralela a la costa (Bhatacharya et al., 2010), las cuales pueden pasar transicionalmente a los asociados cordones litorales (beach ridges) y los coexistentes depósitos de shoreface (Fig. 5.12; Rodríguéz et al., 2000; Bhattacharya y Giosan, 2003; Sømme et al., 2008; Bhattacharya, 2010; Ainsworth et al., 2019). Esta acción oblicua del oleaje no sólo favorece el transporte de las barras de desembocadura en una dirección paralela a la costa, sino que también tiene incidencia en el transporte del sedimento de grano fino aportado por los canales distributarios y explicaría la alta proporción de depósitos de la AF1 en el perfil FT, ubicado al noreste del área de estudio (Fig. 5.13). Las direcciones de paleocorrientes medidas en las estructuras mecánicas de las diferentes asociaciones de facies (Tabla 5.1; Fig. 5.13), así como también la dirección en la que inclinan las clinoformas presentes indican que la dirección de progradación del sistema era hacia el sudeste (Fig. 5.14).

\subsubsection{Unidad superior de la Formación La Anita}

La unidad superior de la Formación La Anita no presenta gradaciones verticales ni laterales con los depósitos de la unidad inferior estando ambas unidades limitadas por la SER (Figs. 5.12 y 5.13). Se encuentra cubierta por los UCCD (sensu Tettamanti et al., 2018) conformando una progresiva continentalización 
de la cuenca en este sector. La unidad superior se caracteriza por presentar una coloración amarillenta y abarca a las AF6, AF7, AF8 y AF9 (Figs. 5.10 y 5.11). La forma en la que estas asociaciones de facies se disponen permite a su vez diferenciar a la unidad superior de la Formación La Anita en dos intervalos. Un intervalo inferior, comprendido entre la SER y la superficie de correlación, dominado por la amalgamación de canales de la AF8. La amalgamación de estos canales podría indicar un patrón de apilamiento agradante, pero la presencia de depósitos relativamente más profundos por encima de estos sugiere un patrón de apilamiento retrogradante (Fig. 5.13; Madof et al., 2016), y por encima de este un intervalo superior compuesto por las AF6, AF7, AF8 y AF9 que se disponen conformando un arreglo progradante y evidencia la acumulación en un sistema de acumulación progradacional (Fig. 5.11; Madof et al., 2016).

Esta unidad se caracteriza por presentar depósitos de canales distributarios multiepisódicos en su intervalo más inferior, justo por encima de la SER, y también en el intervalo más superior de la unidad (Figs. 5.10b y 5.11). La depositación dentro de estos canales sugiere un dominio de sedimentación a partir de procesos fluviales con alta capacidad de erosión y poca capacidad de selección de los sedimentos. Los depósitos de la AF8 que constituyen el intervalo más inferior de la unidad superior presentan los mayores tamaños de grano de toda la unidad y carecen de rasgos de bioturbación y de otros que evidencien la influencia de procesos marinos como las olas y las mareas (Fig. 5.12b). Por otro lado, los depósitos de la AF8 que se encuentran en la sección más superior de esta unidad presentan estructuras biogénicas aisladas (suite de Arenicolites isp., Ophiomorpha isp. y Psilonichnus isp.). La presencia de estructuras asociadas a condiciones de agua dulce como Psilonichnus isp. y agua salada y/o salobre como Ophimorpha isp. sugiere la influencia de procesos marinos que facilitaban la ins- 
talación de condiciones salobres dentro de los canales, como podrían ser las corrientes mareales (Fig. 5.10b; MacEachern et al., 2005; Gingras et al., 2011; Buatois et al., 2012).

Los depósitos de frente deltaico distal y las barras de desembocadura (AF6 y AF7) de la unidad superior se diferencian considerablemente de los de la unidad inferior (AF2 y AF3). Los depósitos de frente deltaico distal (AF6) fueron interpretados como producto de la sedimentación episódica a partir de corrientes de turbidez asociadas a descargas fluviales, los cuales fueron afectados por un intenso retrabajo por organismos de la fauna bentónica pero no presentan rasgos que evidencien retrabajo por procesos de oleaje ni mareales (Fig. 5.12b). La AF6 grada vertical y lateralmente a los depósitos de barras de desembocadura (AF7) los cuales presentan un tamaño de grano mayor. La AF7 se diferencia de la AF3 debido a que presentan mayor granulometría, peor selección con presencia de matriz limosa, y los cuerpos se disponen conformando clinotemas de alto ángulo y con acreción frontal (Fig. 5.7). No se identificaron rasgos que evidencien efectos de oleas o mareas lo que sugiere que la depositación se encontraba dominada enteramente por procesos asociados a descargas fluviales (Fig. 5.12b).

Los depósitos de las áreas interdistributarias saturadas en agua de la AF9 se presentan, como ya se expuso con anterioridad, en asociación vertical con los canales distributarios multiepisódicos de la AF8 (Fig. 5.13), los cuales reflejan una depositación dominada por procesos fluviales e influenciada por la acción de mareas. El sedimento de estas áreas interdistributarias proviene directamente de los canales distributarios y por ello se interpreta que su acumulación también se encuentra dominada por procesos fluviales (Fig. 5.12b). La presencia de estructuras que evidencian el accionar de procesos pedogenéticos soporta la idea de que durante la acumulación los procesos marinos no tuvieron lugar ac- 
tivamente. Sin embargo, la presencia de icnoasociaciones que reflejan comportamientos asociados a organismos marinos (suite de Ophiomorpha isp., Palaeophycus isp., Planolites isp., Thalassinoidesisp. y Teichichnusisp.) indican que eventualmente existían condiciones de agua salobre y esto podría vincularse con el accionar de procesos mareales (Fig. $5.12 \mathrm{~b}$ ).

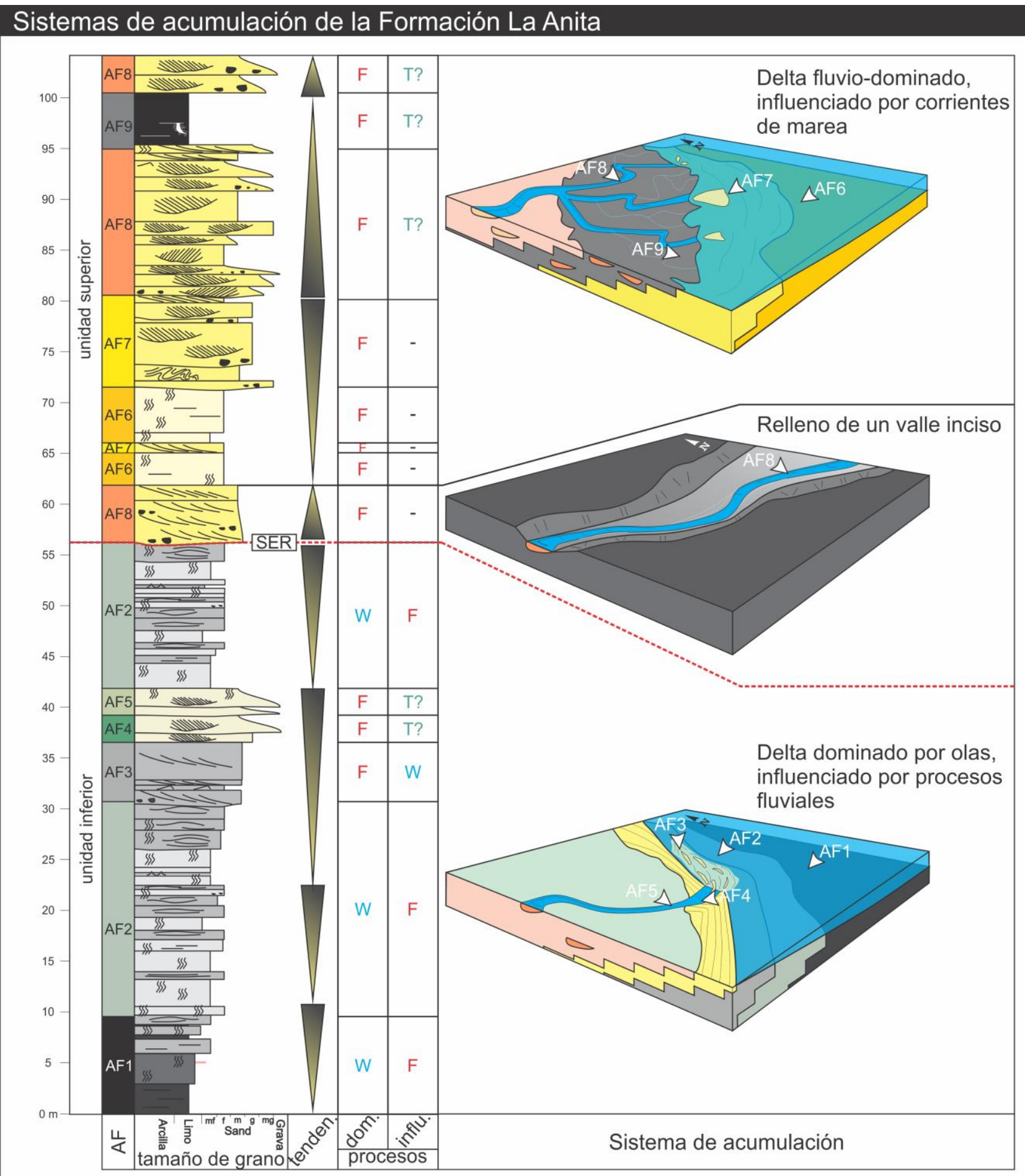

Figura 5.14. Interpretación de los tres sistemas de acumulación de la Formación La Anita y su relación estratigráfica. 
De esta manera, la unidad superior de la Formación La Anita evidencia la acumulación bajo una fuerte dominancia de procesos fluviales (Figs. 5.12b y 5.13). El intervalo inferior de esta unidad se encuentra caracterizado por la superposición de cuerpos canalizados que carecen de evidencia de procesos marinos con un patrón de apilamiento agradacional a retrogradacional, dependiendo de la orientación de la línea de costa (sensu Madof et al., 2016), y que se encuentran inmediatamente por encima de la SER (Figs. 5.12b y 5.13) y se interpreta como el relleno de un valle inciso a partir de canales fluviales multiepisódicos de alta sinuosidad (Fig. 5.14; Blum y Törnqvist, 2000; Blum y Aslan, 2006; Fielding, 2010; Kurcinka et al., 2018; Moyano Paz et al., 2018, 2020). Por encima del relleno del valle inciso, y separados mediante una superficie de máxima inundación marina (ver Capítulo 8), se encuentran las sedimentitas del intervalo superior de esta unidad que constituyen una sucesión granocreciente que evidencian la depositación en un ambiente progradacional de agua salobre con dominancia de procesos fluviales, pero con influencia de corrientes de marea (Figs. 5.12b y 5.13). Este sistema es interpretado como un sistema deltaico dominado por procesos fluviales e influenciado por mareas (Fig. 5.14; Ainsworth et al., 2008, 2011; Moyano Paz et al., 2020). Las barras de desembocadura y los canales distributarios presentan una amplia dispersión en las direcciones de las paleocorrientes medidas (Tabla 5.1; Fig. 5.13) como es esperable en un delta fluvio-dominado. Sin embargo, la dirección de progradación del sistema sugerida a partir de direcciones predominantes de paleocorrientes y por la dirección de acreción frontal de los clinotemas de la AF7 era, al igual que en la unidad inferior, hacia el sudeste, lo que indicaría que la paleopendiente regional no varió de un sistema a otro (Fig. 5.14). Este sistema deltaico podría haberse desarrollado dentro del valle inciso lo que podría haber protegido al sistema de la influen- 
cia de oleaje y favorecer la amplificación de mareas (Ainsworth et al., 2011). Sin embargo, el mayor desarrollo de barras de desembocadura hacia las márgenes de la mayor incisión sugiere que el desarrollo de el sistema deltaico fluviodominado no ocurrió dentro de un valle (Fig. 5.13).

\subsection{CONSIDERACIONES FINALES}

El análisis que se presenta en este capítulo permitió, a partir de las 18 facies sedimentarias definidas en el Capítulo 4, reconocer 9 combinaciones de grupos de facies las cuales se encontraban genéticamente relacionadas y de tal manera se definieron 9 asociaciones de facies sedimentarias para la Formación La Anita, cada una con un significado ambiental particular (Tabla 5.1), lo que permitió interpretar 3 sistemas de acumulación diferentes (Fig. 5.14). A partir de diferencias en su coloración y en la distribución espacial de las AFs se dividió a la Formación La Anita en dos unidades, unidad inferior y unidad superior, limitadas ambas por una superficie de erosión regional (SER; Figs. 5.12 y 5.13).

La unidad inferior consiste en una sucesión con un arreglo vertical somerizante (progradacional) y se caracteriza por depósitos de prodelta dominado por olas (AF1), frente deltaico distal dominado por olas (AF2), barras de desembocadura influenciadas por olas (AF3), caneles distributarios terminales (AF4) y canales distributarios (AF5). Esta sucesión somerizante corresponde a un sistema deltaico dominado por olas, e influenciado por procesos fluviales (Ainsworth et al., 2008, 2011). Este sistema deltaico presentaba una dirección de progradación hacia el sudeste.

La unidad superior de la Formación La Anita presenta dos sucesiones (Fig. 5.13 y 5.14). La sucesión que se encuentra en el intervalo más inferior de esta unidad se caracteriza por cuerpos canalizados amalgamados de grano grueso de 
la AF8 que se presentan con un arreglo agradacional a retrogradacional (Fig. 5.13), la cual fue interpretada como el relleno fluvial de un valle inciso (Fig. 5.14). Por encima de esta sucesión y a través de una superficie de inundación marina (ver Capitulo 8: Análisis estratigráfico secuencial y factores de control), se desarrolla la sucesión progradacional que caracteriza al intervalo más superior de esta unidad (Fig. 5.13). Esta sucesión somerizante se caracteriza por los depósitos de frente deltaico distal fluvio-dominados (AF6), barras de desembocadura fluvio-dominadas (AF7), canales distributarios multiepisódicos de alta sinuosidad (AF8) y de áreas interdistributarias pantanosas (AF9) y se interpretó como un sistema deltaico fluvio-dominado, influenciado por corrientes de mareas (Fig. 5.12; Ainsworth et al., 2008, 2011).

Los sistemas de acumulación interpretados para la Formación La Anita reflejan la acumulación en ambientes marinos marginales con variaciones en la dominancia relativa de diferentes procesos sedimentarios. Debido a la dinámica de estos sistemas es que diferentes condiciones de estrés fisicoquímico ocurren en sus subambientes las cuales impactan directamente la actividad de la fauna bentónica y por ende en el contenido icnológico que estos depósitos presentan y será abordado en el siguiente capítulo de este trabajo de tesis (Capítulo 6: Análisis icnológico). Por otra parte, la relación espacial y temporal entre los 3 sistemas de acumulación será tratada en el Capítulo 8. 


\section{Capítulo VI \\ ANÁLISIS ICNOLÓGICO Y DE ESTRÉS \\ AMBIENTAL}

\subsection{INTRODUCCIÓN}

\subsection{1 ¿Qué es la icnología?}

La icnología es la disciplina que se dedica al estudio de las trazas producidas por organismos (animales, vegetales y bacterias) dentro o sobre un sustrato, las cuales representan un registro de su actividad, e incluye a todos los rasgos asociados con la bioturbación, bioerosión y biodepositación (Pemberton et al., 1992; Bromley, 1990, 1996; MacEachern et al., 2010; Buatois y Mángano, 2011). Las trazas fósiles son rasgos primarios dentro de las sucesiones sedimentarias, comprenden la expresión predominante de la vida animal (particularmente en sucesiones clásticas), y se encuentran fuertemente controladas por las facies sedimentarias (MacEachern et al., 2010). Los organismos productores de trazas son muy sensibles a las características ambientales, y por lo tanto sus trazas pueden proporcionar valiosa información acerca de las condiciones ambientales del medio, las cuales no podrían alcanzarse simplemente mediante un análisis de facies convencional el cual hace foco principalmente en los procesos físi$\cos$.

\subsection{2 ¿Por qué realizar un análisis icnológico en estos depósitos?}

Los procesos depositacionales que se encuentran operando en costas deltaicas favorecen el desarrollo de condiciones de estrés fisicoquímico que impactan de manera directa sobre la fauna bentónica, y por ende también en las características icnológicas de sus depósitos. Las trazas fósiles presentes en sucesiones 
deltaicas reflejan estas condiciones de estrés fisicoquímico, como lo son por ejemplo los flujos rápidos de sedimentos, elevada turbidez del agua, reducción periódica de la oxigenación, fluctuaciones en los niveles de salinidad, y la energía de las olas y de las corrientes de marea (MacEachern et al., 2005; Bann et al., 2008; Buatois et al., 2012, 2019; Dasgupta et al., 2019; Canale et al., 2020; Moyano Paz et al., 2020). Una descripción detallada, no solo de los tipos de bioturbaciones presentes en las diferentes capas de los depósitos deltaicos de la Formación La Anita, sino también la determinación de la diversidad de estructuras por capa y el Índice de Bioturbación (IB) de las mismas, reflejaría el rol que tuvieron estos diferentes factores de estrés durante la depositación en los diferentes subambientes deltaicos.

\subsection{3 ¿Cómo se realizó el análisis icnológico para el caso de estudio?}

Para llevar a cabo el análisis icnológico de la Formación La Anita durante el trabajo de campo se describieron capa a capa las características de las trazas fósiles. Este trabajo incluyó la identificación de las trazas y la abundancia relativa de los diferentes icnogéneros, se describieron las orientaciones de las trazas, así como también su tamaño, presencia/ausencia y tipo de pared, y estilo de relleno de los tubos. Para registrar las intensidades de bioturbación y sus variaciones laterales y verticales, se determinó capa a capa el Índice de Bioturbación de estas siguiendo los criterios proporcionados por Taylor y Goldring (1993).

\subsection{ICNOLOGÍA DE LA FORMACIÓN LA ANITA}

6.2.1 Icnología de la Asociación de Facies 1 (AF1): Prodelta dominado por olas

Descripción: Los niveles pelíticos y las capas de areniscas con HCS de esta asociación de facies (AF1) por lo general se presentan sin rasgos de bioturbación 
o con algunas trazas aisladas (IB 0-2 y 0-1, respectivamente). Por lo contrario, las facies heterolíticas de la AF1 presentan los mayores valores de IB (IB 2-3). En los depósitos de esta asociación fueron reconocidos ocho icnogéneros diferentes: Arenicolites isp., Diplocraterion isp., Gyrochorte isp., Ophiomorpha isp., Palaeophycus isp., Planolites isp., Rhizocorallium isp. y Skolithos isp. (Fig. 6.1). Arenicolites isp. fue registrado en niveles arenosos y consisten en excavaciones verticales simples con forma de "U" los cuales suelen apreciarse como pares de aberturas circulares en vista en planta (Fig. 6.1a). Diplocraterion isp. fue registrado tanto en las facies heterolíticas como en las arenosas, y consiste en excavaciones verticales con forma en " $U$ " de hasta $10 \mathrm{~cm}$ de longitud y $4 \mathrm{~cm}$ de ancho, los cuales se caracterizan por presentar spreiten (Fig. 6.1a y b). Gyrochorte isp. se presenta tanto en las facies pelíticas como en las heterolíticas y consiste en excavaciones horizontales de hasta $0,5 \mathrm{~cm}$ de ancho que se encuentran levemente curvadas y se expresan como pares de almohadillas elongadas las cuales se disponen en serie a lo largo de ejes y se separan por pequeñas depresiones (Fig. 6.1c). Las excavaciones de Ophiomorpha isp. se registraron en los depósitos arenosos de la AF1 y consisten en sistemas tridimensionales (3D) de galerías constituidos por túneles horizontales y ejes verticales (shafts) de hasta $2 \mathrm{~cm}$ de diámetro y con paredes finas e irregulares (Fig. 6.1d y e). Estas paredes irregulares representan la impresión de pellets adheridos a las paredes (Fig. 6.1d y e). Palaeophycus isp. se presenta tanto en facies arenosas como en heterolíticas y consiste en excavaciones de hasta $1 \mathrm{~cm}$ de diámetro, horizontales simples, cilíndricas y rectas que se encuentran rellenas por arena y pueden presentar revestimientos o lining pelíticos (Fig. 6.1a). Planolites isp. se presenta exclusivamente en niveles pelíticos de la AF1 y consiste en excavaciones horizontales simples, rectas, sin lining en sus paredes y con un relleno arenoso, de diámetros comprendidos entre los 2-5 mm (Fig 6.1f). Rhizocorallium isp. fue registrado en 
facies arenosas de esta asociación y consiste en excavaciones en forma de " $U$ " con spreiten las cuales se diferencian de Diplocraterion isp. por la orientación de los túneles. Rhizocorallium isp. puede presentarse con dos orientaciones: como túneles horizontales curvados, localizados en los topes de cuerpos arenosos y suelen presentar abundantes fitodetritos adheridos en sus paredes, o como excavaciones inclinadas que se enroscan dentro de los cuerpos arenosos (Fig. 6.1g, h y i). Skolithos isp. se presenta tanto en depósitos arenosos como en heterolíticos y consiste en excavaciones verticales simples y rectas de hasta $14 \mathrm{~cm}$ de longitud (Fig. 6.1a y b).

Interpretación: Los bajos valores de IB y la baja diversidad de trazas fósiles presente en las facies pelíticas ricas en materia orgánica de los depósitos de prodelta dominado por olas y la presencia de estructuras asociadas a comportamientos detritívoros (por ejemplo: Planolites isp.) estaría asociado a variaciones en las condiciones de oxigenación del medio (MacEachern et al., 2005; Buatois et al., 2012). Las capas de areniscas depositadas durante los eventos de tormenta de esta asociación también muestran unos bajos valores de IB y una reducida diversidad de trazas fósiles, con presencia de estructuras adaptadas a la colonización de sustratos bajo condiciones de alta energía (por ejemplo: Rhizocorallium isp. y Ophiomorpha isp.). La presencia de Diplocraterion isp. indica variaciones verticales en la posición de la interfase sedimento-agua como resultado de la erosión o de una alta tasa de sedimentación (Buatois y Mángano, 2011). Luego de los eventos de tormenta, los sustratos arenosos y heterolíticos eran fuertemente colonizados por organismos oportunistas de la fauna bentónica, evidenciado en los mayores valores de IB registrados para esta asociación. La ausencia de trazas fósiles asociadas a comportamientos suspensívoros de alimentación es consistente con la interpretación de un ambiente de prodelta y 
refleja una elevada turbidez del agua producida por una abundante cantidad de sedimento en suspensión (Moslow y Pemberton, 1988; Gingras et al., 1998; Ma-

cEachern et al., 2005; Moyano Paz et al., 2020).

\section{Asociación de Facies 1: Prodelta dominado por olas}
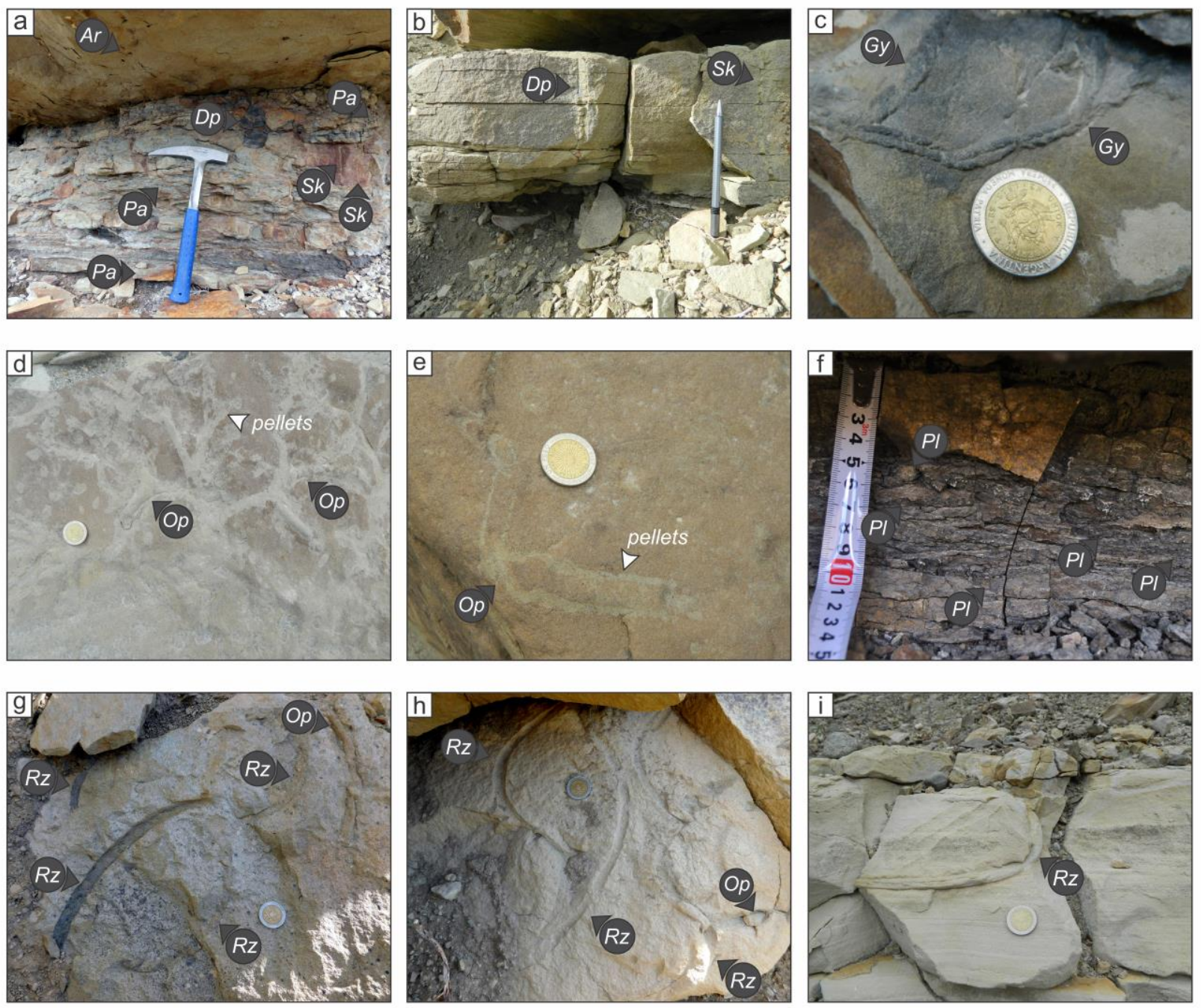

Figura 6.1. Características icnológicas de la asociación de prodelta dominado por olas. a) Vista en perfil de depósitos heterolíticos bioturbados con Palaeophycus isp. (Pa), Diplocraterion isp., (Dp), Skolithos isp., (Sk), y Arenicolites isp. $(A r$; piqueta de escala $=33 \mathrm{~cm}$ de longitud $)$ b) Detalle de una capa de arenisca con estratificación entrecruzada monticular con estructuras verticales de Diplocraterion isp. $(D p)$ y Skolithos isp. ( $S k$; lápiz de escala $=15 \mathrm{~cm}$ de longitud). c) Detalle del tope de una capa heterolítica mostrando la presencia de Gyrochorte isp. ( $G y$, moneda de escala = 2,2 cm de diámetro). d) Vista de un plano de estratificación con galerías de Ophiomorpha isp. ( $O p$ ) con detalle de los pellets (flechas blancas; moneda de escala $=2.2 \mathrm{~cm}$ de diámetro). e) Vista en sección de areniscas con galerías de Ophiomorpha isp. $(O p)$ con pellets revistiendo las paredes de las galerías (flechas blancas; moneda de escala $=2,2 \mathrm{~cm}$ de diámetro). f) Vista en sección de la facies de fangolitas con laminación paralela y tubos horizontales de Planolites isp. $(P I)$ g y h) Vista del tope de un cuerpo arenoso con estratificación entrecruzada monticular con excavaciones horizontales e inclinadas en forma de "U" asociadas a Rhizocorallium isp. (Rz) con abundantes fitodetritos adheridos en sus paredes y Ophiomorpha isp. ( $O p$; moneda de escala $=2,2 \mathrm{~cm}$ de diámetro). i) Vista en sección de un cuerpo arenoso con laminación paralela donde se observa una excavación robusta, inclinada y curvada atribuida a Rhizocorallium isp. (Rz, moneda de escala $=2,2 \mathrm{~cm}$ de diámetro). 
6.2.2 Icnología de la Asociación de Facies 2 (AF2): Frente deltaico distal dominado por olas

Descripción: Las intensidades de los IB de las areniscas que constituyen la AF2 son muy variados. Las capas de areniscas estratificadas suelen presentarse sin rasgos de bioturbación o presentar algunas excavaciones aisladas (IB 1-2), mientras que las capas de areniscas masivas presentan los mayores valores de IB (IB 3-6). En estos depósitos de frente deltaico distal dominado por olas se han reconocido trazas de escape y 9 icnogéneros asociados a madrigueras y a alimentación de la fauna bentónica: Chondrites isp., Cylindrichnus isp., Diplocraterion isp., Ophiomorpha isp., Palaeophycus isp., Rhizocorallium isp., Rosselia isp., Schaubcylindrichnus isp. y Skolithos isp. (Fig. 6.2) Las trazas de escape (fugichnia) se encuentran en las capas de areniscas que presentan laminación horizontal o HCS y registran movimientos verticales del organismo productor (tracemaker) luego de ser cubiertos por capas eventuales (Fig. 6.2a). Chondrites isp. se presenta en algunas de las capas de areniscas masivas y consiste en sistemas de excavaciones que se ramifican lateralmente (Fig. 6.2b). Estos túneles miden hasta $0,5 \mathrm{~cm}$ de ancho y se encuentran rellenos por material pelítico. Cylindrichnus isp. se presenta en las capas de areniscas masivas y también hacia los topes de los niveles de areniscas estratificadas, y consiste en excavaciones verticales rectas a levemente curvadas que presentan una forma subcónica y llegan a medir hasta $1 \mathrm{~cm}$ de largo (Fig. 6.2c). Cylindrichnus isp. suele aparecer en asociación con Rosselia isp. (Fig. 6.2c). Diplocraterion isp. se encuentra en las capas de areniscas con HCS y consiste en excavaciones verticales en forma de "U" que se presentan con un spreiten asociado y alcanzan los $5 \mathrm{~cm}$ de longitud y $1 \mathrm{~cm}$ de ancho (Fig. 6.2d). Ophiomorpha isp. se presenta tanto en las areniscas masivas, fuertemente bioturbadas, como en las capas de areniscas estratificadas y consis- 
te en sistemas de excavaciones 3D que constituyen galerías similares a las presentes en la AF1 pero que comúnmente preservan los pellets a lo largo de las paredes (Fig. 6.2e). Palaeophycus isp. se encuentra en las facies de areniscas masivas y consiste en excavaciones horizontales, cilindricas, sin ningún tipo de ramificaciones y que se encuentran rellenas por un tamaño de grano arena (Fig. 6.2f). Rhizocorallium isp. se presenta tanto en las facies masivas como en las estratificadas y consiste en excavaciones horizontales o inclinadas curvadas con una forma de "U" y que presentan asociado un spreiten (Fig. 6.2g y h). Rhizocorallium isp. llega a medir hasta $3 \mathrm{~cm}$ de ancho, frecuentemente presenta abundantes fitodetritos adheridos en sus paredes (Fig. 6.2h), también suelen registrarse, en una vista en perfil, como pares de aperturas circulares conectadas por un spreiten. Rosselia isp. se encuentra tanto en las facies masivas como en las estratificadas, y consiste en excavaciones verticales rectas cuya abertura superior se expande otorgándole una forma característica de embudo, y se encuentran rellenas por sedimentos de grano fino (Fig. 6.2c y f). La longitud de Rosselia isp. varía entre los 2 y $20 \mathrm{~cm}$, y sus ensanchamientos máximos entre 0,5 y 4 centímetros. Schaubcylindrichnus isp. se presenta en las facies de areniscas masivas y consiste en excavaciones horizontales verticalmente yuxtapuestas las cuales son subcirculares en una vista en sección transversal y miden hasta $0,5 \mathrm{~cm}$ de diámetro (Fig. 6.2i). Skolithos isp. se encuentra tanto en las capas de areniscas masivas como en las estratificadas, y consiste en excavaciones verticales rectas y simple de hasta $3 \mathrm{~cm}$ de longitud (Fig. 6.2c).

Interpretación: La marcada alternancia entre capas de areniscas masivas con alto IB y areniscas estratificadas con abundantes estructuras de tipo HCS que caracteriza a los depósitos de la AF2, indica el patrón de "lam-scram" que caracteriza la depositación bajo la alternancia de olas de buen tiempo y eventos de 
tormenta (Fig. 5.2a; Howard y Frey, 1984; MacEachern y Pemberton, 1992;

Pemberton y MacEachern, 1997; Bann et al., 2004, 2008; MacEachern y Bann, 2008; Buatois y Mángano, 2011, Buatois et al., 2012; Moyano Paz et al., 2020; Schwarz et al., 2020). Las capas generadas por los depósitos de tormenta presentan los valores más bajos de IB y las estructuras biogénicas presentes se encuentran adaptadas para la colonización de sustratos bajo condiciones de alta energía y elevadas tasas de sedimentación. Por otra parte, los niveles de areniscas masivas altamente bioturbados reflejan un intenso retrabajo del sustrato por los organismos productores de trazas durante condiciones de baja energía y baja tasa de sedimentación. La ausencia de estructuras biogénicas asociadas a comportamientos suspensívoros de alimentación por parte de los organismos productores de trazas, es consistente con la interpretación de estos depósitos como acumulación en un ambiente de frente deltaico distal, al igual que la presencia de abundantes fitodetritos adheridos a las paredes de algunas excavaciones (Bann et al., 2008; Arregui et al., 2019).

Figura 6.2 (página siguiente). Características icnológicas de la asociación de facies de frente deltaico distal dominado por olas. a). Fotografía de detalle de una capa de arenisca con estratificación entrecruzada monticular con la presencia de una traza de escape (es). b) Vista de un plano de estratificación con presencia de Chondrites isp. ( $C h$; lupa de escala $=5,5 \mathrm{~cm}$ de longitud). c) Detalle de una vista en sección de un cuerpo arenoso bioturbado con estructuras verticales de Rosselia isp., $(R o)$, Skolithos isp., $(S k)$ y Cylindrichnus isp. ( $C y$, moneda de escala $=2,2 \mathrm{~cm}$ de diámetro). d) Vista en perfil de un nivel arenoso con estratificación entrecruzada monticular con Diplocraterion isp. (Dp; barra de escala $=2 \mathrm{~cm})$. e) Corte en sección de un cuerpo arenoso con presencia de galerías de Ophiomorpha isp. ( $O p$; moneda de escala $=2,2 \mathrm{~cm}$ de diámetro). f) Vista en sección de un nivel bioturbado con excavaciones de Palaeophycus isp. (Pa) y Rosselia isp. (Ro; moneda de escala $=2,2 \mathrm{~cm}$ de diámetro). $\mathrm{g}$ y h) Detalles de planos de estratificación de cuerpos. arenosos con presencia de Rhizocorallium isp. $(R z)$. i) Detalle de una vista en perfil de una capa de arenisca bioturbada mostrando Schaubcylindrichnus isp. ( $S c h$; moneda de escala $=2,2 \mathrm{~cm}$ de diámetro). 


\section{Asociación de Facies 2: Frente distal dominado por olas}
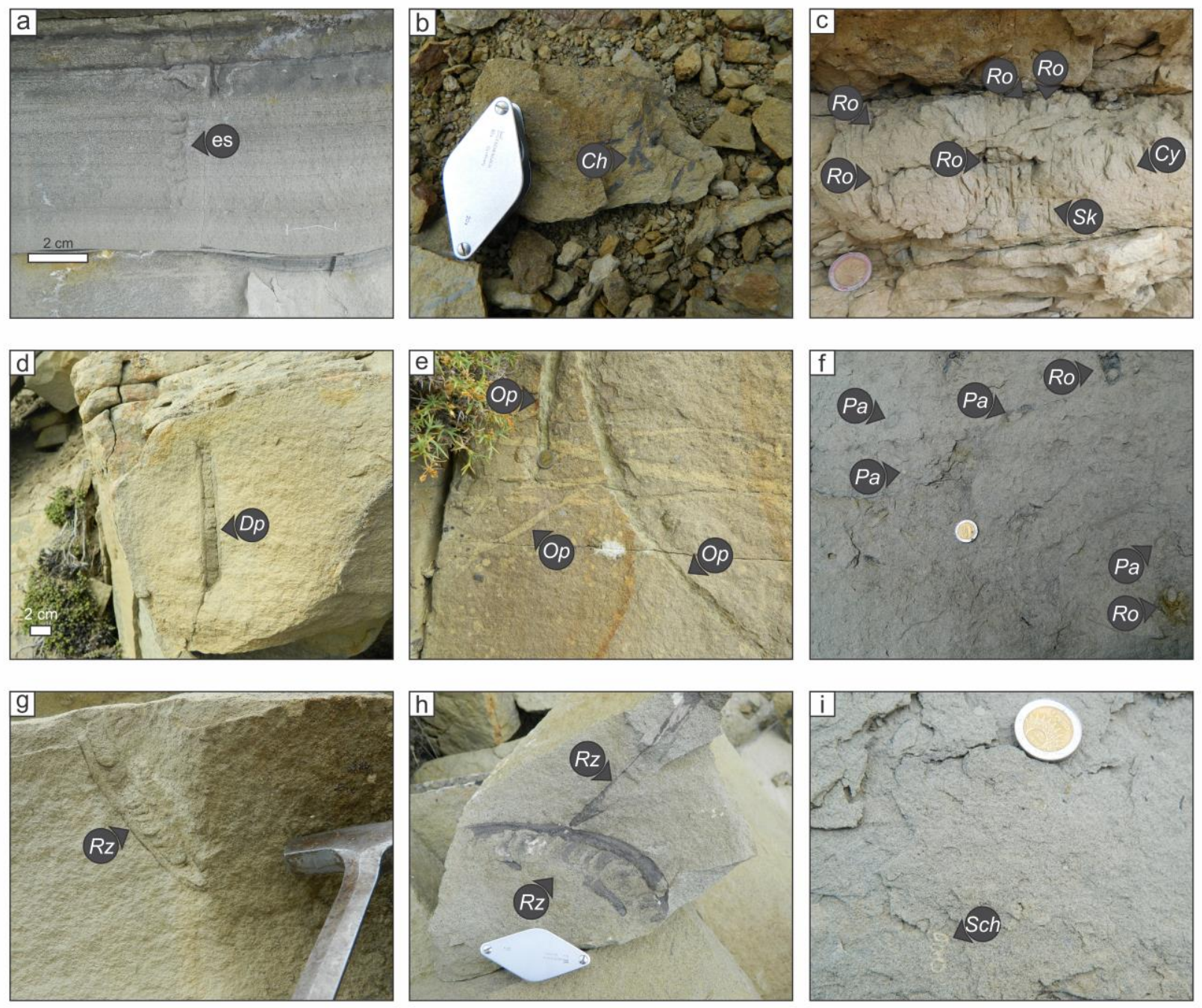

6.2.3 Icnología de la Asociación de Facies 3 (AF3): Barras de desembocadura influenciadas por olas

Descripción: Los cuerpos arenosos de la asociación de facies de barras de desembocadura influenciadas por olas (AF3) se caracterizan por carecer de estructuras biogénicas o por presentar algunas trazas aisladas (IB 0-1). Dentro de esta asociación se han reconocido 5 icnogéneros: Diplocraterion isp., Gordia isp., Lockeia isp., Macaronichnus isp. y Ophiomorpha isp. (Fig. 6.3). Diplocraterion se presenta hacia los topes de los cuerpos arenosos y consiste en excavaciones verticales con forma de " $\mathrm{U}$ " que presentan un spreiten asociado y llegan a medir 8 
cm de longitud y $4 \mathrm{~cm}$ de ancho (Fig. 6.3a). Gordia isp. aparece en la base de los cuerpos arenosos y consiste en rastros horizontales lisos, carentes de ramificaciones, de hasta 0,3 mm de diámetro (Fig. 6.3b). Lockeia isp. también se registra hacia la base de estos cuerpos arenosos y consiste en pequeños cuerpos con forma de almohadilla elongada con un hiporelieve convexo (Fig. 6.3b y c). Las dimensiones de Lockeia isp., son $\sim 0,5 \mathrm{~cm}$ de ancho y $\sim 1 \mathrm{~cm}$ de longitud. Macaronichnus isp. no es común dentro de esta asociación, sin embargo, se ha registrado un cuerpo arenoso con abundantes excavaciones de este icnogénero. Consiste en excavaciones horizontales simples, cilíndricas que no presentan ningún tipo de ramificación y se encuentran rellenos por sedimentos de tamaño arena, el cual contrasta por diferencia de color con la capa hospedante de estas estructuras (FIg. 6.3d). Ophiomorpha isp. se presenta hacia el tope de los cuerpos arenosos de esta asociación y consiste en excavaciones dominantemente verticales las cuales se caracterizan por presentar pellets adheridos a lo largo de las paredes (Fig. 6.3e).

Interpretación: Esta asociación de facies fue interpretada como depósitos de barras de desembocadura influenciadas por olas (Enge et al., 2010; Moyano Paz et al., 2018, 2020). Estas barras de desembocadura se forman bajo condiciones de alta energía, de baja salinidad y buena oxigenación del agua asociada a las descargas fluviales. Estas condiciones repercuten directamente en las características icnológicas de esta asociación, observándose bajos valores de IB y la presencia de estructuras adaptadas para la colonización de sustratos expuestos a altas condiciones energéticas y altas tasas de sedimentación. La falta de estructuras biogénicas asociadas a comportamientos suspensívoros de alimentación también sugiere una elevada turbidez en el agua producto de la elevada canti- 
dad de sedimento en suspensión (Moslow y Pemberton, 1988, Gingras et al., 1998; MacEachern et al., 2005; Buatois y Mángano, 2011).

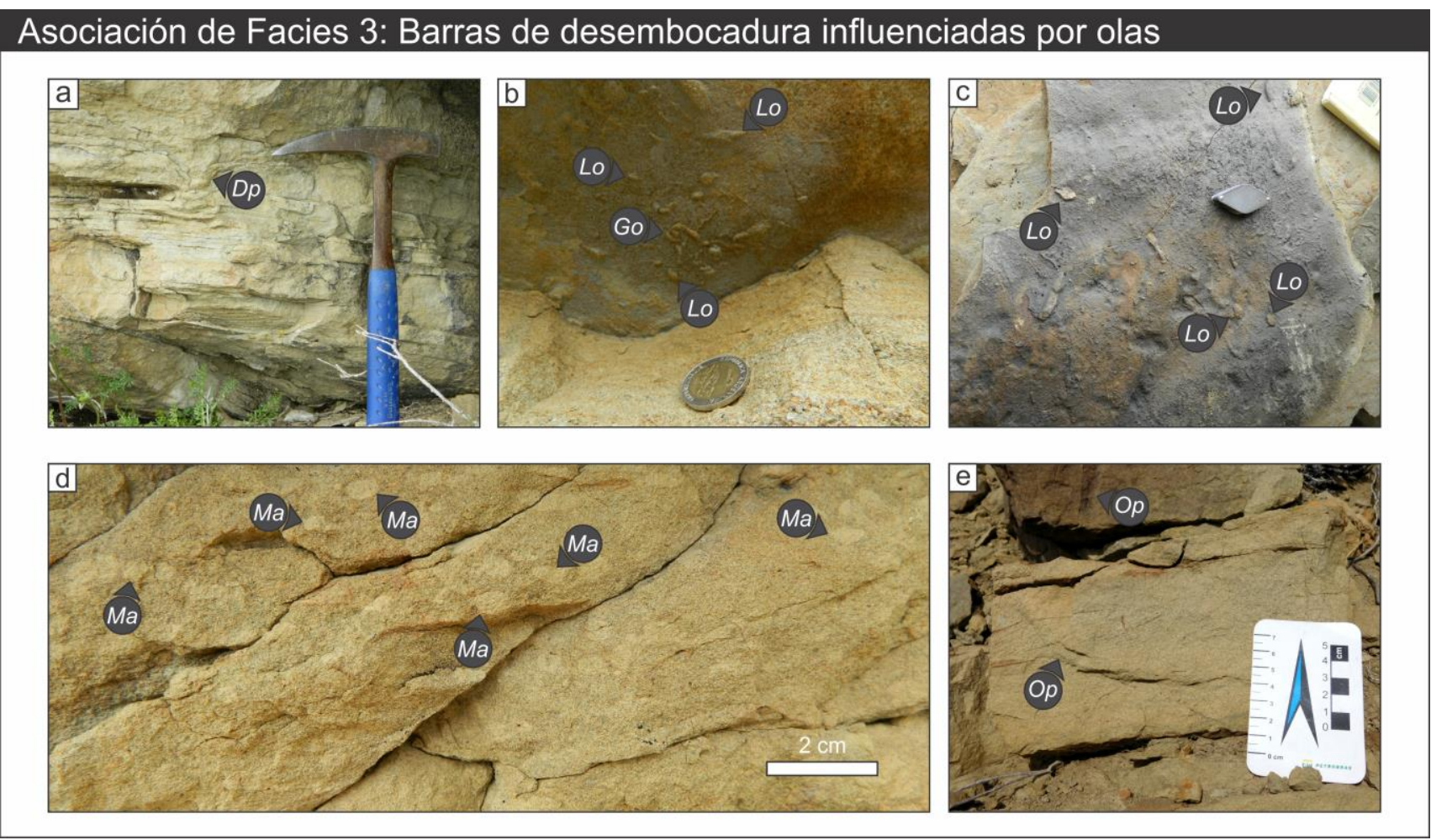

Figura 6.3. Características icnológicas de la asociación de barras de desembocadura influenciadas por olas. a). Detalle de la facies de areniscas con estratificación entrecruzada en artesa acompañada de una excavación de Diplocraterion isp. $(D p)$ en forma de "U" con spreiten asociado (piqueta de escala $=33 \mathrm{~cm}$ de longitud). b y c) Detalle de la base de cuerpos arenosos presentes en esta asociación con presencia de Gordia isp. (Go) y Lockeia isp. (Lo). Moneda de escala en b $=2,2$ $\mathrm{cm}$ de diámetro, lupa de escala en $\mathrm{c}=5,5 \mathrm{~cm}$ de diámetro. d) Detalle de una vista en sección de un cuerpo arenoso con abundantes excavaciones de Macaronichnus isp. (Ma). e) Vista en sección de cuerpos arenosos tabulares con laminación ondulítica y excavaciones verticales de Ophiomorpha isp. ( $O p)$.

6.2.4 Icnología de la Asociación de Facies 4 (AF4): Canales distributarios terminales

Descripción: Los cuerpos no amalgamados que constituyen a esta asociación (AF4) suelen carecer de rasgos de bioturbación (IB 0), pero en ocasiones pueden llegar a presentar algunas estructuras aisladas (IB 1). Se han reconocido tres icnotaxones diferentes principalmente hacia los topes de los cuerpos: Ophiomorpha isp., Schaubcylindrichnus coronus y Siphonichnus isp. (Fig. 6.4). Ophiomorpha isp. se presenta hacia los topes de los cuerpos arenosos y consiste en sistemas $3 \mathrm{D}$ constituidos por túneles horizontales y ejes verticales conformando galerías de hasta $3 \mathrm{~cm}$ de diámetro (Fig. 6.4a). Schaubcylindrichnus coronus con- 
siste en excavaciones horizontales levemente arqueadas apiladas verticalmente (Fig. 6.4b). Siphonichnus isp. consiste en tubos verticales rectos de hasta $15 \mathrm{~cm}$ de longitud que se caracterizan por presentar una estructura lineal asociada a las paredes (Fig. 6.4c).

\section{Asociación de Facies 4: Canales distributarios terminales}
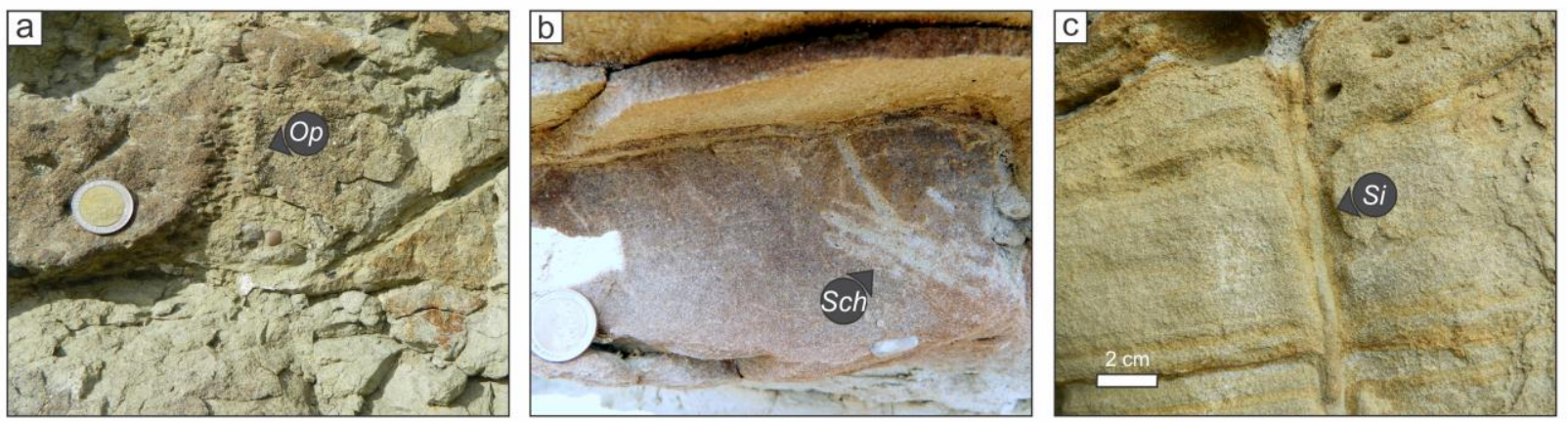

Figura 6.4. Características icnológicas de la asociación de canales distributarios terminales. a) Detalle de Ophiomorpha isp. $(O p)$ en un corte en sección (moneda de escala $=2,2 \mathrm{~cm}$ diámetro). b) Detalle de Schaubcylindrichnus coronus (Sch) en una vista en sección de un cuerpo arenoso con estratificación entrecruzada en artesa (moneda de escala $=2,2 \mathrm{~cm}$ de diámetro). c) Detalle de Siphonichnus isp. ( $S i)$ en una vista en sección de una capa de arena con estratificación entrecruzada en artesa.

Interpretación: La baja abundancia y diversidad de estructuras orgánicas que presenta esta asociación de canales distributarios terminales refleja condiciones estresantes para la colonización del sustrato por organismos productores de trazas tales como fluctuaciones en la salinidad del agua y/o condiciones de alta energía (MacEachern et al., 2005; Buatois y Mángano, 2011; Moyano Paz et al., 2020). La presencia de trazas fósiles marinas dentro de estos canales es evidencia directa de la influencia de procesos marinos, como por ejemplo corrientes de mareas, durante la depositación.

\subsubsection{Icnología de la Asociación de Facies 5 (AF5): Canales distributarios}

Descripción: La intensidad de los rasgos de bioturbación de la AF5 es muy variable. Hacia la base, estos cuerpos lenticulares se caracterizan por carecer de estructuras biogénicas o por presentar un muy bajo IB (IB 0-1), pero la intensidad de las excavaciones aumenta gradualmente hacia los topes de los cuerpos 
(IB 3-5). Se han reconocido un total de tres icnogéneros en estos depósitos: Ophiomorpha isp., Psilonichnus isp. y Skolithos isp. (Fig. 6.5). Ophiomorpha isp. es el icnogénero que se presenta con mayor frecuencia dentro de esta asociación y consiste en sistemas 3D de túneles horizontales y chimeneas verticales que constituyen galerías de hasta $2 \mathrm{~cm}$ de diámetro, las cuales se caracterizan por presentar pellets adheridos a lo largo de sus paredes (Fig. 6.5a). Psilonichnus isp. consiste en excavaciones verticales, las cuales eventualmente se disponen de una forma levemente inclinada, que se caracterizan por presentar una forma de "Y" (Fig. 6.5b). Estas excavaciones alcanzan los $2 \mathrm{~cm}$ de diámetro y suelen presentar rasgos de oxidación a lo largo de los márgenes de las paredes (Fig. 6.5b). Skolithos isp. se presenta principalmente hacia el tope de los cuerpos lenticulares de esta asociación y consiste en excavaciones verticales simples, sin ramificaciones, que alcanzan los $6 \mathrm{~cm}$ de longitud y unos pocos milímetros de diámetro (Fig. 6.5c).

Interpretación: El incremento vertical del IB en estos depósitos de canales terminales podría vincularse al progresivo abandono de estos (Buatois et al., 2012). Las estructuras biogénicas de esta asociación reflejan influencia marina, sin embargo, la baja diversidad de estructuras presentes es indicativa de condiciones de estrés fisicoquímico que inhibieron la colonización del sustrato por parte de los organismos productores, probablemente asociado a fluctuaciones en la salinidad del medio en relación a las descargas fluviales, y las altas condiciones energéticas (MacEachern et al., 2005; Buatois y Mángano, 2011; Buatois et al., 2012; Moyano Paz et al., 2020). La presencia del icnogénero Psiolonichnus el cuál es típico de ambientes de agua dulce es una evidencia directa de la posición más proximal de estos canales. Sin embargo, la presencia de Ophiomorpha isp. sugiere variaciones de salinidad mediante la instalación de condiciones sa- 
lobres producto de la influencia de procesos marinos (Frey y Pemberton, 1987;

MacEachern et al., 2005, 2007).

\section{Asociación de Facies 5: Canales distributarios}
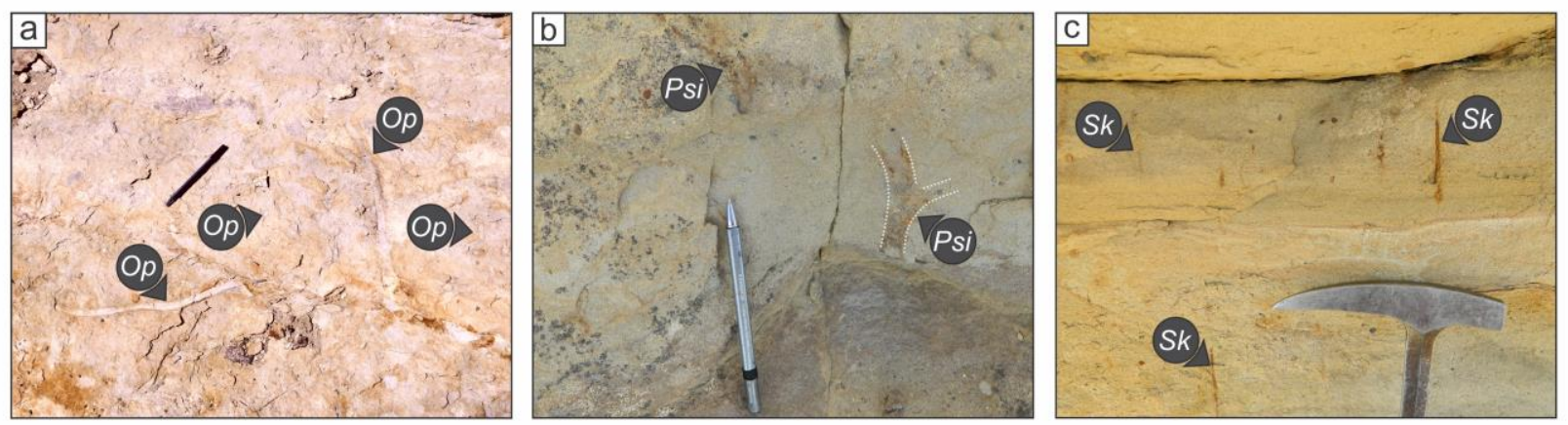

Figura 6.5. Características icnológicas de la asociación de canales distributarios. a) Detalle de las galerías de Ophiomorpha isp. $(O p)$ en una vista oblicua del afloramiento (lápiz de escala $=15 \mathrm{~cm}$ de longitud). b) Detalle de las excavaciones en forma de "Y" de Psilonichnus isp. (Psi) observadas en una vista en sección (lápiz de escala = $15 \mathrm{~cm}$ de longitud). c) Detalle de excavaciones verticales simples de Skolithos isp. (Sk) observadas en un corte en sección.

6.2.6 Icnología de la Asociación de Facies 6 (AF6): Frente deltaico distal fluvio-dominado

Descripción: Los depósitos de la asociación de frente deltaico distal fluviodominado (AF6) presenta elevados valores de IB (IB 4-5), siendo este el motivo del aspecto masivo que presentan. Aunque la intensidad de bioturbación es elevada, la diversidad de trazas fósiles que se ha registrado es baja y solo se han reconocido dos icnotaxones para esta asociación: Ophiomorpha nodosa y $\mathrm{Pa}$ laeophycus isp. Ophiomorpha nodosa es la icnoespecie dominante en esta asociación de facies y consiste en sistemas 3D de excavaciones que constituyen galerías con túneles horizontales y chimeneas verticales de hasta $3 \mathrm{~cm}$ de diámetros y paredes irregulares robustas de hasta $1 \mathrm{~cm}$ de espesor con pellets adheridos a las mismas (Fig. 6.6a, b, c y d). Palaeophycus isp. consiste en excavaciones horizontales rectas a levemente curvadas, simples, cilíndricas y sin ramificaciones de hasta 0,7 $\mathrm{mm}$ de diámetro que se encuentran rellenas con sedimentos de granulometría arena (Fig. 6.6e). En las capas de esta asociación donde se preser- 
van las estructuras sedimentarias, las trazas fósiles presentan los menores tamaños, mientras que en los niveles bioturbados las trazas se presentan con tamaños más robustos.

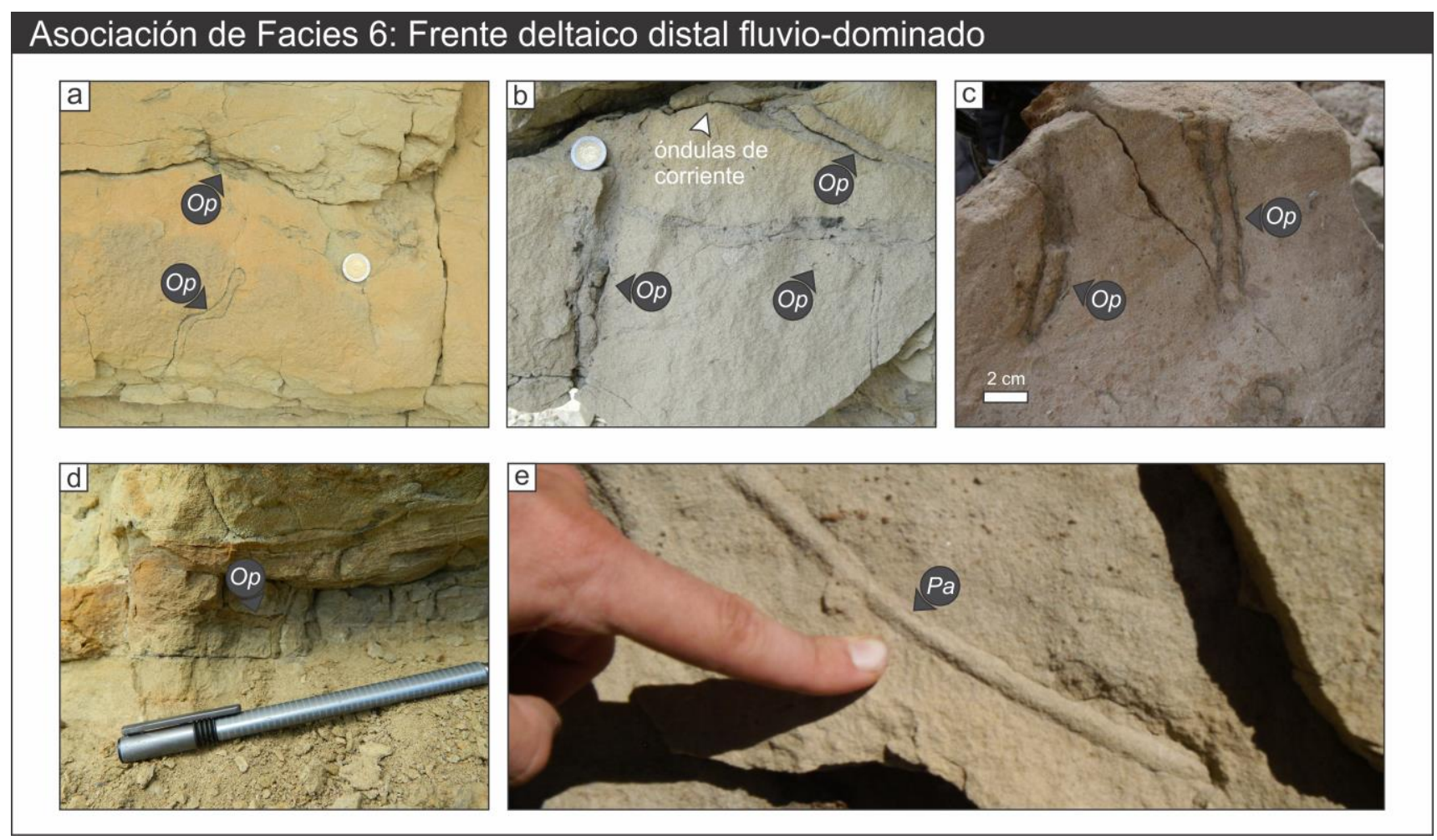

Figura 6.6. Características icnológicas de la asociación de frente deltaico distal fluvio-dominado. a, b y c) Detalle de las robustas galerías de Ophiomorpha nodosa., $(O p)$, vistas en sección en las capas masivas por bioturbación. Moneda de escala en a y b $=2,2 \mathrm{~cm}$ de diámetro. d) Detalle de una galería de Ophiomorpha nodosa $(O p)$ de reducido tamaño vista en perfil (lápiz de escala $=15 \mathrm{~cm}$ de longitud). e) Detalle de Palaeophycus isp. $(P a)$ en una vista en planta.

Interpretación: La ausencia de estructuras asociadas a comportamientos suspensívoros de alimentación, en conjunto con la baja diversidad de estructuras que se encuentran dentro de esta asociación, la cual presenta en una suite prácticamente monoespecífica, sugieren que la óptima colonización del sustrato se encontraba condicionada por condiciones de estrés físico-químico del medio tales como elevada turbidez del agua producto de una alta carga en suspensión de sedimento (Moslow y Pemberton, 1988, Gingras et al., 1998; MacEachern et al., 2005; Buatois y Mángano, 2011; Moyano Paz et al., 2020). Los tamaños reducidos de las galerías y excavaciones de Ophiomorpha nodosa podrían vincularse con condiciones fluctuantes de salinidad (MacEachern et al., 2005; 
Gingras et al., 2011). Las capas altamente bioturbadas sugieren una baja periodicidad de los eventos responsables de su acumulación (Enge et al., 2010; Moyano Paz et al., 2020).

6.2.7 Icnología de la Asociación de Facies 7 (AF7): Barras de desembocadura fluvio-dominadas

Descripción: Los depósitos de la asociación de facies de barras de desembocadura fluvio-dominadas (AF7) típicamente carecen de rasgos de bioturbación, solo presentan algunas trazas fósiles aisladas representando una suite de trazas empobrecida (IB 0-1). Solo se han reconocido dos icnogéneros para esta asociación: Lockeia isp. y Ophiomorpha isp. (Fig. 6.7). Lockeia isp. se encuentra hacia base de los cuerpos de esta asociación y consiste en cuerpos alargados con forma de almohadilla similares a los de la AF3 pero más robustos (Fig. 6.7a). Lockeia isp. alcanzan dimensiones de hasta $1 \mathrm{~cm}$ de ancho y $3 \mathrm{~cm}$ de longitud. Ophiomorpha isp. se encuentra principalmente hacia los topes de los cuerpos arenosos de esta asociación y consiste en sistemas 3D de galerías similares a las presentes en la AF6, pero se caracterizan por presentar una gran concentración de fitodetritos adheridos a las paredes (Fig. 6.7b).

Interpretación: La baja abundancia y diversidad de estructuras biogénicas dentro de esta asociación de barras de desembocadura fluvio-dominadas es indicativa de que las condiciones ambientales no eran propicias para la colonización del sustrato por parte de los organismos productores de trazas. Esta configuración de estrés fisicoquímico en el medio se interpreta como asociadas a condiciones de agua salobre con alta tasa de sedimentación, con fluctuaciones en la salinidad del medio y con alta concentración de restos vegetales (MacEachern et al., 2005; Gingras et al., 2011; Arregui et al., 2019; Moyano Paz et al., 2020). 


\section{Asociación de Facies 7: Barras de desembocadura fluvio-dominadas}
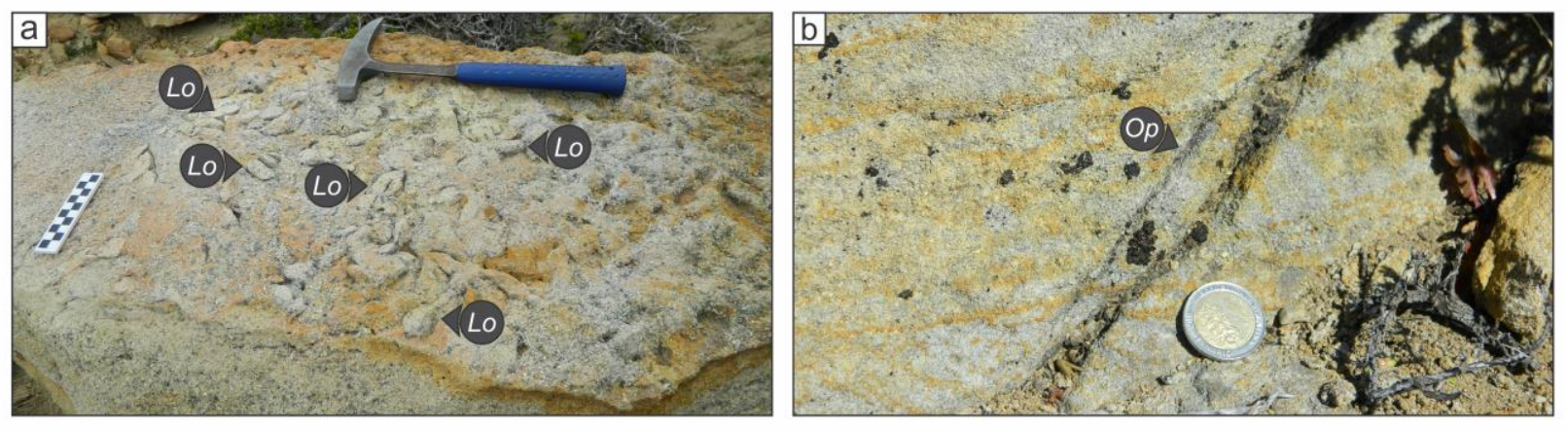

Figura 6.7. Características icnológicas de la asociación de barras de desembocadura fluvio-dominadas. a) Detalle de la base de un cuerpo arenoso con Lockeia isp. ( $L o$; piqueta de escala $=33 \mathrm{~cm}$ de longitud). b) Vista en sección de una capa de arenisca con estratificación entrecruzada en artesa y Ophiomorpha isp. ( $O p$ moneda de escala =2,2 cm de diámetro).

6.2.8 Icnología de la Asociación de Facies 8 (AF8): Canales distributarios multiepisódicos

Descripción: Los depósitos de esta asociación de facies (AF8) se caracterizan por presentarse sin rasgos de bioturbación (IB 0). Sin embargo, localmente pueden presentar estructuras biogénicas aisladas (IB 1-2) en los depósitos que se encuentran hacia el tope de la unidad superior. Se han reconocido cuatro icnogéneros en los depósitos de canales distributarios multiepisódicos: Arenicolites isp., Ophiomorpha isp., Psilonichnus isp. y Teredolites isp. (Fig. 6.8). Arenicolites isp. se presenta hacia los topes de los cuerpos lenticulares de la AF8 que se encuentran hacia el tope de la unidad superior y consiste en excavaciones verticales con forma de "U" en una vista en perfil (Fig. 6.8a) y en aperturas pares, rellenas de arena, en una vista en planta (Fig. 6.8b). Ophiomorpha isp. se registró tanto en el tope del intervalo inferior que constituye el relleno fluvial del valle inciso, así como también en los canales del intervalo superior de la unidad. Se presenta como excavaciones verticales con pellets y fitodetritos aglutinados a lo largo de sus paredes (Fig. 6.8c). Psilonichnus isp. se encuentra también hacia el tope de los cuerpos lenticulares del intervalo superior y consiste en excavaciones verticales que se ramifican en forma de "Y" y que llegan a alcanzar los $20 \mathrm{~cm}$ de longitud y 1,5 cm de diámetro (Fig. 6.8d). Teredolites isp. se presenta en los 
fragmentos de troncos petrificados que se encuentran dentro de esta asociación y consiste en abundantes perforaciones, subcilíndricas, de hasta $3 \mathrm{~mm}$ de diámetro (Fig. 6.8e).

\section{Asociación de Facies 8: Canales distributarios multiepisódicos}
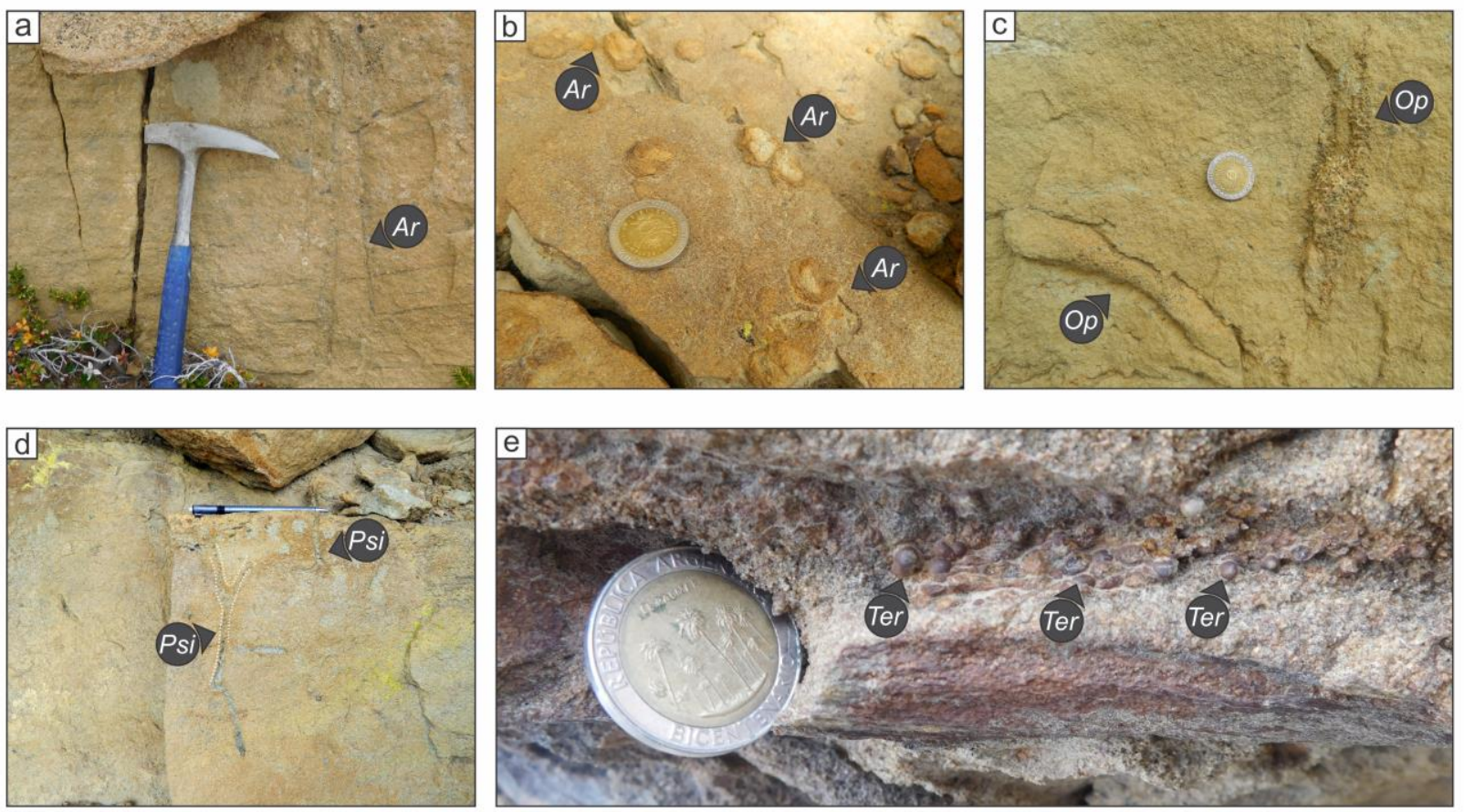

Figura 6.8. Características icnológicas de la asociación de canales distributarios multiepisódicos. a). Detalle de una vista en sección (piqueta de escala $=33 \mathrm{~cm}$ de longitud) y b) vista en planta de Arenicolites isp. ( $A r$, moneda de escala $=2,2$ $\mathrm{cm}$ de diámetro). c) Detalle de Ophiomorpha isp. ( $O p)$ en una vista en perfil (moneda de escala $=2,2 \mathrm{~cm}$ de diámetro). d) Detalle de una vista en perfil con desarrollo de Psilonichnus isp. (PSi) hacia el tope de un cuerpo lenticular (lápiz de escala $=15 \mathrm{~cm}$ de longitud). e) Detalle de Teredolites isp., (Ter) en un fragmento de tronco ubicado en la base de uno de los cuerpos canalizados (moneda de escala $=2,2 \mathrm{~cm}$ de diámetro).

Interpretación: La ausencia de estructuras biogénicas dentro de los canales que constituyen el relleno fluvial del valle inciso sugiere un medio altamente estresante, asociado al dominio de corrientes fluviales, que inhibió la colonización del sustrato por parte de los organismos (MacEachern et al., 2005; Buatois y Mángano, 2011). La presencia de una superficie con presencia de rasgos de bioturbación compuesta mayoritariamente por Ophiomorha isp. hacia el techo del relleno del valle incidido estaría asociado a una superficie de inundación marina (ver Capítulo 8). Los depósitos de la AF8 que se ubican en el intervalo superior de esta unidad presentan una baja abundancia y diversidad de trazas fósiles y estos se interpreta como producto de condiciones altamente estresantes que 
inhibieron la colonización del sustrato por los organismos productores de trazas tales como alta energía y agua salobre o dulce (MacEachern et al., 2005; Buatois y Mángano, 2011, Buatois et al., 2012). La presencia del icnogénero Psiolonichnus isp. dentro de estos depósitos, el cual no se encuentra asociado a condiciones marinas abiertas, si no que muestra una relación directa configuraciones altamente energéticas, con presencia de agua dulce y variaciones de salinidad soporta esta interpretación (Frey y Pemberton, 1987; MacEachern et al., 2005, 2007). Las perforaciones de Teredolites isp., en los fragmentos de madera, se interpretan como generadas en medios terrestres previo a su depositación (Buatois y Mángano, 2011). Por su parte, la presencia de Ophiomorpha isp. en alguno de los canales, sugiere la instalación de condiciones de agua salobre producto de la acción de corrientes mareales durante periodos de baja descarga (MacEachern et al., 2005; Bann et al., 2008; Buatois y Mángano, 2011, Buatois et al., 2012).

6.2.9 Icnología de la Asociación de Facies 9 (AF9): Áreas interdistributarias saturadas en agua

Descripción: La intensidad en la que se presentan los rasgos de bioturbación dentro de esta asociación son bajos a medios (IB 1-3), sin embargo, localmente algunos de estos depósitos muestran mayores intensidades (IB 4). Cinco icnotaxones fueron registrados dentro de esta asociación de facies de áreas interdistributarias saturadas en agua: Ophiomorpha isp., Palaeophycus isp., Planolites isp., Thalassioides isp. y Teichichnus isp. (Fig. 6.9). Ophiomorpha isp. se encuentra hacia los topes de los cuerpos arenosos de geometría lobular que intercalan con los depósitos de grano fino de esta asociación y consiste en excavaciones verticales que se caracterizan por presentar pellets adheridos a sus paredes y que llegan a alcanzar los $10 \mathrm{~cm}$ de longitud y 1,5 cm de diámetro (Fig. 6.9b). Palaeophycus isp. se presenta en las facies heterolíticas de esta asociación y consiste en 
excavaciones horizontales, rectas, cilíndricas, sin ramificaciones, que se encuentran rellenas con sedimentos tamaño arena y llegan a medir hasta $1 \mathrm{~cm}$ de diámetro (Fig. 6.9c). Planolites isp. se presenta tanto en las facies pelítias como en las heterolíticas y también en la de las areniscas masivas de esta asociación de facies y consiste en excavaciones horizontales simples, sin ramificaciones que se caracterizan por presentar un relleno activo y llegan a medir hasta $1 \mathrm{~cm}$ de diámetro (Fig. 6.9d y e). Thalassinoides isp. se presenta en las facies pelíticas de esta asociación y fue registrado como excavaciones horizontales que carecen de lineamiento que presentan una forma elíptica en una vista en sección y se encuentran rellenos de sedimentos de granulometría arena (Fig. 6.9d). Teichichnus isp. se presenta tanto en facies arenosas como en las pelíticas y consiste en una serie de láminas concéntricas cóncavas hacia abajo apiladas verticalmente (Fig. 7.9c y f). A demás de los icnogéneros mencionados y descriptos, dentro de esta asociación de facies se han registrado abundantes rizolitos, los cuales llegan a alcanzar los $6 \mathrm{~cm}$ de longitud y 0,5 cm de ancho (Fig. 6.9a).

\section{Asociación de Facies 9: Áreas interdistributarias}
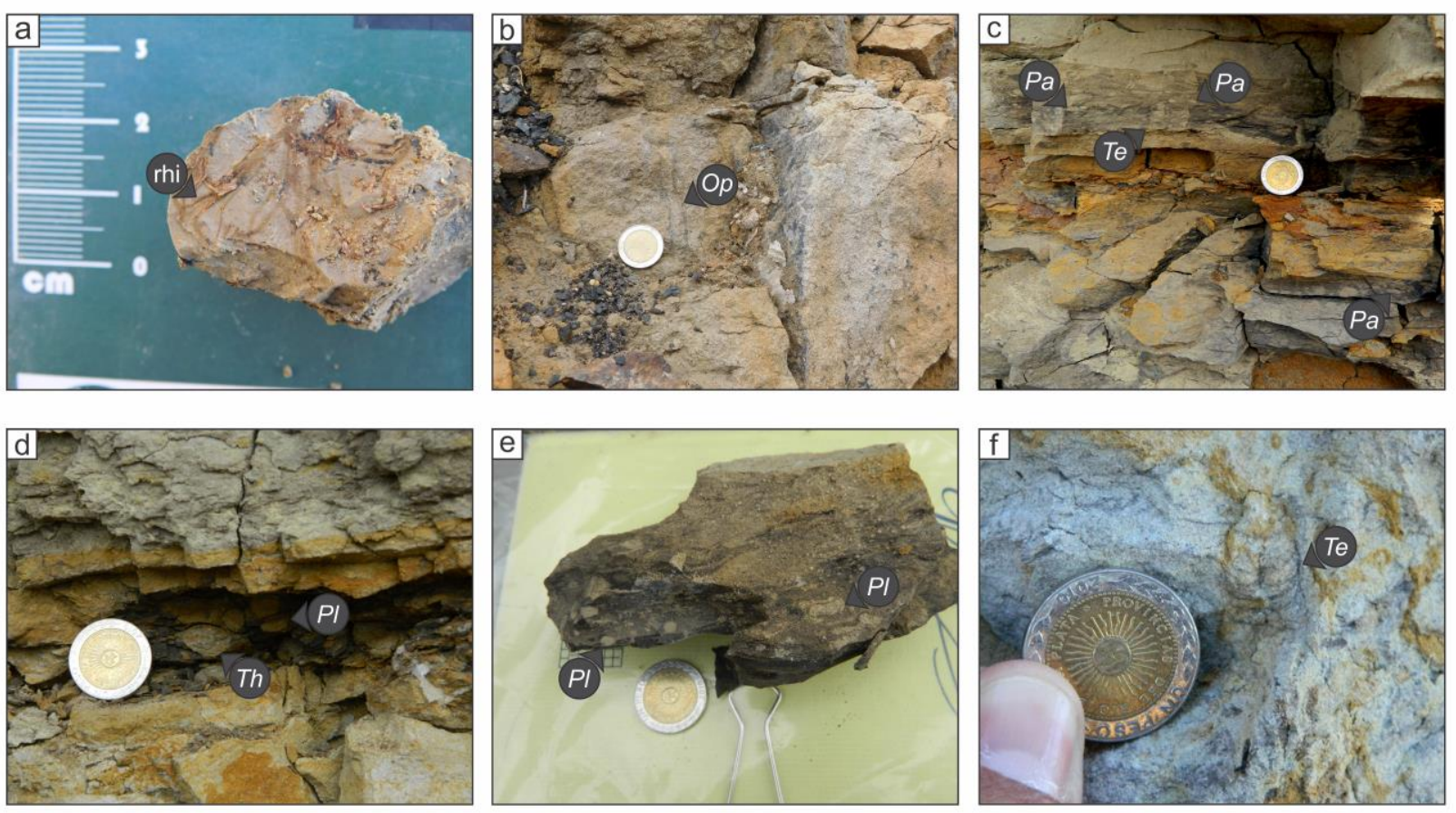
Figura 6.9 (página anterior). Características icnológicas de la asociación de áreas interdistriburarias. a). Fotografía de detalle un agregado en bloque con presencia de rizolitos (rhi). b) Detalle de una vista en perfil de un cuerpo arenoso de geometría lobular con Ophiomorpha isp. ( $O p$ moneda de escala =2,2 cm de diámetro). c) Detalle de una vista en perfil de depósitos heterolíticos con presencia de Palaephycus isp. (Pa) y Teichichnus isp. (Te; moneda de escala $=2,2 \mathrm{~cm}$ de diámetro). d) Capa de pelitas oscuras vista en sección con Planolites isp. (PI) y Thalassinoides isp. (Th; moneda de escala $=2,2 \mathrm{~cm}$ de diámetro). e) Detalle de Planolites isp. $(P I)$ en depósitos heterolíticos (moneda de escala $=2,2 \mathrm{~cm}$ de diámetro). f) Fotografía de detalle de Teichichnus isp. (Te) con su spreiten asociado en una vista en perfil de una capa de arena masiva (moneda de escala $=2,2 \mathrm{~cm}$ de diámetro).

Interpretación: La presencia de rizolitos dentro de las facies finas de esta asociación, en conjunto con el desarrollo de agregados masivos (ver Capítulo 5; Tabla 5.1), es indicativa de procesos pedogenéticos y de desarrollo de suelos. El abundante contenido de materia orgánica preservada, con muy poco grado de descomposición, dentro de esta asociación indica que estos suelos se desarrollaron en condiciones saturadas en agua (Everett, 1983; Retallack, 2001). La moderada a baja intensidad de las excavaciones registradas en esta asociación sugiere que estos sustratos se encontraban expuestos a condiciones de estrés que inhibieron la colonización por parte de los organismos productores de trazas. Estas condiciones de estrés se encontrarían asociadas a condiciones de reducida oxigenación instaladas en estos ambientes lo que permitió la acumulación de materia orgánica prácticamente sin descomponer (Raychaudhuri y Pemberton, 1992; Leithold y Dean, 1998; Gingras et al., 1998; Coates y MacEachern, 1999; MacEachern et al., 2005). Si bien estas áreas interdistributarias saturadas en agua son interpretadas como rellenas a partir de procesos de desborde de los canales interdistributarios de la AF8, la presencia de icnogéneros asociados a condiciones exclusivamente marinas como por ejemplo Ophiomorpha isp., $\mathrm{Pa}$ laeophycus isp. y Teichichnus isp. sugieren la influencia de procesos marinos y la instalación de condiciones de agua salobre, representando fluctuaciones en la salinidad del agua, lo que también representa una condición de estrés para la colonización del sustrato por parte de la fauna bentónica (MacEachern et al., 2005; Buatois et al., 2012). 


\subsection{VARIACIONES VERTICALES EN LA INTENSIDAD Y DIVERSIDAD DE LA BIOTURBACIÓN}

La intensidad en la que se presentan los rasgos de bioturbación y la diversidad de estructuras biogénicas dentro de la Formación La Anita presentan significantes variaciones verticales. Estas variaciones verticales en las características icnológicas tienen una correlación directa con las variaciones observadas entre los tres sistemas de acumulación interpretados para la unidad, y también con las variaciones en la dominancia relativa de los procesos depositacionales (Figs. 5.12 y 6.10). El delta dominado por olas, responsable de la acumulación de la unidad inferior, presenta los valores de IB más altos de la Formación La Anita (Fig. 6.10). El intervalo más inferior de la unidad superior, interpretado como producto de la acumulación de sedimentos en un valle inciso el cual se encuentra dominado por procesos fluviales, se caracteriza por la ausencia casi total de estructuras biogénicas, mientras que el sistema deltaico fluvio-dominado, interpretado por encima del relleno valle inciso, se caracteriza por presentar intensidades relativamente bajas en los rasgos de bioturbación y comúnmente se presentan suites monoespecíficas de trazas (Fig. 6.10).

Las trazas registradas para el prodelta dominado por olas (AF1) son interpretadas como estructuras de vivienda y de comportamientos detritívoros de alimentación por parte de los organismos productores de trazas (MacEachern et al., 2007; Buatois y Mángano, 2011). Las facies pelíticas de esta asociación, las cuales fueron acumuladas a través de procesos de decantación durante condiciones de baja energía durante el buen tiempo, muestran las menores intensidades de bioturbación (IB 0-2) y también la menor icnodiversidad como respuesta al estrés fisicoquímico generado por la acción de los procesos fluviales activos (MacEachern et al., 2005; Bann et al., 2008; Gingras et al., 2011; Buatois 
Variaciones verticales en las características icnológicas

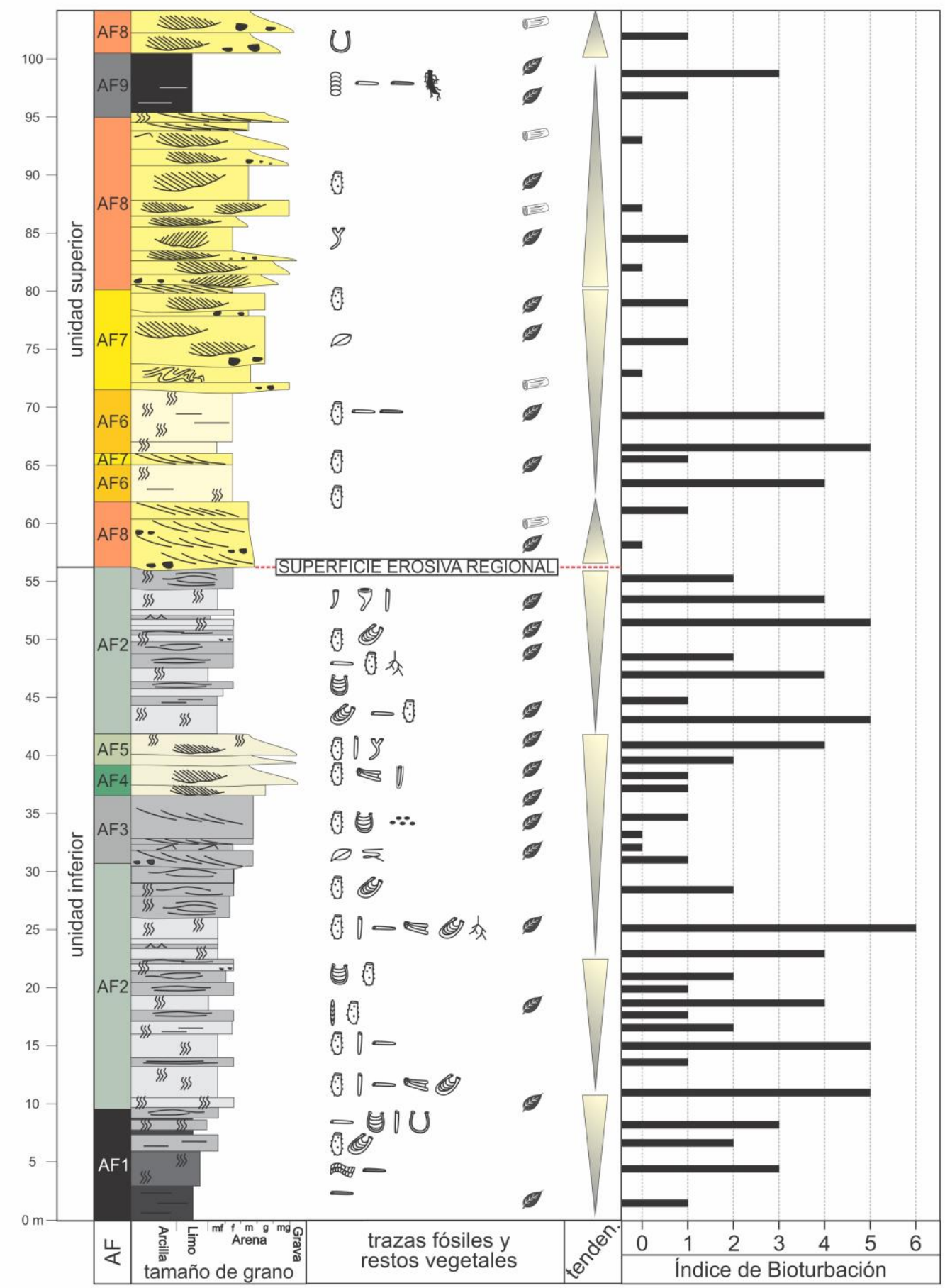

Figura 6.10. Sección esquemática de la Formación La Anita donde se puede ver las contrastantes características icnológicas de sus unidades internas y también de sus diferentes asociaciones de facies. Para las referencias del perfil ver Figura 3.6.

et al., 2012; Dasgupta et al., 2016; Moyano Paz et al., 2020). Estas capas de grano fino se encuentran caracterizadas por la presencia de Planolites isp. y Gyrochorte isp. que representan comportamientos detritívoros de alimentación y de pastoreo en un sustrato rico en contenido orgánico (Figs. 6.10 y 6.11). Las capas ge- 
neradas durante los eventos de tormenta de la AF1 también muestran bajos valores de IB (IB 0-1) y una baja icnodiversidad, y las trazas registradas consisten en Ophiomorpha isp. y Rhizocorallium, las cuales son estructuras adaptadas para la colonización del sustrato bajo condiciones de alta energía (Figs. 6.10 y 6.11; MacEachern et al., 2005; Bann et al., 2008; Knaust, 2013; Moyano Paz et al., 2020). Luego de los eventos de tormenta, los sustratos arenosos y heterolíticos eran colonizados por organismos productores oportunistas resultando en los mayores valores de IB (IB 2-3) y de icnodiversidad dentro de la AF1 (Figs. 6.10 y 6.11). Esta colonización por parte de los organismos productores de trazas una vez finalizadas las tormentas se debe a que estos eventos oxigenan el fondo y remueven el material fino, generando nuevas ventanas de colonización (Bann et al., 2008). Las trazas fósiles registradas dentro de la asociación de frente deltaico distal dominado por olas (AF2) reflejan sólo estructuras de vivienda (Figs. 6.10 y 6.11). Las capas de areniscas acumuladas durante eventos de tormenta muestran los valores de IB más bajos de la asociación (IB 0-2) y se encuentran caracterizadas por estructuras producidas por organismos adaptados para la colonización de sustratos bajo condiciones de alta energía, tales como Ophiomorpha isp., Rhizocorallium isp. y Skolithos isp. (Figs. 6.10 y 6.11; MacEachern et al., 2007, 2010, 2012; Buatois y Mángano, 2011, Knaust et al., 2013, Moyano Paz et al., 2020). Por otro lado, la presencia de Diplocraterion isp. y de trazas de escape (fugichnia) reflejan una alta tasa de sedimentación durante la depositación de estas capas (Figs. 6.10 y 6.11). Los niveles que representan los momentos posteriores a los eventos de tormenta muestran los valores más altos de IB (IB 3-6), así como también la mayor diversidad de trazas (Figs. 6.10 y 6.11). Las barras de desembocadura influenciadas por olas (AF3) se caracterizan por presentar una baja abundancia y diversidad de trazas (IB 0-1), con excavaciones de Ophiomorpha isp. como la estructura más común (Figs. 6.10 y 6.11). Los depósi- 
tos de canales distributarios terminales (AF4) también presentan una muy baja abundancia y diversidad de trazas (IB 0-1; Figs. 6.10 y 6.11), debido a las condiciones de estrés fisicoquímico generadas por los procesos fluviales activos (MacEachern et al., 2005; Bann et al., 2008; Gingras et al., 2011; Buatois et al., 2012; Dasgupta et al., 2016; Moyano Paz et al., 2020). Por último, los canales distributarios (AF5) muestran una variable intensidad en los rasgos de bioturbación (IB 1-6) y una baja diversidad de trazas las cuales se encuentran asociadas a estructuras de vivienda (Figs. 6.10 y 6.11).

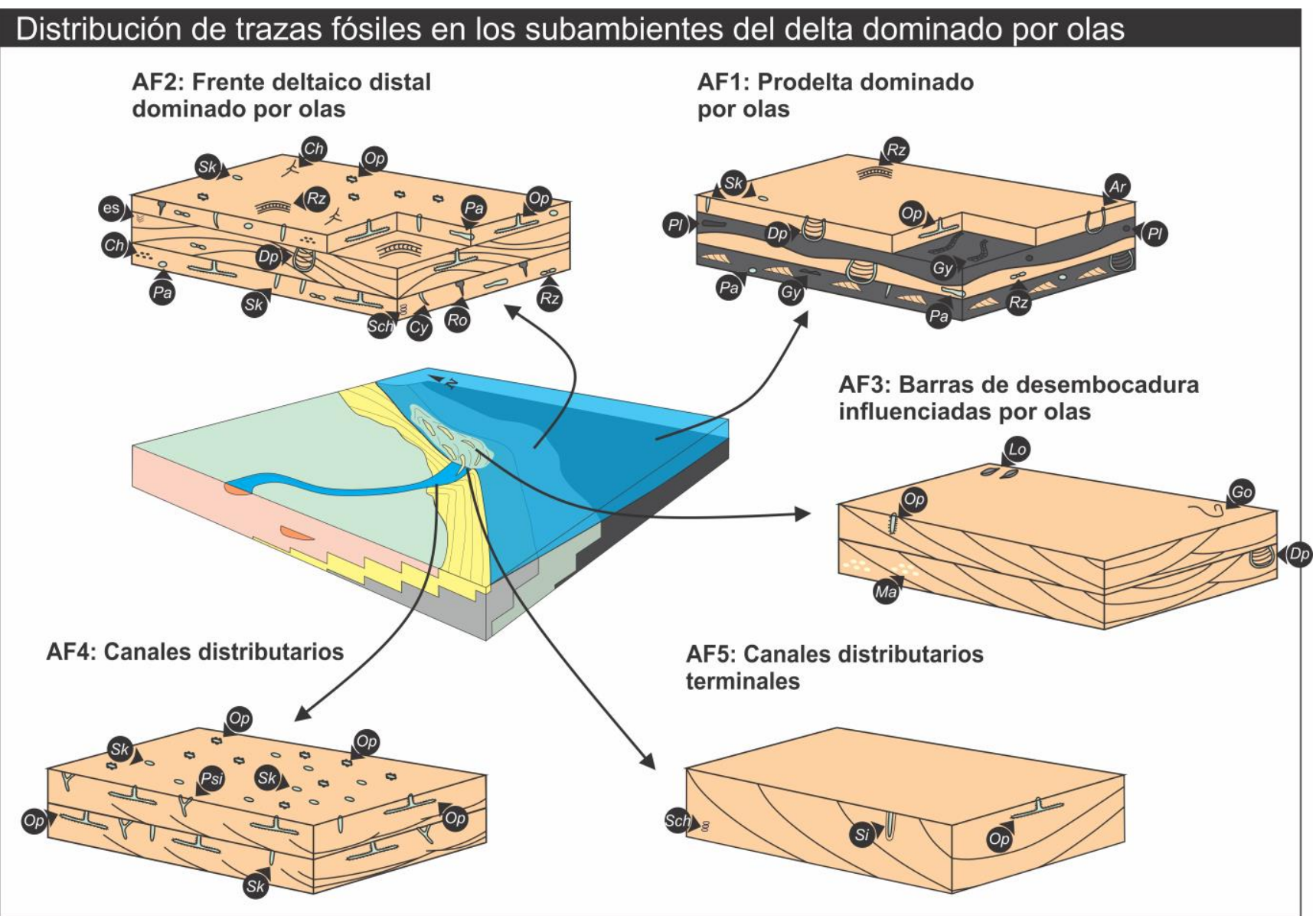

Figura 6.11. Esquema del modelo de acumulación propuesto para el delta dominado por olas, influenciado por procesos fluviales de la unidad inferior de la Formación La Anita mostrando las asociaciones icnológicas presentes en sus diferentes subambientes deltaicos. es $=$ estructuras de escape; $A r=$ Arenicolites isp.; $C h=C h o n d r i t e s$ isp.; $C y=$ Cylindrichnus isp.; $D p=$ Diplocraterion isp.; Go = Gordia isp.; Lo = Lockeia isp.; Ma = Macaronichnus isp.; Op $=$ Ophiomorpha isp.; $\mathrm{Pa}=$ Palaeophycus isp.; $\mathrm{PI}=$ Planolites isp.; Psi $=$ Psilonichnus isp.; Ro $=$ Rosselia isp.; RZ $=$ Rhizocorallium isp.; $S c h=S c h a u b c y l i n d r i c h n u s$ isp.; $S i=$ Siphonichnus isp.; $S k=S k o l i t h o s$ isp.

Los depósitos de la AF8 que son interpretados como el relleno de un valle inciso y que se encuentran caracterizando el intervalo más inferior de la unidad 
superior de la Formación La Anita, inmediatamente por encima de la SER, se caracterizan por la ausencia de trazas fósiles o por presentar estructuras muy aisladas de Ophiomorpha isp. hacia el tope de este relleno (IB 0-1; Fig. 6.10). Los depósitos del delta fluvio-dominado de la unidad superior, que se ubica por encima del relleno del valle inciso, presentan una menor intensidad de bioturbación y también una menor diversidad de trazas en comparación con el sistema deltaico de la unidad inferior (Figs. 6.10 y 6.12). Sin embargo, los depósitos del frente deltaico distal de este sistema (AF6) presentan valores elevados de IB (IB 4-5) pero una muy baja icnodiversidad evidenciando condiciones de estrés fisicoquímico relacionado con las descargas fluviales (Figs. 6.10 y 6.112; MacEachern et al., 2005; Gingras et al., 2011; Buatois et al., 2012, 2019; Canale et al., 2015; Dasgupta et al., 2016; Moyano Paz et al., 2020). Las trazas registradas para esta asociación de frente deltaico distal fluvio-dominado son Ophiomorpha isp. y Palaeophycus isp. las cuales consisten en estructuras de viviendas adaptadas para altas condiciones de energía. La asociación de barras de desembocadura (AF7), se caracteriza por presentar una muy baja abundancia y diversidad de trazas fósiles (IB 0-1; Figs. 6.10 y 6.12), evidenciando nuevamente condiciones de estrés ambiental relacionado con corrientes fluviales activas. Los canales distributarios multiepisódicos de la planicie deltaica del delta fluvio-dominado (AF8) se presentan típicamente sin rasgos de bioturbación, pero con presencia de algunas excavaciones verticales hacia el tope de los cuerpos lenticulares y con una baja diversidad de trazas (IB 0-2; Fig. 6.10). Las estructuras biogénicas que se han registrado dentro de estos depósitos de relleno de canal consisten principalmente en estructuras de vivienda de Arenicolites isp., Ophiomorpha isp. y Psilonichnus isp. (Figs. 6.10 y 6.12) las cuales son indicativas de condiciones de alta energía y evidencian también la influencia de corrientes de mareas dentro de estos canales. Las áreas interdistributarias de la planicie deltaica (AF9) se 
encuentran moderadamente bioturbados (IB 1-4; Fig. 6.10), y se caracterizan por presentar estructuras horizontales tanto de vivienda como de comportamientos detritívoros de alimentación en las facies pelíticas, las cuales muestran los valores más elevados de IB y también la mayor icnodiversidad, y excavaciones verticales de Ophiomorpha isp. en los depósitos arenosos de lóbulos de desborde (Figs. 6.10 y 6.12).

\section{Distribución de trazas fósiles en los subambientes del delta fluvio-dominado}

AF9: Áreas interdistributarias

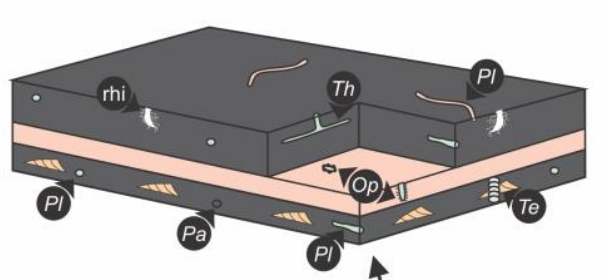

AF6: Frente deltaico distal fluvio-dominado

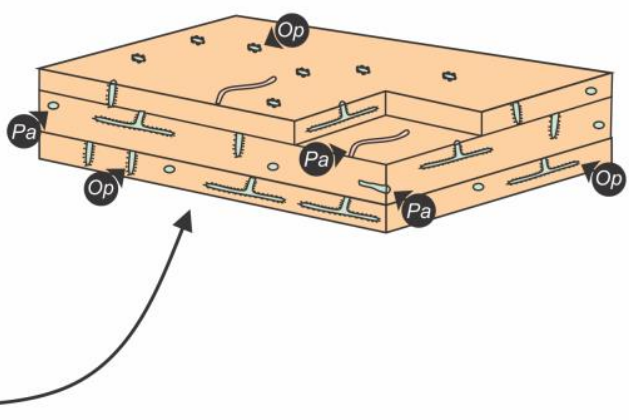

AF7: Barras de desembocadura fluvio-dominadas

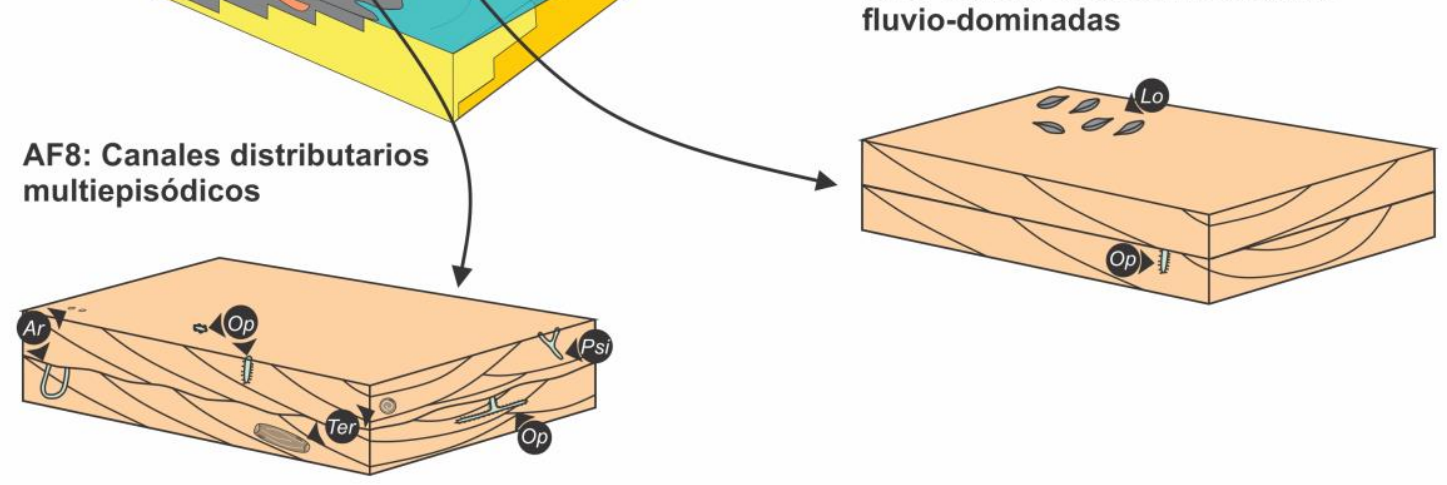

Figura 6.12. Esquema del modelo de acumulación propuesto para el delta fluvio-dominado, influenciado por corrientes de marea de la sección superior de la Formación La Anita mostrando las asociaciones icnológicas presentes de sus diferentes subambientes deltaicos. rhi $=$ rizolitos; $A r=$ Arenicolites isp.; Lo = Lockeia isp.; Op = Ophiomorpha isp.; Pa $=$ Palaeophycus isp.; $P I=$ Planolites isp.; Psi = Psilonichnus isp.; Te = Teichichnus isp.; Ter $=$ Teredolites isp.; Th $=$ Thalassinoides isp. 


\subsection{CARACTERÍSTICAS ICNOLÓGICAS COMO RESPUESTAS A CONDICIONES} DE DOMINIOS DE PROCESOS DE OLEAJE Y FLUVIALES EN SISTEMAS DELTAI$\cos$

La icnología de las costas deltaicas ha sido el foco de varios estudios en los últimos años y hay un interés creciente en comprender cómo diferentes condiciones de estrés fisicoquímico impactan sobre la fauna bentónica y por lo tanto a las trazas de los organismos productores como respuesta a estas condiciones (Gingras et al., 1998, 2011; MacEachern et al., 2005; Bann et al., 2008; MacEachern y Bann, 2008; Bhattacharya y MacEachern, 2009; Carmona et al., 2009; Buatois y Mángano, 2011; Buatois et al., 2012, 2019; Canale et al., 2015, 2020, Korus y Fielding, 2015, Dasgupta et al., 2016; Collins et al., 2017, 2018, 2019; Moyano Paz et al., 2020). La interacción dinámica entre los dominios relativos entre descargas fluviales, energía mareal, acción de oleaje y eventos de tormenta crean diferentes condiciones ambientales que impactan directamente sobre los organismos productores y por lo tanto en la distribución de las trazas. Estos aspectos han sido resaltados recientemente por MacEachern et al. (2005), Bann et al. (2008), MacEachern y Bann, (2008), Buatois y Mángano (2011), Gingras et al. (2011), Buatois et al. (2012), y Dasgupta et al. (2016) entre otros. Los depósitos de la Formación La Anita representan un gran caso para estudiar las variaciones en la icnología en relación con el dominio de procesos de oleaje y de procesos fluviales en sistemas deltaicos y a continuación se presenta una caracterización de los diferentes estreses fisicoquímicos que condicionaron la colonización de estos sustratos.

\subsubsection{Delta dominado por olas, influenciado por procesos fluviales}

Los sistemas deltaicos dominados por olas se diferencian de los sistemas progradantes de shoreface dominados por olas en que el sedimento que llega 
hacia la costa es aportado, en mayor medida, directamente por ríos (Bhattacharya y Giosan, 2003). La icnología puede proporcionar información clave para la identificación de aporte fluvial a lo largo de costas dominadas por olas (MacEachern et al., 2005). El delta dominado por olas, influenciado por procesos fluviales interpretado para la unidad inferior de la Formación La Anita presenta diferentes factores de control que impactaron sobre la fauna bentónica.

Las asociaciones de facies dominadas por olas de prodelta y de frente deltaico distal ( $\mathrm{AF} 1$ y AF2) se encuentran fuertemente controladas por la recurrencia de los eventos de tormenta (Fig. 6.13a), y ambos subambientes presentan dos contrastantes grupos de facies y suites de trazas fósiles que representan la alternancia entre condiciones de buen tiempo y eventos de tormenta. Las suites de trazas de buen tiempo, de estas asociaciones de facies reflejan, la colonización del sustrato por parte de organismos productores bajo condiciones marinas estables y presentan estructuras relacionadas a la Icnofacies de Cruziana (Pemberton y Frey, 1984; MacEachern y Pemberton, 1992; MaEachern et al., 2010; Buatois y Mángano, 2011). Por lo contrario, las suites de trazas de las capas generadas por los eventos de tormenta reflejan la colonización por organismos productores oportunistas adaptados para la colonización de sustratos arenosos y se encuentra dominada por elementos que comúnmente se asocian a la Icnofacies de Skolithos (Pemberton y Frey, 1984; MacEachern y Pemberton, 1992; MacEachern et al., 2010; Buatois y Mángano, 2011). La presencia de trazas de escape y de Diplocraterion isp. también indica que la tasa de sedimentación durante la depositación era elevada (Fig. 6.13a). Otros factores de control también pueden haber tenido un rol importante como condicionante de la abundancia, diversidad y distribución de la fauna bentónica, como la turbidez del agua, que inhibe comportamientos suspensívoros de alimentación (Fig. 6.13a; Moslow y Pember- 
ton, 1988; Gingras, et al., 1998; MacEachern et al., 2005; Buatois y Mángano, 2011; Buatois et al., 2012). Los niveles pelíticos de la asociación de prodelta dominado por olas, enriquecidos en materia orgánica, muestran bajos valores de IB y también una baja diversidad de trazas, y esto podría vincularse a condiciones de baja oxigenación en el agua de fondo debido a la oxidación de los fitodetritos que luego, durante los eventos de tormenta, la columna de agua se mezcla restableciendo sus condiciones de oxigenación (Fig. 6.13a; Rice et al., 1986; Raychaudhuri y Pemberton, 1992; Gingras et al., 1998; Coates y MacEachern, 1999, 2000; MacEachern et al., 2005; Arregui et al., 2019).

Las barras de desembocadura (AF3) se construyen directamente a partir de procesos fluviales y muestran señales de diferentes factores de control asociados a las descargas fluviales que impactaron sobre la fauna bentónica. Condiciones de alta energía y una elevada tasa de sedimentación vinculadas con los flujos rápidos con mucha carga de sedimento en la zona de desembocadura de los canales distributarios habrían sido los principales factores que afectaron a los organismos productores de trazas, debido a que se veían imposibilitados de construir madrigueras permanentes (Fig. 6.13a; Alexander et al., 1991; MacEachern et al., 2005). El acercamiento oblicuo del tren de olas hacia la costa produjo no solo que estas barras se elonguen con una orientación paralela a la costa, sino que también ponían constantemente en suspensión a los sedimentos de grano fino excluyendo la presencia de trazas asociadas a comportamientos de alimentación por suspensión debido a la elevada turbidez del agua (Fig. 13a; MacEachern et al., 2005). La baja abundancia y la baja icnodiversidad de trazas, con una suite dominada por excavaciones verticales Ophiomorpha isp. son rasgos típicos de una Icnofacies de Skolithos empobrecida, y podría ser consecuencia de una respuesta a fluctuaciones en la salinidad asociada a las descargas flu- 
viales (Fig. 6.13a; Beynon et al., 1988; Pemberton y Wightman, 1992; MacEachern et al., 2005; Buatois et al., 2012).

Los depósitos de los canales distributarios terminales (AF4) y los canales distributarios (AF5) muestran evidencias de condiciones estresantes generadas directamente a partir de las descargas fluviales y fluctuaciones en los valores de salinidad. Las bajas intensidades y la distribución aislada de las estructuras biogénicas evidencian que los flujos rápidos de sedimentos fueron el principal factor de control que actuó sobre la fauna bentónica y que restringió la bioturbación a momentos de bajas descargas fluviales (Fig. 6.13a; MacEachern et al., 2005; Buatois y Mángano, 2011). La suite de trazas fósiles presente en estas asociaciones de relleno de canal se encuentra dominada por elementos que cortan verticalmente a las facies y son atribuibles a la Icnofacies de Skolithos, la cual también puede ocurrir en configuraciones de reducida salinidad, o con valores de salinidad fluctuantes (Fig. 6.13a). La afinidad marina de las estructuras biogénicas presentes refleja que algunos procesos marinos se influenciaron fuertemente estos canales durante los momentos de baja descarga fluvial (MacEachern et al., 2005; Gingras et al., 2011; Buatois et al., 2012). La avulsión y el consecuente abandono de canales también podría haber jugado un papel importante en el control del desarrollo de estas icnoasociaciones (Fig. 6.13a; Barnes, 1989, MacEachern et al., 2005; Dasgupta et al., 2016; Moyano Paz et al., 2020).

Es importante destacar que incluso en ambientes donde hay un factor claro que se encuentra controlando la actividad de los organismos productores de trazas, el estrés reflejado en los depósitos resultantes es el producto de una combinación de estos factores dominantes con condiciones de estrés subordinadas que imparten influencias sobre la comunidad bentónica (Fig. 6.13b). 


\section{Distribución de factores de estrés fisicoquímico}

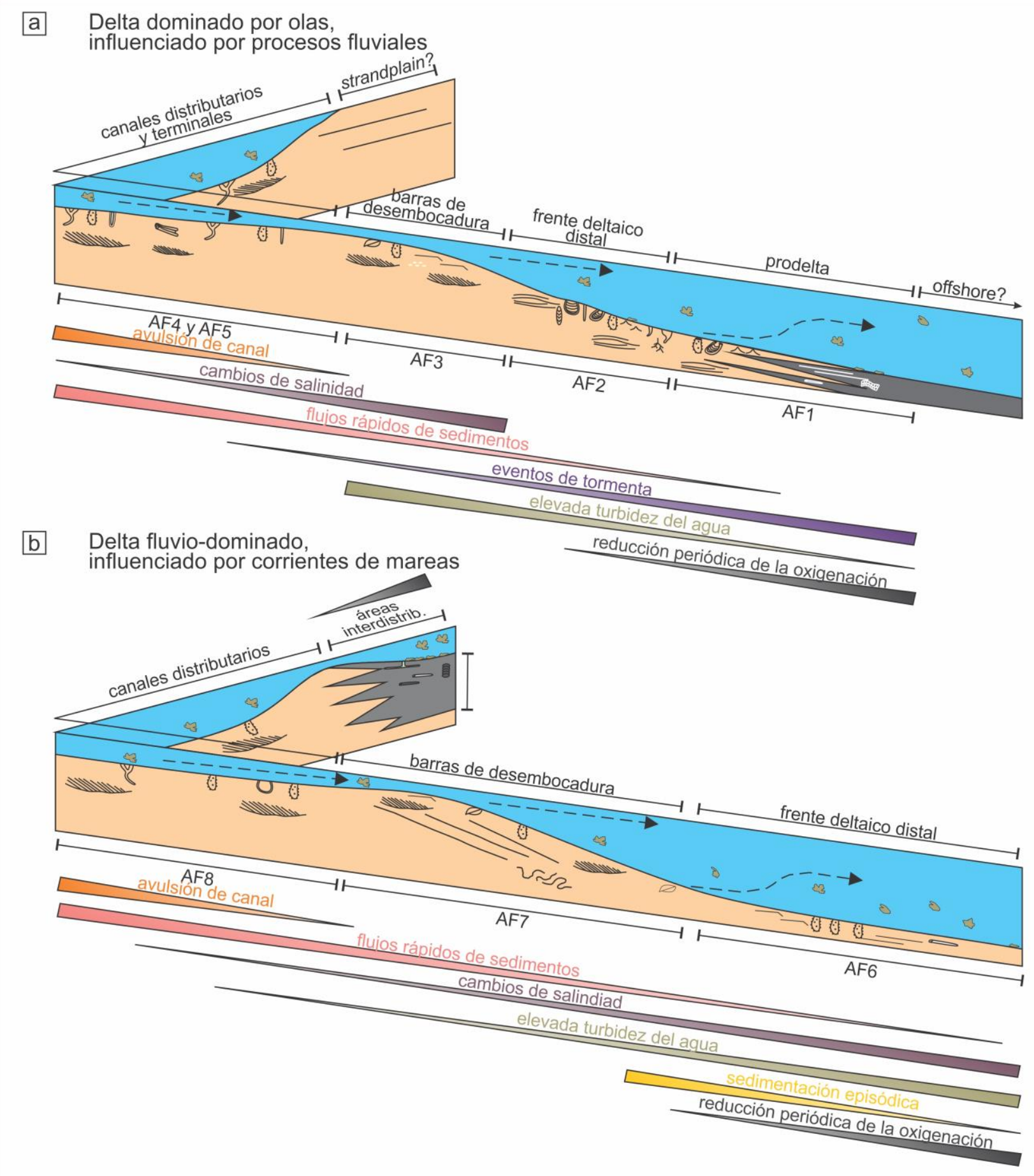

Figura 6.13. Distribución de facies sedimentarias y trazas fósiles para los subambientes deltaicos y su relación con los diferentes factores de control de condiciones de estrés fisicoquímico en: a) delta dominado por olas, influenciado por procesos fluviales de la unidad inferior, y b) delta fluvio-dominado, influenciado por corrientes de mareas de la unidad superior de la Formación La Anita. Para referencias de estructuras sedimentarias y trazas fósiles ver Figura. 3.6.

\subsubsection{Delta fluvio-dominado, influenciado por corrientes de marea}

Los depósitos del sistema deltaico fluvio-dominado de la unidad superior de la Formación La Anita evidencian fuertes condiciones de estrés fisicoquímico 
que impactaron en la colonización de estos sustratos por parte de la fauna bentónica. Estas condiciones de estrés son el resultado de fuertes descargas fluviales que resultan en bajos valores de IB y también en una baja diversidad de trazas fósiles en comparación con el sistema deltaico dominado por olas que caracteriza a la unidad inferior (Moyano Paz et al., 2020).

El frente deltaico distal de este sistema (AF6) muestra evidencias de condiciones de estrés relacionadas a la sedimentación episódica asociada a corrientes gravitatorias densas como el principal factor de control sobre la fauna bentónica (Fig. 6.13b; Canale et al., 2015, 2020; Moyano Paz et al., 2020). La colonización del sustrato parecería estar limitada a los momentos de pausas, entre eventos depositacionales (MacEachern et al., 2005; Moyano Paz et al., 2018, 2020), y las estructuras presentes son atribuibles a una expresión empobrecida de la Icnofacies de Skolithos (Buatois y Mángano, 2011), la cual se encuentra dominada por elementos verticales que cortan a las facies sedimentarias y corresponden a trazas de vivienda. La elevada turbidez del agua también puede haber tenido un rol importante en el desarrollo de la asociación de trazas en este subambiente de frente deltaico distal debido a que la alta carga de material en suspensión inhibe el comportamiento suspensívoro de los organismos productores de trazas (Fig. 6.13b; Moslow y Pemberton, 1988; Gingras et al., 1998; MacEachern et al., 2005; Buatois y Mángano, 2011; Buatois et al., 2012; Canale et al., 2015, 2020; Moyano Paz et al., 2020). La reducida diversidad de estructuras orgánicas y la reducción del tamaño de estas es indicativa de condiciones de salinidad reducidas que también dificultaron la colonización del sustrato (Fig. 6.13b; Howard, 1975; Gingras et al., 1998, 2011; MacEachern et al., 2005). Los depósitos de barras de desembocadura de este delta reflejan condiciones de alta energía y elevadas tasas de sedimentación asociadas a la expansión del flujo en las zonas de desem- 
bocadura y a la rápida velocidad de estas corrientes, siendo estos los factores más importantes que controlan la colonización del sustrato por parte de la fauna bentónica (Fig. 6.13b; MacEachern et al., 2005; Buatois y Mángano, 2011). La supresión de estructuras asignadas a comportamientos suspensívoros de alimentación se atribuye a que la alta carga de sedimentos en suspensión, la cual causa una elevada turbidez del agua y la obstrucción del aparato de alimentación por filtración de los organismos (Fig. 6.13b; Moslow y Pemberton, 1988; Gingras et al., 1998; MacEachern et al., 2005; Buatois y Mángano, 2011; Buatois et al., 2012). La cercana relación que existe entre las barras de desembocadura y los canales distributarios (AF8), así como también la reducción en el número y diversidad de trazas fósiles sería indicativa de que condiciones de reducida salinidad y el establecimiento de condiciones de aguas salobres también influyeron como un importante factor sobre los organismos productores de trazas (Fig. 6.13b; Howard, 1975; Moslow y Pemberton, 1988; Gingras et al., 1998; MacEachern et al., 2005).

Los depósitos de canales distributarios del delta fluvio-dominado (AF8) carecen de rasgos de bioturbación o presentan bioturbaciones muy esparcidas. Los rápidos flujos cargados en sedimentos, las elevadas tasas de sedimentación y condiciones de alta energía y reducida salinidad dentro de estos canales se consideran como los principales factores de control que condicionaron a esta asociación de trazas fósiles (Fig. 6.13b; Buatois y Mángano, 2011). La turbidez del agua también debió jugar un rol importante en el control de la fauna bentónica ya que no se presentan estructuras relacionadas a comportamientos suspensívoros de alimentación (Fig. 6.13b). Esta suite de trazas fósiles se encuentra dominada por elementos que cortan verticalmente a las facies y las cuales son atribuibles a Icnofacies de Skolithos la cual puede desarrollarse aun en condi- 
ciones de reducida y/o fluctuante salinidad. La avulsión de los canales también puede haber jugado un rol importante en el desarrollo de esta suite de trazas ya que, al cambiar orientación del canal principal, las condiciones de estrés asociadas a la energía del flujo disminuían (Fig. 6.13b; Barnes, 1989; MacEachern et al., 2005). Las áreas interdistributarias de la planicie deltaica (AF9) presentan elevadas concentraciones de restos de plantas muy bien preservados, lo que sugiere que las condiciones de reducida oxigenación en el agua de fondo actuaron como el principal factor de control sobre la colonización del sustrato por los organismos productores de trazas (Fig. 6.13b; Raychaudhuri y Pemberton, 1992; Leithold y Dean, 1998; Gingras et al., 1998; Coates y MacEachern, 1999, 2000; MacEachern et al., 2005).

Al igual que lo observado para el delta dominado por olas de la Formación La Anita, el sistema fluvio-dominado también muestra una compleja interacción de diferentes factores de control, desencadenados a partir de las descargas fluviales, que crearon condiciones de estrés fisicoquímico y controlaron la actividad de la comunidad bentónica (Fig. 6.13b).

\subsection{CONSIDERACIONES FINALES}

El análisis icnológico que se presenta en este capítulo permitió detectar variaciones verticales en la abundancia y diversidad de trazas fósiles dentro de los depósitos de la Formación La Anita. Estas variaciones verticales en el IB de las capas y en la diversidad de las estructuras presentes tiene una correlación directa con los tres sistemas depositacionales interpretados y presentados en el Capítulo 5 de este trabajo de tesis. El estudio de detallado de la icnología de estos depósitos, en conjunto con los rasgos físicos de los mismos, permitió identificar y evaluar diferentes factores de control que crearon condiciones de estrés fisicoquímico los cuales controlaron la distribución y abundancia de la fauna ben- 
tónica, expresado en sus trazas fósiles para los sistemas deltaicos bajo dominio de procesos de oleaje y de descargas fluviales.

Para el sistema deltaico dominado por olas de la unidad inferior de la Formación La Anita el factor de control más importante que actuó sobre la fauna bentónica en los subambientes de prodelta y frente deltaico distal era la recurrencia de eventos de tormenta. La acción del oleaje tiende a suavizar los estreses producidos por las corrientes fluviales de tal modo que en los depósitos de frente deltaico se han registrado estructuras estrictamente relacionadas a condiciones completamente marinas como por ejemplo Chondrites isp. Secundariamente, la turbidez y las condiciones periódicas de baja oxigenación en el agua también jugaron un papel importante controlando a la fauna bentónica y el desarrollo de sus estructuras biogénicas en estos subambientes. Esto se evidencia a partir de la ausencia de estructuras atribuibles a comportamientos suspensívoros de alimentación, a los bajos valores de IB, a la baja diversidad de trazas y a la buena preservación de restos vegetales. Las características icnológicas de los depósitos de frente deltaico proximal, canales distributarios terminales y canales distributarios sugieren que el principal control sobre las condiciones de estrés fisicoquímico se encontraba generadas por corrientes rápidas cargadas en sedimentos.

El sistema deltaico fluvio-dominado de la sección superior de la Formación La Anita presenta menores valores de IB y menor diversidad de estructuras que las del delta dominado por olas, y esto se debe a que las condiciones de estrés para los organismos productores eran más extremas. Los depósitos del frente deltaico distal evidencian que la sedimentación episódica, las condiciones de salinidad variable y la elevada turbidez del agua fueron los factores más importantes que controlaron a la fauna bentónica y a sus resultantes icnoasociacio- 
nes. Dentro de los subambientes de frente deltaico proximal y canales distributarios de este sistema fluvio-dominado, el principal factor que controló la actividad de los organismos productores fueron las elevadas tasas de sedimentación en conjunto con un importante control de variaciones en los niveles de salinidad del agua y de avulsión de los canales. La abundancia de restos vegetales muy bien preservados dentro de los depósitos de las áreas interdistributarias de la planicie deltaica sugieren las condiciones reductoras asociadas a bajos niveles de oxigenación en el agua fueron el factor de control que mayor impacto tuvo sobre la fauna bentónica.

Aunque no se han reconocido procesos físicos que evidencien depositación directa generada por procesos mareales dentro de las asociaciones canalizadas (AF4, AF5 y AF8), la presencia de trazas fósiles con afinidades marinas de estos cuerpos sugiere la instalación de condiciones de agua salobre facilitada por procesos mareales.

Los mayores valores de Índice de Bioturbación y la mayor diversidad de estructuras biogénicas presentes en el delta dominado por olas en comparación con el fluvio-dominado resaltan la habilidad de las olas para dispersar los estreses producidos por las descargas fluviales, creando condiciones más favorables para la colonización de los sustratos por parte de los organismos productores de trazas. 


\section{ANÁLISIS COMPOSICIONAL Y DIAGENÉTICO}

\subsection{INTRODUCCIÓN}

7.1.1 ¿Qué son los análisis composicionales y diagenéticos de sucesiones sedimentarias?

Los análisis composicionales de sucesiones sedimentarias consisten en el estudio de los componentes detríticos y no detríticos (alotígenos y autígenos) que constituyen a las rocas clásticas a través de técnicas de laboratorio como petrografía y difracción de rayos X (DRX). La petrografía de rocas psamíticas permite no solo clasificar composicionalmente a estas rocas según diferentes propuestas (Folk et al., 1970; Dott et al., 1964; Pettijohn et al., 1972), sino también realizar consideraciones para determinar variaciones en la participación de áreas fuentes (Dickinson y Rich, 1972; Ingersoll et al., 1984; Critelli y Ingersoll, 1995; Net et al., 2002; Cavazza e Ingersoll, 2005). Por otro lado, los difractogramas de roca total y de la fracción arcilla mediante análisis por DRX permiten realizar consideraciones no solo de posibles áreas fuentes sino también de otro tipo de factores como mecanismos de transporte, condiciones climáticas y diagenéticas (e.g. Gómez-Peral et al., 2011).

La diagénesis involucra a todos los procesos que afectan a los sedimentos luego su depositación, y hasta que sufren los efectos incipientes del metamorfismo (Choquette y Pray, 1970; Burley y Worden, 2003). Los estudios diagenéticos mediante petrografía convencional permiten entender los procesos y factores, así como también desarrollar una cronología relativa de los diferentes trenes diagenéticos. 


\subsection{2 ¿Por qué realizar estos análisis para esta unidad?}

A partir del análisis detallado de los componentes de las sedimentitas que constituyen a la Formación La Anita es posible clasificar composicionalmente a las muestras y comprender los procesos que sufrieron estos sedimentos una vez depositados y posteriormente soterrados, es decir durante la etapa de la diagénesis. Los análisis composicionales toman mucha importancia en la correlación entre unidades que se encuentran expuestas en la superficie y las que se desarrollan en subsuelo donde la información es limitada. Por otro lado, los procesos diagenéticos a los que estuvieron expuestos estos depósitos pueden dar indicios de la calidad y tipo de potenciales reservorios que pueden llegar a constituir estas sedimentitas. Por último, la correcta combinación entre el análisis de componentes detríticos y los datos de paleocorrientes medidos en las estructuras sedimentarias mecánicas constituyen una potente herramienta para determinaciones de posibles áreas fuente de sedimentos, así como también para reconstrucciones paleogeográficas y análisis de cuencas (p. ej. Fildani y Hesler, 2005; Varela et al., 2013; Malkowski et al., 2016).

7.1.3 ¿Cómo se realizó el análisis composicional y diagenético para el caso de estudio?

Para llevar a cabo el análisis de la composición de la Formación La Anita se describieron un total de $\mathbf{2 7}$ láminas delgadas de las distintas asociaciones de facies, y 82 muestras mediante DRX, tanto de roca total como de la fracción arcilla (ver metodología en Capítulo 3). A partir de las láminas delgadas se llevó a cabo el conteo de componentes detríticos siguiendo la metodología de GazziDickinson para muestras de areniscas (Ingersoll et al., 1984) donde se contabilizaron 400 puntos por lámina usando un contador de puntos Swift ${ }^{\circ}$. El objetivo de estos conteos fue el de clasificar a las muestras a partir de su moda 
detrítica utilizando las clasificaciones composicionales de areniscas propuestas por Dott (1964), modificada por Pettijohn et al. (1970) y Folk et al. (1970) y también el de realizar un análisis de áreas fuente. Por otro lado, se realizó el reconocimiento de los procesos y productos diagenéticos, y se estableció una cronología de estos con el objetivo de conocer la historia diagenética a la que estuvieron expuestos estos depósitos.

Para el análisis composicional por DRX, se analizaron 82 muestras provenientes de las localidades GF (Galpón de Freile), EA (Estancia Anita), CT (Campo el Tropilla), CC (Cerro Calafate) y RG (Río Guanaco). El muestreo para estos análisis involucró tanto a areniscas como a pelitas, con el fin de detectar la mayor variabilidad posible en cada una de las localidades donde aflora la Formación La Anita. Los difractogramas fueron procesados con el programa Origin $^{\circledR}$ donde se identificaron las diferentes especies minerales que componen cada una de las muestras y posteriormente se realizó un análisis semicuantitativo siguiendo la metodología de Moore y Rreynolds (1989).

\subsection{COMPOSICIÓN DE LA FORMACIÓN LA ANITA}

\subsubsection{Petrografía de areniscas}

\subsubsection{Componentes detríticos}

Se han reconocido un total de 7 componentes detríticos principales en las areniscas analizadas: cuarzos monocristalinos, feldespatos potásicos, plagioclasas, cuarzos policristalinos, líticos volcánicos, líticos sedimentarios y fitodetritos. A continuación, se describirán las principales características de cada uno de estos componentes.

\subsection{Cuarzo monocristalino}


Es el tipo de cristaloclasto más abundante de las muestras estudiadas, se presenta en proporciones entre $12,5 \%$ y $22,5 \%$, con un promedio total de $18,79 \%$. Los clastos de cuarzo monocristalino se presentan con formas subangulosas a subredondeadas (Fig. 7.1a y b). Presentan características típicas de origen volcánico tales como, extinción neta (no ondulatoria), superficies libres de inclusiones, presencia parcial de caras cristalinas y perímetros con engolfamientos (Pettijohn et al., 1987; Tucker et al., 1988; Blatt, 1992).

\subsection{Feldespatos potásicos}

Los feldespatos potásicos se presentan en escasas proporciones, representando entre $3 \%$ y $9 \%$, con un promedio del $5,9 \%$ en las muestras analizadas. Son los más abundantes de los feldespatos y comúnmente se presentan con formas subangulosas a subredondeadas. Se presentan en dos variedades: i) la ortosa es la variedad más abundante y frecuentemente se presentan con maclas de tipo Carlsbad (Fig. 7.1c y d), y ii) una variedad menos frecuente es el microclino que se presenta con su típica macla de enrejado (Fig. 7.1eyf).

\subsection{Plagioclasas}

Las plagioclasas son menos abundantes que los feldespatos potásicos, se presentan en cantidades entre $1 \%$ y $4,25 \%$ y el promedio de estos componentes es del $2,92 \%$ en las muestras analizadas. Los cristaloclastos de plagioclasa se presentan con formas subangulosas y se caracterizan por presentar maclas polisintéticas de tipo albita (Fig. 7.1g y h).

\subsection{Cuarzos policristalinos}

Los cuarzos policristalinos se presentan en escasas proporciones, entre $1,75 \%$ y $11,5 \%$, representando un promedio de $6,42 \%$ de las muestras 
analizadas. Los litoclastos de cuarzo policristalino se caracterizan por presentar internamente cristales alargados y con extinción ondulosa (Fig. 7.1g y h), lo cual podría sugerir un origen metamórfico para estos componentes. En menor proporción estos litoclastos se componen internamente por cristales equidimensionales que presentan bordes con engolfamientos y podrían sugerir un origen plutónico (Fig. 7.2a y b).

\subsection{Líticos volcánicos}

Los líticos de origen volcánico son el componente detrítico más abundante de las muestras analizadas, se presentan en cantidades de entre $25 \%$ y $50 \%$, con un promedio del $42 \%$. Estos clastos presentan formas dominantemente subredondeadas y a partir de las texturas que presentan se reconocieron dos tipos de líticos volcánicos: i) aquellos que presentan una textura andesítica con presencia de fenocristales de plagioclasas desorientados (Fig. 7.2c y d), y ii) los que se caracterizan por presentar una textura felsítica con microlitos de cuarzo y feldespato potásico (Fig. 7.2c y d).

\subsection{Líticos sedimentarios}

Estos componentes son muy escasos y se presentan en porcentajes menores al 2\%. Los más abundantes son los intraclastos limosos, redondeados que internamente son masivos (Fig. 7.2e y f). Estos componentes comúnmente se presentan constituyendo parte de la pseudo-matriz (ver 7.5 DIAGÉNESIS DE LA FORMACIÓN LA ANITA). 


\section{Componentes detríticos}
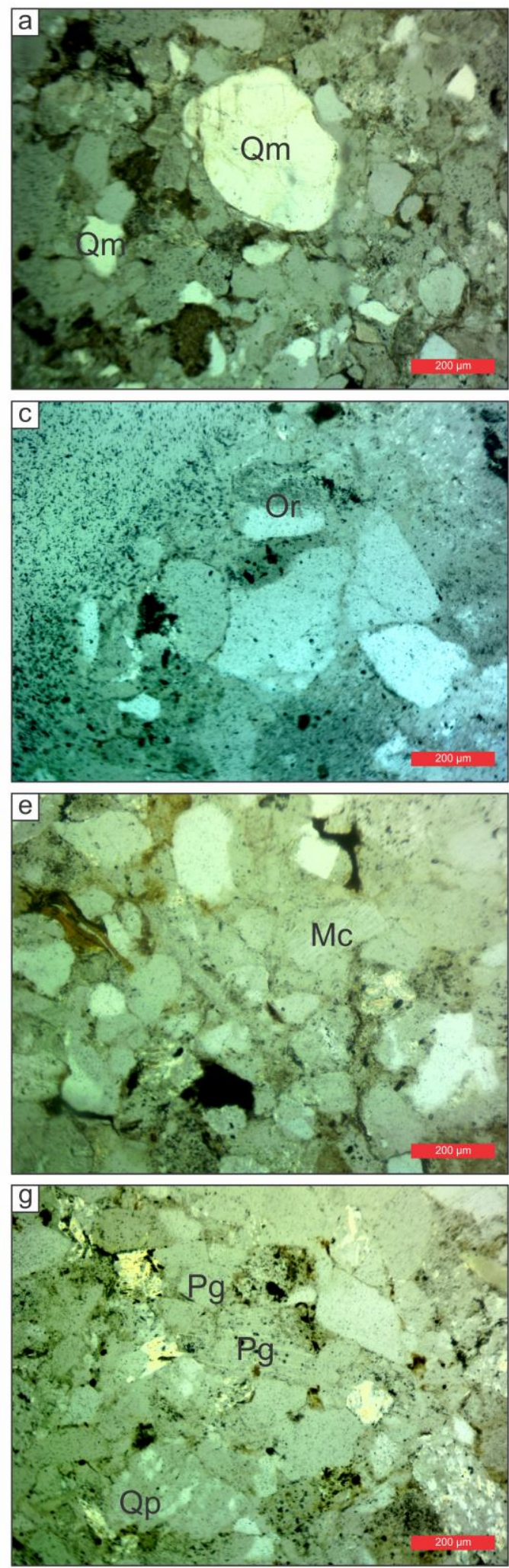
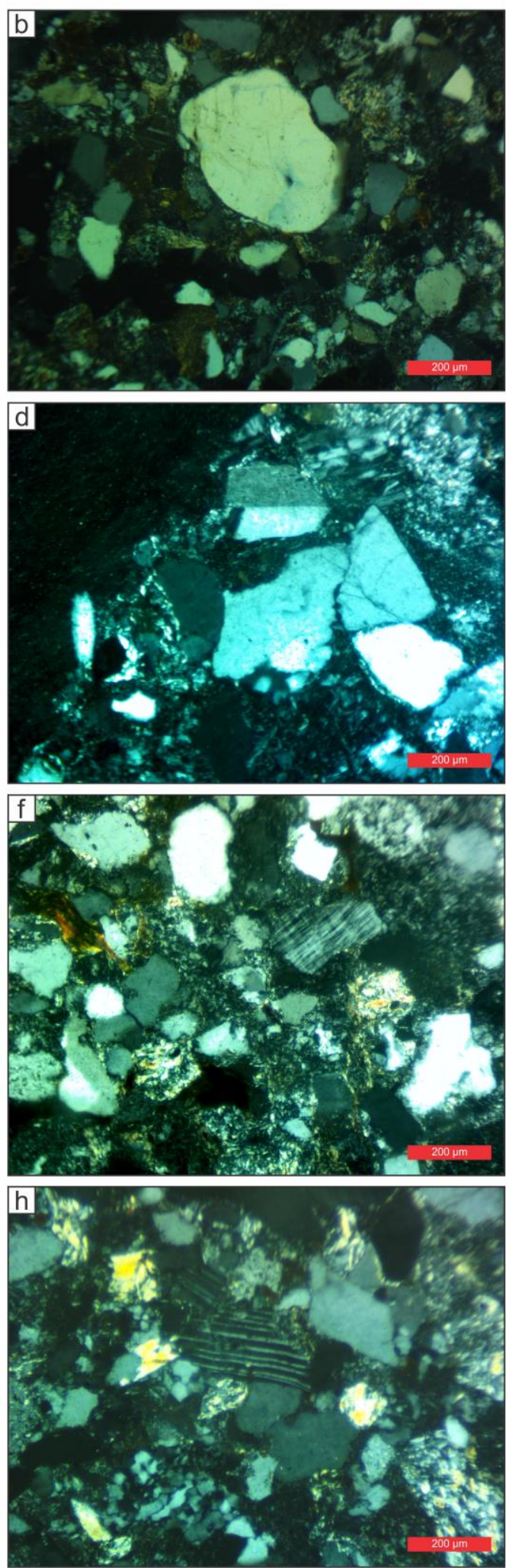

Figura 7.1. Microfotografías de componentes detríticos, en todos los casos se muestran sin nicoles a la izquierda y con nicoles a la derecha. a y b) Cuarzo monocristalino. c y d) Ortosa con macla de Carlsbad. e y f) Microclino con macla en enrejado. g y h) Plagioclasa con macla polisintética y cuarzo policristalino metamórfico. 


\section{Componentes detríticos}
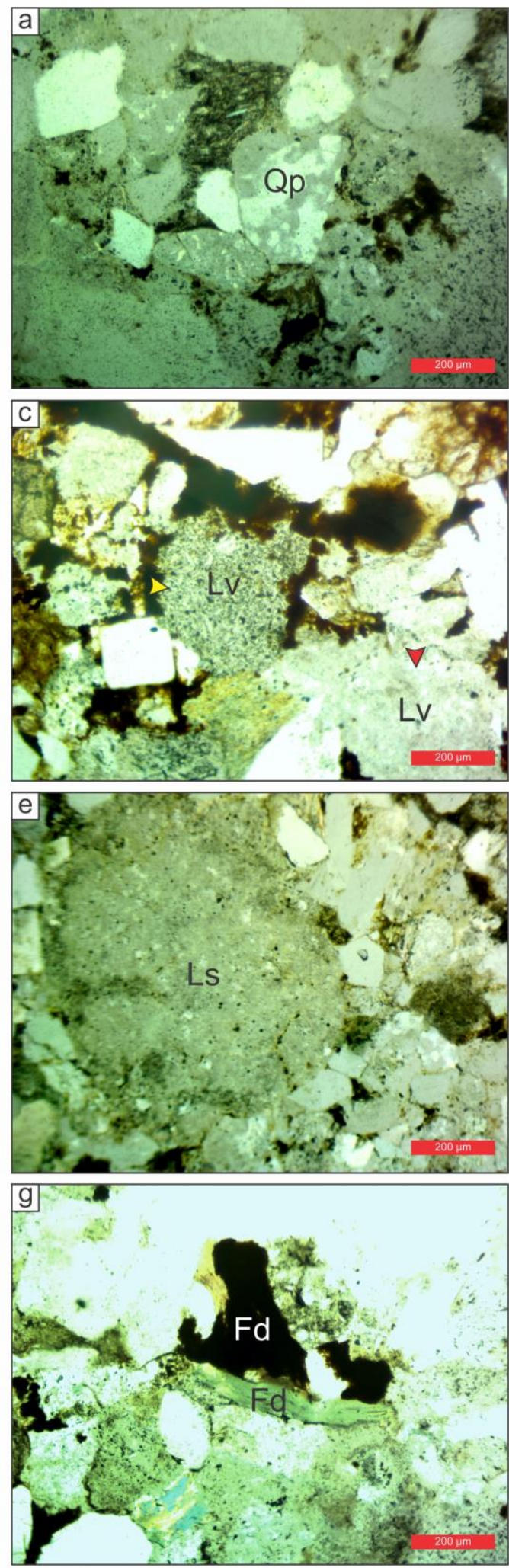
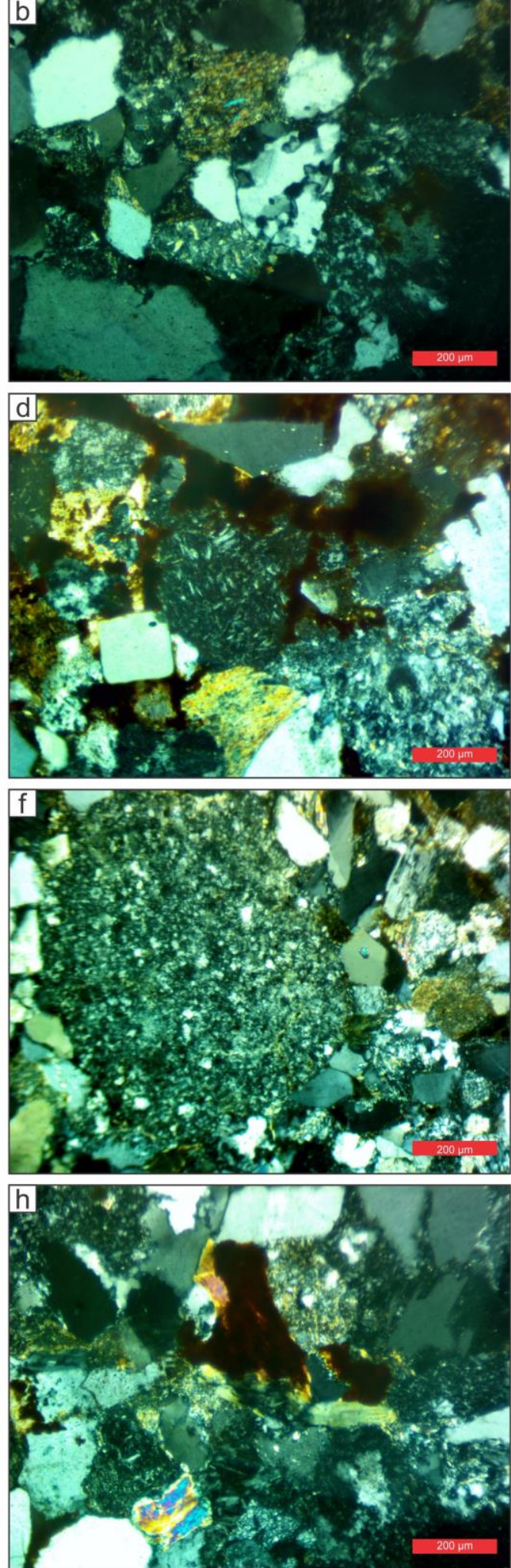

Figura 7.2. Microfotografías de componentes detríticos, en todos los casos se muestran sin nicoles a la izquierda y con nicoles a la derecha. a y b) Cuarzo policristalino de origen plutónico. c y d) Líticos volcánicos con textura andesítica (flecha amarilla) y textura felsítica (flecha roja). e y f) Lítico sedimentario. g y h) Fitodetritos. 


\subsection{Fitodetritos}

Los fitodetritos son restos de materia orgánica que se encuentran en las muestras formando tanto parte del esqueleto como de la matriz de las muestras. Su abundancia varía entre 0,25\% y $8 \%$, con un promedio de $4 \%$. Estos restos de materia orgánica se presentan de dos tipos: i) con una coloración castaña clara y preservando algunos rasgos de su textura vegetal original, evidenciando un bajo grado de descomposición, y ii) de una coloración más oscura y sin rasgos de texturas originales, lo que podría indicar un mayor grado de descomposición de la materia orgánica (Fig. 7.2g y h). Estos componentes suelen presentarse constituyendo parte de la pseudo-matriz (ver 7.5 DIAGÉNESIS DE LA FORMACIÓN LA ANITA).

\subsubsection{Areniscas de la Formación La Anita}

Las areniscas de la Formación La Anita $(\mathrm{N}=32)$ presentan una textura clasto sostén con escasa matriz pelítica. El tamaño de grano de estas muestras varía entre arena muy fina y muy gruesa, y su selección varía de pobremente seleccionadas a bien seleccionadas. Los clastos se presentan subredondeados a subangulosos y en orden decreciente de abundancia se encuentran compuestos por fragmentos líticos, cuarzo monocristalino y feldespatos.

Los porcentajes de los componentes de las muestras de areniscas analizadas de la Formación La Anita fueron recalculados para ser representados en los diagramas ternarios composicionales propuestos por Folk et al. (1970) y por Dott (1964), modificado por Pettijohn et al., (1972). Según la clasificación de Folk et al. (1970), todas las muestras analizadas corresponden a litoarenitas (Fig. 7.3). Para la clasificación de Dott (1964), modificada por Pettijohn et al. (1972), la cual discrimina a las muestras no solo por sus componentes detríticos sino 
también por el contenido de matriz se utilizó solo el triángulo correspondiente a las arenitas ya que no se analizaron muestras con un contenido de matriz mayor al 15\%. De esta manera, según la clasificación de Dott (1964), modificada por Pettijohn et al. (1972), el total de las muestras analizadas corresponden a arenitas líticas (Fig. 7.3).

\section{Clasificación composicional de areniscas}

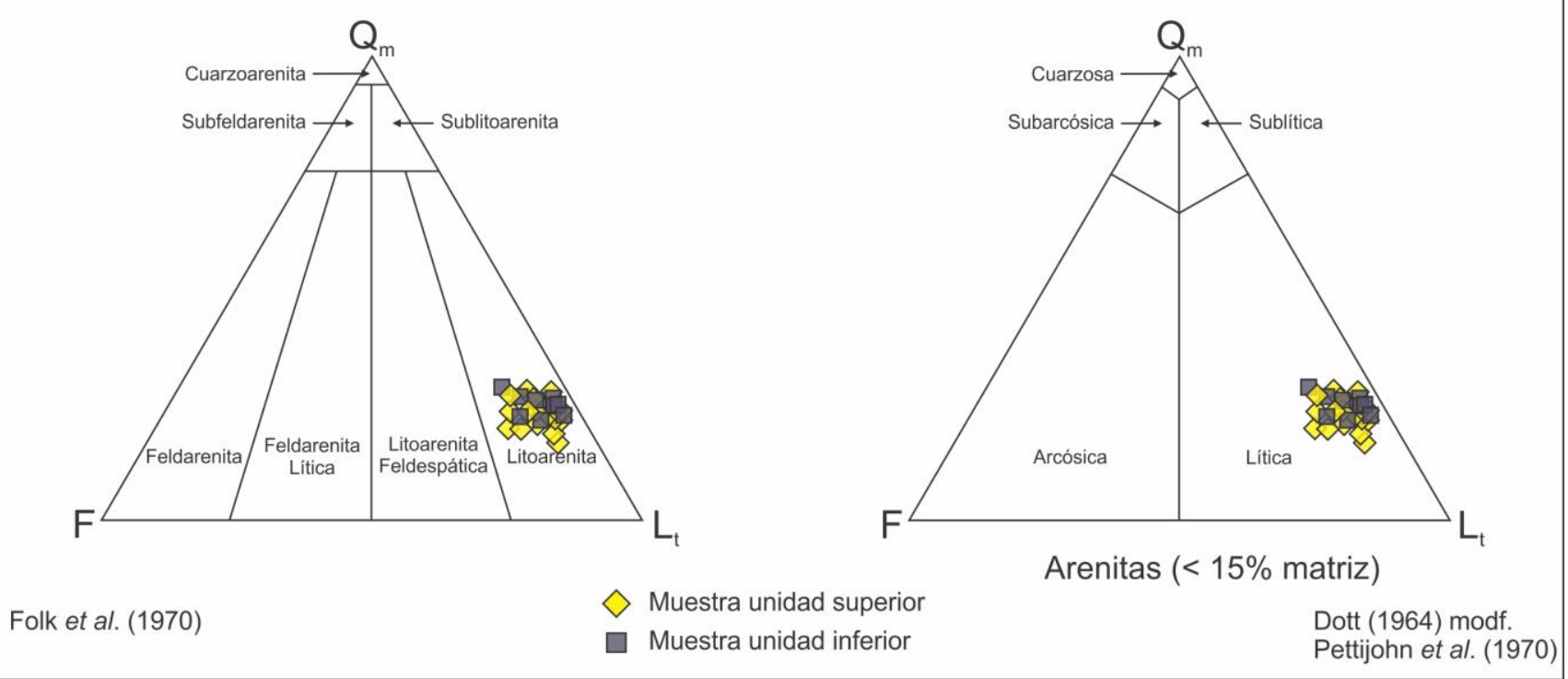

Figura 7.3. Clasificación de areniscas de la Formación La Anita a partir de modas detríticas.

\subsubsection{Difracción de rayos X (DRX)}

Las 82 muestras analizadas fueron obtenidas de los perfiles RG, GF, EA, CT y CC, y corresponden tanto a areniscas como a pelitas. La semicuantificación de las especies minerales obtenidas a partir de este estudio se representa en las Figuras 7.4, 7.5, 7.6, 7.7 y 7.8 y también en el Anexo 2.

En los estudios de roca total se reconocieron proporciones variables de cuarzo, feldespatos potásicos, plagioclasa, calcita, dolomita y arcilla. El cuarzo es el mineral dominante en la mayoría de las muestras analizadas, su contenido es abundante a muy abundante y se presenta con valores comprendidos entre $30 \%$ y $95 \%$, con un valor promedio de $77,5 \%$. Las plagioclasas son muy escasas a escasas, rara vez moderadas, se presentan en valores comprendidos entre $2 \%$ y 
$23 \%$, con un valor promedio de $8,5 \%$. Los feldespatos potásicos son muy escasos a escasos, algunas muestras presentan ausencia o trazas de estos minerales, se presentan con valores comprendidos entre $1 \%$ y $13 \%$, con valor promedio de 3,4\%. La calcita y la dolomita se presentan como minerales muy escasos, y no siempre se encuentran presentes en las muestras analizadas, sus valores son comúnmente inferiores al 5\%, pero se han registrado valores excepcionales de calcita que llegan a 45\%. Estos valores excepcionales se registraron solamente en el perfil CT y se encuentran asociados a la presencia de niveles de areniscas bioclásticas (ver apartado 7.5 DIAGÉNESIS DE LA FORMACIÓN LA ANITA). Las arcillas de las muestras analizadas se presentan en proporciones variables, varían de muy escasas a abundantes, con valores comprendidos entre $2 \%$ y $35 \%$, y un valor promedio de $8 \%$. Los valores de las arcillas son mayores en los intervalos pelíticos, donde aumentan en detrimento del cuarzo.

En los estudios de la fracción arcilla se reconocieron argilominerales del grupo de la illita (I), interestratificados de illita/esmectita (I/Sm), clorita $(\mathrm{Cl})$, caolinita (K), esmectita $(\mathrm{Sm})$ e interestratificados de clorita/esmectita $(\mathrm{Cl} / \mathrm{Sm})$. La illita se presenta en muy variables proporciones, variando entre escasa a muy abundante, con valores comprendidos entre $5 \%$ y $60 \%$, y un valor promedio de $24,5 \%$. La clorita es un argilomineral que no se encuentra presente en todas las muestras, pero cuando lo hace se presenta como muy escasa a moderada, se registró en valores comprendidos entre $0 \%$ y $20 \%$ y en un valor promedio de 4,75\%. La caolinita también se presenta en variables proporciones, desde escasa a muy abundante, con valores comprendidos entre $5 \%$ y $95 \%$ y con un valor promedio de $34,5 \%$. El contenido de caolinita disminuye considerablemente en los intervalos pelíticos donde se observa un enriquecimiento de esmectita. La 
esmectita no se encuentra presente en todas las muestras analizadas y comúnmente se encuentra ausente, pero cuando se presenta se encuentra como escasa a muy abundante con valores que alcanzan el $60 \%$, pero con un valor promedio total de $4,38 \%$. Los interestratificados de illita/esmectita tampoco están presentes en todas las muestras, pero cuando se registra lo hace en variables proporciones las cuales se comprenden entre $5 \%$ y $90 \%$, el valor promedio de los interestratificados de I/Sm es de 27,47\%. Los interestratificados de clorita/esmectita tampoco se encuentran presentes en todas las muestras, de hecho, en el perfil CC no se registraron valores de este argilomineral. $\mathrm{La} \mathrm{Cl} / \mathrm{Sm}$ cuando se encuentra presente llega a alcanzar valores del $30 \%$, pero el promedio total de este interestratificado en todas las muestras analizadas es del $4,53 \%$. 


\section{Difracción de Rayos X: Perfil Río Guanaco}

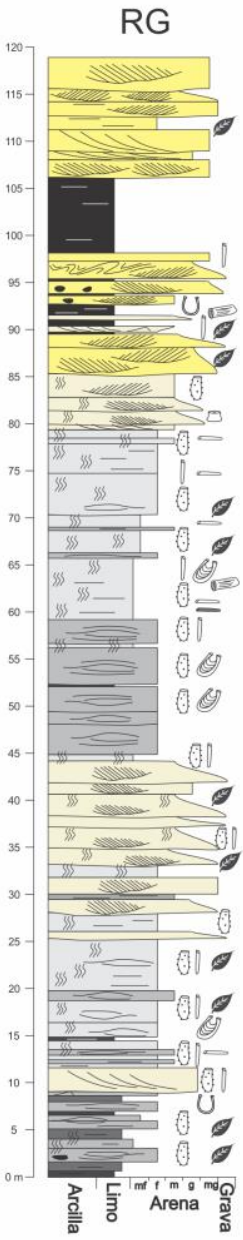

\section{Roca total}

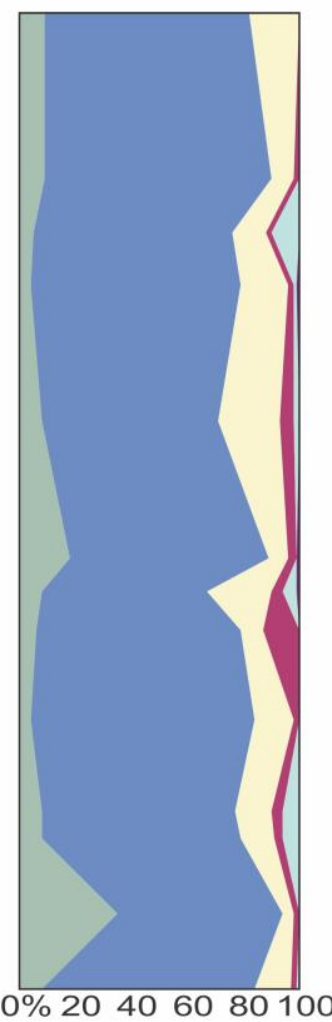

Arcilla

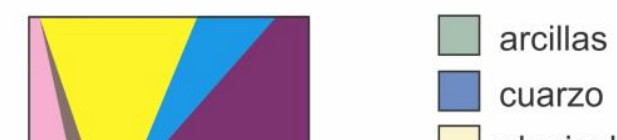

$\square$ plagioclasa

$\square$ feldespato potásico

$\square$ calcita

dolomita

$\square$ illita

$\square$ clorita

$\square$ caolinita

I/Sm

$\square$ esmectita

$\square \mathrm{Cl} / \mathrm{Sm}$

Figura 7.4. Análisis semicuantitativo de especies minerales a partir de difracción de rayos $\mathrm{X}$ en el perfil Río Guanaco.

Figura 7.5 (página siguiente). Análisis semicuantitativo de especies minerales a partir de difracción de rayos X en el perfil Galpón de Freile. 


\section{Difracción de Rayos X: Perfil Galpón de Freile}
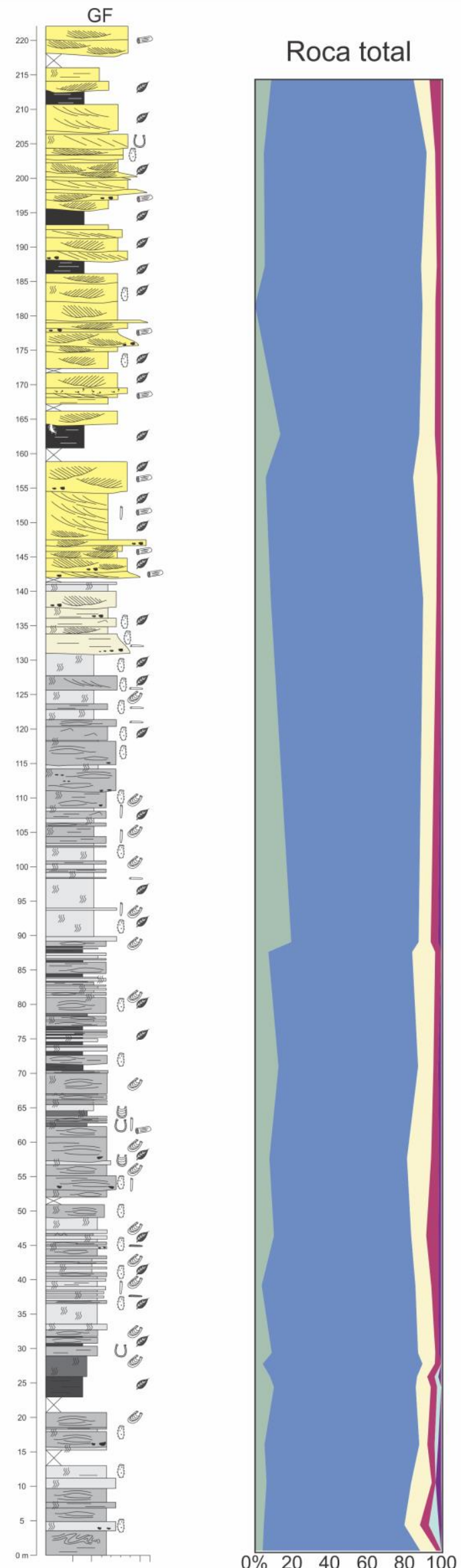

Arcillas

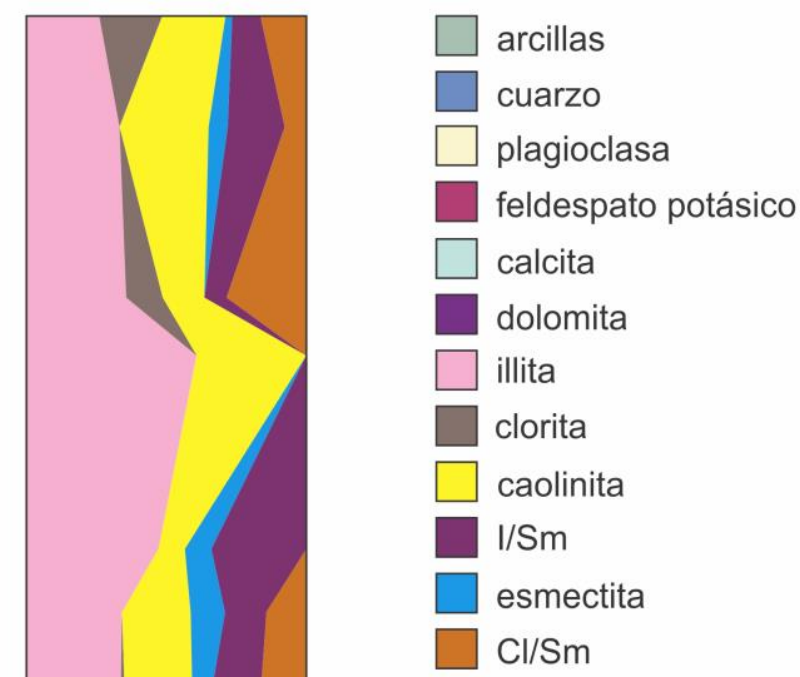




\section{Difracción de Rayos X: Perfil Estancia Anita}

EA

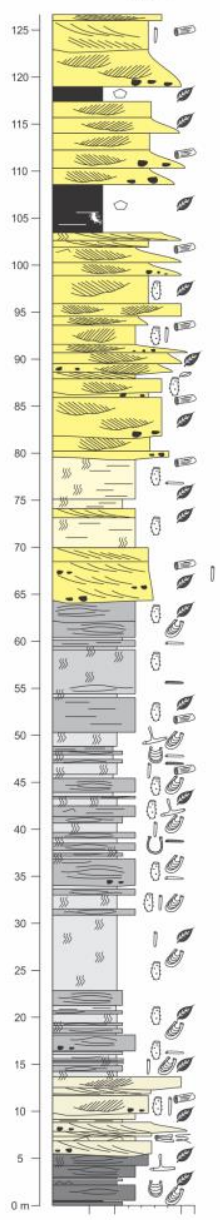

\section{Roca total}

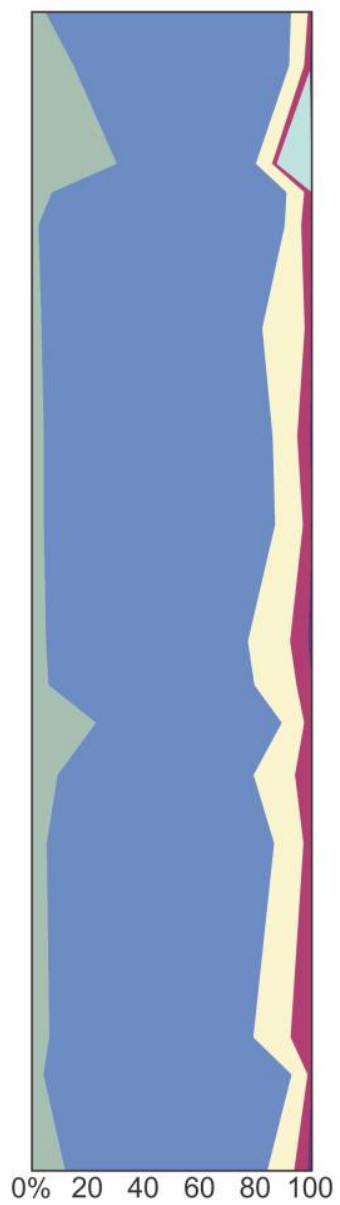

\section{Arcilla}

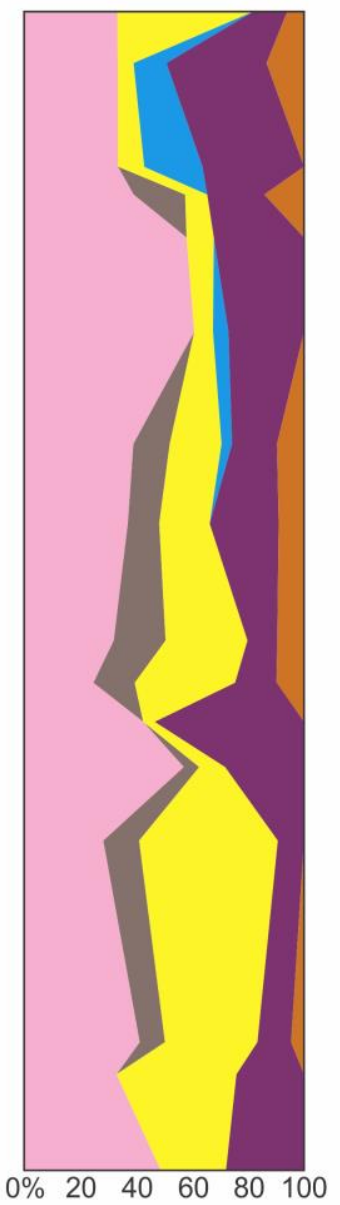

arcillas

cuarzo

$\square$ plagioclasa

$\square$ feldespato potásico

$\square$ calcita

dolomita

$\square$ illita

$\square$ clorita

$\square$ caolinita

$\mathrm{I} / \mathrm{Sm}$

$\square$ esmectita

$\square \mathrm{Cl} / \mathrm{Sm}$

Figura 7.6. Análisis semicuantitativo de especies minerales a partir de difracción de rayos $\mathrm{X}$ en el perfil Estancia Anita. 


\section{Difracción de Rayos X: Perfil Campo el Tropilla}
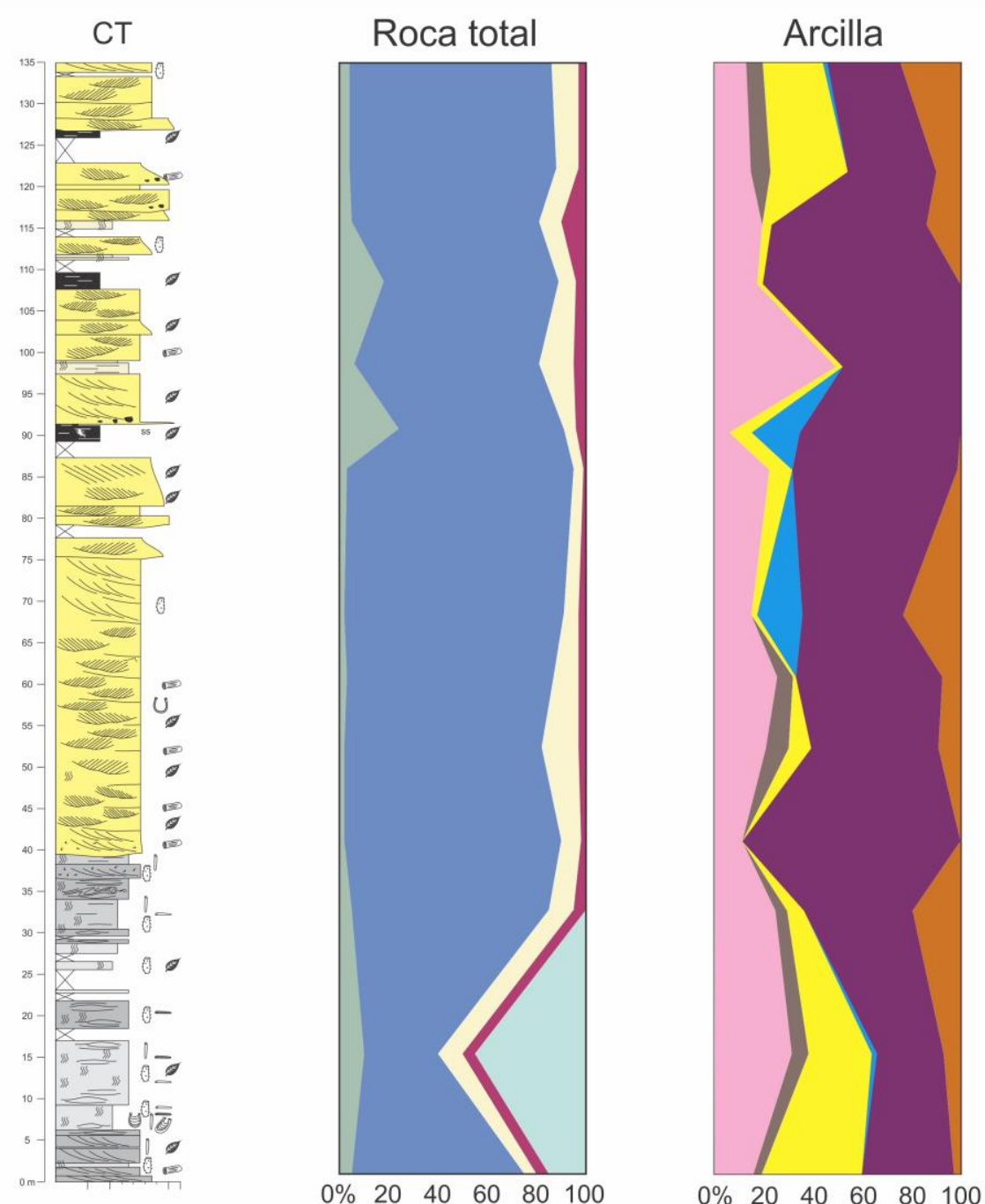

$\square$ arcillas

cuarzo

$\square$ plagioclasa

feldespato potásico

$\square$ calcita

dolomita

$\square$ illita

clorita

$\square$ caolinita

$\mathrm{I} / \mathrm{Sm}$

$\square$ esmectita

$\square \mathrm{Cl} / \mathrm{Sm}$

Figura 7.7. Análisis semicuantitativo de especies minerales a partir de difracción de rayos $\mathrm{X}$ en el perfil Campo el Tropilla.

\subsection{VARIACIONES COMPOSICIONALES EN LA FORMACIÓN LA ANITA}

A partir del análisis petrográfico realizado en las areniscas de la Formación La Anita se puede observar que la totalidad de las muestras se clasifican como arenitas líticas con escaso contenido de matriz (Fig. 7.3). No se observan diferencias significativas en las modas detríticas entre las muestras analizadas de la unidad inferior con respecto a la unidad superior, así como tampoco se reconocen tendencias verticales claras que permitan hacer diferenciaciones, siendo la composición de estas muy homogénea. Estas diferencias tampoco se 
observan en los diagramas que discriminan por tipos de líticos presentes en las distintas muestras (ver 7.4 PROCEDENCIA DE ARENISCAS).

\section{Difracción de Rayos X: Perfil Cerro Calafate}
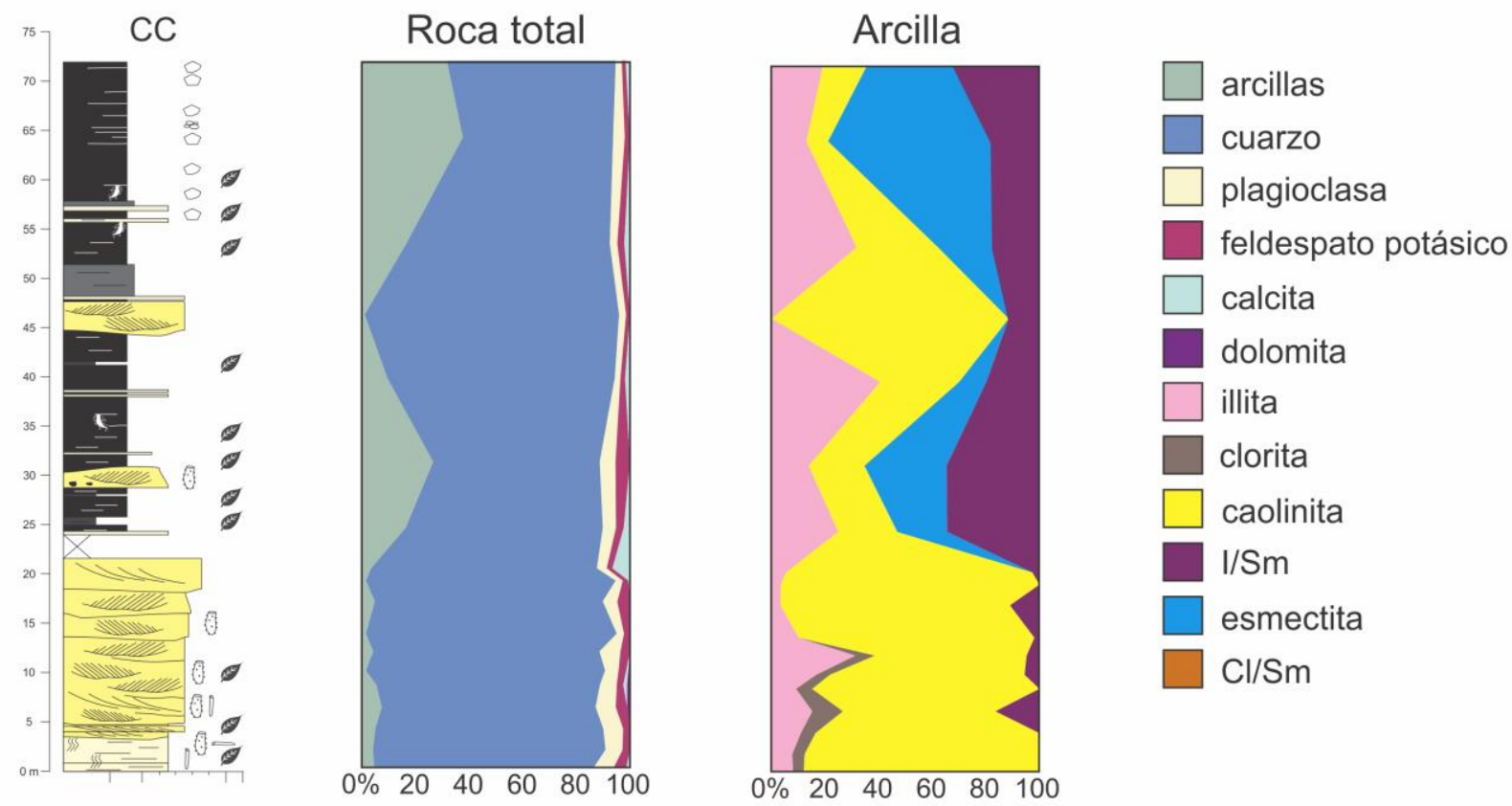

Figura 7.8. Análisis semicuantitativo de especies minerales a partir de difracción de rayos $\mathrm{X}$ en el perfil Cerro Calafate.

El estudio de roca total y de la fracción arcilla a partir de DRX muestra la misma tendencia que el análisis petrográfico donde no se reconoce una tendencia vertical clara. Sin embargo, el análisis de la fracción arcilla podría permitir hacer algunas consideraciones significativas, para las cuales previamente es interesante resaltar lo siguiente.

Los argilominerales que se encuentran en sucesiones sedimentarias pueden ser de un origen detrítico o autigénico. Los de origen detrítico son aquellos que provienen desde una fuente externa y que han sido poco modificados durante su transporte. Por otro lado, los autigénicos son aquellos argilominerales que han sido formados, o reformados in situ (Wilson y Pittman, 1977). La esmectita tiende a desaparecer en sucesiones que han alcanzado un grado de diagénesis elevado, producto de su transformación a illita (Pollastro, 
1993; Merriman y Peacor, 1999; Raigemborn et al., 2014). Un rasgo interesante que se desprende del estudio de la fracción arcilla del presente trabajo es la presencia de argilominerales del grupo de la esmectita en niveles de granulometrías finas tanto de la unidad inferior como de la superior de la Formación La Anita, pero su participación es considerablemente mayor en la unidad superior, aumentando en detrimento de la caolinita. Cabe destacar que, para la Formación Cerro Fortaleza, la cual se encuentra por encima de la Formación La Anita, se ha descripto a la esmectita como el argilomineral dominante de dicha unidad (Varela et al., 2013). Si bien para la discriminación entre argilominerales de origenes detríticos y autigénicos suelen realizarse observaciones bajo microscopios electrónicos de barrido, los análisis de DRX son útiles para realizar aproximaciones en base a la cristalinidad que muestran los picos. De esta manera, se considera que la caolinita y la esmectita presente en los depósitos de la Formación La Anita son argilominerales neoformados en el ambiente de acumulación o formados en el sistema alimentador con un bajo grado de transporte (Fig. 7.9).

La esmectita puede originarse como producto de la alteración de componentes volcánicos o volcaniclásticos o a partir de procesos autigénicos bajo diversidad condiciones climáticas (Chamley, 1989; Galán, 2006; Raigemborn et al., 2014). Por su parte, la caolinita es el producto de la alteración de esmectita, micas, feldespatos y material de origen volcánico bajo condiciones de climas tropicales, cálidos y húmedos (Senkayi et al., 1987; Chamley, 1989; Marfil et al., 2003; Galán, 2006; Raigemborn et al., 2014).

Figura 7.9 (página siguiente). Difractográmas de la fracción arcilla de la unidad inferior y superior de la Formación La Anita mostrando los picos agudos y cristalinos de la caolinita (K) y la esmectita (Sm) evidenciando su potencial origen autigénico. $\mathrm{Cl}$ = clorita; $\mathrm{I} / \mathrm{S}=$ interestratificados de illita/esmectita; $\mathrm{I}=$ Illita. 


\section{Argilominerales de la Formación La Anita}
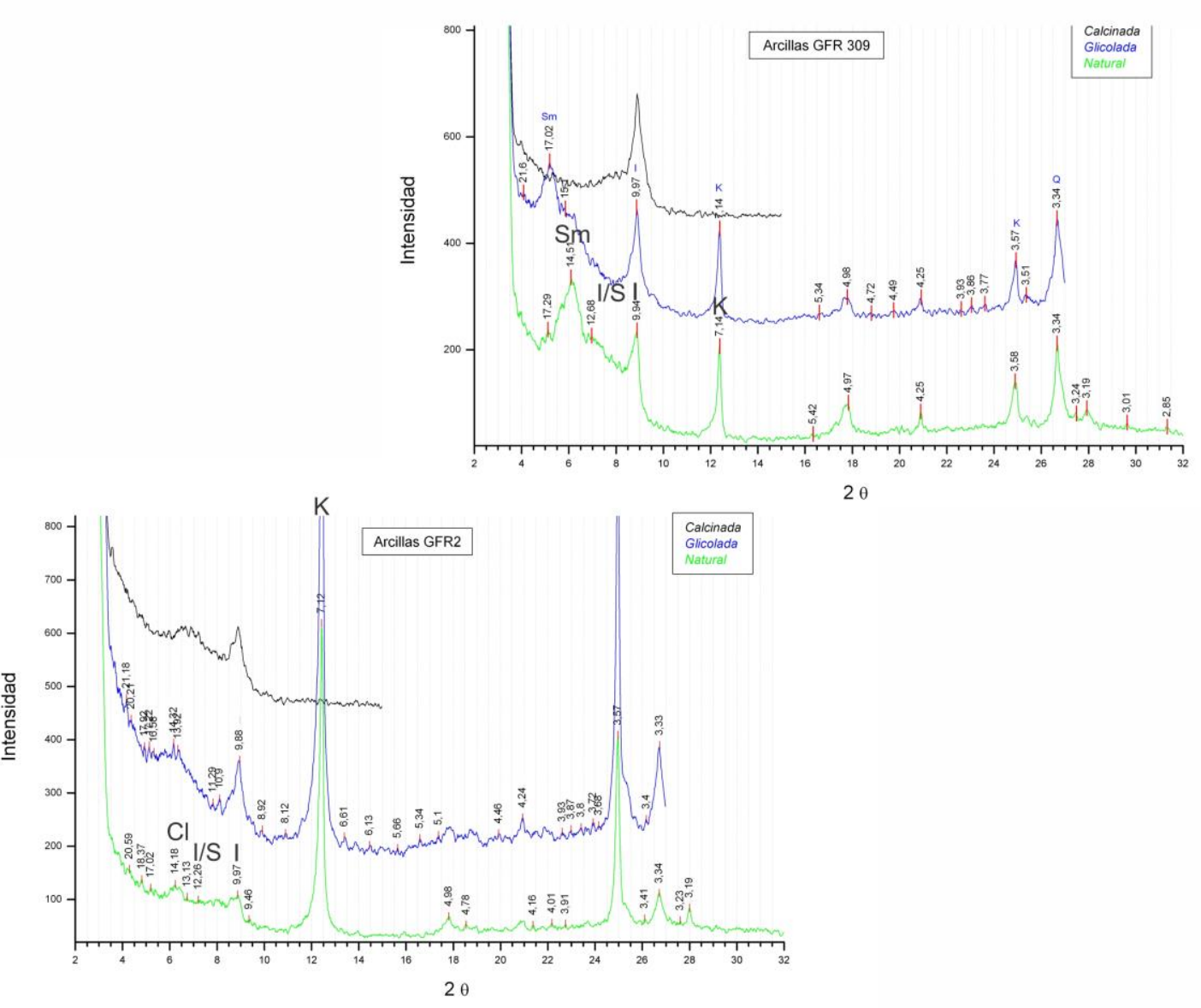

El análisis por DRX evidencia lo contrario y esto podría estar reflejando un cambio en las condiciones paleoclimáticas, o por lo menos en el régimen de precipitaciones de la unidad inferior con respecto a la unidad superior. Si bien existen trabajos paleoclimáticos globales donde se postula que para el Cretácico Superior el clima era dominantemente cálido y húmedo sin fluctuaciones importantes de escala global a diferencia del Cretácico Inferior y Superior temprano (Jenkyns, 1980; Barron et al., 1989; Föllmi, 2012; Friedrich et al., 2012; Robinson et al., 2017; O'Brien et al., 2017; O'Connor et al., 2019). La presencia de caolinita y la escasa a nula participación de esmectita en los depósitos de la unidad inferior podría indicar altas condiciones de oxigenación $\mathrm{u}$ oxidantes bajo climas tropicales con altas precipitaciones y una elevada tasa de meteorización química (Thiry, 2000; Raigemborn et al., 2014), lo que 
muestra concordancia con el análisis de los procesos depositacionales para dicha unidad la cual refleja una alta recurrencia en eventos de tormenta. Es por esto que se plantea que la abundancia de caolinita, asociada a climas tropicales y altas precipitaciones presenta concordancia con el análisis de procesos depositacionales para la unidad inferior donde se menciona una alta recurrencia en eventos de tormenta que ocurrían en la zona costera. Por otro lado, el incremento de esmectita en detrimento de la caolinita, que se observa principalmente en los intervalos de grano fino de la unidad superior, podría asociarse a la formación de esmectita en suelos pobremente drenados, saturados en agua, bajo condiciones climáticas más templadas con estaciones bien diferenciadas (Raigemborn et al., 2014). El cambio entre condiciones más tropicales, con alta recurrencia de eventos de tormenta para la unidad inferior interpretado a partir de los argilominerales y la dominancia relativa de procesos depositacionales de oleaje de tormenta, hacia condiciones más templadas y estacionales en la unidad superior sugeridas por la presencia de esmectita y por los rasgos de sedimentación episódica, podría explicar el cambio en los procesos depositaiconales dominantes en los depósitos de frente deltaico en la unidad superior de la Formación La Anita. A su vez, las evidencias de depositación episódica en los depósitos del frente deltaico distal de la unidad superior que se trataron en los capítulos 5 y 6 se condice con una estacionalidad en las descargas fluviales asociadas al clima. Otra alternativa que podría plantearse es que existió un cambio en el área de aporte de sedimentos y esto será tratado con mayor detalle a continuación.

\subsection{PROCEDENCIA DE ARENISCAS}

Las cuencas de antepaís de retroarco y sus áreas fuente suelen ser heterogéneas en términos composicionales debido a que se forman en áreas 
caracterizadas por un magmatismo activo en conjunto con un régimen de deformación compresivo que afecta a material de la corteza. Este tipo de cuencas recibe material clástico de diversas fuentes tales como: i) el arco magmático, ii) la faja plegada y corrida, y iii) el cratón estable y levantamientos de bloques continentales en la periferia de la cuenca (Nie et al., 2012 Fig. 7.10a). La Cuenca Austral-Magallanes durante su estadio de antepaís obtuvo una configuración donde recibió material detrítico de las tres fuentes previamente mencionadas (Varela et al., 2013; Richiano et al., 2015; Malkowski et al., 2017; Sickmann et al., 2019). El desarrollo y evolución de la faja plegada y corrida desencadenó el levantamiento del basamento metasedimentario Paleozoico denominado Complejo Metamórfico de los Andes Orientales (CMAO) y del Complejo El Quemado (CEQ; 157-145 Ma) el cual se encuentra constituido principalmente por rocas volcánicas y volcaniclásticas ácidas asociadas al sinrift de la cuenca (Fig. 7.10; Pankhurst et al., 2000). Las zonas periféricas que aportaron sedimentos hacia la cuenca se asocian al evento volcánico de Chon Aike más antiguo (200-157 Ma) representado en los Macizos Norpatagónico y Deseado (Fig. 7.10; Pankhurst et al., 2000; Varela et al., 2013; Malkowski et al., 2017; Sickmann et al., 2019). Por último, el desarrollo del arco magmático asociado al Batolito Patagónico comenzó a desarrollarse durante el Cretácico asociado al régimen compresivo del margen oeste de Sudamérica (Fig. 7.10; Ramos et al., 1982; Bruce et al., 1991; Hervé et al., 2007).

El estudio petrográfico de los componentes detríticos de las muestras de areniscas de la Formación La Anita permitió realizar un análisis de procedencia para estas muestras y realizar comparaciones con estudios previamente publicados con edades de circones detríticos $(\mathrm{U}-\mathrm{Pb})$ asociados a las diferentes áreas fuentes de componentes clásticos y estudios convencionales de 
procedencia (Macellari et al., 1989; Romans et al., 2011; Varela et al., 2013; Richiano et al., 2015; Malkowski et al., 2017; Sickmann et al., 2019). La composición de los componentes detríticos que constituyen una sucesión sedimentaria se encuentra en estrecha relación con: su procedencia, grado de transporte, ambiente depositacional, clima y diagénesis (Dickinson y Suczek, 1979; Ingersoll et al., 1993).

\section{Áreas fuente de material detrítico}

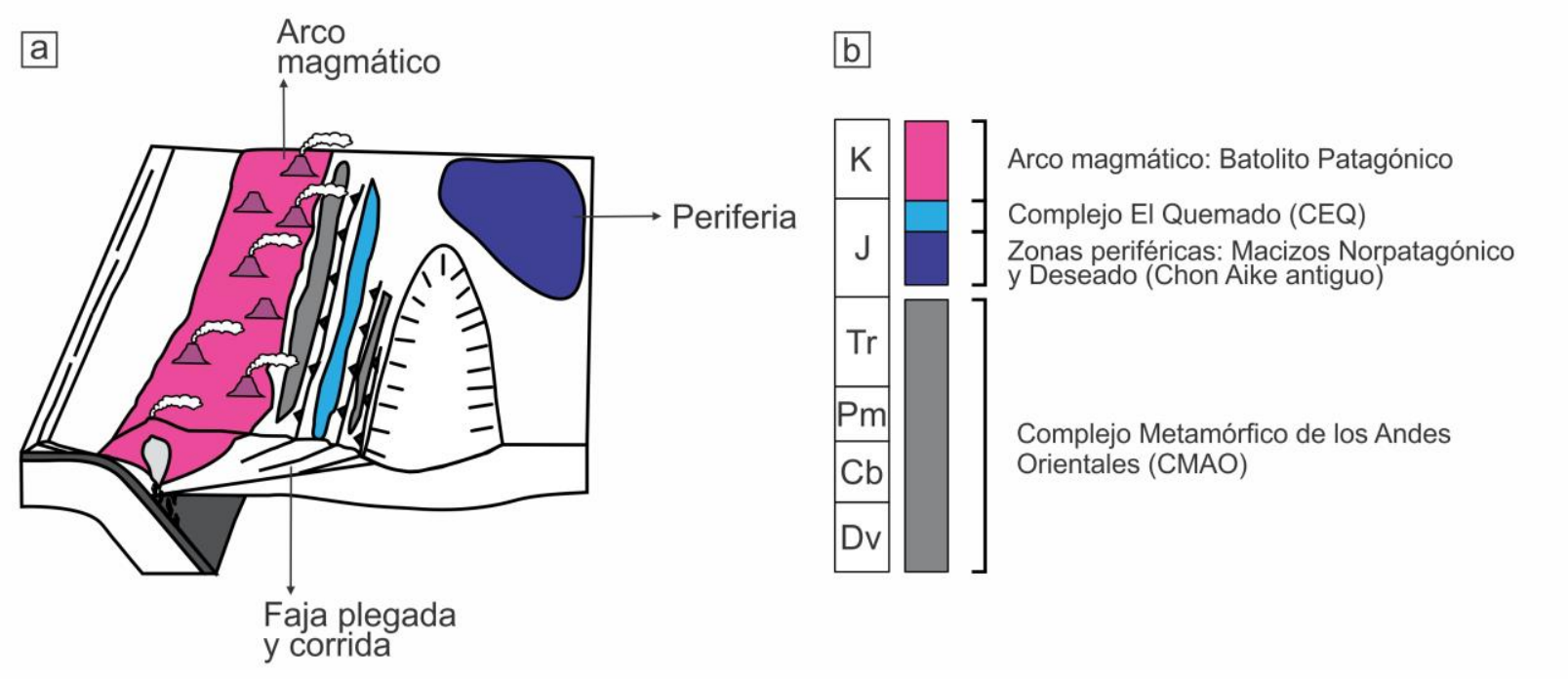

Figura 7.10. a) Esquema conceptual de áreas fuentes para cuencas de antepaís de retroarco adaptado para el caso de la Cuenca Austral-Magallanes (modificado de Nie et al., 2012; Sickmann et al., 2019). b) Estratigrafía de las áreas fuente de material detrítico de la Cuenca Austral-Magallanes (modificado de Sickmann et al., 2019)

Para realizar el análisis de procedencia de las psamitas de la Formación La Anita se utilizaron los diagramas ternarios de cuarzo total, feldespatos y líticos (QtFL; Fig. 7.11a; Dickinson et al., 1983) y de cuarzo monocristalino, feldespatos y líticos totales (QmFLt; Fig 7.11b y c; Dickinson et al., 1983; Dickinson, 1988). Estos diagramas ternarios relacionan las modas detríticas de las areniscas con el ambiente geotectónico del área fuente de la cual provienen. La elección de estos diagramas ternarios para discriminar la procedencia de las areniscas se fundamenta en que utilizan componentes que se encuentran presentes en todas las unidades y que hay una gran cantidad de trabajos publicados que los utilizan, en ocasiones con datos de U-Pb en circones detríticos y geoquímica que 
dan sustento a las interpretaciones (Fildani y Hessler, 2005; Romans et al., 2011; Varela et al., 2013; Richiano et al., 2015; Cereceda, 2016; Malkowski et al., 2017; Sickmann et al., 2019). Debido a que la totalidad de las muestras analizadas se corresponden a arenitas líticas, también se utilizó el diagrama de cuarzo policristalino, líticos volcánicos y líticos sedimentarios (QpLvLs; Dickinson y Suczek, 1979), para diferenciar muestras con aporte de ambientes orogénicos de las muestras procedentes del arco magmático (Fig. 7.11d).

Al ubicar las muestras en los diagramas se puede observar una baja dispersión de datos (Fig. 7.11 a, b, c y d). Según el diagrama QtFL de Dickinson et al. (1983), las areniscas de la Formación La Anita se encuentran agrupadas en el límite de los campos de orógeno reciclado y arco transicional (Fig. 7.11a). En los diagramas QmFLt se observa mayor afinidad al campo de orógeno reciclado, transicional a lítico para el diagrama de Dickinson et al. (1983; Fig. 7.11b) y en el sector de suites de arenas de orógeno reciclado para el diagrama de Dickinson, (1988; Fig. 7.11c). En ambos casos se mantiene, cierta afinidad con los campos de arco transicional y de arenas volcaniclásticas para muestras de la unidad superior.

Por otra parte, se utilizó el diagrama QpLvLs de discriminación por tipo de líticos el cual permitió diferenciar con mayor certeza aquellas muestras con aporte de orógenos de las muestras procedentes del aco magmático. Las muestras de la Formación La Anita se encuentran dominantemente en el campo de arco magmático (Fig. 7.11d). 

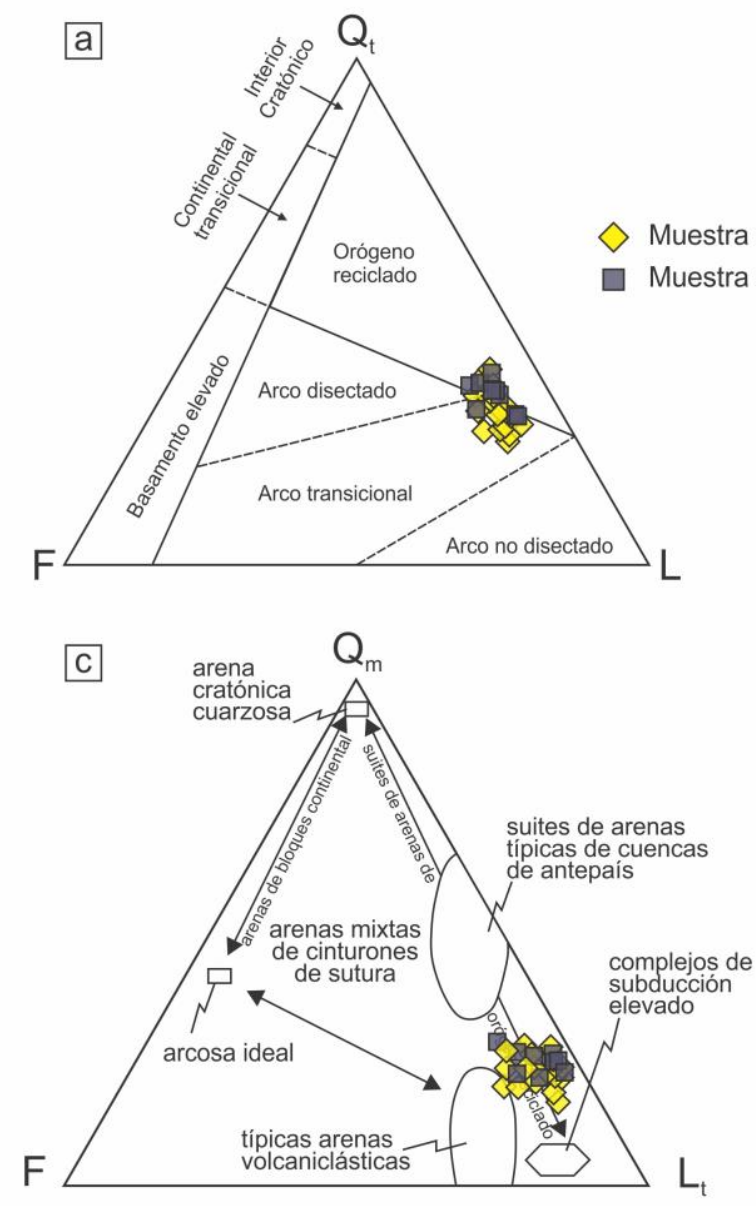
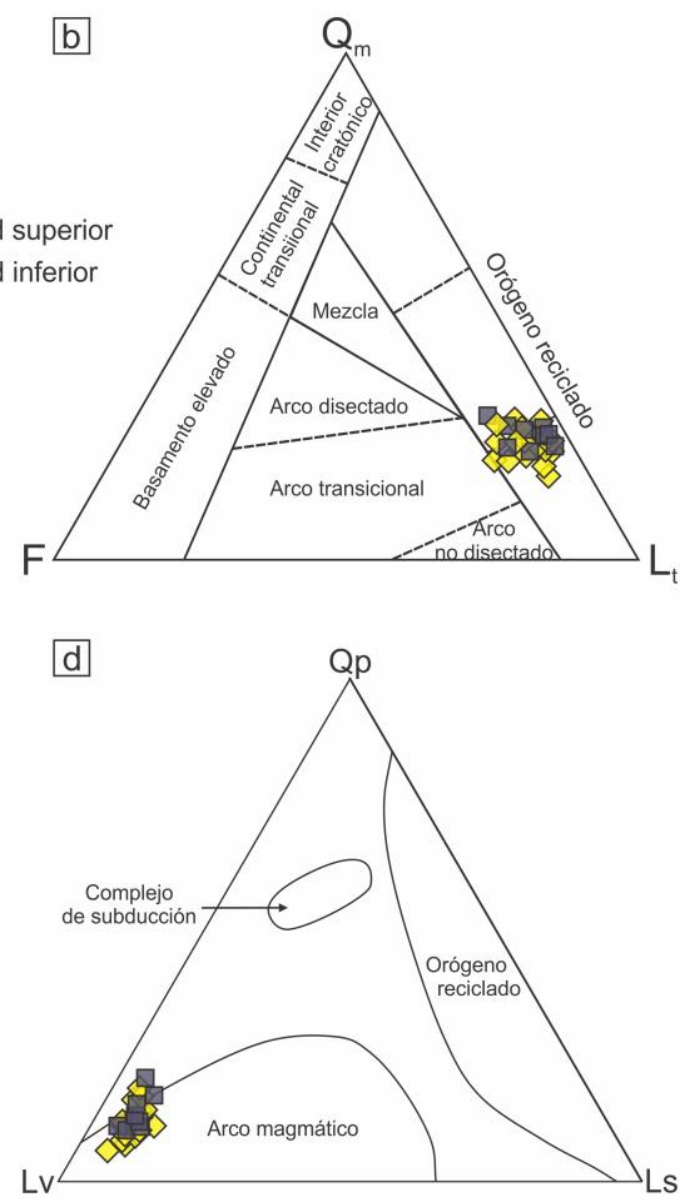

Figura 7.11. Diagramas de discriminación de procedencia de areniscas. a) Diagrama QtFL y b) QmFLt de Dickinson et al., 1983. c) Diagrama QmFLt de Dickinson, (1988) d) Diagrama de QpLvLs de discriminación por tipo de lítico (Dickinson y Suczek, 1979).

Los resultados obtenidos en los diferentes diagramas son homogéneos y no se reconoce una diferencia en la procedencia de las muestras analizadas de la unidad inferior con las de la unidad superior (Fig. 7.11). La procedencia de un orógeno reciclado implicaría que estos sedimentos conforman de un ciclo depositacional secundario el cual retrabajó los componentes de un orógeno. De esta manera se plantea que las muestras analizadas tienen rasgos mixtos con afinidad tanto de arco cómo de un orógeno reciclado elevado por la faja plegada y corrida. Las direcciones de paleoflujo medidas en las estructuras sedimentarias de los depósitos de la Formación La Anita indican una dirección de progradación hacia el sudeste tanto para la unidad inferior como para la 
superior (Tabla 5.1), indicando que las áreas fuentes que aportaron el material clástico se encontraban hacia el oeste/noroeste (Fig. 7.12).

\section{Procedencia de areniscas}
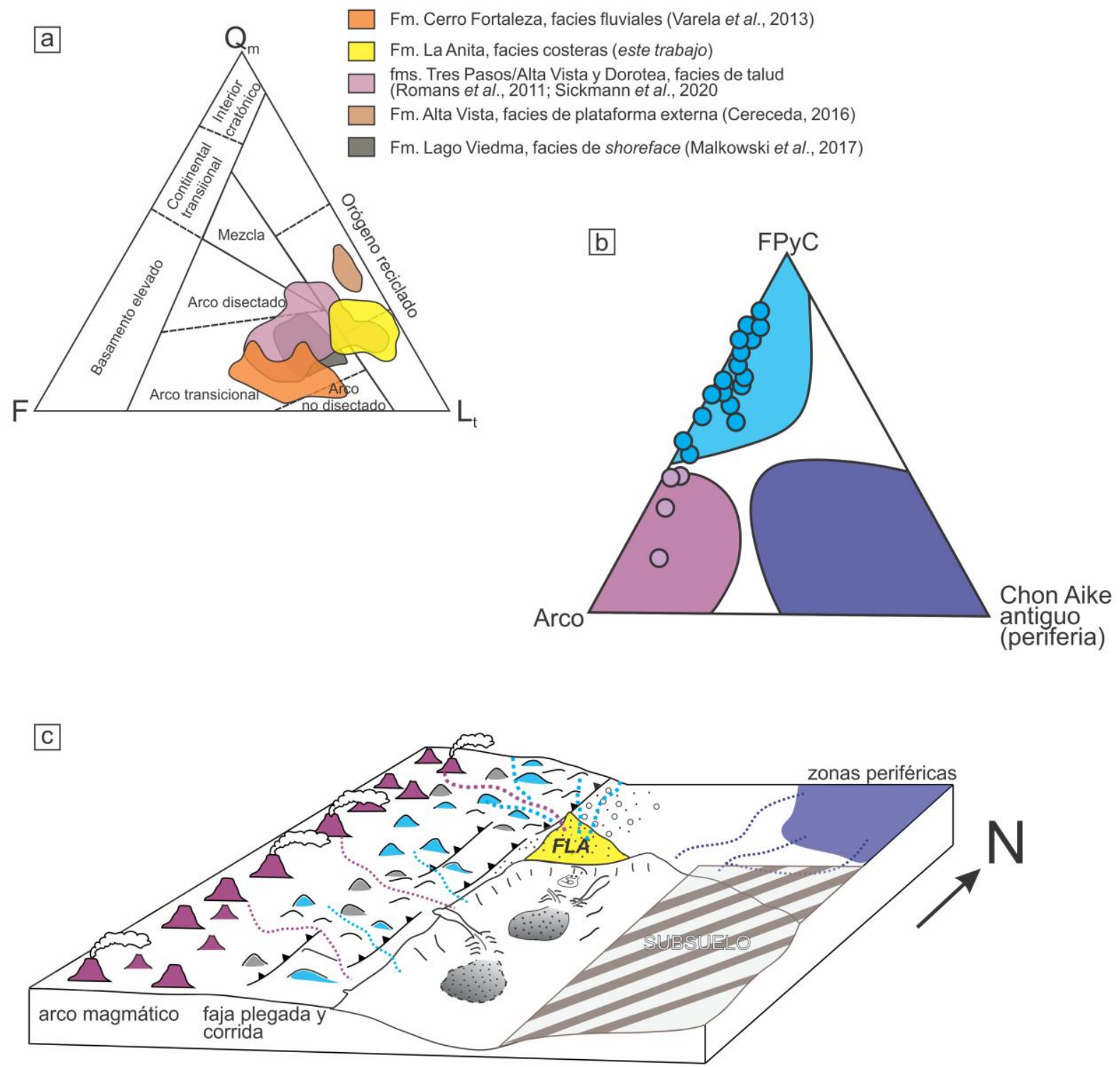

Figura 7.12. a) Comparación de los resultados obtenidos a partir de diagramas de discriminación de procedencia de areniscas con trabajos previos sobre unidades estratigráficas adyacentes a la Fm. La Anita. b) Diagrama de origen de circones detríticos (Sickmann et al., 2019). c) Esquema de cuáles fueron las fuentes que aportaron material detrítico a la Formación La Anita (FLA).

Los resultados obtenidos muestran cierta similitud con trabajos previos publicados para unidades infra y suprayacentes y unidades coetáneas de la cuenca (Fig. 7.12a; Romans et al., 2011; Varela et al., 2013; Cereceda, 2016; 
Malkowski et al., 2017; Sickmann et al., 2019). Recientemente, Sickmann et al. (2019) presentó un detallado estudio donde se diferencia el origen de los circones detríticos presentes basado en las edades de los mismos. Para el intervalo Alta Vista/Tres Pasos-La Anita/Dorotea al sur del Lago Argentino esta discriminación confirma y soporta las inferencias realizadas sobre un origen de arco y de faja plegada y corrida para las muestras analizadas para la Formación La Anita (Fig. 7.12b). Si bien el desarrollo de la faja plegada y corrida afectó tanto al Complejo Metamórfico de los Andes Orientales como al Complejo El Quemado, la escasa proporción de componentes metamórficos, los cuales quedan prácticamente restringidos a cuarzos policristalinos, indica que el aporte de esta fuente fue principalmente a partir de elevaciones del Complejo El Quemado (Fig. 7.12d).

\subsection{DIAGÉNESIS DE LA FORMACIÓN LA ANITA}

\subsubsection{Procesos y productos diagenéticos}

Múltiples factores tales como la composición inicial, la naturaleza de las aguas porales y el contenido de materia orgánica intervienen en la diagénesis de las rocas silicoclásticas (Tucker, 2001). El estudio mediante petrografía convencional permitió entender los procesos y factores generadores, así como desarrollar una cronología relativa de los eventos diagenéticos acontecidos permitiendo armar la historia diagenética a la que estuvieron sometidos estos depósitos. A continuación, se tratarán los procesos y productos postdepositacionales reconocidos en las psamitas de la Formación La Anita:

- Compactación: se reconoce a partir de los contactos entre granos, generalmente planos y cóncavo-convexos y ocasionales suturados (Figs. 7.13a, b, c y d). Este proceso afecta a todos los componentes y se observó 
en todas las muestras estudiadas. Otro rasgo de compactación física observado en todos los perfiles es la presencia de microfracturas. Se reconocen habitualmente transgranulares e intragranulares cerradas (Figs 7.13e, f, g y h), aunque en el perfil Campo El Tropilla (CT) también se observan frecuentemente microfracturas abiertas. En el perfil Galpón de Freile (GF) también se reconoció pseudo-matriz, mientras que en CT se observaron procesos de compactación química representado por la presencia de microestilolitas (Fig. 7.14a, b, c y d).

- Disolución: afecta selectivamente a los cristaloclastos de feldespato, intraclastos y a los litoclastos volcánicos, generando una porosidad intragranular subordinada (Fig. 7.14e y f) o, menos habitualmente, porosidad móldica o sobredimensionada. El tamaño de estos poros no supera en ningún caso los $62 \mu \mathrm{m}$ (microporos) y no se reconoce conectividad entre ellos. Este proceso se limita al perfil Galpón de Freire.

- Autigénesis de arcillas: Se identifica la generación de arcillas, potencialmente sericita, como reemplazo parcial o casi total de cristaloclastos de feldespato potásico y litoclastos volcánicos (Fig. 7.14g y f). Este proceso se extiende ampliamente a todas las muestras estudiadas.

- Cementación hematítica: Se registra formando un cemento poiquilotrópico que afecta la totalidad de la muestra o menos habitualmente forma parches (Fig. 7.15a y b). La hematita rellena espacios porales, generando revestimientos o coatings y en ocasiones alterando algunos clastos. Si bien está presente en muestras aisladas de todos los perfiles estudiados, se desarrolla especialmente hacia el tope del perfil Campo El Tropilla. 
Procesos diagenéticos
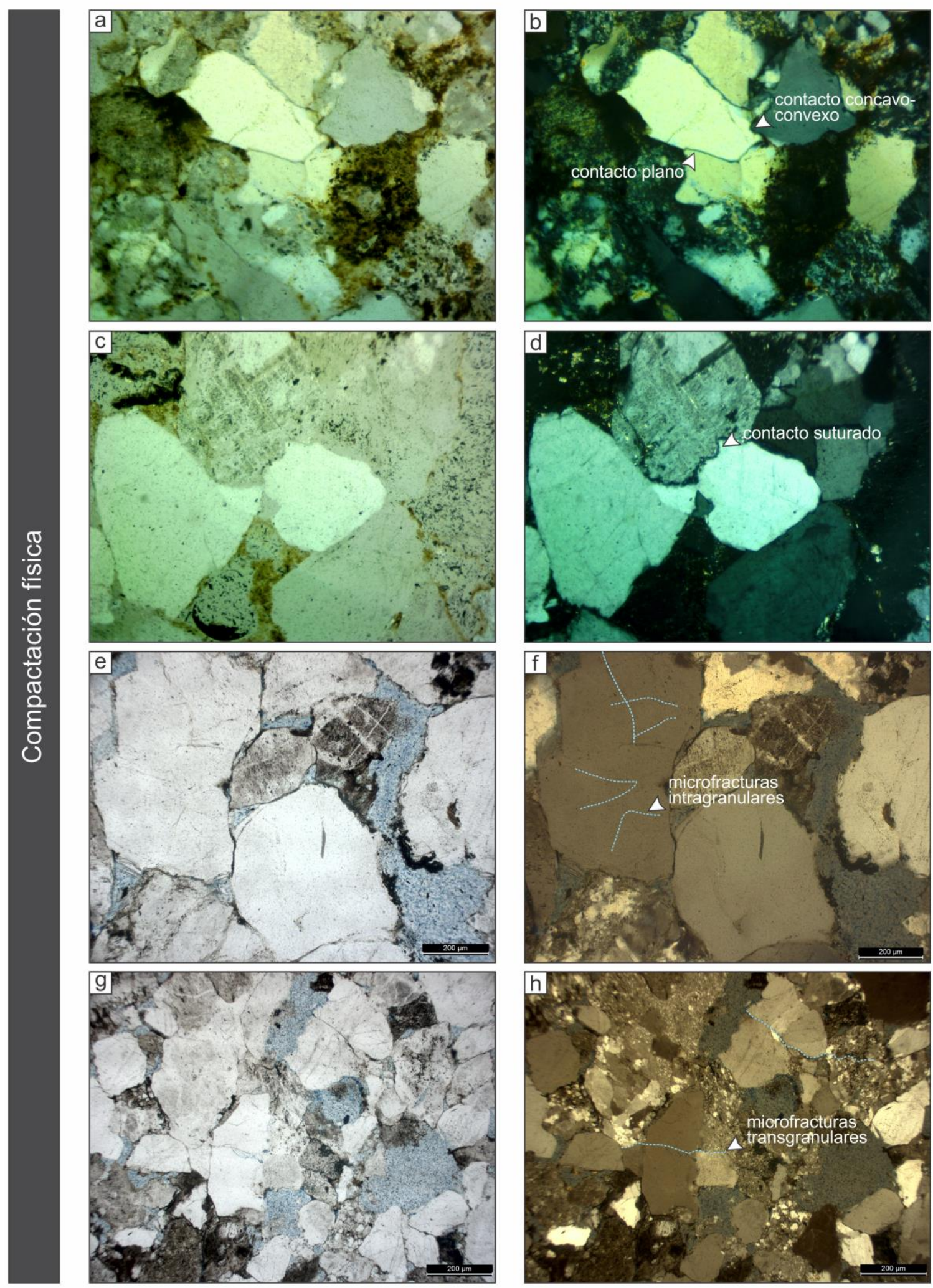

Figura 7.13. Procesos diagenéticos de la Formación La Anita en todos los casos se muestran sin nicoles a la izquierda y con nicoles a la derecha. 
Procesos diagenéticos
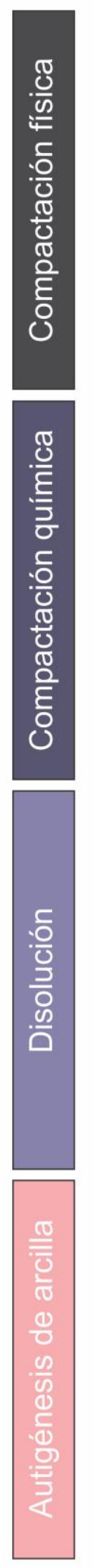
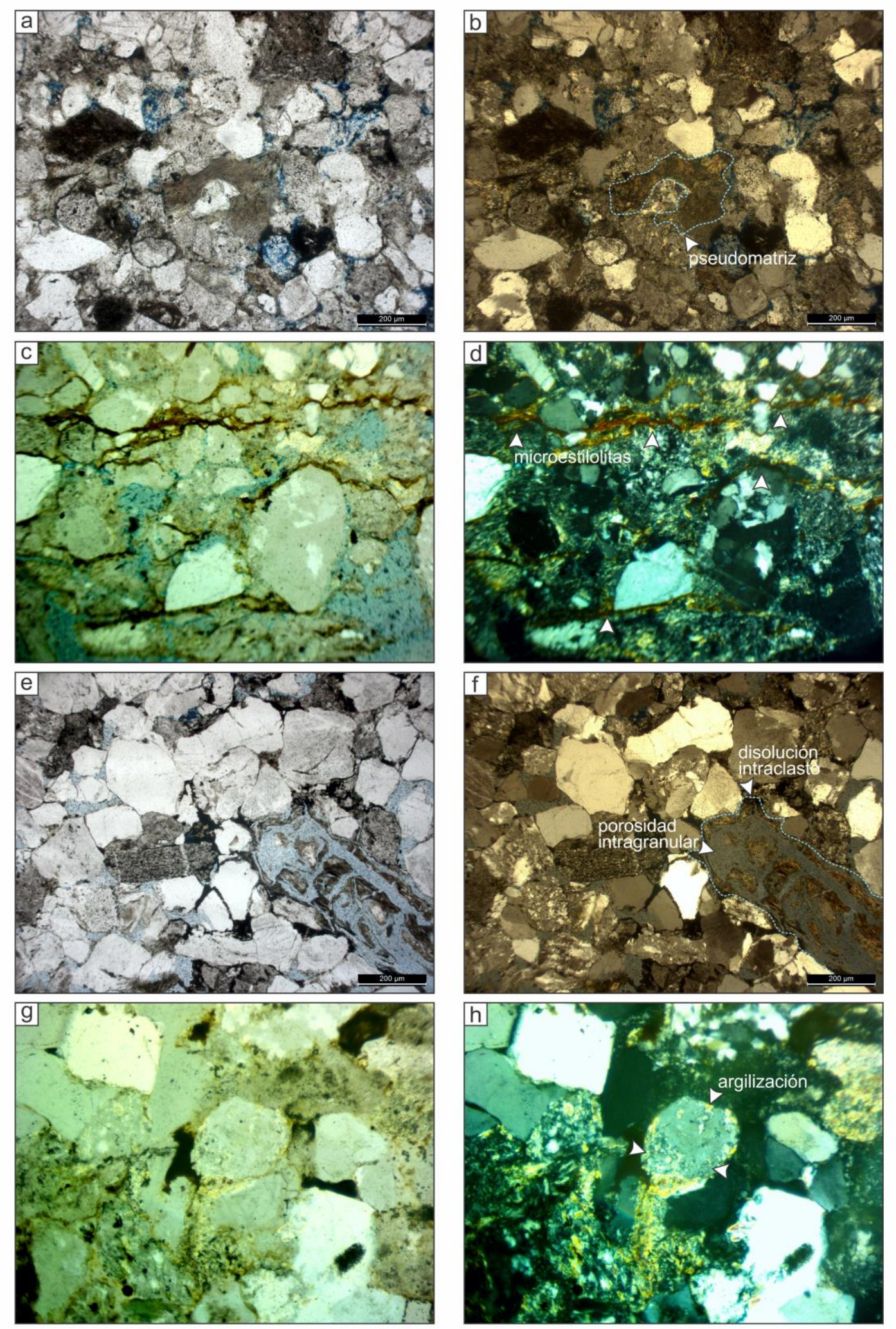

Figura 7.14. Procesos diagenéticos de la Formación La Anita en todos los casos se muestran sin nicoles a la izquierda y con nicoles a la derecha. 
- Revestimientos o coating de arcilla: se disponen tapizando los granos y generando halos de espesor variable que en ningún caso supera los 10 $\mu \mathrm{m}$. Se registran en todos los perfiles estudiados y generalmente se encuentran cubiertos por sobrecrecimientos de cuarzo (Fig. 7.15c y d).

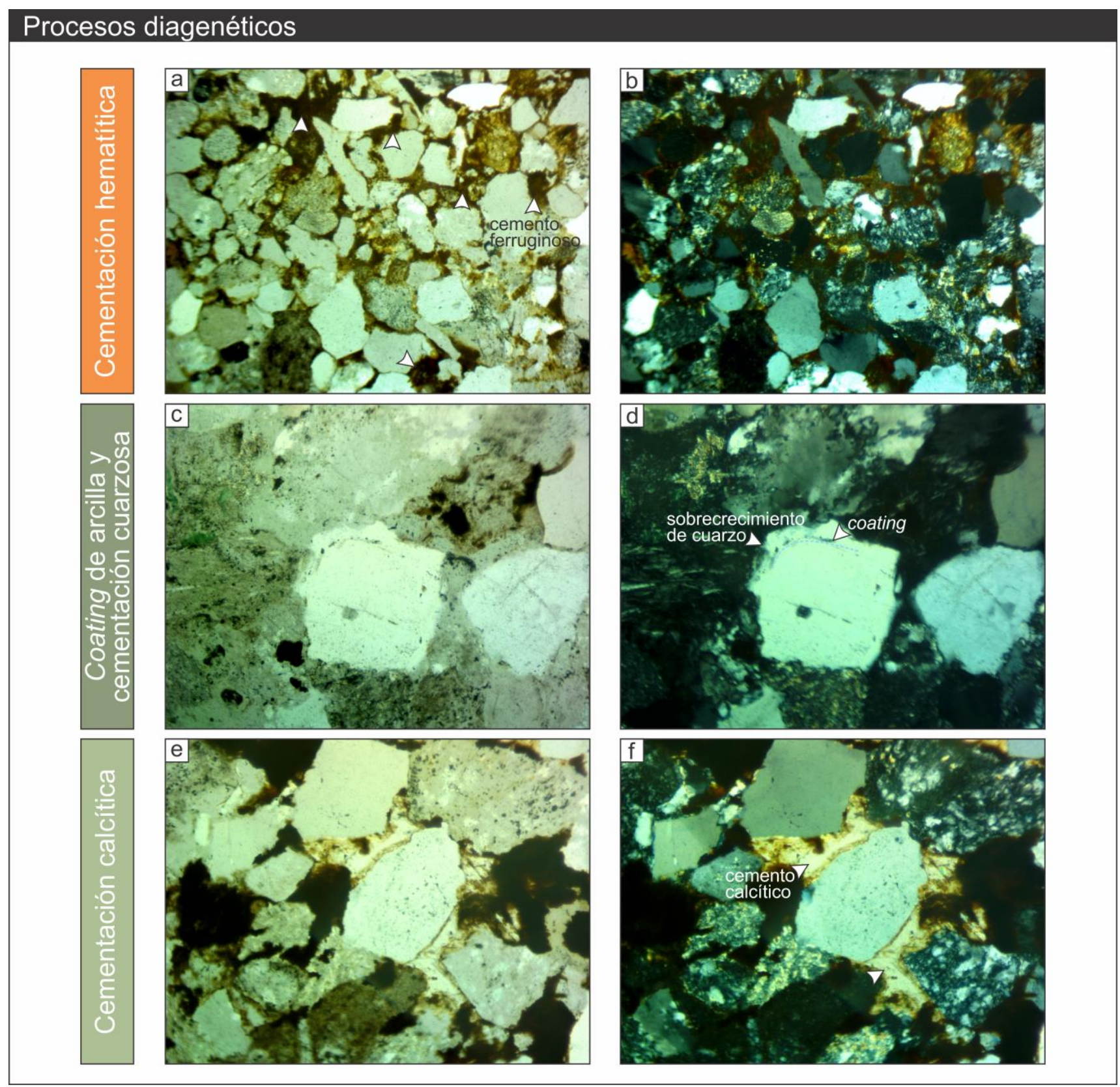

Figura 7.15. Procesos diagenéticos de la Formación La Anita en todos los casos se muestran sin nicoles a la izquierda y con nicoles a la derecha.

- Cementación cuarzosa: este cemento se observa como sobrecrecimiento de los granos de cuarzo en continuidad óptica y cristalográfica y su límite suele distinguirse por la presencia de coating de arcillas (Fig. 7.15c y d). 
Aunque no está presente en todas las muestras, se reconoce formando halos de distinto espesor que nunca superan los $20 \mu \mathrm{m}$ en todos los perfiles estudiados.

- Cementación calcítica: se distinguen cristales generalmente subesparíticos y ocasionalmente esparíticos de calcita inequigranular, que con frecuencia alcanzan buen desarrollo de los individuos y aparecen como cemento poiquilotrópico, es decir, rellenando los espacios porales entre los elementos que conforman el esqueleto (Fig. 7.15e y f). Se reconoce en muestras aisladas de los perfiles Galpón de Freire y Cerro Calafate.

- Migración de bitumen: se reconoce comúnmente como relleno de poros, aunque también es usual su distinción como revestimientos o coating de clastos, relleno de microfracturas abiertas (Fig. 7.16a y b) y tapizado de poros (pore lining; Fig. 7.16 c y d). Se reconoció en distintas cantidades en muestras de todos los perfiles estudiados.

- Piritización: Se observa como el desarrollo de cristales de pirita subhedrales a euhedrales de hasta $15 \mu \mathrm{m}$ aislados o de forma framboidal (Fig. 7.14e y f). Se encuentra frecuentemente dispersa en la matriz y ocasionalmente asociada a componentes del esqueleto. Se registró pirita en todos los perfiles estudiados. 


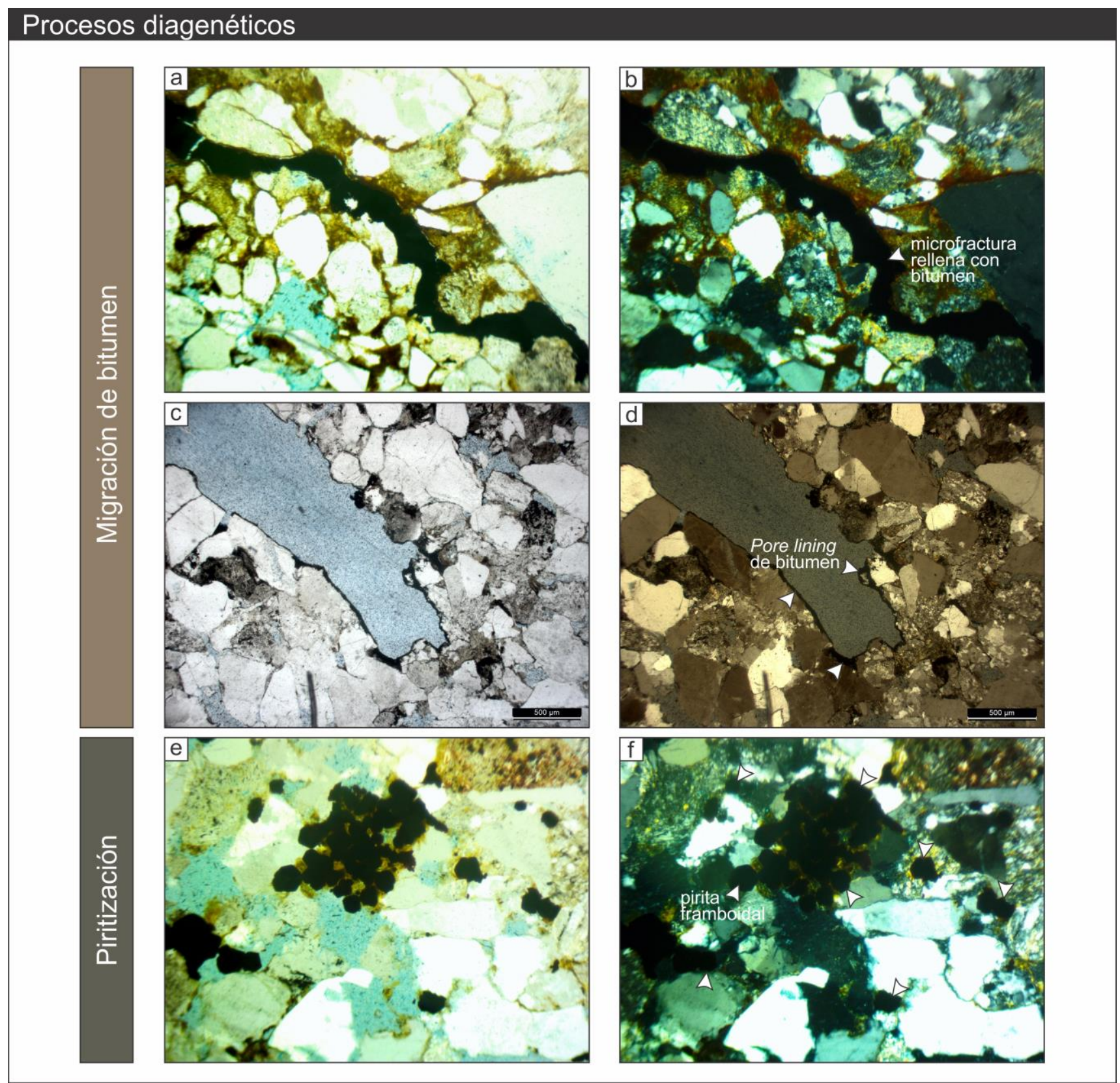

Figura 7.16. Procesos diagenéticos de la Formación La Anita en todos los casos se muestran sin nicoles a la izquierda y con nicoles a la derecha.

\subsubsection{Historia diagenética}

Los procesos diagenéticos reconocidos pudieron ser ordenados temporalmente sobre la base de las relaciones de corte observadas petrográficamente y las condiciones de presión y temperatura en las que éstos se llevan a cabo. De esta forma, se propone una historia diagenética para la Formación La Anita (Fig. 7.17). 
La historia diagenética comienza con un primer episodio de compactación que reduce el volumen general de la roca por reorganización mecánica de los componentes. A partir de las relaciones de corte entre los distintos productos, es posible concluir que el proceso afectó de manera constante desde las etapas tempranas de eogénesis hasta las etapas tempranas de mesogénesis. El mismo se ve representado principalmente por contactos planos, cóncavos convexos y ocasionalmente suturados entre los granos. Posteriormente, se reconoce la alteración parcial o casi total de cristaloclastos de feldespato y litoclastos volcánicos a partir de la autigénesis de arcillas.

La mesogénesis más temprana se ve representada por la generación de revestimientos o coatings de arcillas y posterior cementación cuarzosa que actúan reduciendo el tamaño de los poros y las gargantas porales. Para entender la generación de los revestimientos o coating de arcilla, son necesarios análisis de microscopía electrónica de barrido que permitan conocer en detalle la composición y la vinculación con la alteración de feldespatos y líticos volcánicos. Autores como Richiano et al. (2015) han propuesto para formaciones con similares características composicionales de la misma cuenca, la generación de coatings a expensas de la descomposición de los feldespatos. El origen del cemento cuarzoso, por otro lado, ha sido ampliamente debatido en la bibliografía (Tucker, 2001; Gluyas et al., 2000; Worden y Morad, 2000), y para el caso de las areniscas de la Formación La Anita, hacen falta estudios de más detalle para poder vincular la presencia de este cemento con procesos como la alteración de trizas de vidrio volcánico a esmectita y la transformación diagenética de argilominerales esmectíticos a illíticos que sugieren Spalletti et al. (2005) y Gómez Dacal (2018) para facies de areniscas siliciclásticas de la cuenca. 
El estadio mesogenético más avanzado se ve caracterizado por una intensa cementación carbonática de tipo poiquilotrópica que sólo está presente en algunos sectores de los perfiles estudiados. La fuente de los fluidos cementantes podría estar relacionada con la baja a nula proporción de fragmentos esqueletales de organismos carbonáticos en estos niveles, cuya actividad queda registrada en la presencia de trazas fósiles. Según Tucker (2001), este tipo de cemento es el más frecuente en areniscas clasto-soportadas y se generaría en profundidad por incremento del $\mathrm{pH}$ junto con la temperatura. Un segundo episodio de compactación es reconocido a partir de la observación de microfracturas cerradas intergranulares o transgranulares. Este proceso es interpretado como de mesogénesis intermedia-tardía por la relación de corte observada con el cemento carbonático. En todos los perfiles estudiados se reconoció la presencia de distintas cantidades de bitumen, que comúnmente actúa reduciendo el espacio poral y ocluyendo gargantas porales. Es posible distinguirlo tanto como tapizado o relleno de poros, coating de clastos y como relleno de microfracturas. Si bien la generación del bitumen a partir de la maduración de la materia orgánica pudo haberse generado desde la diagénesis temprana con temperaturas inferiores a los $50^{\circ} \mathrm{C}$ (Tissot y Welte, 1984), el relleno de las microfracturas permite ubicar una etapa de migración posteriormente al segundo evento de compactación.

En algunas muestras aisladas, especialmente hacia el tope del perfil Campo El Tropilla, se observó abundante cemento de hematita rellenando espacios porales, generando revestimientos o coatings y en ocasiones alterando algunos clastos. La fuente de este cemento suele estar relacionada con la disolución de silicatos de hierro y magnesio y posterior autigénesis de la hematita asociada al aumento de la temperatura (Lu et al., 1994). No obstante, la abundancia de este 
cemento registrada en las muestras estudiadas y la ausencia de silicatos restos de silicatos de hierro y magnesio sugeriría una fuente externa.

El último proceso reconocido es la piritización que se habría producido desde una etapa de mesogénesis temprana, siendo el último en culminar. La piritización se desarrolla a partir de fluidos porales euxínicos (Gómez Dacal, 2018). Berner (1984), postula que la degradación de la abundante materia orgánica presente en el sedimento generaría condiciones reductoras locales en las aguas porales, que generaron a la precipitación de pirita.

Si bien la historia diagenética antes descripta es similar para toda el área estudiada, es posible observar algunas particularidades en las secciones sedimentarias:

- Galpón de Freire: en este perfil el primer proceso de compactación es algo más intenso que en el resto de los sectores estudiados ya que además de los contactos cóncavo-convexos y suturados es posible reconocer pseudo-matriz. Por otro lado, es el único de los perfiles en los cuales se ha reconocido un proceso de disolución, que afecta preferencialmente a los clastos de feldespatos y líticos volcánicos, genera porosidad secundaria intragranular y se ubica temporalmente, basándose en las relaciones de corte, después del proceso de compactación y antes del de alteración.

- Campo El Tropilla: hacia el tope de esta sucesión se reconoció mayor cantidad de cemento de hematita. Adicionalmente, en esta sección es posible interpretar un proceso de compactación tardía más intenso que en el resto de los perfiles estudiados. La compactación física se ve representada por esfuerzos tensionales que mantienen las microfracturas intragranulares y transgranulares abiertas. Adicionalmente, se suma una componente de compactación química, 
representada por estilolitas simples en las que eventualmente se registran concentraciones de materia orgánica. La presencia de estilolitas coincide con los mayores tenores de materia orgánica que se registran en esta sección sedimentaria. Por otro lado, la morfología de las mismas sustenta que este proceso se haya llevado a cabo durante la mesogénesis (Gómez-Peral, 2008).

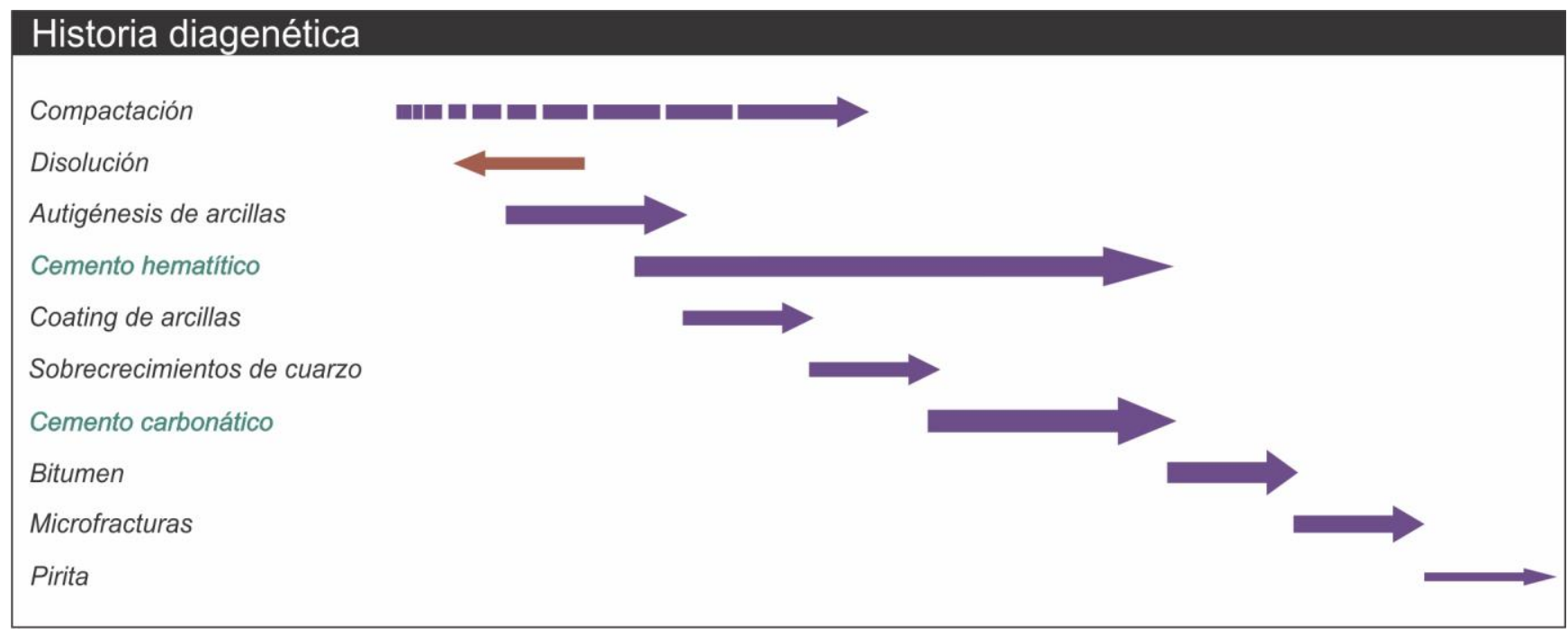

Figura 7.14. Historia diagenética propuesta para las muestras analizadas de la Formación La Anita. Las flechas de color violeta representan procesos de disminución de la porosidad general mientras que las de color rojo aquellos procesos asociados a un aumento de esta. El espesor de las flechas se encuentra directamente asociado a la magnitud de cada proceso diagenético. Los procesos escritos en negro fueron observados en todas las muestras, mientras que los de color verde se reconocieron en algunos de los perfiles estudiados.

\subsection{CONSIDERACIONES FINALES}

El análisis petrográfico de areniscas realizado en Formación La Anita permitió conocer 7 componentes detríticos principales que constituyen a estas sedimentitas reconociéndose en orden decreciente de abundancia: líticos volcánicos, cuarzo monocristalino, cuarzo policristalino, feldespatos potásicos, fitodetritos, plagioclasas y líticos sedimentarios. Estas muestras fueron clasificadas utilizando diagramas ternarios Qm-F-Lt propuestos por Folk et al. (1970) y Dott (1965, modificado por Pettijohn et al., 1972), clasificándose como litoarenitas y como arenitas líticas respectivamente (Fig. 7.3). 
Se estudiaron 82 muestras por DRX tanto en roca total como en la fracción arcilla. En los estudios de roca total se reconocieron proporciones variables de, en orden decreciente de abundancia: cuarzo, plagioclasa, feldespato potásico, arcilla, calcita y dolomita. Por otro lado, en el estudio de la fracción arcilla se reconocieron variables proporciones de caolinita, illita, interestratificados de illita esmectita, clorita, esmectita e interestratificados de clorita esmectita.

A partir del análisis petrográfico y de Difracción de Rayos X no se reconocen diferencias significativas entre los componentes detríticos de la unidad inferior y de la unidad superior de la Formación La Anita. Sin embargo, en el estudio de la fracción arcilla mediante DRX se destaca un incremento en la proporción de esmectita en detrimento de la caolinita en la unidad superior con respecto a la unidad inferior. Este enriquecimiento en esmectita podría sugerir influencia de un control climático en la composición de estos depósitos, evolucionando desde condiciones de clima cálido y húmedo con abundantes precipitaciones donde se favorecía la meteorización química en la unidad inferior hacia condiciones de climas templados y estacionales para la unidad superior.

El análisis de procedencia de areniscas demostró que las muestras analizadas presentan afinidad con una zona de orógeno reciclado en los diagramas ternarios de Dickinson et al. (1983) y Dickinson (1988). A partir de estos resultados y considerando que las direcciones de paleoflujo medidas en estructuras sedimentarias mecánicas muestran una dirección promedio hacia el sudeste se propone que el Complejo El Quemado, el cual fue elevado durante el estadio de antepaís de la cuenca y el arco volcánico del Batolito Patagónico desarrollado a fines del Cretácico fueron las fuentes que proporcionaron los componentes clásticos de la Formación La Anita. 
El estudio diagenético mediante petrografía convencional permitió identificar 9 procesos diagenéticos: compactación física y química, disolución, autigénesis de arcillas, cementación hematítica, revestimientos o coating de arcillas, cementación cuarzosa, cementación calcítica, migración de bitumen y piritización. A partir de la relación de corte y las condiciones de presión y temperatura bajo las cuales estos procesos se llevan a cabo se propuso una historia diagenética para la Formación La Anita. 


\section{DISCUSIONES: ESQUEMA ESTRATIGRÁFICO SECUENCIAL, FACTORES DE CONTROL E IMPLICANCIAS PALEOGEOGRÁFICAS}

\subsection{INTRODUCCIÓN}

\subsection{1 ¿Qué es la estratigrafía secuencial?}

La estratigrafía secuencial es la disciplina que estudia los patrones cíclicos de sedimentación dentro de sucesiones sedimentarias, los cuales se desarrollan como respuesta a variaciones en las tasas de aporte de sedimento y de variaciones en las tasas en las cuales se crea el espacio para acumularlo (Vail et al., 1991; Posamentier y Allen, 1999; Catuneanu, 2006). Consiste en una subdivisión de sucesiones sedimentarias contemporáneas en paquetes o unidades que se denominan secuencias, las cuales se encuentran limitadas por superficies de erosión o de no depositación (Vail et al., 1977). La estratigrafía de secuencias representa una metodología para el análisis de sucesiones en un esquema cronoestratigráfico y es considerada una eficaz herramienta para interpretaciones genéticas y la predicción de rellenos de cuencas sedimentarias (Weimer y Poisamentier, 1993; Catuneanu 2006; Catuneanu et al., 2009).

8.1.2 ¿A qué nos referimos cuando hablamos de secuencias, cortejos depositacionales y superficies estratigráficas clave?

Las secuencias sedimentarias se definen como una sucesión relativamente concordante de estratos genéticamente relacionados y se encuentran limitadas tanto en su techo como en su base por discordancias o por sus correlativas concordancias (Mitchum et al., 1977; Vail et al., 1977). Las secuencias se subdividen a su vez en cortejos depositacionales, mencionados comúnmente en la biblio- 
grafía como "systems tracts", los cuales se definen como un conjunto de sistemas depositacionales contemporáneos (Brown y Fisher, 1977). Galloway (2004), describió a los cortejos depositacionales como unidades estratigráficas genéticas que incluyen estratos depositados dentro de sistemas de dispersión de sedimentos sincrónicos. Los sistemas de dispersión de sedimentos son relativamente estables durante la depositación de cada cortejo particular (Galloway, 2004; Catuneanu, 2006).

Los cortejos se definen en base a su patrón vertical de apilamiento de estratos, su posición dentro de la secuencia y por los tipos de superficies limitantes, y son asignados a posiciones particulares a lo largo de una curva ideal de cambios de nivel de base de la línea de costa, cuando el aporte de sedimentos es constante (Fig. 8.1; Posamentier y Allen, 1999; Catuneanu, 2006). Los cambios significativos, o reorganizaciones dentro de los sistemas de dispersión, ocurren en los límites de los cortejos depositacionales y corresponden a los cuatro momentos dentro de un ciclo de nivel de base (Fig. 8.1). De este modo una secuencia ideal se subdivide en cuatro cortejos depositacionales: de mar bajo (lowstand systems tract), transgresivo (transgressive systems tract), de mar alto (highstand systems tract), y de caída (falling stage systems tract; Vail, 1987; Posamentier y Vail, 1988; Posamentier et al., 1988; Hunt y Tucker, 1992; Fig. 8.1).

Las superficies estratigráficas son superficies que marcan cambios en los regímenes depositacionales, es decir reflejan cambios en los ambientes sedimentarios, en la carga de sedimentos, en los tipos de procesos depositacionales y/o en la energía de estos procesos, y son generadas a partir de las variaciones del nivel de base y de los factores alocíclicos (externos) que condicionan la sedimentación (Catuneanu et al., 2006). La correcta identificación e interpretación de superficies estratigráficas es la clave para comprender el marco estrati- 


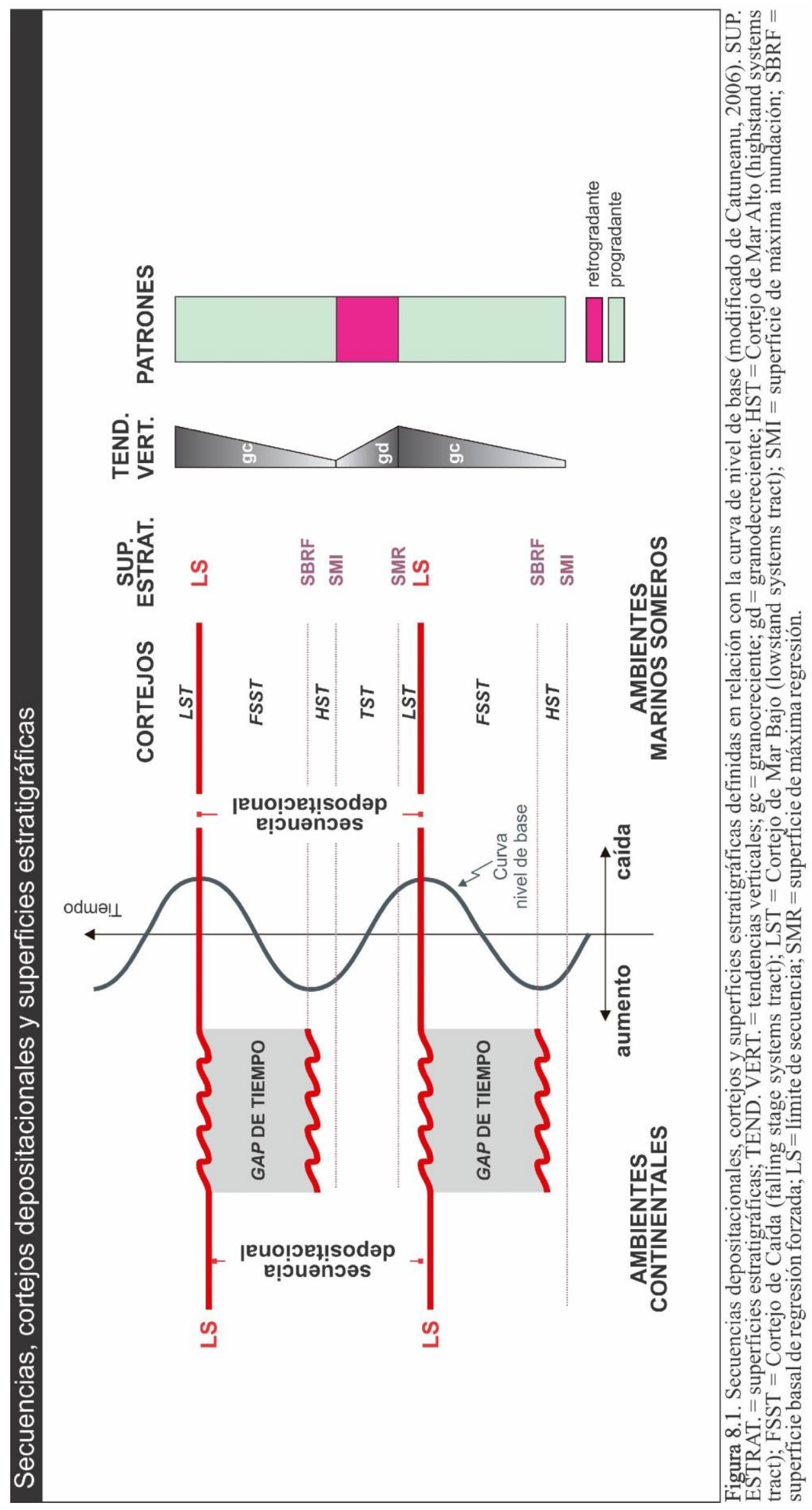


gráfico secuencial de cualquier sucesión sedimentaria. Las superficies estratigráficas que delimitan cortejos depositacionales o secuencias son denominadas superficies estratigráfico-secuenciales y son utilizadas para conformar el marco secuencial.

Es importante resaltar que la naturaleza de las secuencias, de los cortejos y también de las discontinuidades estratigráficas dependen de factores como los cambios relativos del nivel de base, la tasa de subsidencia, el aporte de sedimento, los procesos depositacionales dominantes durante el transporte y acumulación de sedimentos, y también de la geometría y configuración de la cuenca sedimentaria (Fig. 8.1; Weimer y Posamentier, 1993).

8.1.3 ¿Cuáles son los principales factores que actúan sobre la sedimentación?

Una de las premisas más importantes de la estratigrafía secuencial es que permite realizar predicciones de facies desde escalas de ambientes depositacionales a escalas de rellenos de cuencas sedimentarias (Catuneanu, 2006). Esto implica que las tendencias depositacionales dentro de los diferentes sistemas de acumulación que formen parte de un mismo cortejo sedimentario responden a mecanismos, o factores, de control externos (alocíclicos) los cuales actúan desde escala de cuenca a escalas globales. Estos factores alocíclicos controlan las tendencias depositacionales y proporcionan las bases para la diferenciación de secuencias en cortejos, y de esta manera ayudan a generar modelos de acumulación predictivos (Catuneanu et al., 2009; Burgess, 2016).

Los controles alocíclicos o externos son el clima, la tectónica, los cambios del nivel del mar (eustacia) y el vulcanismo, y controlan principalmente el aumento o disminución de espacio para acumular sedimentos (espacio de acomo- 
dación) y la cantidad y el tipo de sedimento disponible para ser transportado y acumulado (Catuneanu, 2003, 2006; Catuneanu et al., 2009). La interacción entre el espacio de acomodación disponible y la cantidad de aporte de sedimento se refleja en los diferentes patrones de apilamiento y en las tendencias depositacionales dentro de las sucesiones sedimentarias (Madof et al., 2016; Burguess , 2016).

Existen también otros factores de control que operan a una escala menor y son denominados controles autocíclicos, o controles internos. Estos son importantes a la escala de los subambientes depositacionales y su accionar se refleja en, por ejemplo, avulsiones de canales fluviales o de lóbulos deltaicos (Madof et al., 2016).

\subsubsection{Consideraciones para el caso de la Formación La Anita}

Teniendo en cuenta los factores que controlan a las secuencias, cortejos y superficies estratigráficas, es importante resaltar dos cuestiones particulares para el caso de la Cuenca Austral-Magallanes durante su estadio de antepaís. El régimen tectónico y el desarrollo del cinturón orogénico hacia el oeste eran el principal control sobre la tasa de subsidencia de la cuenca y el aporte de sedimento. Esta actividad tectónica tiene pulsos de actividad y quietud téctonica alternantes durante el Cretácico Tardío (Fosdick et al., 2011; Varela, 2015). Un aspecto no menor a tener en cuenta para los análisis estratigráfico-secuenciales en la cuenca es la presencia de facies de talud descriptas para las formaciones Alta Vista en Argentina y Tres Pasos en Chile y también el desarrollo de depósitos turbidíticos y de abanicos de fondo de cuenca de la Formación Cerro Toro, lo que vincula a la cuenca con un perfil con quiebre de pendiente o perfil tipo pla- 


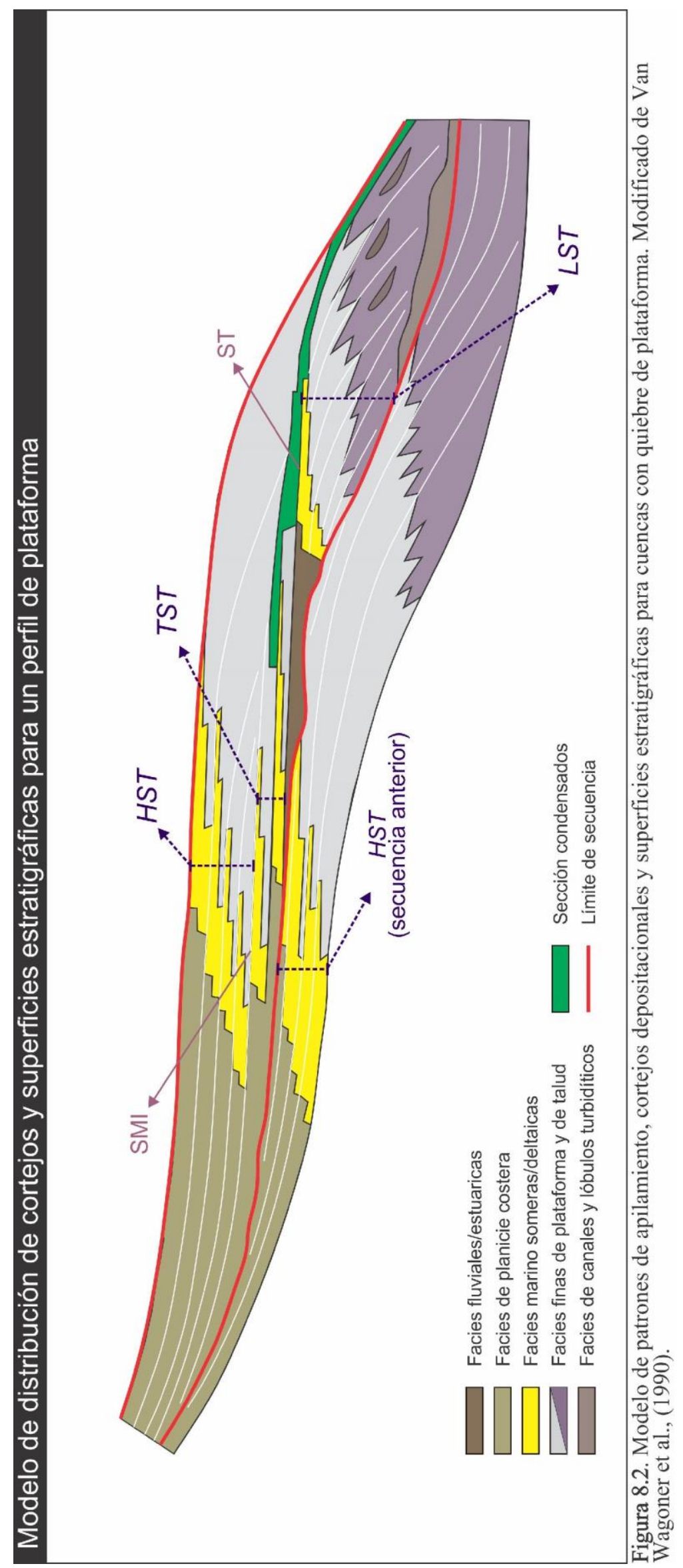


taforma. Las cuencas con quiebre de plataforma han sido muy utilizadas para la generación de modelos de patrones estratales y cortejos depositacionales (Fig. 8.2; Van Wagoner et al., 1990).

\subsection{ESQUEMA ESTRATIGRÁFICO SECUENCIAL DE LA FORMACIÓN LA ANITA}

\subsubsection{Patrones de apilamiento y tendencias verticales}

Como se mencionó en el Capítulo 5 y se representó en la Figura 5.11, los depósitos de la Formación La Anita presentan diferentes patrones de apilamiento. De este modo se diferenciaron tres intervalos depositacionales con un patrón de apilamiento característico: uno para la unidad inferior la cual se encuentra relacionada a los depósitos de la subyacente Formación Alta Vista, y dos patrones de apilamiento para la unidad superior de la Formación La Anita.

La unidad inferior caracteriza por gradar verticalmente desde los depósitos pelíticos de talud y plataforma externa de la Formación Alta Vista (Schwartz y Graham, 2015; Malkowski et al., 2017; Moyano Paz et al., 2018) y se encuentra limitada al tope por la superficie erosiva regional. Esta unidad se interpreta como el producto de la acumulación en un sistema deltaico dominado por procesos de oleaje, influenciado por descargas fluviales y se encuentra caracterizado por las AF1, AF2, AF3, AF4 y AF5. El patrón de apilamiento vertical (vertical stacking pattern) de las asociaciones que constituyen a esta unidad es dominantemente agradante a progradante, con un amplio dominio de los depósitos de frente deltaico distal dominado por olas (AF2; Fig. 8.3).

Figura 8.3 (página siguiente). Esquema estratigráfico secuencial con distribución de los tres paquetes con patrones de apilamiento distintivos, ubicación de superficies estratigráficas clave y cortejos depositacionales de la Formación La Anita. LS = límite de secuencia; SMI = superficie de máxima inundación; HST= Cortejo de Mar Alto; TST= Cortejo de Transgresivo; $L S T=$ Cortejo de Mar bajo. 
త్రి

造高

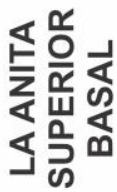

RELLENO FLUVIAL DE VALLE INCISO

DELTA FLUVIODOMINADO

DELTA DOMINADO POR OLAS

TALUD

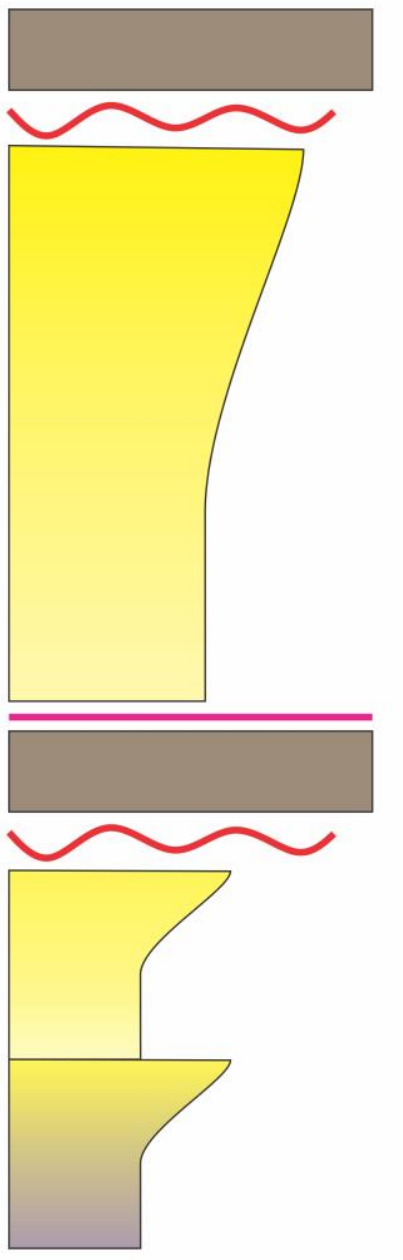

LST

HST

SMI

La base de la unidad superior coincide con la superficie de erosión regional (SER) la cual divide a las dos unidades definidas para la Formación La Anita y se encuentra cubierta por los Depósitos Continentales del Cretácico Superior representando una continentalización progresiva de la cuenca en la región del Lago Argentino (Moyano Paz et al., 2018; Tettamanti et al., 2018; Cuitiño et al., 2019; Figs. 2.3 y 8.3). Es importante destacar que los depósitos de la unidad superior de la Formación La Anita no muestran gradaciones verticales y tampoco laterales con los depósitos que caracterizan a la unidad inferior de la formación. El intervalo inferior de la unidad superior, ubicado justo por encima de la SER y y por debajo de los depósitos de frente deltaico del delta fluvio-dominado. Este intervalo es interpretado como el relleno fluvial de un valle inciso, se caracteriza 
por la amalgamación lateral y vertical de cuerpos canalizados de la AF8 caracterizando un patrón de apilamiento dominantemente agradacional a retrogradacional (Fig. 8.3). El intervalo superior de esta unidad apoya sobre los depósitos del relleno del valle inciso, a través de una superficie de inundación marina y son cubiertos por los UCCD mediante una superficie erosiva (Fig. 8.3; Tettamanti et al., 2018). Este intervalo se interpreta como la acumulación en un ambiente deltaico fluvio-dominado, influenciado por corrientes de mareas (Fig. 8.3) el cual se encuentra caracterizado por las AF6, AF7, AF8 y AF9. El patrón de apilamiento vertical de las asociaciones del delta fluvio-dominado es fuertemente progradante (Fig. 8.3).

8.2.2 Superficies estratigráficas clave y cortejos depositacionales de la Formación La Anita

Las dos unidades de la Formación La Anita podrían ser atribuidas como parte de la misma secuencia depositacional, donde los dos sistemas deltaicos podrían considerarse como dos lóbulos activos de un delta asimétrico (Bhattacharya y Giosan, 2003), o podrían formar parte de dos secuencias diferentes. Para el primer caso ambas unidades deberían estar genéticamente relacionadas, representando variaciones temporales en la trayectoria de la línea de costa y paleogeografía, y deberían mostrar direcciones oblicuas de progradación según lo sugerido por Charvin et al. (2010). No obstante, los datos obtenidos en los afloramientos de la Formación La Anita indican que la unidad inferior y la unidad superior no se encuentran genéticamente relacionadas debido a que: i) no se han registrado gradaciones entre ambas unidades lo que podría evidenciar que se encuentran asociadas lateralmente, ii) las direcciones de paleoflujo indican que ambos sistemas se encontraban progradando en la misma dirección, y 

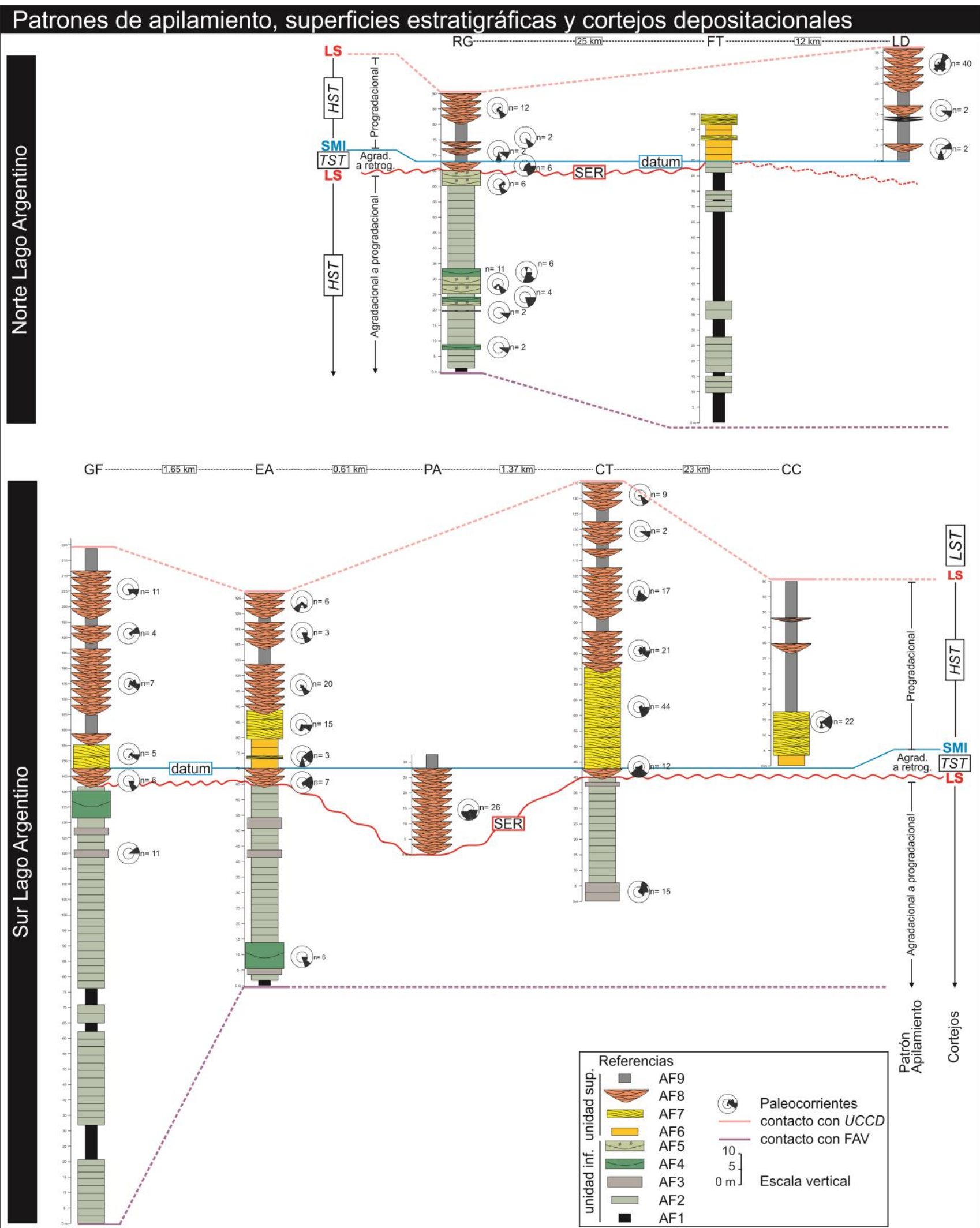

Figura 8.4. Panel de correlación de la distribución de las asociaciones de facies de la Formación La Anita donde se marcan las tendencias verticales y patrones de apilamiento, las superficies estratigráficas clave y los cortejos depositacionales. SER; superficie de erosión regional; $\mathrm{LS}=$ límite de secuencia; $\mathrm{SMI}=$ superficie de máxima inundación; $\mathrm{si}=$ superficie de inundación; $H S T=$ Cortejo de Mar Alto; $T S T=$ Cortejo Transgresivo; $L S T=$ Cortejo de Mar Bajo. 
con una trayectoria de la línea de costa similar, y iii) ambas unidades se encuentran separadas por la superficie de erosión regional (SER).

Esta superficie de erosión regional consiste en una incisión regional de bajo ángulo que incide aproximadamente 50 metros sobre los depósitos del delta dominado por olas, influenciado por procesos fluviales de la unidad inferior. Esta superficie se encuentra inmediatamente cubierta por los depósitos gruesos canalizados amalgamados multiepisódicos (AF8) que representan el relleno fluvial de un valle inciso lo que permite interpretar a la superficie erosiva regional como un límite de secuencia gatillado por una caída del nivel relativo del mar (Figs. 8.3 y 8.4; Catuneanu, 2006; Catuneanu et al., 2009; Moyano Paz et al., 2018).

Por debajo del límite de secuencia interpretado, se encuentran los depósitos de la unidad inferior de la Formación La Anita los cuales gradan verticalmente desde los depósitos de talud dominantemente pelíticos de la Formación Alta Vista (Malkowski et al., 2017; Daniels et al., 2017; Bauer et al., 2020). Esta sucesión somerizante, que involucra a parte de los depósitos de talud de la Formación Alta Vista y al delta dominado por olas de la Formación La Anita se interpreta como el Cortejo de Mar Alto (HST; highstand systems tract; Figs. 8.3 y 8.4) de la primera secuencia, indicado por el patrón progradante y arreglo somerizante de estos depósitos y por su ubicación inmediatamente por debajo del límite de secuencia interpretado (Figs. 8.3 y 8.4; Catuneanu, 2006; Catuneanu et al., 2009; Moyano Paz et al., 2018).

Los depósitos que conforman a la unidad superior de la Formación La Anita presentan un arreglo más complejo y forman parte un ciclo de variación relativo de cambio del nivel del mar completo (Figs. 8.3 y 8.4). La erosión asociada al límite de secuencia ocurrió durante un lapso de tiempo en el que no hubo lugar 
a la acumulación de sedimentos, o que la tasa de acumulación era menor a la tasa de erosión. Se interpreta que durante este tiempo la acumulación de sedimentos se restringió al depocentro de la cuenca y se encuentra asociada a un Cortejo de Mar Bajo (LST: lowstand systems tract; Figs. 8.3 y 8.4; Catunenu, 2006). El intervalo más inferior de esta unidad, representado por el relleno de un valle inciso se interpreta como un Cortejo Transgresivo (TST; transgressive systems tract; Catuneanu et al., 2006; Figs. 8.3 y 8.4) debido al patrón vertical agradacional a retrogradacional. El límite superior del TST se encuentra marcado por la aparición de los depósitos del frente deltaico fluvio-dominado (AF6 y AF7), y se interpreta como la superficie de máxima inundación (SMI; Figs. 8.3 y 8.4; Catuneanu, 2006; Catuneanu et al., 2009; Moyano Paz et al., 2018, 2020). La SMI también se presenta separando a los depósitos del valle inciso de los depósitos finos de la planicie deltaica representando el desconfinamiento del relleno fluvial del valle inciso (Fig. 8.4). La expresión de esta superficie de inundación se pierde progresivamente hacia el norte del área de estudio (Moyano Paz et al., 2018; Figs. 8.3 y 8.4). Por su parte, los depósitos del delta fluvio-dominado, influenciado por corrientes de marea que se encuentran por encima del TST muestran un patrón de apilamiento de sus asociaciones de facies fuertemente progradante. Es por esto y por su ubicación por encima de la SMI, que este intervalo de la unidad superior se interpreta como el HST de esta segunda secuencia (Catuneanu, 2006, Catuneanu et al., 2009; Kurcinka et al., 2018; Moyano Paz et al., 2018). Por encima del HST de la unidad superior de la Formación La Anita y a través de una superficie erosiva, la cual representa un nuevo límite de secuencia asociado a una caída relativa del nivel del mar, se encuentran los depósitos de las formaciones Cerro Fortaleza y La Irene (al norte y al sur del Lago Argentino respectivamente) los cuales han sido interpretados como parte de una Cuña de Mar Bajo (LST wedge; sensu Tettamanti et al., 2018). 


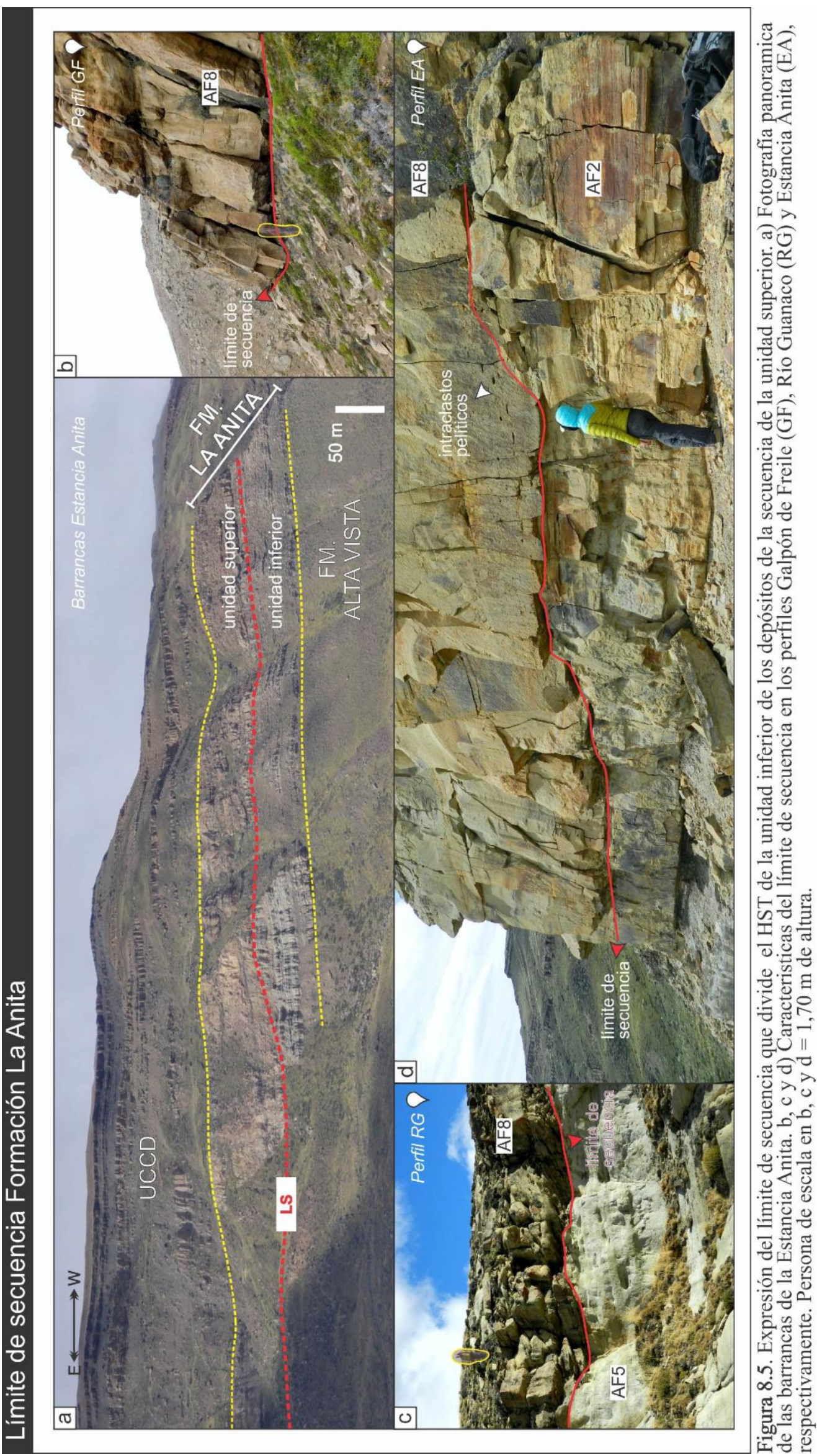


El límite de secuencia que separa a las dos secuencias depositacionales involucradas y que también delimita a la unidad inferior y a la superior de la Formación La Anita, se genera producto de una caída relativa del nivel del mar dejando, al menos, parte de la plataforma expuesta y favoreciendo la incisión de cuerpos canalizados y por lo tanto corresponde a un límite de secuencia "Tipo 1" (Van Wagoner et al., 1988; Catuneanu, 2006). Dicho límite de secuencia tiene una clara expresión en toda la región del Lago Argentino y se encuentra acompañado por un abrupto salto de facies que separa los depósitos deltaicos dominados por olas de la unidad inferior del relleno de los cuerpos canalizados asociados al relleno del valle inciso del intervalo más inferior de la unidad superior (Fig. 8.5). Este límite de secuencia es todavía materia de discusión y sin duda se necesitarán estudios de más detalle para una mejor comprensión y detectar su expresión tanto hacia los depósitos más profundos como hacia los depósitos continentales coetáneos.

8.2.3 Discusión sobre la evolución temporal de las secuencias y superficies estratigráficas de la Formación La Anita

Si bien la falta de datos de edades de las unidades de la Cuenca AustralMagallanes ha sido una traba en cierto punto para comprender la evolución del relleno de la misma, en los últimos años se han publicado una serie de trabajos con edades de máxima depositación calculadas a partir de circones detríticos, los cuales han clarificado varias controversias y llenado parte de un vacío en el entendimiento del relleno de la cuenca (Schwartz et al., 2017; Malkowski et al., 2017a, b; Sickmann et al., 2018, 2020; Daniels et al., 2017, 2019; Ghiglione et al., en prensa; entre otros).

En esta serie de trabajos se obtuvieron las primeras edades $\mathrm{U}-\mathrm{Pb}$ para los depósitos de la Formación La Anta en circones detríticos (Sickmann et al., 2018; 
Ghiglione et al., en prensa). Ghiglione et al. (en prensa) dataron la unidad inferior de la Formación La Anita en los afloramientos del Cerro Tetas al norte del Lago Argentino (Fig. 3.2) y la unidad superior en la localidad del Cerro Calafate (Perfil CC), al sur del Lago Argentino (Fig. 3.2). Sickmann et al. (2018) realizaron dataciones en el tope de la unidad superior en la zona del Norte del Lago Argentino en las barrancas de la estancia La Angostura y en la desembocadura del Río Guanaco (Fig. 3.2).

\section{Evolución temporal de la Formación La Anita}

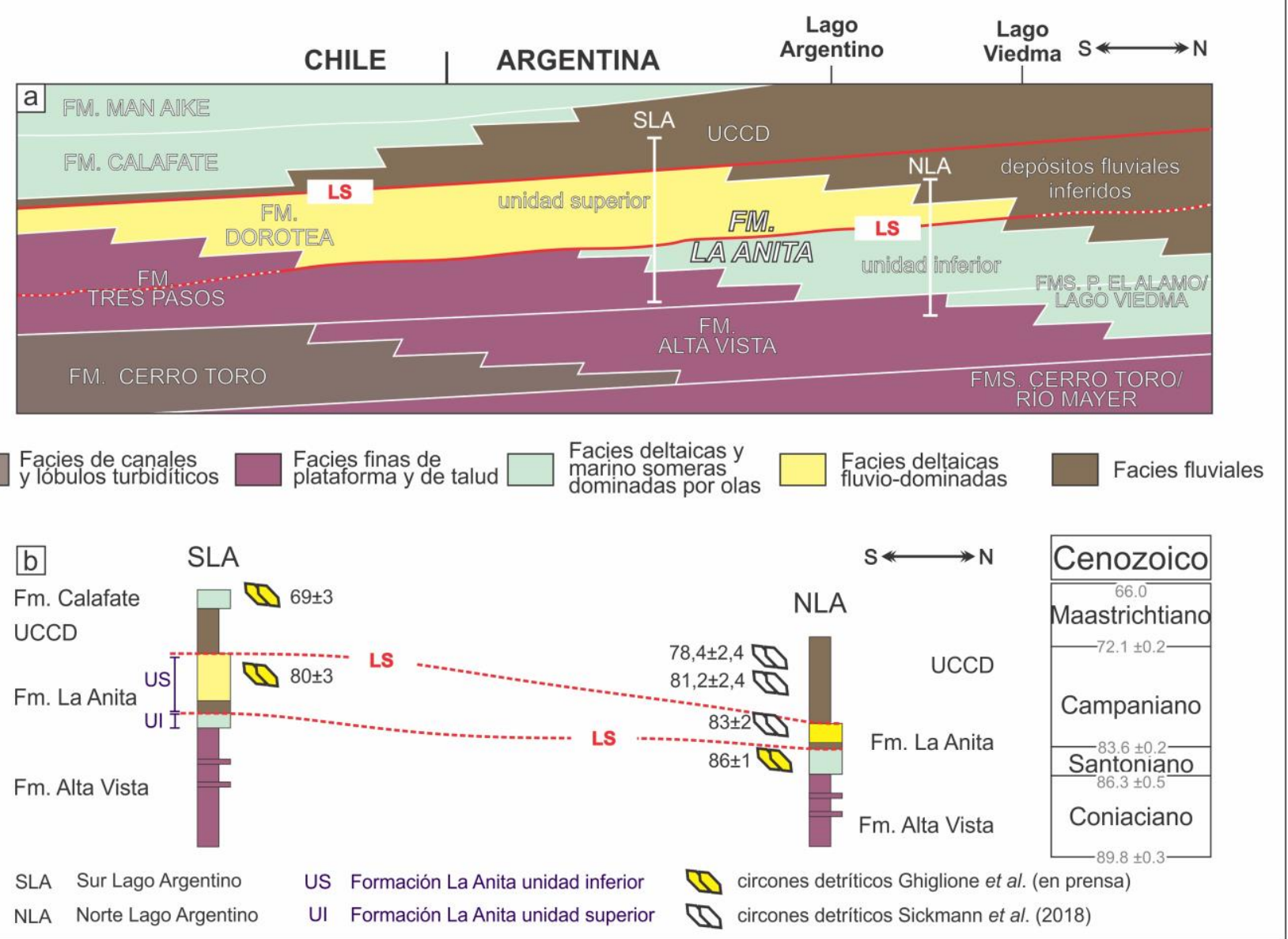

Figura 8.6. a) Distribución litoestratigráfica y patrones estratales de las unidades del Cretácico Superior de la Cuenca Austral-Magallanes. b) Perfiles estratigráficos simplificados del norte del Lago Argentino (NLA) y del sur (SLA) con la ubicación de las muestras datadas.

La edad de máxima depositación para los depósitos de la unidad inferior de la Formación La Anita al norte del lago es de $86 \pm 1 \mathrm{Ma}$, ubicándose cerca del límite Coniaciano-Santoniano (Ghiglione et al., en prensa; Fig. 8.6). Los circones detríticos datados para los depósitos de la unidad superior en cambio arrojaron 
edades de $83 \pm 2$ y $82,3 \pm 2,6 \mathrm{Ma}$ en el norte del Lago Argentino, indicando una

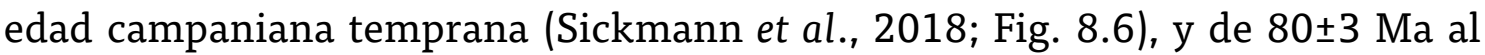
sur del lago, indicando también una edad campaniana para esta unidad en este sector (Ghiglione et al., en prensa; Fig. 8.6).

La presencia de edades más jóvenes de la unidad superior al sur del Lago Argentino muestra correlatividad con la dirección de progradación del sistema planteada en el Capítulo 5. Las edades obtenidas al tope de la unidad superior, cerca del contacto con la Formación Cerro Fortaleza (UCCD), por Sickmann et al. (2018), serían al menos 4 ma más jóvenes que los depósitos de la unidad inferior (Fig. 8.6b). Esto implicaría que el límite de secuencia en cuestión que separa a la secuencia que involucra a la unidad inferior de la secuencia de la unidad superior podría representar un tiempo de entre 1 y 2 millones de años.

Esta consideración temporal del límite de secuencia ubicaría a la SER como una superficie de tercer orden (Vail et al., 1991; Catuneanu, 2006). La jerarquía de esta discontinuidad escapa a la escala en la que operan los controles autocíclicos (internos) a los sistemas de acumulación, reflejando de esta manera que la caída relativa del nivel del mar debió obedecer a la interacción de controles alocíclicos (externos). El límite de secuencia en cuestión pone en contacto depósitos deltaicos dominados por olas y depósitos fluviales restringidos a un valle inciso (Figs. 8.3, 8,4, 8.5 y 8.6), por lo que representaría un cambio abrupto en la configuración de los sistemas depositacionales. De esta manera, el primer estadio de reconfiguración se encuentra representado por el límite de secuencia (LS) asociado a la SER, el cual se habría desarrollado durante la caída del nivel de base de largo término y representaría un momento de erosión y no depositación. El segundo estadio de reconfiguración ocurrió durante un estadio de ascenso del nivel de base de corto término, el cual interrumpió a los procesos de erosión 
y favoreció la amalgamación de rellenos de canal con un patrón agradante a retrogradante, los cuales son delimitados hacia el tope por la superficie de máxima inundación que marca el final del TST y el comienzo de la regresión normal del HST de la unidad superior. A continuación, se presenta una discusión sobre los posibles factores de control que podrían haber controlado la caída relativa del nivel del mar, la generación de este límite de secuencia y la evolución vertical de las secuencias.

\subsection{FACTORES DE CONTROL ALOCÍCLICOS EN EL DESARROLLO DE LA FOR- MACIÓN LA ANITA}

Los cambios en la arquitectura secuencial de las sucesiones sedimentarias son el resultado de las variaciones en la relación de la tasa de creación de espacio de acomodación (A) y la tasa de aporte de sedimentos (S). Estas variaciones son promovidas por la interacción de los diferentes factores externos que son, como se mencionó en el comienzo de este capítulo, principalmente el clima, la tectónica y la eustacia. De este modo, la interacción entre estos controles define y controla a las secuencias, a sus cortejos y a las superficies estratigráficas de ambos (Vail et al., 1991, Shanley y McCabe, 1994; Catuneanu, 2006). La combinación entre la tectónica y la eustacia producen cambios relativos en el nivel del mar y controla la cantidad de espacio disponible para alojar sedimentos. Por otra parte, la cantidad y tipo de sedimento disponible se encuentra controlado por la combinación entre la tectónica y el clima (Schumm, 1993).

8.3.1 Incidencia de los factores de control en el desarrollo del límite de secuencia y en la evolución de la Formación La Anita

Una caída relativa del nivel del mar y por ende una disminución en el espacio de acomodación de una cuenca puede generarse tanto a partir de descensos 
eustáticos, como también por procesos de levantamiento tectónicos (Vail et al., 1991; Romans et al., 2016).

Existen numerosos trabajos que registran variaciones del nivel del mar en distintas cuencas del mundo con el fin de confeccionar curvas eustáticas globales de nivel del mar (Vail et al., 1977, 1982; Haq et al., 1987, 1988; Kominz et al., 2008; Haq, 2014; entre otros). El principal objetivo de estas curvas globales es asociar y correlacionar señales estratigráficas de distintas cuencas del mundo. De este modo, se han confeccionado curvas de largo término y de corto término, las cuales reflejan variaciones de baja y alta frecuencia respectivamente (Fig. 8.7). Sin embargo, son escasos los estudios de variaciones del nivel del mar cerca de las paleolatitudes de la Cuenca Austral-Magallanes o estas no se encuentran bien ajustadas (Daniels et al., 2017). Si bien la curva de corto término de Haq (2014) muestra una caída prominente del nivel del mar cerca de los 83,5 Ma (Fig. 8.7a), esta expresión no queda del todo clara en las curvas de alto término (Fig. 8.7b). A su vez, los otros picos de caída de nivel eustático que se observan en la curva son difícil de correlacionar con los eventos del nivel del mar de la Cuenca Austral-Magallanes, de hecho, no hay trabajos realizados en la cuenca que vinculen a las variaciones relativas del nivel del mar con descensos o ascensos eustáticos. De este análisis, se desprende que es poco posible correlacionar a los descensos eustáticos de la curva global de Haq et al. $(1987,1988)$ y de Haq (2014) con las variaciones del nivel del mar en la Cuenca AustralMagallanes y que posiblemente la confección de una curva para la cuenca reflejaría diferencias con las cartas globales por causas tales como tasa de subsidencia vinculada a la actividad tectónica producto de la orogenia andina (Hallam, 1991; Fosdick et al., 2011; Varela, 2015; Sachse et al., 2015; Ghiglione et al., 2016, en prensa). 
El otro factor que tiene capacidad de generar variaciones relativas del nivel del mar y de esta manera disminuir la tasa de acomodación disponible en una cuenca sedimentaria son los procesos tectónicos, los cuales también tienen influencia directa en la generación de material detrítico durante la exposición de

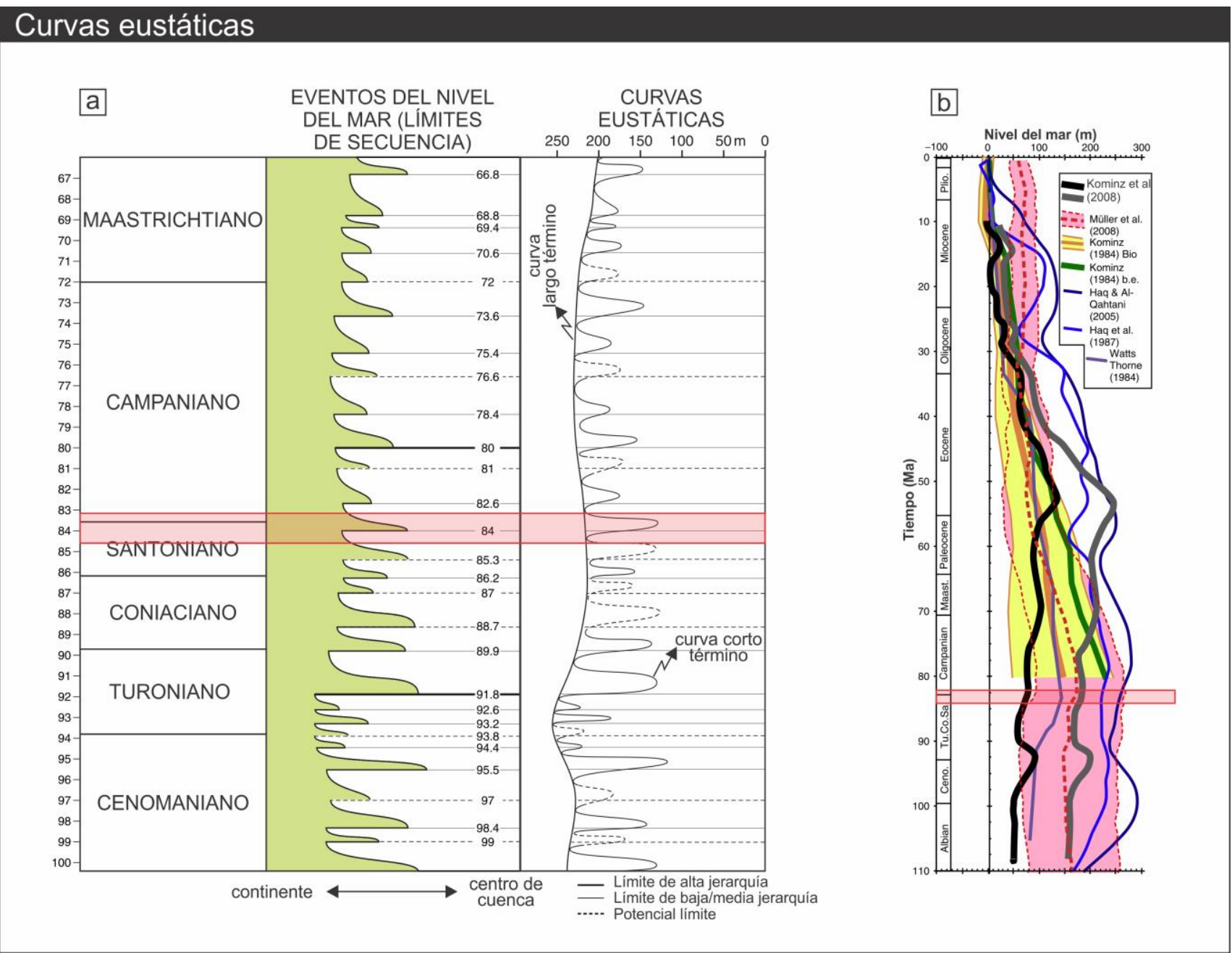

Figura 8.7. a) Curvas eustáticas propuestas por Haq et al. (2014) donde se pueden ver las variaciones de corto término y de largo término. b) Recopilación de curvas de largo termino para diferentes cuencas sedimentarias (modificado de Komiz et al., 2008). Los rectángulos rojos indican el posible lapso de caída del nivel de base asociado al límite de secuencia de la Formación La Anita.

áreas fuente (Vail et al., 1991). Por ejemplo, los procesos de alzamiento tectónico (uplift) y de denudación de las zonas de aporte de material clástico pueden generar ciclos regresivos-transgresivos de segundo y tercer orden. La subsidencia de la Cuenca Austral-Magallanes en el estadío de antepaís fue controlada por procesos tectónicos y por la carga del arco y la faja plegada y corrida (Fosdick et 
al., 2011, 2020; Sachse et al., 2015; Sickmann et al., 2019; Daniels et al., 2019). Entre los 88 y 74 Ma (Coniaciano-Campaniano) se produjo la deformación y generación de fallas inversas de la faja plegada y corrida que afectaron al Complejo El Quemado (Fosdick et al., 2011). A su vez, durante el Campaniano el Complejo El Quemado fue intruido por cuerpos plutónicos de alrededor de $80 \mathrm{Ma}$, desencadenando una migración hacia el este del arco magmático y de la deformación del antepaís (Calderón et al., 2009; Fosdick et al., 2011). La generación de fallas inversas y la reactivación de estructuras jurásicas del estadio extensional de la cuenca tenían una orientación axial al eje del foredeep de la Cuenca AustralMagallanes (Hubbard et al., 2008; Fosdick et al., 2011). De esta manera se postula que la intensa actividad tectónica asociada al arco magmático y a la faja plegada y corrida actuaron como el principal factor en el desarrollo de la caída relativa del nivel del mar que generó el límite de secuencia que separa la unidad superior de la unidad inferior de la Formación La Anita.

El crecimiento del arco magmático y de la faja plegada y corrida genera una carga que produce flexión en la corteza provocando que la misma se combe hacia abajo aumentando el espacio de acomodación (Heller et al., 1988; Varela, 2015). Durante estos momentos de levantamiento tectónico y de generación de espacio de acomodación las redes de drenaje no se llegan a integrar y actúan de manera ineficiente, siendo poco el sedimento que llega a ser transportado hasta las zonas distales de las cuencas (Heller et al., 1988; Leeder, 1993; Varela, 2015). Las principales superficies de inundación marina suelen estar asociadas a grandes pulsos de levantamiento y evolución de fallas inversas de la faja plegada y corrida (Kamola y Huntoon, 1995, Houston et al., 2000).

Por otro lado, durante los tiempos de actividad tectónica reducida (momentos de quietud tectónica,) la migración y crecimiento del arco y de la faja plega- 
da y corrida es menor lo que produce un rebote isostático de la corteza disminuyendo el espacio de acomodación (Heller et al., 1988, Watts, 1989). Sumado a la disminución del espacio de acomodación, durante los momentos de quietud tectónica se favorece la integración de las redes de drenaje fluvial y se produce la denudación de las zonas elevadas (Leeder, 1993; Schwarz et al., 2006; Varela, 2015). De esta manera durante los momentos de quietud tectónica se produce una importante caída en la relación de espacio de acomodación/aporte de sedimento.

Por otra parte, en cuanto al factor climático se infiere una posible variación en las condiciones paleoclimáticas a partir de las tendencias verticales de los argilominerales, debido principalmente a que en la unidad inferior hay una tendencia de mayor presencia de caolinita, mientras que en la unidad superior la presencia de caolinita disminuye y aumenta la presencia de esmectita (Figs. 7.4, 7.5, 7.6 y 7.7). Lo que podría asociarse a una evolución desde condiciones que se corresponden con climas tropicales con altas precipitaciones durante la acumulación de la unidad inferior hacia condiciones más templadas con precipitaciones moderadas durante la depositación de la unidad superior (Fig. 8.8; Thiry, 2000; Raigemborn et al., 2014; Varela et al., 2018). Esto se encuentra en concordancia con lo expresado por Friedrich et al. (2012) donde se postula una tendencia global de enfriamiento desde el Turoniano hasta el Campaniano medio. Se interpreta que el factor climático podría haber atenuado levemente las señales tectónicas especialmente durante la acumulación de la unidad superior (Fig. 8.8), desfavoreciendo a la denudación de las zonas elevadas e incorporando menor cantidad de material clástico en los sistemas de transferencia que alcanzaban la depositación en las zonas costeras (Romans et al., 2016). Sin embargo, la señal tectónica habría superado esta pequeña merma en las precipitaciones y 
la cantidad de material clástico aportado durante el momento de la acumulación de la unidad superior fue mayor al de la unidad inferior.

Por lo previamente expresado, se proponen cuatro estadios relacionados con momentos de levantamiento y quietud tectónica como principal control sobre la evolución de en las variaciones de espacio de acomodación y aporte de sedimento dentro de la Formación La Anita (Fig. 8.8). De este modo, se interpreta un primer momento asociado a un periodo de levantamiento tectónico y a la generación de espacio de acomodación producto de la carga del arco y de la faja plegada y corrida durante la acumulación de los depósitos de HST de la unidad inferior (t1; Fig. 8.8). Durante el t1 el levantamiento tectónico produjo que la tasa de creación espacio de acomodación fuera similar a la cantidad de sedimento que podría ser transportado hacia las líneas de costa debido a que las redes de drenaje de los sistemas fluviales no se encontraban integradas. Esto posiblemente promovió que gran cantidad de sedimento se acumulara al pie de las zonas elevadas y el material que era transportado hacia el sistema deltaico fuese relativamente menor (Heller et al., 1988; Leeder, 1993). De esta manera el material clástico que llegaba hacia la zona de desembocadura de los canales distributarios era fácilmente redistribuido por la acción de olas y esto a su vez se favorecía por la alta recurrencia de los eventos de tormenta.

El segundo momento se correspondería a un momento de quietud tectónica y de reducción en el espacio de acomodación (t2; Fig. 8.8). Durante este momento se produce un alivio en la carga que producían las zonas elevadas resultando en un rebote isostático que provoca la caída relativa del nivel del mar dejando parte de la plataforma expuesta y produciendo la erosión asociada al límite de secuencia que separa a la unidad inferior de la unidad superior de la Formación La Anita (Fig. 8.8; Heller et al., 1988; Varela, 2015). Para este tiempo, se da lugar 
t4: HST -

unidad superior

t3: TST -

unidad superior

t2: $L S T$ -

unidad superior

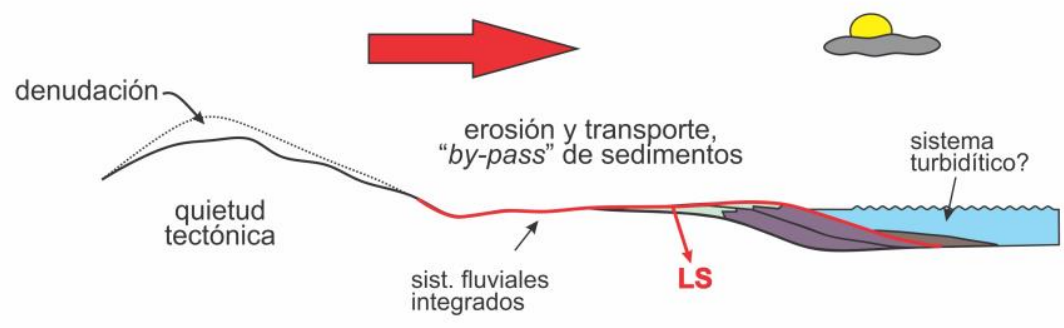

t1: HST -

unidad inferior

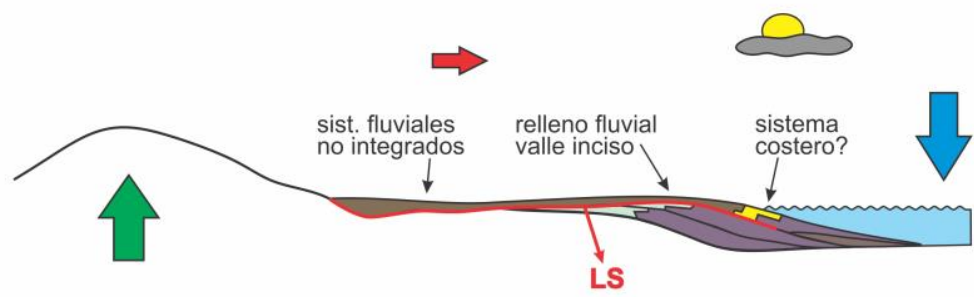

integrados
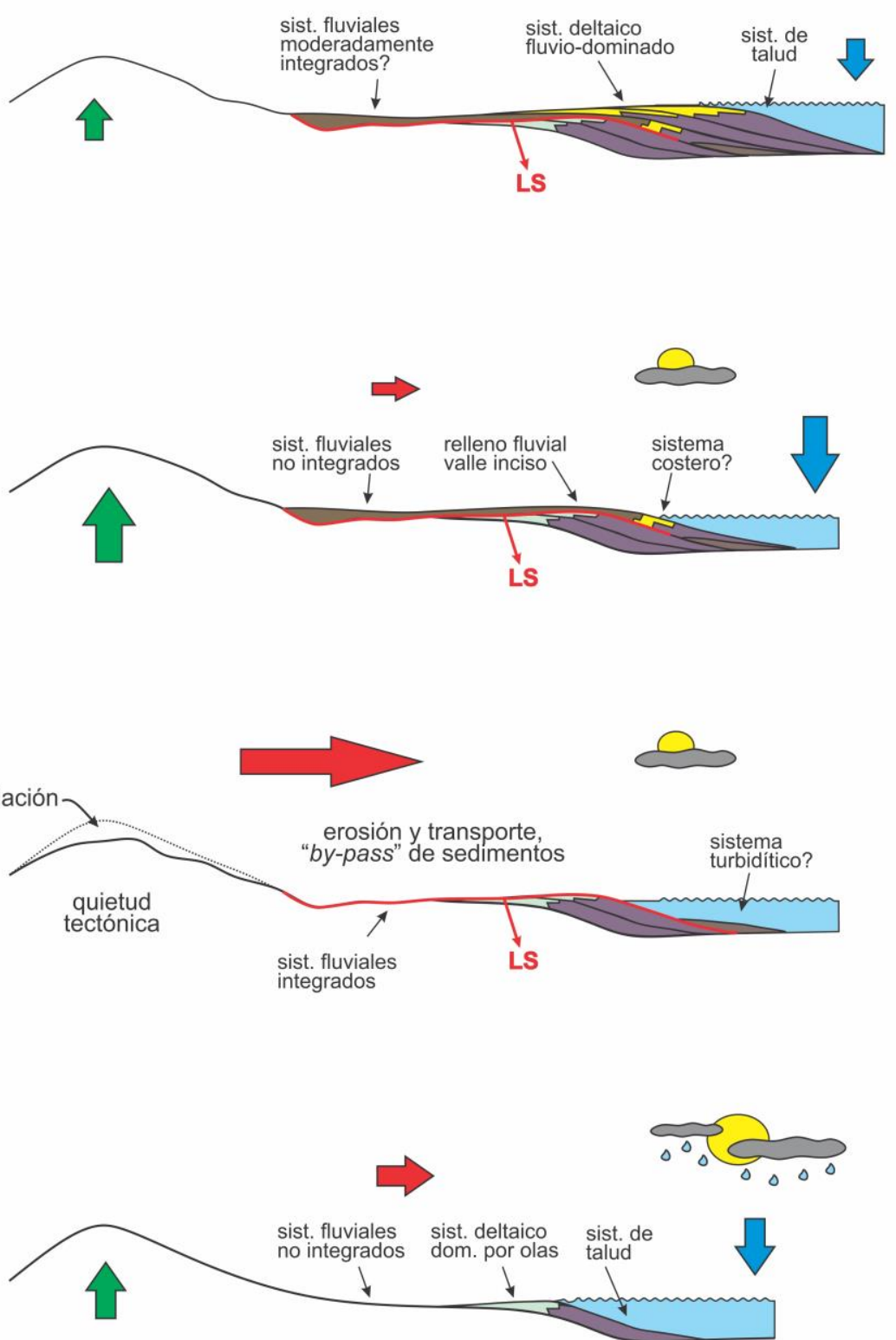

subsidencia aporte de sedimento

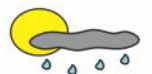
clima tropical clima templado y estacional

Figura 8.8. Esquema de la incidencia de los factores de control alocíclicos en la evolución temporal de la Formación La Anita.

a un dominio de los procesos de erosión y de transporte que provocan un "bypass" de sedimentos hacia el centro de la cuenca. Esto se deba a la integración de las redes de drenaje y a la erosión retrocedente de los sistemas fluviales, lo que 
explica la generación del valle inciso y la ausencia de depósitos asociados a un Cortejo de Mar Bajo dentro de la Formación La Anita (Fig. 8.8; Heller et al., 1988; Leeder, 1993; Catuneanu, 2006).

El comienzo de una fase transgresiva inmediatamente posterior a la fase erosiva tuvo lugar debido a un segundo pulso de levantamiento tectónico y/o reactivación de fallas inversas que provocó que la tasa de generación de espacio de acomodación sea mayor a la tasa de aporte de sedimento, provocando el inicio de la transgresión marina (t3; Fig. 8.8; Kamola y Huntoon, 1995, Houston et al., 2000). Durante este momento se produce la acumulación de los depósitos de relleno de canales fluviales dentro del valle incidido durante la fase erosiva (Fig. 8.8).

El cuarto y último momento que se propone para la evolución vertical de la Formación La Anita ocurre al finalizar el TST, luego de la SMI, y se correspondería con un nuevo evento de levantamiento tectónico y de generación de espacio de acomodación (t4; Fig. 8.8). Para este nuevo evento de levantamiento tectónico se propone que la tasa de crecimiento de las zonas positivas fue menor, o al menos de menor velocidad que los anteriores (Fig. 8.8). De esta manera, la menor jerarquía del proceso de levantamiento tectónico produciría consecuentemente que la tasa de aporte de sedimento sea mayor que la tasa de generación de espacio de acomodación (Fig. 8.8). Es por lo tanto que la menor tasa de levantamiento de crecimiento de zonas elevadas o de crecimiento más pausado provocó no solo que los sistemas fluviales sean más eficientes, sino que también ocurra mayor incorporación de material detrítico y que sea trasladado de manera más eficaz hacia las zonas costeras. Esta mayor efectividad en la transferencia de sedimentos hacia la línea de costa, acompañado de una menor recurrencia de eventos de tormenta producto de un clima más templado y estacional, resultó 
en que la dominancia de los procesos depositacionales para este sistema deltaico se encuentra asociada a procesos fluviales.

\subsection{EVOLUCIÓN PALEOGEOGRÁFICA}

El relleno del foredeep de la cuenca muestra una evolución desde un estadio de sub-relleno a un estadio de sobre-relleno, desde el Cenomaniano al Campaniano-Maastrichtiano, asociado a la progresiva continentalización desde el inicio de la fase de antepaís de la Cuenca Austral-Magallanes (Malkowski et al., 2017; Daniels et al., 2017; Sickmann et al., 2018; Moyano Paz et al., 2018; Tettamanti et al., 2018; Ghiglione et al., en prensa). Sin embargo, a partir de las reconstrucciones paleoambientales realizadas en los depósitos de la Formación La Anita, así como también del análisis estratigráfico secuencial de la unidad y de la incidencia de los factores de control, es que se plantean tres escenarios paleogeográficos diferentes que tuvieron lugar dentro de un contexto general de continentalización y de progradación de los sistemas hacia el sur-sudeste.

Una primera configuración paleogeográfica corresponde al momento del HST de la unidad inferior cerca del límite Coniaciano-Santoniano (t1; Fig. 8.9; Ghiglione et al., en prensa). La mayor tasa de subsidencia de la cuenca se encontraba hacia el sur, producto del levantamiento asimétrico de la Cordillera de los Andes, favoreciendo el desarrollo de sistemas marinos profundos de fondo abisal y de talud correspondientes a las formaciones Cerro Toro y Alta Vista respectivamente (Fig. 8.9; Hubbard et al., 2008). Los depósitos deltaicos dominados por ola de la Formación La Anita progradaron a una baja velocidad debido al equilibrio entre la tasa de generación de espacio de acomodación y la tasa de aporte de sedimentos durante este momento y a que los sistemas fluviales encargados de transferir el material clástico no se encontrarían integrados, facilitando la rápida redistribución de los sedimentos por la acción del oleaje (t1; 


\section{Evolución paleogeográfica de la región del Lago Argentino}

t1: delta dominado por olas,

influenciado por procesos

fluviales
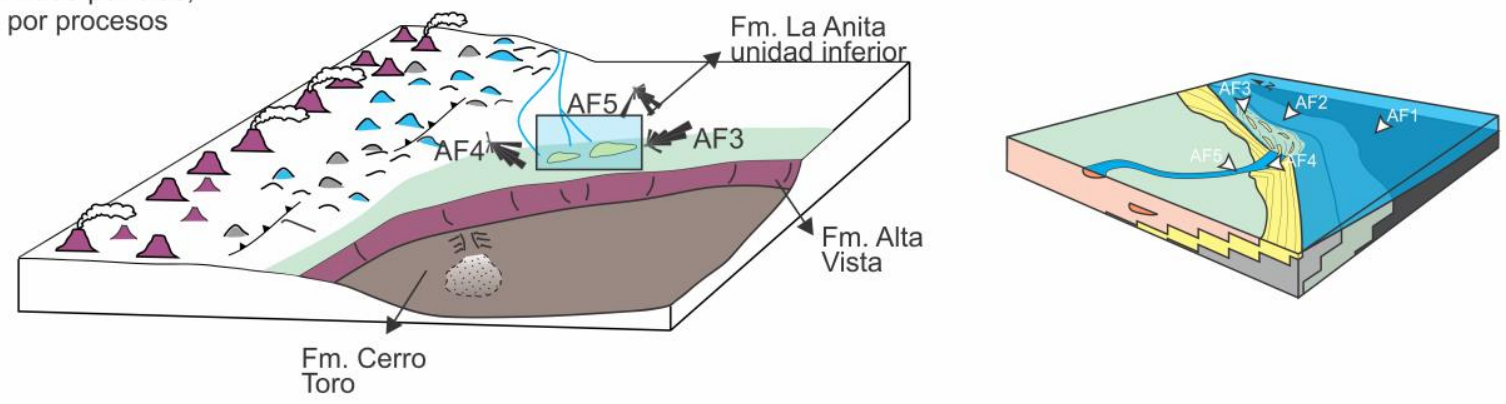

t2: erosión y generación del límite

de secuencia. Momento de no

depositación en la zona costera
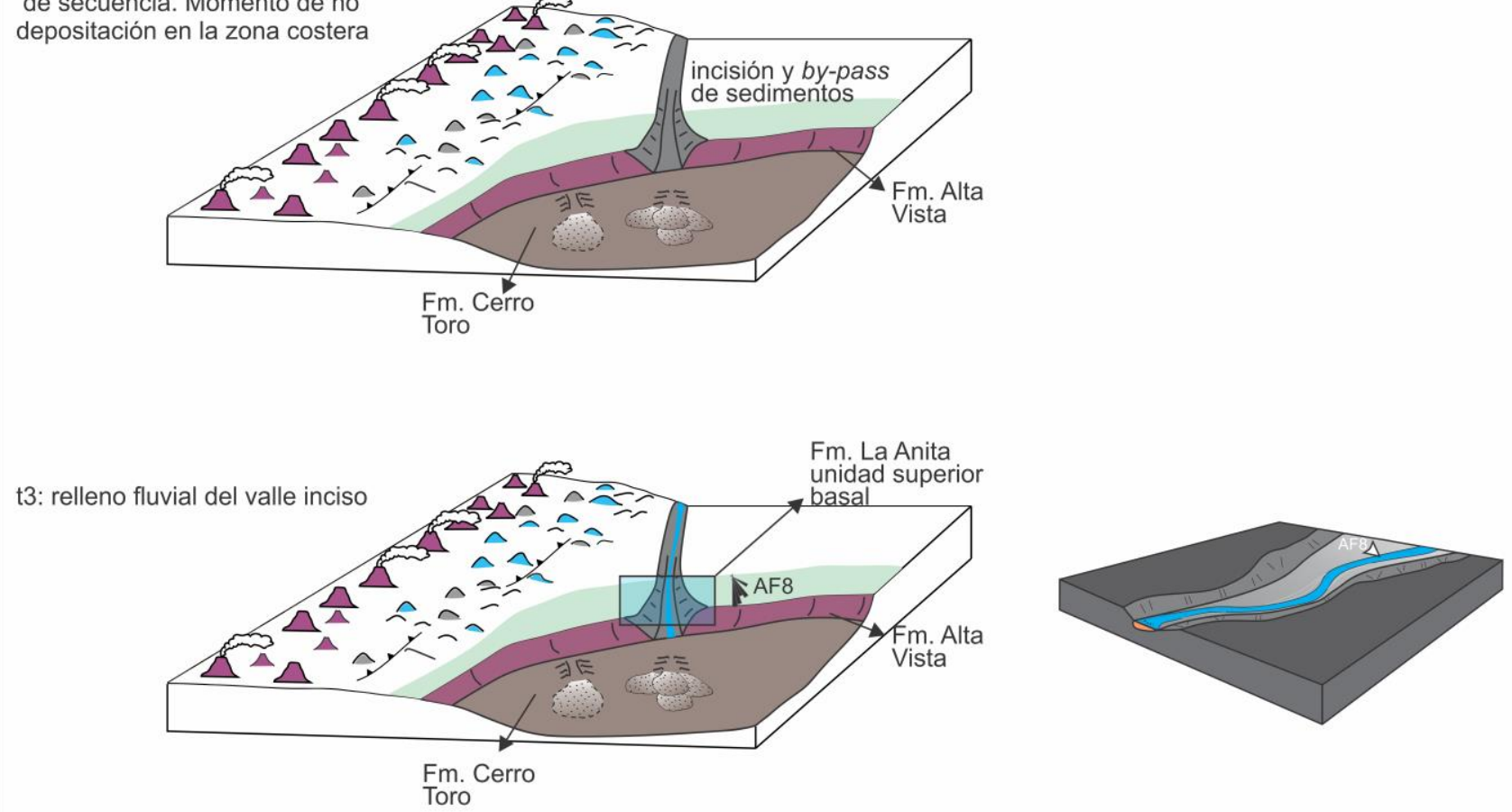

t4: delta fluvio-dominado,

influenciado por corrientes

de mareas
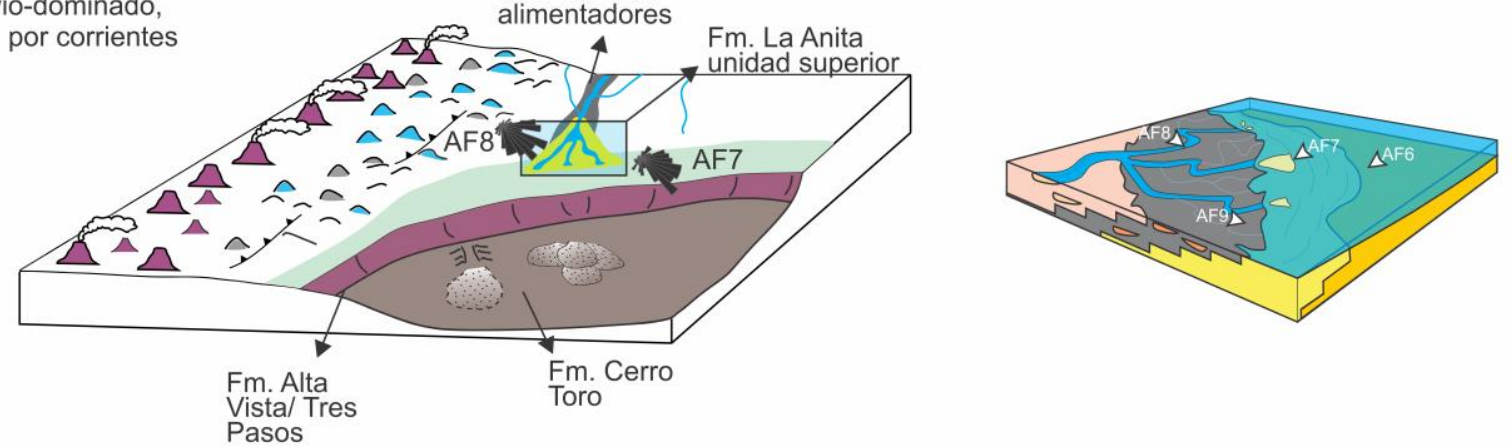

Figura 8.9. Reconstrucción de la paleogeografía de la Cuenca Austral-Magallanes durante la acumulación de los depósitos de la Formación La Anita. 
Figs. 8.8 y 8.9). Esta baja velocidad de progradación se ve reflejada en el patrón vertical de apilamiento de la unidad inferior el cual es dominantemente agradacional (Figs. 8.3 y 8.4 ).

Hacia principios del Campaniano una caída relativa del nivel del mar que gatilló el límite de secuencia de la Formación La Anita, el cual se interpreta aquí como el producto de un momento de quietud tectónica (t2; Figs. 8.8 y 8.9), impactó principalmente en las regiones costeras de la cuenca donde se generó la incisión de un valle (Fig. 8.9). Se propone que durante este momento de LST produjo la integración de los sistemas fluviales que tenían capacidad de transportar gran cantidad de material detrítico generado durante la denudación de las zonas elevadas, sin embargo, la sedimentación durante este momento estuvo restringida a las zonas más profundas de la cuenca, posiblemente como facies de abanicos submarinos y no se han reconocido depósitos de LST en las zonas costeras (Figs. 8.8 y 8.9). El relleno del valle inciso durante la fase transgresiva con depósitos fluviales que escurrían dominantemente hacia el sur, y que caracterizan el TST, marcan una tercera etapa de reconfiguración en la paleogeografía (t3; Fig. 8.9).

El fin de la fase transgresiva se encuentra trazado por la superficie de máxima inundación (SMI; Fig. 8.4) la cual se ubica por encima de los depósitos que constituyen el relleno del valle inciso y coincidiría con un momento en el cual se interpreta un aumento la tasa de generación de espacio de acomodación producto de un nuevo evento de levantamiento tectónico así como también de aporte de sedimentos (t4; Fig. 8.8) dando lugar a una nueva configuración paleogeográfica en la zona costera y en los sistemas continentales hacia los 83-80 Ma (t4; Fig. 8.9). Durante este cuarto y último momento se produjo una nueva reconfiguración de los sistemas depositacionales con la instalación del sistema 
deltaico fluvio-dominado e influenciado por corrientes de mareas, así como el desarrollo de sistemas fluviales progradación de los sistemas hacia el sudeste. 


\section{Capítulo IX \\ CONCLUSIONES}

Los depósitos de la Formación La Anita forman parte del relleno de la Cuenca Austral-Magallanes en su etapa de antepaís, gradan transicionalmente desde los depósitos de grano fino de talud de la Formación Alta Vista y son cubiertos a través de una superficie erosiva por los depósitos continentales del Cretácico Superior (UCCD). Su depositación comenzó en tiempos cercanos al límite Coniaciano-Santoniano (86 Ma) y continuó hasta los $\sim 80 \mathrm{Ma}$ en la zona de estudio. Las exposiciones de lo que se conoce como Formación La Anita se encuentran restringidas a la región del Lago Argentino. Los depósitos costeros que se conocen como Formación Dorotea al sur del área de estudio en Chile representan la continuación de la progradación de la línea de costa.

El análisis de facies sedimentarias realizado en este trabajo de tesis permitió reconocer 18 facies diferentes las cuales reflejan procesos de erosión y transporte de componentes extra e intracuentales hasta su acumulación. Se resalta la dominancia de los procesos depositacionales tractivos por encima de la acumulación por decantación de sedimentos finos transportados por suspensión. Estas 18 facies sedimentarias fueron agrupadas en 9 asociaciones de facies, según su distribución lateral y vertical dentro de litosomas con geometrías y características distintivas, las cuales representan la sedimentación en subambientes sedimentarios particulares. De esta manera, en este trabajo de tesis se definieron asociaciones de: Prodelta dominado por olas (AF1), Frente deltaico distal dominado por olas (AF2), Barras de desembocadura influenciadas por olas (AF3), Canales distributarios terminales (AF4), Canales distributarios (AF5), Frente deltaico distal fluvio-dominado (AF6), Barras de desembocadura fluvio-dominadas 
(AF7), Canales distributarios multiepisódicos de alta sinuosidad (AF8), y Áreas interdistributarias saturadas en agua (AF9). Estas asociaciones indican que tanto los procesos marinos (olas y mareas) como fluviales se encontraban activos y actuando con distinta intensidad durante la acumulación de la unidad.

A partir de la distribución espacial de las asociaciones de facies se propone dividir a la Formación La Anita en dos unidades informales, una inferior y una superior. La unidad inferior grada verticalmente desde las sedimentitas de grano fino de la formación Alta Vista, consiste en una sucesión dominantemente arenosa e incluye a las AF1, AF2, AF3, AF4 y AF5, y es truncada al tope por la superficie de erosión regional (SER). Por su parte, la unidad superior apoya inmediatamente sobre la superficie SER y consiste en una sucesión también dominantemente arenosa caracterizada por las AF6, AF7, AF8 y AF9, y es cubierta por los UCCD a través de una superficie erosiva. Se interpretaron 3 sistemas de acumulación responsables de la acumulación de los depósitos de la Formación La Anita. La unidad inferior refleja la depositación de sedimentos en un sistema deltaico dominado por olas e influenciado por procesos fluviales, mientras que para la unidad superior se interpretó un sistema de relleno fluvial de un valle inciso, inmediatamente por encima de la SER, y un sistema deltaico fluviodominado e influenciado por corrientes de marea.

El sistema deltaico dominado por olas de la unidad inferior presenta un patrón vertical de apilamiento dominantemente agradacional a levemente progradacional. La acción de los procesos de oleaje se encuentra muy bien representada en los sectores más distales del sistema acompañados por la abundante presencia de estructuras generadas durante eventos de tormenta. El acercamiento oblicuo del tren de olas hacia la costa favoreció que las barras de desembocadura se elonguen con una orientación paralela a la línea de costa y provocó 
que exista oblicuidad entre la dirección de migración de estas barras con respecto a las formas de lecho de los canales distributarios y canales terminales. La dirección de progradación de este sistema deltaico fue hacia el sudeste.

El sistema responsable del relleno fluvial del valle inciso se caracteriza por la amalgamación de cuerpos canalizados multiepisódicos que fluían dominantemente hacia el sur. Por encima de estos canales y separados por la superficie de máxima inundación marina (SMI) se desarrolla el sistema deltaico fluviodominado e influenciado por corrientes de mareas el cual presenta un patrón vertical de apilamiento de sus asociaciones de facies fuertemente progradante. La dominancia de los procesos fluviales se encuentra presente en todas las asociaciones de facies que conforman a este sistema de acumulación. La influencia de los procesos mareales se infiere principalmente por la instalación de condiciones de agua salobre dentro de los canales distributarios y en las áreas interdistributarias evidenciada por la presencia de trazas fósiles marinas. La dirección de progradación de este sistema deltaico era hacia el sudeste.

El análisis icnológico de detalle realizado en los sistemas deltaicos de la Formación La Anita permitió reconocer como operaban las condiciones de estrés fisicoquímico en los diferentes subambientes y su impacto en los organismos productores de trazas, y por ende en las trazas fósiles presentes. Las mayores intensidades de bioturbación, así como también la mayor diversidad de estructuras biogénicas se presentan en el sistema deltaico dominado por olas. Por su parte el sistema deltaico fluvio-dominado se caracteriza por presentar intensidades relativamente bajas y suites monoespecíficas de trazas. Para el sistema deltaico dominado por olas de la unidad inferior se interpreta que los principales factores que impactaron sobre la fauna bentónica fueron: reducción periódica de la oxigenación (AF1 y AF2), elevada turbidez del agua (AF1, AF2 y AF3), 
eventos de tormenta (AF1, AF2 y AF3), flujos rápidos de sedimentos (AF1, AF2, AF3, AF4 y AF5), cambios de salinidad (AF3, AF4 y AF5), y avulsión de canales (AF4 y AF5). Por otra parte, para el sistema deltaico de la unidad superior se interpretó la siguiente distribución de condiciones de estrés fisicoquímico: reducción periódica de la oxigenación (AF6 y AF9), sedimentación episódica (AF6), elevada turbidez del agua (AF6, AF7 y AF8), flujos rápidos de sedimentos (AF6, AF7 y AF8), y avulsión de canales (AF8). Se resalta la capacidad de la acción del oleaje para dispersar los estreses producidos por las descargas fluviales, generando condiciones más favorables para la colonización de los sustratos por parte de los organismos productores de trazas. También se destaca el uso de la icnología y la detección de condiciones de estrés como una herramienta clave para el reconocimiento de sistemas deltaicos fósiles y su diferenciación con otros sistemas costeros.

Los estudios petrográficos de las 27 láminas delgadas correspondientes a muestras de areniscas de la Formación La Anita permitieron reconocer un total de 7 componentes detríticos principales: cuarzos monocristalinos, feldespatos potásicos, plagioclasas, cuarzos policristalinos, líticos volcánicos, líticos sedimentarios y fitodetritos. Los porcentajes en los cuales se presentan estos componentes fueron recalculados para la utilización de diagramas ternarios composicionales y de esta manera todas las muestras fueron clasificadas como Litoarenitas (Folk et al., 1970) y como Arenitas líticas (Dott 1964; Pettijohn et al., 1972). El estudio de 82 muestras por DRX permitió reconocer en los diagramas de roca total, en orden decreciente de abundancia: cuarzo, plagioclasa, feldespato potásico, arcilla, calcita y dolomita. Por otro lado, en el estudio de la fracción arcilla se reconocieron proporciones variables de caolinita, illita, interestratificados de illita esmectita, clorita, esmectita e interestratificados de clorita esme- 
ctita. A partir del análisis petrográfico y de DRX no se reconocen diferencias significativas entre los componentes detríticos de la unidad inferior y de la superior. Sin embargo, en el estudio de la fracción arcilla se destaca un incremento en la proporción de esmectita en detrimento de la caolinita en la unidad superior con respecto a la unidad inferior. Se propone que este enriquecimiento en esmectita sugiere la influencia de un control climático en la composición de estos depósitos evolucionando desde condiciones de clima tropical, cálido y húmedo con abundantes precipitaciones, hacia condiciones de climas más templados y estacionales para la unidad superior.

Del análisis de procedencia de las areniscas de la Formación La Anita se interpreta que las muestras analizadas muestran afinidad con una zona de orógeno reciclado en los diagramas ternarios de Dickinson et al. (1983) y Dickinson (1988). A partir de la combinación de estos resultados obtenidos en los diagramas ternarios con las direcciones de paleoflujo medidos en las estructuras sedimentarias mecánicas se propone que las zonas elevadas que funcionaron como fuente de material clástico durante el momento de la acumulación de la Formación La Anita se encontraban asociadas a elevaciones del Complejo El Quemado y del arco magmático que se desarrolló hacia fines del Cretácico.

El estudio de la diagénesis de estos depósitos permitió identificar 9 procesos diagenéticos: compactación, disolución, autigénesis de arcillas, cementación hematítica, revestimiento o coating de arcillas, cementación cuarzosa, cementación calcítica, migración de bitumen y piritización. Se destaca la dominancia de procesos que desencadenan en una disminución del espacio poral por sobre el aumento de este. Se destaca también, que los sedimentos de la Formación La Anita alcanzaron una etapa de mesogénesis temprana durante su soterramiento. 
Se interpreta a la superficie SER que separa a las dos unidades como un límite de secuencia gatillado por una caída relativa del nivel del mar y por lo tanto las dos unidades forman parte de dos secuencias depositacionales, las cuales no se encuentran genéticamente relacionadas. Los depósitos deltaicos dominados por olas de la unidad inferior, los cuales gradan verticalmente desde los depósitos de grano fino de talud de la Formación Alta Vista, se interpretan como parte de un Cortejo de Mar Alto (HST) por su patrón vertical de apilamiento y por su posición inmediatamente debajo del límite de secuencia. Por otra parte, los depósitos que constituyen a la unidad superior forman parte de un ciclo del nivel del mar completo. No se reconocen en el área de estudio depósitos del Cortejo de Mar Bajo (LST), ya que se interpreta que durante esta etapa en la zona costera hubo un dominio de procesos de erosión y de "by-pass" de sedimentos hacia el centro de la cuenca siendo los rasgos de erosión la única señal del $L S T$. El intervalo más basal de esta unidad, caracterizado por el relleno fluvial de un valle inciso se interpreta como un Cortejo Transgresivo (TST). Este intervalo de TSTse encuentra delimitado al tope por la SMI la cual es seguida por la aparición de los depósitos de frente deltaicos fluvio-dominados. Estos depósitos deltaicos con un patrón de apilamiento fuertemente progradante se interpretan como el $H S T$ de esta secuencia. El contacto de la Formación La Anita con los depósitos continentales de las formaciones Cerro Fortaleza y La Irene se interpreta como otro límite de secuencia.

Estos cambios en la arquitectura secuencial son el resultado de variaciones en la relación de la tasa de creación de espacio de acomodación y la tasa de aporte de sedimentos. Se interpreta que la intensa actividad tectónica asociada al desarrollo del arco magmático y de la faja plegada y corrida actuaron como el principal factor de control en el desarrollo no solo de la caída relativa del nivel 
del mar y la generación del límite de secuencia, sino también en el control sobre el espacio de acomodación disponible y la cantidad de aporte de sedimento. De este modo, se interpretan cuatro estadios en la evolución temporal de la Formación La Anita, los cuales están relacionados con momentos de levantamiento y de quietud tectónica como principal control sobre las variaciones de espacio de acomodación y aporte de sedimento. El factor climático también jugó un rol importante; como se mencionó anteriormente se interpreta una variación en las condiciones paleoclimáticas a partir de las tendencias verticales de los argilominerales, evolucionando desde condiciones de climas tropicales con altas precipitaciones durante la acumulación de la unidad inferior hacia condiciones más templadas con precipitaciones moderadas durante la depositación de la unidad superior. Sin embargo, el impacto del control climático se ve reflejado más fuertemente en la dinámica de los sistemas deltaicos, tanto en la recurrencia de los eventos de tormenta de la unidad inferior y en la sedimentación episódica del sistema deltaico fluvio-dominado de la unidad superior. Esta variación en las condiciones paleoclimáticas podría haber atenuado levemente las señales tectónicas especialmente durante la acumulación de la unidad superior desfavoreciendo la denudación de las zonas elevadas producto de la disminución de las precipitaciones. Sin embargo, se interpreta que la magnitud de la señal tectónica supero esta merma en las precipitaciones y controlo la cantidad de material clástico aportado.

Los cuatro momentos con diferentes relaciones de espacio de acomodación y aporte de sedimento que se proponen son: un primer momento asociado a un periodo de levantamiento tectónico y a la generación de espacio de acomodación producto de la carga del arco y de la faja plegada y corrida durante la depositación del HST de la unidad inferior (t1). Durante este primer momento, el le- 
vantamiento produjo que la tasa de creación espacio de acomodación sea similar a la cantidad de sedimento que podría ser transportado hasta la línea de costa. El segundo momento se corresponde a un momento de quietud tectónica y de reducción del espacio de acomodación (t2). Durante este momento dominaron los procesos de erosión en las zonas elevadas produciendo el alivio de la carga tectónica y un consecuente rebote isostático que provocó la caída relativa del nivel del mar. Bajo estas condiciones se favoreció la integración de los sistemas fluviales los cuales transportaban el material clástico hacia el centro de cuenca. El comienzo de la fase transgresiva posterior a la erosión se encuentra vinculado a un nuevo evento de creación de espacio de acomodación para el cual la tasa de aporte de sedimentos era considerablemente baja y se produjo el relleno fluvial de los valles incididos que caracterizan el TST(t3). El cuarto y último momento que se propone en la evolución vertical de la Formación La Anita ocurre al finalizar el TSTy se corresponde con un nuevo evento de levantamiento tectónico y de generación de espacio de acomodación (t4). Durante este último momento, la tasa de crecimiento de las zonas elevadas fue menor provocando que la tasa de generación de espacio de acomodación también sea menor y que los sistemas fluviales transporten el material clástico de una manera más eficiente hacia las zonas costeras. 


\section{REFERENCIAS BIBLIOGRÁFICAS}

AINSWORTH, R.B., FLINT S.S., HOWELL J.A., 2008. Predicting coastal depositional style: Influence of basin morphology and accommodation to sediment supply ratio within a sequence stratigraphic framework. En: G.J. Hampson, R.J. Steel, P.B. Burgess and R.W. Dalrymple (Eds.), Recent Advances in Models of Siliciclastic Shallow-Marine Stratigraphy. Society for Sedimentary Geology, Special Publication, 90: 237-263.

AINSWORTH, R.B., VAKARELOV, B.K., NANSON R.A., 2011. Dynamic spatial and temporal prediction of changes in depositional processes on clastic shorelines: Toward improved subsurface uncertainty reduction and management. AAPG Bulletin 95: 267-297.

AINSWORTH, R.B., VAKARELOV, BK., MACEACHERN, J.A., NANSON, R.A., LANE, T.I., RARITY F., DASHTGARD, S.E., 2016. Process-driven architecture variability in mouth-bar deposits: a case study from a mixed-process mouth-bar complex, Drumheller, Alberta, Canada. Journal of Sedimentary Research 86, 512541.

AINSWORTH, B.R., VAKARELOV, B.K., EIDE, C.H., HOWELL, J.A., BOURGET, J., 2019. Linking the high-resolution architecture of modern and ancient wavedominated deltas: Processes, products, and forcing factors. Journal of Sedimentary Research 89: 168-185.

ALEXANDER, C.R., DEMASTER, D.J., NITTROUER, C.A., 1991. Sediment accumulation in modern epicontinental shelf setting: the Yellow sea. Marine Geology 98: 51-72.

ALLEN, J.R.L., 1982. Studies in fluvialite sedimentation: bars, bar complexes and sandstone sheets (low-sinousity braided streams) in the Brownstones (L. Devonian), Wish Borderds. Sedimentary Geology 33: 237-293.

ARBE, H.A., 1986. Estratigrafía, discontinuidades y evolución sedimentaria del Cretácico en la Cuenca Austral, Prov. De Santa Cruz. En: Chebli G., Spalletti, L.A. (Eds.) Cuencas Sedimentarias Argentinas. Instituto Superior de Correlación Geológica, Universidad Nacional de Tucumán, Serie de Correlación Geológica 6: 419-442. 
ARBE, H.A., 2002. Análisis estratigráfico del Cretácico de la Cuenca Austral. En: M.J. Heller (Ed.), Geología y Recursos Naturales de Santa Cruz. XV Congreso Geológico Argentino 103-128.

ARBE, H.A., HECHEM, J., 1984. Estratigrafía y facies de depósitos continentales, litorales y marinos del Cretácico superior, lago Argentino. Actas IX Congreso Geológico Argentino 7: 124-158.

ARBE, H., FERNÁNDEZ BELL FANO, F., 2002. Formación Springhill en el área costa afuera. En: M., Schiuma, G., Hinterwimmer and G., Vergani, (Eds.), Rocas Reservorio de las Cuencas Productivas Argentinas, V Congreso de Exploración y Desarrollo de Hidrocarburos, Mar del Plata, 75-89.

ARNOTT, R.W.C., SOUTHARD, J.B., 1990. Exploratory flow-duct experiments on combined-flow bed configurations, and some implications for interpreting storm-event stratification. Journal of Sedimentary Research 60: 211-219.

ARREGUI, M.G., BUATOIS, L.A., RODRIGUEZ, E., 2019. Shrimps and leaves: phytodetrital pulses and bioturbation in deposits of a river-dominated delta (Middle Jurassic Lajas Formation, Neuquén basin, Argentina). Palaeogeography, Palaeoclimatology, Palaeoecology 516: 179-189.

ASQUITH, D.O., 1970. Depositional topography and major marine environments, Late Cretaceous, Wyoming. AAPG Bulletin 54: 1184-1224.

ASQUITH, D.O., 1974. Sedimentary models, cycles, and deltas, Upper Cretaceous, Wyoming. AAPG Bulletin 58: 2274-2283.

BANN, K.L., FIELDING, C.R., MACEACHERN, J.A., TYE, S.C., 2004. Differentiation of estuarine and offshore marine deposits using integrated ichnology and sedimentology: Permian Pebbly Beach Formation, Sydney Basin, Australia. En: McIlroy, D. (Ed.), The Application of Ichnology to Palaeoenvironmental and Stratigraphic Analysis. The Geological Society of London, Special Publication, 228: 179-211.

BANN, K.L., TYE, S.T., MACEACHERN, J.A., FIELDING, C.R., JONES, B.G., 2008. Ichnological and sedimentologic signatures of mixed wave- and stormdominated deltaic deposits: examples from the early Permian Sydney Basin, Australia. En: G.J. Hampson, R.J. Steel, P.B. Burgess y R.W. Dalrymple (Eds.), Recent Advances in Models of Siliciclastic Shallow-Marine Stratigraphy. Society for Sedimentary Geology, Special Publication, 90: 293-332. 
BARNES, R. S. K. 1989. What, if anything, is a brackish-water fauna?. Earth and Environmental Science Transactions of The Royal Society of Edinburgh, 80(3-4): 235-240.

BARRON, E.J., HAY, W.W., THOMPSON, S., 1989. The hydrologic cycle. A major variable during Earth history. Palaeogeography, Palaeoclimatology, Palaeoecology 75: 157-174.

BAUER, D.B., HUBBARD, S.M., COVAULT, J.A., ROMANS, B.W., 2020. Inherited depositional topography control on shelf-margin oversteepening, readjustment, and coarse-grained sediment delivery to deep water, Magallanes Basin, Chile. Frontiers in Earth Science, 7, 358.

BENYON, B.M., PEMBERTON, S.G., BELL, D.A., LOGAN, C.A., 1988. Environmental implications of ichnofossils from the lower cretaceous grand rapids formations, cold lake oil sands deposits. En: James, D.P., Leckie, D.A. (Eds.), Sequences, Stratigraphy, Sedimentology: Surface and Subsurface. Canadian Society of Petroleum Geologists, Memoir, 275-290.

BERNER, R.A., 1984. Sedimentary pyrite formation: an update. Geochimica et Cosmochimica Acta 48: 605-615.

BEYNON, B.M., PEMBERTON, S.G., 1992. Ichnological signature of brackish water deposit, an example from the Lower Cretaceous Grand Rapids Formation, Cold Lake oil sands area, Alberta. En: Pemberton, S.G. (Ed.), Applications of Ichnology to Petroleum Exploration: A Core Workshop. Society for Sedimentary Geologists, 17: 199-221.

BHATTACHARYA, J.P. 1993. The expression and interpretation of marine flooding surfaces and erosional surfaces in core; examples from the Upper Cretaceous Dunvegan Formation, Alberta foreland basin, Canada. Sequence stratigraphy and facies associations, 125-160.

BHATTACHARYA, J.P., 2006. Deltas. En: Posamentier, H.W., Walker, R.G. (Eds.), Facies Models, Society for Sedimentary Geology, Special Publication, 84: 237-292.

BHATTACHARYA, J.P., 2010. Deltas. En: R.W. Dalrymple and N.P. James (Eds), Facies Models, Fourth Edition, 233-262.

BHATTACHARYA, J.P., GIOSAN, L., 2003. Wave-influenced deltas: geomorphological implications for facies reconstruction. Sedimentology, 50: 187-210. 
BHATTACHARYA, J.P., MACEACHERN, J.A., 2009. Hyperpycnal rivers and prodeltaic shelves in the Cretaceous seaway of North America. Journal of Sedimentary Research 79: 184-209.

BIDDLE, K., ULIANA, M., MITCHUM, R. JR., FITZGERALD M., WRIGHT, R., 1986. The stratigraphic and structural evolution of central and eastern Magallanes Basin, Southern America. En: P. Allen and P. Homewoods (Eds.), Foreland basins. International Association of Sedimentologists, Special Publication 8: 4161.

BISCAYE, P.E., 1965. Mineralogy and sedimentation of recent deep-sea clay in the Atlantic Ocean and adjacent seas and oceans. Geological Society of America Bulletin 76: 803-832.

BLATT, H., 1992. Sedimentary Petrology. W.H. Freeman and company, New York, $514 \mathrm{pp}$.

BLUM, M.D., TÖRNQVIST, T.E., 2000. Fluvial responses to climate and sea-level change: a review and look forward. Sedimentology 47: 2-48.

BLUM, M.D., ASLAN, A., 2006. Signatures of climate vs. sea-level change within incised valley-fill successions: quaternary examples from the Texas Gulf Coast. Sedimentary Geology 190: 177-211.

BOYD, R., DALRYMPLE, R., ZAITLIN, B.A., 1992. Classification of clastic coastal depositional environments. Sedimentary Geology, 80: 139-150.

BRIDGE, J.S., 1997. Thickness of sets of cross strata and planar strata as function of formative bed-wave geometry and migration, and aggradation rate. Geology 25 (11): 971-974.

BRIDGE, J.S., DEMICCO, R., 2008. Earth surface processes, landforms and sediment deposits. Cambridge University Press, 815 pp.

BRIDGE, J. S., JALFIN G.A., GEORGIEFF, S.M., 2000. Geometry, lithofacies, and spatial distribution of cretaceous fluvial sandstone bodies, San Jorge Basin, Argentina: outcrop analog for the hydrocarbon-bearing Chubut Group. Journal of Sedimentary Research, 70 (2): 341-359.

BRINDLEY, G.W., 1961. Experimental Methods. En: Brown, G. (Ed.), The X-Ray identification and crystal structure of Clay Minerals. Mineralogical Society, 1-50. 
BRINDLEY, G.W., BROWN, G., 1980. Quantitative X-ray mineral analysis of clays. Crystal structures of clay minerals and their X-ray identification, 5: 411-438.

BROMLEY, R.G., 1990. Trace Fossils: Biology and Taphonomy. Unwin Hyman, Londres, $280 \mathrm{pp}$.

BROMLEY, R.G., 1996. Trace Fossils: Biology, Taphonomy and Applications, Second Edition. Champan and Hall, Londres, $361 \mathrm{pp}$.

BROWN, L.F.JR., FISHER, W.L., 1977. Seismic stratigraphic interpretation of depositional systems: examples from Brazilian rift and pull apart basins. En: Payton, C.E. (Ed.), Seismic Stratigraphy-Applications to Hydrocarbon Exploration, AAPG Memoir 26: 213-248.

BRUCE, R.M., NELSON, E.P., WEAVER, S.G., LUX, D.R., 1991, Temporal and spatial variations in the southern Patagonian batholith; constraints on magmatic arc development. En: Harmon, R.S., Rapela, C.W., (Eds.), Andean Magmatism and its Tectonic Setting. GSA Special Paper 265: 1-12

BUATOIS, L.A., MÁNGANO, M.G., 2011. Ichnology: Organism-Substrate Interactions in Space and Time. Cambridge University Press, 358 pp.

BUATOIS, L.A., SANTIAGO, N., HERRERA, M., PLINK-BJÖRKLUND, P., STEEL, R.J., ESPIN, M., PARRA, K., 2012. Sedimentological and ichnological signatures of changes in wave, river and tidal influence along a Neogene tropical deltaic shoreline. Sedimentology 59: 1568-1612.

BUATOIS, L.A., MÁNGANO, M.G., PATTINSON, A.J., 2019. Ichnology of prodeltaic hyperpycnite-turbidite channel complexes and lobes from the Upper Cretaceous Prairie Canyon Member of the Mancos Shale, Book Cliffs, Utah, USA. Sedimentology 66: 1825-1860.

BURGESS, P.M., 2016. RESEARCH FOCUS: The future of the sequence stratigraphy paradigm: Dealing with a variable third dimension. Geology, 44(4): 335-336.

BURLEY, S.D., WORDEN, R.H., 2003. Sandstones Diagenesis Recent and Ancient. Burley, S., Worden R. (Eds.). International Association of Sedimentologists Special Publication 4: 3-44.

CALDERÓN, M., FOSDICK, J., ALVAREZ, J., SÁNCHEZ, A., GALAZ, G., 2009, Doubly-vergent structures in metamorphic rocks that enclose the Sarmiento 
ophiolite complex at Senos Lolos and Encuentros, southern Patagonian Andes (51-52 ${ }^{\circ}$ S): Congreso Geológico Chileno Proceedings, p. S8-004

CALDERÓN, M., HERVÉ, F., FUENTES, F., FOSDICK, J.C., SEPÚLVEDA F., GALAZ, G., 2016. Tectonic evolution of Paleozoic and Mesozoic andean metamorphic complexes and the Rocas Verdes ophiolites in southern Patagonia. En: Ghiglione, M.C. (Ed.), Geodynamic Evolution of the Southernmost Andes. Springer, Cham, pp. 7-36.

CARMONA, N.B., BUATOIS, L.A., PONCE, J.J., MÁNGANO, M.G., 2009. Ichnology and sedimentology of a tide-influenced delta, Lower Miocene Chenque Formation, Patagonia, Argentina: trace-fossil distribution and response to environmental stresses. Palaeogeography, Palaeoclimatology, Palaeoecology 273: 75-86.

CANALE, N., PONCE, J.J. CARMONA, N.B., DRITTANTI, D.I., OLIVERA, D.E., MARTÍNEZ, M.A., BOURNOD, C.N., 2015. Sedimentología e Ichnología de deltas fluvio-dominados afectados por descargas hiperpícnicas de la Formación Lajas (Jurásico Medio), Cuenca Neuquina, Argentina. Andean Geology 42 (1): 114-138.

CANALE, N., PONCE, J., CARMONA, N., PARADA, M., DRITTANTI, D., 2020, Sedimentology and ichnology of a river-dominated delta, Lajas Formation (Middle Jurassic), Neuquén basin, Argentina. Andean Geology 47 (1): 179-206.

CATUNEANU, O., 2003. Sequence Stratigraphy of Clastic Systems. Geological Association of Canada, Short Course Notes, Vol. 16, p. 248.

CATUNEANU, O, 2006. Principles of sequence stratigraphy, Amsterdam, Elsevier $386 \mathrm{pp}$.

CATUNEANU, O., ABREU, V., BHATTACHARYA, J.P., BLUM, M.D., DALRYMPLE, R.W., ERIKSSON, P.G., FIELDING, C.R., FISHER, W.L., GALLOWAY, W.E., GIBLING, M.R., GILES, K.A., HOLBROOK, J,M., JORDAN, R., KENDALL, C.G.ST.C., MARCUDA, B., MARTINSEN, O.J., MIALL, A.D., NEAL, J.E., NUMMEDAL, D., POMAR, L., POSAMENTIER, HW., PRATT, B.R., SARG, J.F., SHANLEY, K.W., STEEL, R.J., STRASSER, A., TUCKER, M.E., WINKER, C., 2009. Towards the standardization of sequence stratigraphy. Earth Science Reviews 92: 1-33.

CAVAZZA, W., AND INGERSOLL, R.V., 2005, Detrital modes of the Ionian Forearc Basin fill (Oligocene-Quaternary) reflect the tectonic evolution of the 
Calabria-Peloritani Terrane (Southern Italy): Journal of Sedimentary Research 75: 268-279.

Cereceda, A., 2016. Sedimentología de los depósitos marinos de las formaciones Cerro Toro y Alta Vista, Cretácico Superior, Cuenca Austral. Tesis Doctoral, Universidad Nacional de La Plata, La Plata. 271 pp.

CHAMLEY, H., 1989. Clay Sedimentology. Springer, Berlin, 623 pp.

CHARVIN, K., HAMPSON, G.J. GALLAGHER, K.L. LABOURDETTE, R., 2010. Intra-parasequence architecture of an interpreted asymmetrical wavedominated delta. Sedimentology, 57: 760-785.

CHOQUETTE, P.W., PRAY, L.C., 1970. Geologic nomenclature and classification of porosity in sedimentary carbonates. AAPG Bulletin, 54(2): 207-250.

CLIFTON, H.E., 2006. A reexamination of facies models for clastic shorelines. In: H.W. Posamentier and R.G. Walker (Eds.), Facies Models, Society for Sedimentary Geology, Special Publication 84: 293-337.

COATES, L., MACEACHERN, J.A., 1999. The ichnological signature of wave- and river-dominated deltas: dunvegan and Basal Belly River formations, WestCentral Alberta. En: Wrathall, B., Johnston, G., Arts, A., Rozsw, L., Zonneveld, J.P., Arcuri, D., McLellan, S. (Eds.), Digging Deeper, Finding a Better Bottom Line. Canadian Society of Petroleum Geologists \& Petroleum Society, Core Conference, 99-114.

COATES, L., MACEACHERN, J.A., 2000. Differentiating River- and WaveDominated Deltas from Shorefaces: Examples from the Cretaceous Western Interior Seaway, Alberta, Canada. GeoCanada 2000, Millennium Geoscience Summit, Calgary, Alberta, Extended Core Conference Abstract, Sin compaginar.

COLLINS, D.S., JOHNSON, H.D., ALLISON, P.G., DAMIT, A.R., 2017. Coupled 'storm-flood' depositional model: application to the miocene-modern baram delta province, northwest borneo. Sedimentology 64: 1203-1235.

COLLINS, S.D., JOHNSON, H.D., ALLISON, P.A., DAMIT, A.R., 2018. Mixed process, humidtropical, shoreline-shelf deposition and preservation: Middle miocene-modern baram delta province, northwest borneo. Journal of Sedimentary Research 88: 399-430.

COLLINS, S.D., JOHNSON, H.D., BALDWIN, C.T., 2019. Architecture and preservation in the fluvial to marine transition zone of a mixed-process humid- 
tropical delta: Middle Miocene Lambir Formation, Baram Delta Province, northwest Borneo. Sedimentology 67: 1-46.

COLLINSON, J.D., 1969. The sedimentology of the Grindslow Shales and the Kinderscout Grit: a deltaic complex in the Namurian of northern England. Journal of Sedimentary Petrology 39: 194-221.

COLLINSON, J.D., THOMPSON, D., 1989. Sedimentary Structures, Second Edition. Chapman y Hall, London, 207 pp.

COLLINSON, J.D., MOUNTNEY, N., THOMPSON, D., 2006. Sedimentary Structures. Tercera Edición. Terra Publishing, Herpenden, England, 292 pp.

CRITELLI, S., INGERSOLL, R.V., 1994. Sandstone petrology and provenance of the Siwalik Group (northwestern Pakistan and western-southeastern Nepal). Journal of Sedimentary Research 64(4): 815-823.

CUITIÑO J.I., VARELA, A.N., GHIGLIONE, M.C., RICHIANO, S., POIRÉ, D.G., 2019. The Austral-Magallanes Basin (southern Patagonia): a synthesis of its stratigraphy and evolution. Latin American Journal of Sedimentology and Basin Analysis 26 (2): 155-166.

DALRYMPLE, R.W., ZAITLIN, B.A., BOYD, R., 1992. Estuarine facies models: conceptual basis and stratigraphic implications. Journal of Sedimentary Petrology 62: 147-173.

DALRYMPLE, R.W., 2010. Interpreting sedimentary successions: facies, facies analysis and facies models. En: James, N.P., Dalrymple, R.W. (Eds.) Facies models, Fourth Edition, 3-18.

DALZIEL, I.W.D., 1981. Back-arc extension in the southern Andes: A review and critical reappraisal. Royal Society of London Philosophical Transactions 300: 319335.

DANIELS, B.G., AUCHTER, N.C., HUBBARD S.M., ROMANS, B.W., MATTHEWS, W.A., STRAIGHT, L., 2017. Timing of deep-water slope evolution constrained by large-n detrital and volcanic ash zircon geochronology, Cretaceous Magallanes Basin, Chile. GSA Bulletin, 130: 438-454.

DANIELS, B.G., HUBBARD, S.M., ROMANS, B.W., MALKOWSKI, M.A., MATTHEWS, W.A., BERNHARDT, A., KAEMPFE, S.A., JOBE, Z.R. FOSDICK, J.C., SCHWARTZ, T.M., FILDANI, A., GRAHAM, S.A., 2019. Revised chronostratigraphic framework for the Cretaceous Magallanes-Austral Basin, 
Última Esperanza Province, Chile. Journal of South American Earth Sciences, 94: 102209.

DASGUPTA, S., BUATOIS, L.A., MÁNGANO, M.G., 2016. Living on the edge: evaluating the impact of stress factors on animal-sediment interactions in subenvironments of a shelf-margin delta, the Mayaro Formation, Trinidad. Journal of Sedimentary Research 86, 1034-1066.

DICKINSON, W.R., (1988). Provenance and sediment dispersal in relation to paleotectonics and paleogeography of sedimentary basins. En: New perspectives in basin analysis. Springer, Nueva York, 3-25.

DICKINSON, W.R., RICH, E.I., 1972. Petrologic intervals and petrofacies in the Great Valley Sequence, Sacramento Valley, California. GSA Bulletin, 83 (10): 3007-3024.

DICKINSON, W.R., SUCZEK, C., 1979. Plate tectonics and sandstone composition. AAPG Bulletin 63, 2164-2182.

DICKINSON, W., BREARD, L., BRAKENRIDGE, G., ERJAVEC, J., FERGUSON, R., INMAN, K., KNEPP, R., LINDBERG, F., RYBERG, P., 1983. Provenance of North American Phanerozoic sandstones in relation to tectonic setting. GSA Bulletin 94, 222-235.

DUMAS, S., 2004. Oscillatory-flow and combined-flow bed forms: Experimental ingestigation and implications for the shallow marine rock record. Tesis Doctoral, Universidad de Ottawa, Canada, 192 pp.

DUMAS, S., ARNOTT, R.W.C., 2006. Origin of hummocky and swaley crossstratification- The controlling influence of unidirectional current strength and aggradation rate. Geology 34: 1073-1076.

DOTT, R.H., 1964. Wacke, graywacke and matrix-what approach to immature sandstone classification. Journal of Sedimentary Petrology 34: 625-632.

DOTT, R.H., BOURGEOS, J., 1982. Hummocky stratification: Significance of its variable bedding sequences. GSA Bulletin, 91: 663-680.

EIDE, C.H., HOWELL, J.A., BUCKLEY, S.J. 2015. Sedimentology and reservoir properties of tabular and erosive offshore transition deposits in wavedominated, shallow-marine strata: Book Cliffs, USA. Petroleum Geology, 21: 5573. 
ENGE H.D., HOWELL, J.A. BUCKLEY, S.J., 2010. The geometry and internal architecture of stream mouth bars in the Panther Tongue and the Ferron Sandstone members, Utah, U.S.A. Journal of Sedimentary Research, 80: 10811031.

EVERETT, K.R., 1983. Histosols. En: L.P. Wilding, N.E. Smeck and G.F. Hall (Eds.), Pedogenesis and Soil Taxonomy, II. The Soil Orders, Elsevier Science Publishers, 1-53.

FÉRAUD, G., ALRIC, V., FORNARI, M., BERTRAND, H., HALLER, M., 1999. 40Ar/39Ar dating of the Jurassic volcanic province of Patagonia: migrating magmatism related to Gondwana breakup and subduction. Earth and Planetary Science Letters 172: 83-98.

FERUGLIO, E., 1938. El Cretácico superior del Lago San Martín y de las relaciones adyacentes. Physis, 12: 293-342.

FERUGLIO, E., 1944. Estudios geológicos y glaciológicos en la región del lago Argentino (Patagonia). Boletín de la Academia Nacional de Ciencias, Córdoba, 37: 3-255.

FERUGLIO, E., 1949. Descripción Geológica de la Patagonia. Yacimientos Petrolíferos Fiscales (YPF), I, II, III.

FIELDING, C., 2010. Planform and facies variability in asymmetric deltas: facies and depositional architecture of the Turonian Ferron Sandstone in the Western Henry Mountains, south-central Utah, U.S.A. Journal Sedimentary Research, 80: 455-479.

FILDANI, A., HESSLER, A.M., 2005. Stratigraphic record across a retroarc basin inversion: Rocas Verdes-Magallanes basin, Patagonian Andes, Chile. GSA Bulletin 117: 1596-1614.

FILDANI, A., COPE, T.D., GRAHAM S.A., WOODEN, J.L., 2003. Initiation of the Magallanes Foreland basin: Timing of the southernmost Patagonian Andes Orogeny revised by detrital zircon provenance analysis. Geology, 31: 1081-1084.

FILDANI, A., HUBBARD, S.M., ROMANS, B.W., 2009. Stratigraphic evolution of deep-water architecture: examples of controls and depositional styles from the Magallanes Basin, Chile. SEPM Field Trip Guide 10, 73pp.

FÖLLMI, K.B., 2012. Early Cretaceous life, climate and anoxia. Cretaceous Research, 35: 230-257. 
FOLK, R.L., ANDREWS, P.B., LEWEIS, D.W., 1970. Detrital sedimentary rock classification and nomenclature for use in New Zealand. New Zealand Journal of Geology and Geophysics 13: 937-968.

FOSDICK, J.C., ROMANS, B.W., FILDANI, A., BERNHARDT, A., CALDERÓN, M., GRAHAM, S.A., 2011. Kinematic evolution of the Patagonian retroarc fold-andthrust belt and Magallanes foreland basin, Chile and Argentina, 51 $30^{\circ}$ 'S. GSA Bulletin, 123: 1679-1698.

FOSDICK, J.C., GROVE, M., GRAHAM, S.A., HOURIGAN, J.K., LOVERA, O., ROMANS, B.W., 2015. Detrital thermochronologic record of burial heating and sediment recycling in the Magallanes foreland basin, Patagonian Andes. Basin Research, 27 (4): 546-572.

FOSDICK, J., VANDERLEEST, R.A., BOSTELMANN, E.J., LEONARD, J.S., UGALDE, R., OYARZÚN, J.L., GRIFFIN, M., 2020. Revised Timing of Cenozoic Atlantic Incursions and Changing Hinterland Sediment Sources during Southern Patagonian Orogenesis. Lithosphere 2020: 1-18.

FREY, R.W., PEMBERTON, S.G., 1987. The Psilonichnus ichnocoense, and its relationship to adjacent marine and nonmarine ichnocoenses along the Georgia coast. Bulletin of Canadian Petroleum Geology 35: 333-357.

FRIEDRICH, O., NORRIS, R.D., ERBACHER, J., 2012. Evolution of middle to Late Cretaceous oceans-a 55 my record of Earth's temperature and carbon cycle. Geology, 40 (2): 107-110.

FURQUE, G., 1973. Descripción geológica de la Hoja 58b, Lago Argentino. Servicio Nacional de Minería y Geología, Boletín 140, 1-49 pp.

GALÁN, E., 2006. Genesis of clay minerals. En: Berhaya, F., Theng, B.K.G., Lagaly, G. (Eds.), Handbook of Clay Science, Developments in Clay Science. Elsevier, The Netherlands, pp. 1129-1162.

GALLOWAY, W.E., 1975. Process framework for describing the morpholofic and stratigraphic evolution of deltaic depositional systems. En: Broussard, M.L., (Ed.), Deltas, Models for Exploration. Houston Geological Society 87-98.

GALLOWAY, W.E., 2004. Accommodation and the sequence stratigraphic paradigm. Reservoir, Canadian Society of Petroleum Geologists 31 (5): 9-10.

GEORGE, S.W., DAVIS, S.N., FERNÁNDEZ, R.A., MANRÍQUEZ, L.M., LEPPE, M.A., HORTON, B.K., CLARKE, J.A., 2019. Chronology of deposition and 
unconformity development across the Cretaceous-Paleogene boundary, Magallanes-Austral Basin, Patagonian Andes. Journal of South American Earth Sciences, 97, 102237.

GHIGLIONE, M.C., SUAREZ, F., AMBROSIO, A., da POIAN, G., CRISTALLINI, E.O., PIZZIO, M.F., REINOSO, R.M., 2009. Structure and evolution of the Austral basin fold-thrust belt, southern Patagonian Andes. Revista de la Asociación Geológica Argentina, 65, 215- 226.

GHIGLIONE, M.C., LIKERMAN, J., BARBERÓN, V., GIAMBIAGI, L.B., AGUIRREURRETA, B., SUAREZ, F., 2014. Geodynamic context for the deposition of coarse-grained deep-water axial channel systems in the Patagonian Andes. Basin Research, 26: 726-745.

GHIGLIONE, M.C., RAMOS, V., CUITIÑO, J., BARBERÓN, V., 2016. Growth of the Southern Patagonian Andes $\left(46-53^{\circ} \mathrm{S}\right)$ and its relation with subduction processes. En: Folguera, A., Naipauer, M., Sagripanti, L., Ghiglione, M.C., Orts, D.L., Giambiagi, L. (Eds.), Growth of the Southern Andes. Springer Earth System Sciences, 201-240.

GHIGLIONE. M.C., RAGGIO, M.F., RAMOS, M.E., RONDA, G., MOYANO PAZ, D., VARELA, A.N., VALENCIA, V.A. (en prensa). Santonian-Campanian littoral to continental depocenter of the Austral-Magallanes basin: regional correlation, sediment sourcing and geodynamic setting. Cretaceous Research prensa.

GIACOSA R., FRACCHIA, D., HEREDIA, N., 2012. Structure of the Southern Patagonian Andes at 49 S. Geológica Acta 10: 265-282.

GINGRAS, M.K., MACEACHERN, J.A., PEMBERTON, S.G., 1998. A comparative analysis of the ichnology of wave and river-dominated allomembers of the Upper Cretaceous Dunvegan Formation. Bulletin of Canadean Petroleum Geologists 46: 51-73.

GINGRAS, M.K., MACEACHERN, J.A., DASHTGARD, S.E., 2011. Process ichnology and the elucidation of physico-chemical stress. Sedimentary Geology 237: 115-134.

GLUYAS, J., GARLAND, C., OXTOBY, N.H., HOGG, A.J.C., 2000. Quartz cement: the Miller's tale. En: Worden, R.H., Morad, S. (Eds.) Quartz Cementation in Sandstones. International Association of Sedimentologists, Special Publication 29: 199-218. 
GÓMEZ DACAL, A.R., 2018. Petrología, geoquímica y diagénesis de sedimentitas y fósiles carbonáticos del Jurásico Superior - Cretácico Inferior de las cuencas Neuquína y Austral, Argentina. Tesis Doctoral, Universidad Nacional de La Plata, La Plata, 299 pp.

GÓMEZ PERAL, L.E., 2008. Petrología y diagénesis de las unidades sedimentarias precámbricas de Olavarría, Provincia de Buenos Aires. Tesis Doctoral, Universidad Nacional de La Plata, La Plata, 619 pp.

GÓMEZ-PERAL, L.E., RAIGEMBORN, M.S., AND POIRÉ, D.G., 2011, Petrología y evolución diagenética de las facies silicoclásticas del Grupo Sierras Bayas, Sistema de Tandilia, Argentina. Latin American Journal of Sedimentology and Basin Analysis 18: 3-41.

GRANT, W.D., MADSEN, O.S., 1979. Combined wave and current interaction with a rough bottom. Journal of Geophysical Research: Oceans, 84 (4): 1797-1808.

GUGLIOTTA, M., FLINT, S.S., HODGSON, D.M., VEIGA, G.D., 2015. Stratigraphic record of river-dominated crevasse subdeltas with tidal influence (Lajas Formation, Argentina). Journal of Sedimentary Research, 85, 265-284.

GUTIÉRREZ, N.M., LE ROUX, J.P., VÁSQUEZ, A., CARREÑO, C., PEDROZA, V., ARAOS, J., OYARZÚN, J.L., PINO, J.P., RIVERA, H.A., HINOJOSA, L.F., 2017. Tectonic events reflected by palaeocurrents, zircon geochronology, and palaeobotany in the Sierra Baguales of Chilean Patagonia. Tectonophysics 695:76-99.

HALLAM, A., 1991. Relative importance of regional tectonics and eustasy for the Mesozoic of the Andes. En: Macdonald, D.I.M. (Ed.), Sedimentation, Tectonics and Eustasy: Sea-Level Changes at Active Margins. International Association of Sedimentologists, Special Publication 14: 187-200.

HAQ, B.U., 2014. Cretaceous eustasy revisited. Global and Planetary change 113: 44-58.

HAQ, B.U., HARDENBOL, J., VAIL, P.R. 1987. Chronology of fluctuating sea levels since the Triassic (250 million years ago to present). Science 235: 11561166.

HAQ, B.U., HARDENBOL, J., VAIL, P.R., 1988. Mesozoic and Cenozoic chronostratigraphy and cycles of sea-level change. An overview of sequence stratigraphy and key definitions. En: Wilgus, C.K., Hastings, B.S., Kendall, C.G.St.C., Posamentier, H.W., Ross, C.A., Van Wagoner, J.C. (Eds.), Sea Level 
Changes- An integrated approach. Society for Sedimentary Geologys, Special Publication 42: 71-108.

HARRELL, J., 1984. A visual comparator for degree of sorting in thin and plane sections. Journal of sedimentary research, 54 (2): 646-650.

HELLER, P.L., ANGEVINE, C.L. WINSLOW, N.S., 1988. Twophase stratigraphic model of foreland-basin sequences. Geology, 16: 501-504.

HERVÉ, F., PANKHURST, R.J., FANNING, C.M., CALDERÓN, M., YAXLEY, G.M., 2007. The South Patagonian batholith: 150 my of granite magmatism on a plate margin. Lithos, 97(3-4), 373-394.

HOUSTON, W.S., HUNTOON, J.E. KAMOLA, D.L., 2000. Modeling of Cretaceous Foreland-basin parasequences, Utah, with implications for timing of Sevier thrusting. Geology, 28: 267-270.

HOWARD, J.D., 1975. The sedimentological significance of trace fossils. In: Frey, R.W. (Ed.), The Study of Trace Fossils: A Synthesis of Principles, Problems and Procedures in Ichnology. Pringer-Verlag, New York, 131-146.

HOWARD, J.D., FREY, R.W., 1984. Characteristic trace fossils in nearshore to offshore sequences, Upper Cretaceous of east-central Utah. Canadian Journal of Earth Sciences 21 (2): 200-219.

HUBBARD, S.M., ROMANS, B.W., GRAHAM, S.A., 2008. Deepwater foreland basin deposits of the Cerro Toro Formation, Magallanes Basin, Chile: architectural elements of a sinuous basin axial channel belt. Sedimentology 55:1333-1359.

HUBBARD, S.M., FILDANI, A., ROMANS, B.W., COVAULT, J.A., MCHARGUE, T.R., 2010. High relief slope clinoform development: insights from outcrop, Magallanes Basin, Chile. Journal of Sedimentary Research 80:357-375.

HUNT, D., TUCKER, M.E., 1992. Stranded parasequences and the forced regressive wedge systems tract: deposition during base-level fall. Sedimentary Geology 81: 1-9.

INGERSOLL, R.V., BULLARD, T.F., FORD, R.L., GRIMM, J.P., PICKLE, J.D., SARES, S.W., 1984. The effect of grain size on detrital modes: a test of the GazziDickinson point-counting method. Journal of Sedimentary Research, 54 (1): 103116. 
INGERSOLL, R.V., BULLARD, T.F., FORD, R.L., GRIMM, J.P., PICKLE, S.W.S., 1984. The effect of grain size on detrital modes: a test of the Gazzi.Dickinson poit-counting method. Journal of Sedimentary Research 54: 103-116.

INGERSOLL, R.V., KRETCHMER, A.G., VALLES, P.K. 1993. The effect of sampling scale on actualistic sandstone petrofacies. Sedimentology 40: 937-953.

ISLA, M.F., SCHWARZ, E., VEIGA, G.D., 2018. Bedset characterization within a wave-dominated shallow-marine succession: An evolutionary model related to sediment imbalances. Sedimentary Geology 374: 36-52.

JENKYNS, H.C., 1980. Cretaceous anoxic events: from continents to oceans. Journal of the Geological Society 137: 171-188.

KAMOLA, D.L. HUNTOON, J.E., 1995. Repetitive strata patterns in a foreland basin sandstone and their possible tectonic significance. Geology, 23, 177-180.

KNAUST, D., 2013. The ichnogenus Rhizocorallium: classification, trace makers, palaeoenvironments and evolution. Earth Science Reviews 126: 1-47.

KOMINZ, M.A., BROWNING, J.V., MILLER, K.G., SUGARMAN, P.J., MIZINTSEVA, S., SCOTESE, C.R., 2008. Late Cretaceous to Miocene sea-level estimates from the New Jersey and Delaware coastal plain coreholes: An error analysis. Basin Research 20 (2): 211-226.

KORUS, J.T., FIELDING, C.R., 2015. Enhaced bioturbation on the down-drift flank of a Turonian asymmetrical delta: Implications for seaway circulation, river nutrients and facies models. Sedimentology 62, 1899-1922.

KRAEMER, P.E., 1998. Structure of the Patagonian Andes. Regional Balance cross section at 50 S.L, Argentina. International Geology Review 40: 896-915.

KRAEMER, P.E., RICCARDI, A.C., 1997. Estratigrafía de la region comprendida entre los lagos Argentino y Viedma (49 40'-50¹0' LS), Provincia de Santa Cruz. Revista de la Asociación Argentina de Geología, 52: 333-360.

KRAEMER, P.E., PLOSZKIEWICZ, J.V., RAMOS, V.A., 2002. Estructura de la cordillera patagónica austral entre los 46 y 52으. Sn: Haller, M.J. (Ed.), Geología y Recursos Naturales de Santa Cruz. Relatorio del XV Congreso Geológico Argentino, 353-364. 
KURCINKA C., DALRYMPLE, R.W., GUGLIOTTA, M., 2018. Facies and architecture of river-dominated to tide-influenced mouth bars in the lower Lajas Formation (Jurassic), Argentina, AAPG Bulletin, 102: 885-912.

LEANZA, A.F., 1967. Descripción de la fauna de Placenticeras del Cretátcico superior de Patagonia Austral con consideraciones acerca de su posición estratigráfica. Academia Nacional de Ciencias. Córdoba, 46, 5-28.

LEANZA, A.F., 1969. Sobre el descubrimiento de depósitos del piso coniaciano en Patagonia Austral y descripción de una nueva especie de ammonites (Peroniceras santacrucense N. sp.).

LEANZA, A.F., 1972. Andes Patagónicos Australes. En: A.F. Leanza (Ed.) Geología Regional Argentina, 689-706.

LECLAIR, S.F., BRIDGE, J.S., 2001. Quatitative interpretation of sedimentary structures formed by river dunes. Journal of Sedimentary Research 71: 713-716.

LEEDER, M.R., 1993. Tectonic controls upon drainage basin development, river channel migration and alluvial architecture: implications for hydrocarbon reservoir development and characterization. Geological Society of London Special Publication 73: 7-22.

LEEDER, M., 1999. Sedimentology and sedimentary basins, from turbulence to tectonics. Blackwell Science, 592 pp.

LEITHOLD, E.L., DEAN, W.E., 1998. Depositional processes and carbon burial on a Turonian prodelta at the margin of the Western Interior Seaway. In: Dean, W.E., Arthur, M.A. (Eds.), Stratigraphy and Paleoenvironments of the Cretaceous Western Interior Seaway, Usa. Society for Sedimentary Geology, Special Publication 6: 189-200.

LI, W., BHATTACHARYA, J.P., ZHUE, Y., GARZA, D., BLANKENSHIP, E., 2011. Evaluating delta asymmetry using three-dimensional facies architecture and ichnological analysis, Ferron 'Notom Delta', Capital Reed, Utah, USA. Sedimentology, 58: 478-507.

LLUCH, JJ., SPALLETTI, L.A., 1976. Minerales de las arcillas en los sedimentos actuales de la región del Cerro San Lorenzo, provincia de Santa Cruz. Revista de la Asociación Geológica Argentina 31 (1): 23-32.

LU., G., MCCABE, C., HENRY, D.J., SCHEDL, A., 1994. Origin of hematite carrying a Late Paleozoic remagnetization in a quartz sandstone bed from the 
Silurian Rose Hill Formation, Virginia, USA. Earth and Planetary Science Letters 126: 235-246

MACEACHERN, J.A., PEMBERTON, S.G., 1992. Ichnological aspects of Cretaceous shoreface successions and shoreface variability in the Western Interior Seaway of North America. In: Pemberton, S.G. (Ed.), Applications of Ichnology to Petroleum Explorations. Society for Sedimentary Geology, Core Workshop, 17: 57-84.

MACEACHERN, J.A., GINGRAS, M.K., 2007. Recognition of brackish-water trace fossil assemblages in the Cretaceous western interior seaway of Alberta. En: R. Bromley, L.A. Buaois, M.G. Mángano, J. Genise, R. Melchor (Eds.), Sediment-Organism Interactions: A Multifaceted Ichnology. Society for Sedimentary Geology, Special Publication 88: 149-194.

MACEACHERN, J.A., BANN, K.L., 2008. The role of ichnology in refining shallow marine facies models: recent advances in models of siliciclastic shallow-marine stratigraphy. En: Hampson, G.J., Steel, R.J., Burgess, P.B., Dalrymple, R.W. (Eds.), Recent Advances in Models of Siliciclastic Shallow-Marine Stratigraphy, vol. 90. Society for Sedimentary Geology, Special Publication, pp. 73-116.

MACEACHERN, J.A., BANN, K.L., BHATTACHARYA, J.P., HOWELL, C.D., 2005. Ichnology of deltas. En: Bhattacharya, J.P., and Giosan, L. (Eds.), River Deltas: Concepts, Models and Examples. Society for Sedimentary Geology, Special Publication 83: 49-86.

MACEACHERN, J.A., BANN, K.L., PEMBERTON S.G., GINGRAS, M.K., 2007. The ichnofacies paradigm: high resolution paleoenvironmental interpretation of the rock record. En: J.A. MacEachern, K.L. Bann, M.K. Gingras and S.G. Pemberton (Eds.), Applied Ichnology. Society for Sedimentary Geology, Short Course Notes 52: 65-93.

MACEACHERN, J.A. PEMBERTON, S.G., GINGRAS, M.K., BANN, K.L., 2010. Ichnology and Facies Models. En: Dalrymple R.W., and James, N.P. (Eds.), Facies Models 4. Geological Association of Canada, St. John's, Geotext 6: 19-58.

MACEACHERN, J.A., BANN, K.L., M.K. GINGRAS, ZONNEVELD, J.P., DASHTGARD, S.E., PEMBERTON, S.G., 2012. The ichnofacies paradigm. Developments in Sedimentology, 64: 103-138. 
MACELLARI, C.E., BARRIO, C.A., MANASSERO, M.J., 1989. Upper Cretaceous to Paleocene depositional sequences and sandstone petrography of southwestern Patagonia (Argentina and Chile). Journal of South American Earth Science, 2: 223239.

MADOF, A.S., HARRIS, A.D., CONNELL, S.D., 2016. Nearshore along-strike variability: Is the concept of the systems tract unhinged?. Geology, 44(4): 315318.

MALKOWSKI, M.A., SHARMAN, G.R., GRAHAM, S.A., FINDANI, A., 2015. Characterization and diachronous initiation of coarse clastic deposition in the Magallanes-Austral foreland basin, Patagonian Andes. Basin Research, 29: 298326.

MALKOWSKI, M.A., GROVE, M., GRAHAM, S.A., 2016. Unzipping the Patagonian Andes- long-lived influence of rifting history on foreland basin evolution. Lithosphere 8:23-28.

MALKOWSKI, M.A., SCHWARTZ, T., SHARMANN, G.R., SICKMANN, Z.T., GRAHAM, S.A., 2017a. Stratigraphic and provenance variations in the early evolution of the Magallanes-Austral foreland basin: Implications for the role of longitudinal versus transverse sediment dispersal during arc-continent collision. The Geological Society of America Bulletin, 129: 349-371.

MALKOWSKI, M.A., SHARMAN, G.R., GRAHAM, S.A., FILDANI, A., $2017 \mathrm{~b}$. Characterisation and diachronous initiation of coarse clastic deposition in the Magallanes-Austral foreland basin, Patagonian Andes. Basin Research 29:298326.

MALKOWSKI, M.A., JOBE, Z.R., SHARMAN, G.R., GRAHAM, S.A., 2018. Downslope facies variability within deep-water channel systems: insights from the Upper Cretaceous Cerro Toro Formation, southern Patagonian. Sedimentology 65:1918-1946.

MANASSERO, M.J., 1988. Petrografía y procedencia de las areniscas cretácicas superiores de la Cuenca Austral Argentina. Revista de la Asociación Geológica, 47: 73-82.

MARENSSI, S., GULER, V., CASADÍO, S., GUERSTEIN, R., PAPÚ, O., 2004. Sedimentology and palynology of the Calafate Formation (Maastrichtian), Austral Basin, Southern Patagonia, Argentina. Cretaceous Research 25 (6): 907918. 
MARFIL, R., DELGADO, A., ROSSI, C., LA IGLESIA, A., RAMSEYER, K., 2003. Origin and diagenetic evolution of kaolin in reservoir sandstones and associated shales of the Jurassic and Cretaceous, Salam Fields, Western Desert (Egypt). En: Worden, R.H., Morad, S. (Eds.), Quartz Cementation in Sandstones, Clay Mineral Cement in Sandstones. International Association of Sedimentologists, Special Publication, 34: 319-342

MARINELLI, R.V., 1998. Reservorios Deltaicos de La Formación Piedra Clavada. Boletín de Informaciones Petroleras, 15: 28-37.

MERRIMAN, R.J., PEACOR, D.R., 1999. Very low-grade metapelites: mineralogy, microfabrics and measuring reaction progress. En: Frey, M., Robinson, D. (Eds.), Lowgrade Metamorphism. Blackwell Sciences, Oxford, 10-60.

MIALL, A.D., 1977. A review of the braided river depositional model of alluvial stratigraphy: theory and application. Journal of Sedimentary Research 65: 7-31.

MIALL, A.D., 1978. Lithofacies types and vertical profile models in braided river deposits: a summary. En: Miall A.D. (Ed.), Fluvial Sedimentology. Canadian Society of Petroleum Geologists Bulletin, Memories 5: 579-604.

MIALL, A.D., 1985. Architectural-element analysis: a new method of facies analysis applied to fluvial deposits. Earth Science Reviews 22: 216-308.

MIALL, A.D., 1996. The geology of fluvial deposits: Sedimentary facies, basin analysis and petroleum geology. Springer-Verlag, Berlin, 582 pp.

MIALL, A.D., 2006. Reconstructing the architecture and sequence stratigraphy of the preserved fluvial records as a tool for reservoir development: A reality check. AAPG Bulletin 90 (7): 989-1002.

MIDDLETON, G.V., 1978, Facies. En: Fairbridge, R.W., Bourgeois, J., (Eds.), Encyclopedia of Sedimentology. Stroudsburg, Pennsylvania, Dowden, Hutchinson \& Ross, p. 323-325.

MITCHUM, R. M., VAIL, P.R., THOMPSON, S., 1977. Seismic stratigraphy and global changes in sea level, part 2: the depositional sequence as the basic unit for stratigraphic analysis. En: C.E. Payton, (Ed.), Seismic stratigraphy: application to hydrocarbon exploration. AAPG Memoir 26: 53-6.

MJØS, R., WALDERHAUG, O., PRESTHOLM, E., 1993. Crevasse splays sandstones geometries in the Middle Jurassic Ravenscar Group Yorkshire, UK. 
In: M. Marzo and C. Puigdefáfregas (Eds.), Alluvial Sedimentation, International Association of Sedimentologists, Special Publication 17: 167-184.

MOORE, D.M., REYNOLDS, JR.R.C., 1989. X-Ray Diffraction and the Identification and Analysis of Clay Mineral. Oxford University Press, 329 pp.

MOSLOW, T.F., PEMBERTON, S.G., 1988. An Integrated approach to the sedimentological analysis of some Lower Cretaceous shoreface and delta front sandstone sequences. En: James, D.P., Leckie, D.A. (Eds.), Sequences, Stratigraphy, Sedimentology: Surface and Subsurface. Canadian Society of Petroleum Geologists, Memoir, 15: 373-386.

MOYANO PAZ, D., TETTAMANTI, C., VARELA, A.N., CERECEDA, A., POIRÉ, D.G., 2018. Depositional processes and stratigraphic evolution of the Campanian deltaic system of La Anita Formation, Austral-Magallanes Basin, Patagonia, Argentina. Latin American Journal of Sedimentology and Basin Analysis 26 (2): 155-166.

MOYANO PAZ, D., RICHIANO, S., VARELA, A.N., GÓMEZ DACAL, A.R., POIRÉ D.G., 2020. Ichnological signatures from wave- and fluvial-dominated deltas: The La Anita Formation, Upper Cretaceous, Austral-Magallanes Basin, Patagonia. Marine and Petroleum Geology 114: 104168.

MULDER, T., SYVITSKI, J.P., 1995. Turbidity currents generated at river mouths during exceptional discharges to the word oceans. Journal of Geology 103 (3): 285-299.

MYROW, P.M., SOUTHARD, J.B., 1991. Combined-flow model for vertical stratification sequences in shallow-marine storm-deposited beds. Journal of Sedimentary Petrology 61: 202-210.

MYROW, P.M., SOUTHARD, J.B., 1996. Tempestite deposition. Journal of Sedimentary Research, 66: 875-887.

NET, L., ALONSO, S., AND LIMARINO, C., 2002, Source rock and environmental control on clay mineral associations, Lower section of Paganzo Group (Carboniferous), Northwest Argentina: Sedimentary Geology152: 183-199.

NIE, J., HORTON, B.K., SAYLOR, J.E., MORA, A., MANGE, M., GARZIONE, C.N., BASU, A., MORENO, C.J., CABALLERO, V., PARRA, M., 2012, Integrated provenance analysis of a convergent retroarc foreland system: $\mathrm{U}-\mathrm{Pb}$ ages, heavy minerals, $\mathrm{Nd}$ isotopes, and sandstone compositions of the Middle Magdalena Valley basin, northern Andes, Colombia: Earth-Science Reviews 110: 111-126 
NULLO, F., BLASCO, G., RISSO, C., COMBINA, A., OTAMENDI, J., 2006. El Calafate, provincial de Santa Cruz. Instituto de Geológíco Minero Argentino. Boletin, 396, 86.

O'BRIEN, C.L., ROBINSON, S.A., PANCOST, R.D., SINNINGHE DAMSTÉ, J.S., SCHOUTEN, S., LUNT, D.J., ALSENZ, H., BORNEMANN, A., BOTTINI, C., BRASSELL, S.C., FARNSWORTH, A., FORSTER, A., HUBER, B.T., INGLIS, G.N., JENKYNS, H.C., LINNERT, C., LITTLER, K., MARKWICK, P., MCANENA, A., MUTTERLOSE, J., NAAFS, B.D.A., PÜTTMANN, W., SLUIJS, A., VAN HELMOND, A.G.M., VELLEKOOP, J., WAGNER, T. \& WROBEL., N.E., 2017. Cretaceous seasurface temperature evolution: Constraints from TEX86 and planktonic foraminiferal oxygen isotopes. Earth Science Reviews 172: 224-247.

O'CONNOR, L.K., ROBINSON, S.A., NAAFS, B.D.A., JENKYNS, H.C., HENSON, S., CLARKE, M., PANCOST, R.D. 2019. Late Cretaceous temperature evolution of the southern high latitudes: A TEX86 perspective. Paleoceanography and Paleoclimatology 34: 436-45.

ODINO BARRETO, A.L., CERECEDA, A., GÓMEZ-PERAL, L.E., CORONEL, M.D., TETTAMANTI, C., POIRÉ, D.G., 2018. Sedimentology of the shallow marine deposits of the Calafate Formation during the Maastrichtian transgression at Lago Argentino, Austral-Magallanes basin, Argentina. Latin American Journal of Sedimentology and Basin Analysis 25(2): 69-92.

OLARIU, C. BHATTACHARYA, J.P., 2006. Terminal distributary channels and delta front architecture of river-dominated delta systems. Journal of Sedimentary Research, 76: 212-233.

OLARIU, C., STEEL, R.J., PETTER, A.L., 2010. Delta-front hyperpycnal bed geometry and implications for reservoir modeling: Cretaceous Panther Tongue delta Book Cliffs, Utah. AAPG Bulletin 94: 819-845.

OLSEN, T., STEEL, R.J., HOGSETH, K., SKAR, T., ROE, S.L., 1995. Sequential architecture in a fluvial succession: sequence stratigraphy in the Upper Cretaceous Mesaverde Group, Price Canyon, Utah. Journal of Sedimentary Research, 65 (2): 265-280.

PANKHURST, R.J., RILEY, T.R., FANNING, C.M., KELLEY, S.P., 2000. Episodic silicic Volcanism in Patagonia and Antartic Peninsula: Chronology of magmatism associated with the break-up of Gondwana. Journal of Petrology 41: 605-625. 
PAOLA, C., BORHMAN, L., 1991. Reconstructing random topography from preserved stratification. Sedimentology 38: 553-565.

PEMBERTON, S.G., FREY, R.W., 1984. Ichnology of storm-influenced shallow marine sequence: Cardium Formation (Upper Cretaceous) at Seebe, Alberta. En: Stott, D.F., Glass, D.J. (Eds.), The Mesozoic of Middle North America. Canadian Society of Petroleum Geologists, Memoir, 9: 281-304

PEMBERTON, S.G., WIGHTMAN, D.M., 1992. Ichnological characteristics of brackish water deposits. En: Pemberton, S.G. (Ed.), Applications of Ichnology to Petroleum Exploration, A Core Workshop. Society for Sedimentary Geology, Core Workshop 17: 414-167.

PEMBERTON, S.G., MACEACHERN, J.A., 1997. The ichnological signature of storm deposits: the use of trace fossils in event stratigraphy. En: Brett, C.E. (Ed.), Paleontological Event Horizons; Ecological Evolutionary Implications. Columbia University Press, New York, 73-109.

PEMBERTON, S.G., MACEACHERN, J.A., RANGER, M.J., 1992. Trace fossil facies models: environmental and allostratigraphic significance. In: Walker, R.G., James, N.P. (Eds.), Facies Models: Response to Sea Level Change. St. John's Newfoundland. Geological Association of Canada, 47-72.

PETTIJOHN, F.J., POTTER, P., SIEVER, R., 1972. Sand and Sandstone ( $1^{\text {st }}$ edition). Springer-Verlag, Berlin, 618 pp.

PEREZ-ARLUCEA, M., SMITH, N.D., 1999. Depositional patterns following the 1870s avulsion of the Saskatchewan River (Cumberland Marshes, Saskatchewan, Canada). Journal of Sedimentary Research, 69: 62-73.

PERONI, G., CAGNOLATTI, M., PEDRAZZINI, M., 2002. Cuenca Austral: marco geológico y reserva histórica de la actividad petrolera. En: M. Schiuma, G. Hinterwimmer, and G. Vergani (Eds.), Simposio Rocas Reservorio de las Cuencas Productivas de la Argentina. V Congreso de Exploración y Desarrollo de Hidrocarburos, 11-19.

PLINT, A.G., 2010. Wave- and storm-dominated shoreline and shallow-marine systems. In R.W. Dalrymple and N.P. James (Eds), Facies models 4, Geological Association of Canada, 167-200.

POLLASTRO, R.M., 1993. Considerations and applications of the illite/smectite geothermometer in hydrocarbon-bearing rocks of Miocene to Mississippian age. Clays and Clay Minerals 41: 119-133. 
POIRÉ, D.G., FRANZESE, J.R., 2010. Mesozoic clastic sequences from a Jurassic rift to Cretaceous foreland basin, Asutral Basin, Patagonia, Argentina. En: del Papa, C., Astini, R. (Eds.), Field Excursion Guidebook, 18 International Sedimentological Congress, Argentina. FE-C13, 53 pp.

PONCE, J.J., OLIVERO, E.B., MARTINIONI, D.R., LÓPEZ CABRERA, M.I., 2007. Sustained and episodic gravity flow deposits and related bioturbation patterns in Paleogene turbidities (Tierra del Fuego, Argentina). En: Bromley, R.G., Buatois, L.A., Mángano, M.G., Genise, J.F., Melchor, R.N. (Eds.), Sedimentorganisms Interactions: A Multifaceted Ichnology, vol. 88. Society for Sedimentary Geology, Special Publication, 253-266

POSAMENTIER, H.W., VAIL, P.R., 1988. Eustatic controls on clastic deposition II-sequence and systems tract models. En: Wilgus, C.K., Hastings, B.S., Kendall, C.G., Posamentier, H.W., Ross, C.A., Van Wagoner, J.C. (Eds.), Sea Level Changes-An Integrated Approach. Society for Sedimentary Geology, Special Publication 42: 125-154.

POSAMENTIER, H. W. y G. P. ALLEN, 1999. Siliciclastic Sequence Stratigraphy: Concepts and Applications. Society for Sedimentary Geology, 210 pp.

POSAMENTIER, H.W., JERVEY, M.T., VAIL., P.R., 1988. Eustatic controls on clastic deposition I - Conceptual framework. En: Wilgus, C.K. Hasting, B.S., Kendall, C.G., Posamentier H.W., Ross, C.A., Van Wagoner, J.C. (Eds.), Sea-level changes: An integrated approach. Society for Sedimentary Geology, Special Publication 42: 109-204.

POTTER, P.E., MAYNARD, J.B., PRYOR, W.A., 1980. Sedimentology of Shale. Springer-Verlag, Berlin, 306 pp.

POWERS, M.C., 1953. A new roundness scale for sedimentary particles. Journal of Sedimentary Petrology 23: 117-119.

RAIGEMBORN, M.S., GÓMEZ-PERAL, L.E., KRAUSE, J.M., \& MATHEOS, S.D., 2014. Controls on clay minerals assemblages in an early paleogene nonmarine succession: Implications for the volcanic and paleoclimatic record of extraandean patagonia, Argentina. Journal of South American Earth Sciences 52: 1-23.

RAMOS, V.A., 2002. Evolución tectónica. En: Heller, M.J. (Ed.) Geología y Recursos Naturales de Santa Cruz. Relatorio del XV Congreso Geológico Argentino, $928 \mathrm{pp}$. 
RAMOS, V.A., NIEMEYER, H., SKARMETA, J., MUÑOZ, J., 1982. Magmatic evolution of the Austral Patagonian Andes. Earth Science Reviews 18: 411-443.

RAYCHAUDHURI, I., PEMBERTON, S.G., 1992. Ichnologic and sedimentologic characteristics of open marine to storm dominated restricted marine settings with the Vikin/Bow Island formations, south-central Alberta. En: Pemberton, S.G. (Ed.), Applications of Ichnology to Petroleum Exploration, A Core Workshop. Society for Sedimentary Geology, Core Workshop, 17: 119-139.

READING, H.G., LEVELL, B.K., 1996. Controls on the sedimentary record. En Reading, H.G. (Ed.), Sedimentary environments: processes, facies and stratigraphy. Blackwell Science, Oxford, 5-35.

RETALLACK, G.J., 2001. Soils of the past: An introduction to Paleopedology, Second Edition. Blackwell Science, Oxford, 404 pp.

RICCARDI A.C., ROLLERI, E.O., 1980. Cordillera Patagónica Austral. En: Turner, J.C.M. (Ed.) Segundo Simposio de Geología Regional Argentina. Academia Nacional de Ciencia II, 1173-1304.

RICCARDI A.C., 1983. Informe paleontológico de los perfiles Estancia Alta Vista, Arroyo El Turbio. Reporte inédito de Yacimientos Petrolíferos Fiscales (YPF).

RICE, A.L., BILLETT, D.S.M., FRY, J., JOHN, A.W.G., LAMPITT, R.S., MANTOURA, R.F.C., MORRIS, R.J., 1986. Seasonal deposition of phyrodetritus to the deep-sea floor. Proceedings of the Royal Society of Edinburgh 88: 256-279.

RICHIANO, S., 2015; Envieronmental factors affecting the development of the Zoophycus ichnofacies in the lower Cretaceous Río Mayer Formation (Austral Basin, Patagonia). Palaeogeography, Palaeoclimatology, Palaeoecology 439: 17-26.

RICHIANO, S., VARELA, A.N., CERECEDA, A., POIRÉ, D.G., 2012. Evolución paleoambiental de la Formación Río Mayer, Cretácico inferior, Cuenca Austral, provincia de Santa Cruz, Argentina. Latin American Journal of Sedimentology and Basin Analysis 19: 3-26.

RICHIANO, S., POIRÉ D.G., VARELA, A.N., 2013. Icnología de la Formación Río Mayer, Cretácico inferior, sudoeste de Gondwana, Patagonia, Argentina. Ameghiniana, 50:273-286.

RICHIANO, S., VARELA, A.N., GÓMEZ-PERAL, L.E., CERECEDA, A., POIRÉ, D.G., 2015. Composition of the Lower Cretaceous source rock from the Austral Basin (Río Mayer Formation, Patagonia, Argentina): Regional implication for 
unconventional reservoirs in the Southern Andes. Marine and Petroleum Geology, 66: 764-790.

RICHIANO, S., VARELA, A.N., POIRÉ, D.G., 2016. Heterogeneous distribution of trace fossils across initial transgressive deposits in rift basins: an example from the Springhill Formation, Argentina. Lethaia 49:524-539.

ROBBIANO, J.A., ARBE, H., BANGUI, A.,1996. Cuenca Austral Marina. En: V.A. Ramos and M. Turic (Eds.), XII Congreso Geológico Argentino and Congreso de Exploración de Hidrocarburos, 343-358.

ROBINSON, S.A., HEIMHOFER, U., HESSELBO, S.P., PETRIZZO, M.R., 2017. Mesozoic climates and oceans - a tribute to Hugh Jenkyns and Helmut Weissert. Sedimentology 64: 1-15

RODRÍGUEZ, A.B., HAMILTON, M.D., ANDERSON, J.B., 2000. Facies and evolution of the modern Brazos Delta, Texas: wave versus flood influence. Journal of Sedimentary Research 70: 283-295.

RODRÍGUEZ, J., MILLER, M., 2005. Cuenca Austral. En: Frontera Exploratoria de la Argentina. VI Congreso de Exploración y Desarrollo de Hidrocarburos, 307324.

ROMANS, B.W., FILDANI, A., HUBBARD, S.M., COVAULT, J.A., FOSDICK, J.C., GRAHAM, S.A., 2011. Evolution of deep-water stratigraphic architecture, Magallanes Basin, Chile. Marine and Petroleum Geology 28:612-628.

ROMANS, B.W., CASTELLTORT, S., COVAULT, J.A., FILDANI, A., WALSH, J.P., 2016. Environmental signal propagation in sedimentary systems across timescales. Earth Science Reviews 153: 7-29.

RUSSO, A., FLORES, M.A., 1972. Patagonia Austral Extraandina. En: Geología Regional Argentina, Leanza, A.F. (Ed.), Academia Nacional de Ciencias: 707725. Córdoba.

RUSSO, A., FLORES, M. A., DI BENEDETTO, H., 1980. Patagonia Austral Extraandina. En: Turner, J.C.M. (Ed.) Segundo Simposio de Geología Regional Argentina. Academia Nacionalde Ciencias II: 1431-1462. Córdoba.

SANTAMARINA, P.E., BARREDA, V.D., MOYANO PAZ, D., TETTAMANTI, C., IGLESIAS, A., POIRE, D.G., VARELA, A.N., 2020. Palynoflora from the La Anita Formation (Maastrichtian), Austral-Magallanes Basin, Argentina. Revista del Museo Argentino de Ciencias Naturales nueva serie, 22 (1): 47-56. 
SACHSE, V.F., STROZYK, F., ANKA, Z., RODRIGUEZ, F., DI PRIMIO, R., 2015. The tectono-stratigraphic evolution of the Austral Basin and adjacent areas against the background of Andean tectonics, southern Argentina, South America. Basin Research 28 (4): 462-482.

SCHULTZ, M.R., HUBBARD, S.M., 2005. Sedimentology, stratigraphic architecture, and ichnology of gravity-flow deposits partially ponded in a growth-fault-controlled slope mini basin, Tres Pasos Formation (Cretaceous), southern Chile. Journal of Sedimentary Research 75:440-453.

SCHUMM, S.A., 1993. River response to base level change: implications for sequence stratigraphy. Journal of Geology 101: 279-294.

SCHWARZ, E., VEIGA, G.D., SPALLETTI, L.A., MASSAFERRO, J.L., 2011. The transgressive infill of an inherited-valley system: The Springhill Formation (lower Cretaceous) in southern Austral Basin, Argentina. Marine and Petroleum Geology 28: 1218-1241.

SCHWARZ, E., SPALLETTI, L.A., HOWELL, J.A., 2006. Sedimentary response to a tectonically induced sea-level fall in a shallow back-arc basin: the Mulichinco Formation (Lower Cretaceous), Neuquén Basin, Argentina. Sedimentology, 53 (1): 55-81.

SCHWARZ, E., POYATOS-MORÉ, M., BOYA, S., GOMIS-CARTESIO., MIDKANDAL, I., 2020. Architecture and controls of thick, intensely bioturbated, storm-influenced shallow-marine successions: An example from the Jurassic Neuquén Basin Argentina. Palaeogeography, Palaeoclimatology, Palaeoecology 562, p. 110109.

SCHWARTZ, T.M., GRAHAM, S.A., 2015. Stratigraphic architecture of a tideinfluenced shelf edge delta, upper Cretaceous Dorotea Formation, MagallanesAustral basin, Patagonia. Sedimentology 62:1039-1077.

SCHWARTZ, T.M., FOSDICK, J.C., GRAHAM, S.A., 2017. Using detrital zircon $\mathrm{U}-\mathrm{Pb}$ ages to calculate Late Cretaceous sedimentation rates in the Magallanes-Austral basin, Patagonia. Basin Research, 29(6): 725-746.

SENKAYI, A.L., MING, D.W., DIXON, J.B., HOSSNER, L.R., 1987. Kaolinite, opal $\mathrm{CT}$, and clinoptilolite in altered tuffs interbedded with lignite in the Jackson Group, Texas. Clays and Clay Minerals 35: 281-290.

SHANLEY, K.W., MCCABE, P.J., 1994. Perspectives on the sequence stratigraphy of continental strata. AAPG Bulletin, 78 (4): 544-568. 
SICKMANN, Z.T., SCHWARTZ, T.M., GRAHAM, S.A., 2018. Refining stratigraphy and tectonic history using detrital zircon maximum depositional age: an example from Cerro Fortaleza, Austral Basin, southern Patagonia. Basin Research, 30: 708-729.

SICKMANN, Z.T., SCHWARTZ, T.M., MALKOWSKI, M.A., DOBBS, S.C., GRAHAM, S.A., 2019. Interpreting large detrital geochronology data sets in retroarc foreland basins: An example from the Magallanes-Austral Basin, southernmost Patagonia. Lithosphere. https://doi.org/10.1130/L1060.1.

SNEDDEN, J.W., NUMMEDAL, D., AMOS, A.F., 1988. Storm-and fairweather combined flow on the central Texas continental shelf. Journal of Sedimentary Research 58 (4): 580-595.

SØMME, T.O., HOWELL, J.A., HAMPSON, G.J., STORMS, J.E.A., 2008. Genesis, architecture, and numerical modeling of intra-parasequence discontinuity surfaces in wave-dominated deltaic deposits: Upper Cretaceous Sunnyside Member, Blackhawk Formation, Book Cliffs, Utha, U.S.A. En: Hampson, G.J., Steel, R.J., Burgess, P.B., Dalrymple, R.W. (Eds.), Recent Advances in Models of Siliciclastic Shallow-Marine Stratigraphy. Society for Sedimentary Geology, Special Publication 90: 421-441.

SOUTHARD, J.B., BOGUCHAL, L.A., 1990. Bed configuration in steady unidirectional water flows, Synthesis of flume data. Journal of Sedimentary Petrology 60; 658-679.

SPALLETTI, L.A., MATHEOS, S.D., SÁNCHEZ, E., OYARZÁBAL, F., 2005. Análisis diagenético de la Formación Springhill (Santa Cruz, Argentina). VI Congreso de Exploración y Desarrollo de Hidrocarburos, Mar del Plata, CD Actas, 14 pp.

SWIFT, D.J., FIGUEIREDO, A.G., FREELAND, G.L., OERTEL, G.F., 1983. Hummocky cross-stratification and megaripples; a geological double standard? Journal of Sedimentary Research, 53 (4): 1295-1317.

TAYLOR, J.M., 1950. Pore space reduction in sandstones. AAPG Bulletin 34: 710-716.

TAYLOR, A.M., GOLDRING, R., 1993. Description and analysis of bioturbation and ichnofabric. Journal of the Geological Society of London, 150: 141-148.

TETTAMANTI, C., MOYANO PAZ, D., VARELA, A.N., GÓMEZ-PERAL, L.E., POIRÉ, D.G., CERECEDA, A., ODINO, A.L., 2018. Sedimentology and 
stratigraphy of the uppermost Cretaceous Continental Deposits of the AustralMagallanes Basin, Patagonia, Argentina. Latin American Journal of Sedimentology and Basin Analysis, 25(2): 149-168.

THIRY, M., 2000. Palaeoclimatic interpretation of clay minerals in marine deposits: an outlook from the continental origin. Earth Science Reviews 49: 201221.

TISSOT, B.P., WELTED. H., 1984. Petroleum Formation and Occurrence. SpringerVerlag, Berlin, $451 \mathrm{pp}$.

TUCKER, M.E., 1988. Techniques in Sedimentology. Blackwell Scientific Publications, Oxford, $394 \mathrm{pp}$.

TUCKER, M.E., 2001. Sedimentary Petrology. Blackwell Science (3ํㅡ. Ed.), Oxford, $262 \mathrm{pp}$.

ULIANA, V.M.A., BIDDLE, K.T., CERDAN, J., 1989. Mesozoic extension and the formation of Argentine sedimentary basins. En: Tankard A.J., Balkwill, H.R. (Eds.), Extensional Tectonics and Stratigraphy of the North Atlantic Margins. American Association of Petroleum Geology Bulletin, Memoirs 46:599-613.

VAIL, P.R., 1987. Seismic stratigraphy interpretation procedure. En: Bally, A.W. (Ed.), Atlas of Seismic Stratigraphy. AAPG Studies in Geology 27: 1-10.

VAIL, P.R., MITCHUM, R. M.JR., THOMPSON, S., 1977. Seismicstratigraphy and global changes of sea level, part four: globalcycles of relative changes of sea level. AAPG Memoir 26: 83-98.

VAIL, P.R., AUDEMARD, F., BOWMAN, S.A., EISNER. P.N., PEREZ-CRUZ, C., 1991. The stratigraphic signatures of tectonics, eustasy and sedimentology - an overview. En: G. Einsele, W. Ricken, A. Seilacher (Eds.), Cycles and Events in Stratigraphy. Springer-Verlag. New York, 617-659

VAN WAGONER, J. C., POSAMENTIER, H.W., MITCHUM, R.M.JR., VAIL, P.R., SARG, J.F., LOUTIT, T.S., HARDENBOL, J., 1988. An overview of sequence stratigraphy and key definitions. En: Wilgus, C.K., Hastings, B.S., Kendall, C.G.St.C., Posamentier, H.W., Ross, C.A., Van Wagoner, J.C. (Eds.), Sea Level Changes- An integrated approach. Society for Sedimentary Geologys, Special Publication 42: 39-45.

VAN WAGONER, J.C., MITCHUM, R.M.JR., CAMPION, K.M., RAHMANIAN, V.D., 1990. Siliciclastic sequence stratigraphy in well logs, core, and outcrops: 
concepts for high-resolution correlation of time and facies. AAPG Methods in Exploration Series 7: $55 \mathrm{pp}$.

VARELA, A.N., 2011. Sedimentología y modelos depositacionales de la Formación Mata Amarilla, Cretácico de la Cuenca Austral, Argentina. Tesis Doctoral, Universidad Nacional de La Plata, La Plata. 384 pp.

VARELA, A.N., 2015. Tectonic control of accommodation space and sediment supply within the Mata Amarilla Formation (lower Upper Cretaceous) Patagonia, Argentina. Sedimentology, 62: 867-896.

VARELA, A.N., RICHIANO, S., POIRÉ, D.G., 2011. Tsunami vs storm origin for shell bed deposits in a lagoon environment: an example from the Upper Cretaceous of southern Patagonia, Argentina. Latin American Journal of Sedimentology and Basin Analysis 18(1): 63-85.

VARELA, A.N., POIRÉ, D.G., MARTIN, T., GERDESM, A., GOIN, F.J., GELFO, J.N., HOFFMANN, S., 2012a. U-Pb zircon constraints on the age of the Cretaceous Mata Amarilla Formation, Southern Patagonia, Argentina: its relationship with the evolution of the Austral Basin. Andean Geology, 39: 359-379.

VARELA, A.N., VEIGA, G.D., POIRÉ, D.G., 2012b. Sequence stratigraphic analysis of Cenomanian greenhouse palaeosols: A case study from southern Patanoia, Argentina. Sedimentary Geology, 271-272: 67-68.

VARELA, A.N., GÓMEZ-PERAL, L.E., RICHIANO, S., POIRÉ, D.G., 2013. Distinguishing similar volcanic source areas from an integrated provenance analysis: implication from foreland Andean basins. Journal of Sedimentary Research, 83: 258-276.

VARELA A.N., RAIGEMBORN, M.S., RICHIANO, S., WHITE, T., POIRÉ, D.G., AND LIZZOLI, S., 2018. Late Cretaceous paleosols as paleoclimate proxies of high-latitude Southern Hemisphere: Mata Amarilla Formation, Patagonia, Argentina. Sedimentary Geology, 363: 83-95.

VARELA, A.N., RICHIANO, S., D'ELIA, L., MOYANO PAZ, D., TETTAMANTI, C., POIRÉ, D.G., 2019. Sedimentology and stratigraphy of the Puesto El Moro Formation, Patagonia, Argentina: Implications for Upper Cretaceous paleogeographic reconstruction and compartmentalization of the AustralMagallanes Basin. Journal of South American Earth Sciences 92:466-480. 
WALKER, R.G., 1992. Facies, facies models and modern stratgraphic concepts. En: Walker, R.G., James, N.P. (Eds.), Facies Models: Response to Sea Level Change. Geological Association of Canada, Geotext 1, 1-14 pp.

WALKER, R.G., 2006. Facies models revisted. En: En: Posamentier, H.W., Walker, R.G. (Eds.), Facies Models, Society for Sedimentary Geology, Special Publication, 84: 1-18.

WATTS, A.B., 1989. Lithospheric flexure due to prograding sediment loads: implications for the origin of offlap/onlap patterns in sedimentary basins. Basin Research 2: 133-144.

WEIMER, P., POSAMENTIER, H.W., 1993, Recent developments and applications in siliciclastic sequence stratigraphy. En: Weimer, P., Posamentier, H.W. (Eds.), Siliciclastic Sequence Stratigraphy. AAPG Memoir 58: 3-12.

WILSON, M.D., PITTMAN, E.D., 1977. Authigenic clays in sandstones: recognition and influence on reservoir properties and paleoenvironmental analysis. Journal of Sedimentary Petrology 47: 3-31.

WIZEVICH, M.C., 1991. Phtotomosaics of outcrops: useful photographic techniques. En: Miall, A.D., Tyler, N. (Eds.), The three-dimensional facies architecture of terrugenous clastic sediments and its implication for hydrocarbon discovery and recovery. Concepts in Sedimentology and Paleontology, Society for Sedimentary Geologists 3: 22-24.

WORDEN, R.H., MORAD, S., 2000. Quartz cementation in oil field sandstones: a review of the key controversies. En: Worden, R.H., Morad, S. (Eds.), Quartz Cementation in Sandstones. International Association of Sedimentologists, Special Publication 29: 1-20.

WRIGHT L.D., 1977. Sediment transport and deposition at river mouths: a synthesis. Journal of Sedimentary Research, 70: 788-802. 
ANEXO 1:

Tablas de Composición modal de areniscas 


\begin{tabular}{|c|c|c|c|c|c|c|c|c|c|c|c|c|c|}
\hline Cortes & \multicolumn{10}{|c|}{ Conteo de puntos } \\
\hline Muestra & Qm & Qp & Pg & Fk & Ls & Lv & Lm & Cemento & Poro & matriz & $\begin{array}{c}\text { Fitode } \\
\text { tritos }\end{array}$ & psudom. & total \\
\hline G-Fr 5 & 90 & 38 & 10 & 30 & 12 & 172 & 4 & 13 & 15 & 1 & 15 & 0 & 400 \\
\hline G-Fr 23 & 76 & 24 & 12 & 16 & 10 & 198 & 2 & 3 & 30 & 5 & 24 & 0 & 400 \\
\hline G-Fr 38 & 69 & 27 & 9 & 18 & 12 & 183 & 4 & 15 & 18 & 5 & 25 & 0 & 385 \\
\hline G-Fr 99 & 81 & 46 & 7 & 23 & 6 & 173 & 0 & 2 & 34 & 3 & 25 & 0 & 400 \\
\hline G-Fr 107 & 84 & 36 & 9 & 22 & 8 & 183 & 2 & 19 & 7 & 3 & 27 & 0 & 400 \\
\hline G-Fr 216 & 83 & 27 & 11 & 21 & 9 & 168 & 5 & 3 & 48 & 4 & 21 & 0 & 400 \\
\hline G-Fr 326b & 87 & 35 & 16 & 12 & 7 & 159 & 5 & 6 & 53 & 10 & 10 & 0 & 400 \\
\hline G-Fr 264 & 74 & 21 & 15 & 31 & 5 & 163 & 4 & 3 & 50 & 13 & 21 & 0 & 400 \\
\hline G-Fr 398 & 50 & 7 & 4 & 20 & 19 & 100 & 0 & 13 & 50 & 108 & 29 & 0 & 400 \\
\hline CC 1 & 70 & 23 & 15 & 37 & 15 & 183 & 3 & 7 & 12 & 10 & 25 & 0 & 400 \\
\hline CC 2 & 57 & 33 & 15 & 28 & 13 & 183 & 7 & 8 & 8 & 20 & 28 & 0 & 400 \\
\hline CC 3 & 65 & 18 & 11 & 25 & 11 & 187 & 4 & 25 & 24 & 7 & 23 & 0 & 400 \\
\hline CC 4 & 58 & 19 & 16 & 23 & 10 & 183 & 5 & 17 & 36 & 13 & 20 & 0 & 400 \\
\hline CC 5 & 74 & 27 & 7 & 24 & 8 & 194 & 7 & 21 & 10 & 5 & 23 & 0 & 400 \\
\hline CC 6 & 80 & 26 & 9 & 22 & 8 & 188 & 2 & 18 & 26 & 5 & 16 & 0 & 400 \\
\hline CC 7 & 72 & 15 & 9 & 26 & 12 & 174 & 5 & 48 & 11 & 8 & 20 & 0 & 400 \\
\hline CC 8 & 75 & 15 & 9 & 18 & 11 & 189 & 6 & 27 & 10 & 13 & 27 & 0 & 400 \\
\hline CC 9 & 66 & 21 & 12 & 29 & 15 & 193 & 6 & 7 & 29 & 4 & 18 & 0 & 400 \\
\hline CC 10 & 86 & 20 & 11 & 31 & 16 & 145 & 10 & 5 & 51 & 4 & 21 & 0 & 400 \\
\hline CC 11 & 84 & 18 & 16 & 17 & 9 & 157 & 6 & 48 & 27 & 7 & 11 & 0 & 400 \\
\hline CeT 3 & 86 & 19 & 10 & 30 & 11 & 140 & 4 & 4 & 83 & 0 & 13 & 0 & 400 \\
\hline CeT 85 & 84 & 27 & 12 & 18 & 10 & 171 & 2 & 50 & 6 & 2 & 18 & 0 & 400 \\
\hline CeT 102 & 74 & 26 & 16 & 23 & 9 & 182 & 5 & 26 & 15 & 8 & 16 & 0 & 400 \\
\hline CeT 115 & 81 & 38 & 16 & 18 & 6 & 159 & 4 & 18 & 30 & 7 & 23 & 0 & 400 \\
\hline CeT 128 & 69 & 27 & 11 & 22 & 12 & 168 & 6 & 19 & 34 & 7 & 25 & 0 & 400 \\
\hline CeT 143 & 76 & 23 & 16 & 31 & 8 & 176 & 0 & 17 & 24 & 10 & 19 & 0 & 400 \\
\hline CeT 156 & 80 & 35 & 7 & 23 & 6 & 171 & 6 & 6 & 29 & 18 & 15 & 4 & 400 \\
\hline CeT 159 & 74 & 29 & 17 & 20 & 10 & 162 & 9 & 21 & 21 & 12 & 19 & 6 & 400 \\
\hline
\end{tabular}




\begin{tabular}{|c|c|c|c|c|c|c|c|c|c|c|c|c|c|}
\hline Cortes & & & & & Por & cent & taje & es relat & ivos & & & & \\
\hline Muestra & Qm & Qp & Plg & $\mathrm{Fk}$ & LS & LV & LM & Cemento & Poro & matriz & \begin{tabular}{|c|} 
Fitode \\
tritos
\end{tabular} & Pseudom. & dott \\
\hline G-Fr 5 & 22,5 & 9,5 & 2,5 & 7,5 & 3 & 43 & 1 & 3,25 & 3,75 & 0,25 & 3,75 & 0 & 356 \\
\hline G-Fr 23 & 19 & 6 & 3 & 4 & 2,5 & 49,5 & 0,5 & 0,75 & 7,5 & 1,25 & 6 & 0 & 338 \\
\hline G-Fr 38 & 17,25 & 6,75 & 2,25 & 4,5 & 3 & 45,8 & 1 & 3,75 & 4,5 & 1,25 & 6,25 & 0 & 322 \\
\hline G-Fr 99 & 20,25 & 11,5 & 1,75 & 5,75 & 1,5 & 43,3 & 0 & 0,5 & 8,5 & 0,75 & 6,25 & 0 & 336 \\
\hline G-Fr 107 & 21 & 9 & 2,25 & 5,5 & 2 & 45,8 & 0,5 & 4,75 & 1,75 & 0,75 & 6,75 & 0 & 344 \\
\hline G-Fr 216 & 20,75 & 6,75 & 2,75 & 5,25 & 2,25 & 42 & 1,3 & 0,75 & 12 & 1 & 5,25 & 0 & 324 \\
\hline G-Fr 326b & 21,75 & 8,75 & 4 & 3 & 1,75 & 39,8 & 1,3 & 1,5 & 13,3 & 2,5 & 2,5 & 0 & 321 \\
\hline G-Fr 264 & 18,5 & 5,25 & 3,75 & 7,75 & 1,25 & 40,8 & 1 & 0,75 & 12,5 & 3,25 & 5,25 & 0 & 313 \\
\hline G-Fr 398 & 12,5 & 1,75 & 1 & 5 & 4,75 & 25 & 0 & 3,25 & 12,5 & 27 & 7,25 & 0 & 200 \\
\hline CC 1 & 17,5 & 5,75 & 3,75 & 9,25 & 3,75 & 45,8 & 0,8 & 1,75 & 3 & 2,5 & 6,25 & 0 & 346 \\
\hline CC 2 & 14,25 & 8,25 & 3,75 & 7 & 3,25 & 45,8 & 1,8 & 2 & 2 & 5 & 7 & 0 & 336 \\
\hline CC 3 & 16,25 & 4,5 & 2,75 & 6,25 & 2,75 & 46,8 & \begin{tabular}{|l|}
1 \\
\end{tabular} & 6,25 & 6 & 1,75 & 5,75 & 0 & 321 \\
\hline CC 4 & 14,5 & 4,75 & 4 & 5,75 & 2,5 & 45,8 & 1,3 & 4,25 & 9 & 3,25 & 5 & 0 & 314 \\
\hline CC 5 & 18,5 & 6,75 & 1,75 & 6 & 2 & 48,5 & 1,8 & 5,25 & 2,5 & 1,25 & 5,75 & 0 & 341 \\
\hline CC 6 & 20 & 6,5 & 2,25 & 5,5 & 2 & 47 & 0,5 & 4,5 & 6,5 & 1,25 & 4 & 0 & 335 \\
\hline CC 7 & 18 & 3,75 & 2,25 & 6,5 & 3 & 43,5 & 1,3 & 12 & 2,75 & 2 & 5 & 0 & 313 \\
\hline CC 8 & 18,75 & 3,75 & 2,25 & 4,5 & 2,75 & 47,3 & 1,5 & 6,75 & 2,5 & 3,25 & 6,75 & 0 & 323 \\
\hline CC 9 & 16,5 & 5,25 & 3 & 7,25 & 3,75 & 48,3 & 1,5 & 1,75 & 7,25 & 1 & 4,5 & 0 & 342 \\
\hline CC 10 & 21,5 & 5 & 2,75 & 7,75 & 4 & 36,3 & 2,5 & 1,25 & 12,8 & 1 & 5,25 & 0 & 319 \\
\hline CC 11 & 21 & 4,5 & 4 & 4,25 & 2,25 & 39,3 & 1,5 & 12 & 6,75 & 1,75 & 2,75 & 0 & 307 \\
\hline CeT 3 & 21,5 & 4,75 & 2,5 & \begin{tabular}{|l|}
7,5 \\
\end{tabular} & 2,75 & 35 & 1 & 1 & 20,8 & 0 & 3,25 & 0 & 300 \\
\hline CeT 85 & 21 & 6,75 & 3 & 4,5 & 2,5 & 42,8 & 0,5 & 12,5 & 1,5 & 0,5 & 4,5 & 0 & 324 \\
\hline CeT 102 & 18,5 & 6,5 & 4 & 5,75 & 2,25 & 45,5 & 1,3 & 6,5 & 3,75 & 2 & 4 & 0 & 335 \\
\hline CeT 115 & 20,25 & 9,5 & 4 & 4,5 & 1,5 & 39,8 & 1 & 4,5 & 7,5 & 1,75 & 5,75 & 0 & 322 \\
\hline CeT 128 & 17,25 & 6,75 & 2,75 & 5,5 & 3 & 42 & 1,5 & 4,75 & 8,5 & 1,75 & 6,25 & 0 & 315 \\
\hline CeT 143 & 19 & 5,75 & 4 & 7,75 & 2 & 44 & 0 & 4,25 & 6 & 2,5 & 4,75 & 0 & 330 \\
\hline CeT 156 & 20 & 8,75 & 1,75 & 5,75 & 1,5 & 42,8 & 1,5 & 1,5 & 7,25 & 4,5 & 3,75 & 1 & 328 \\
\hline CeT 159 & 18,5 & 7,25 & 4,25 & 5 & 2,5 & 40,5 & 2,3 & 5,25 & 5,25 & 3 & 4,75 & 1,5 & 321 \\
\hline
\end{tabular}




\begin{tabular}{|c|c|c|c|c|c|c|}
\hline Cortes & \multicolumn{5}{|c|}{ Porcentajes relativos } & \\
\hline Muestra & Qt & Qm & F & L & Lt & matriz \\
\hline G-Fr 5 & 35,9550562 & 25,2808989 & 11,2359551 & 52,8089888 & 63,4831461 & 0,25 \\
\hline G-Fr 23 & 29,5857988 & 22,4852071 & 8,28402367 & 62,1301775 & 69,2307692 & 1,25 \\
\hline G-Fr 38 & 29,8136646 & 21,4285714 & 8,38509317 & 61,8012422 & 70,1863354 & 1,2987013 \\
\hline G-Fr 99 & 37,797619 & 24,1071429 & 8,92857143 & 53,2738095 & 66,9642857 & 0,75 \\
\hline G-Fr 107 & 34,8837209 & 24,4186047 & 9,01162791 & 56,1046512 & 66,5697674 & 0,75 \\
\hline G-Fr 216 & 33,9506173 & 25,617284 & 9,87654321 & 56,1728395 & 64,5061728 & 1 \\
\hline G-Fr 326b & 38,0062305 & 27,1028037 & 8,72274143 & 53,271028 & 64,1744548 & 2,5 \\
\hline G-Fr 264 & 30,3514377 & 23,6421725 & 14,6964856 & 54,9520767 & 61,6613419 & 3,25 \\
\hline G-Fr 398 & 28,5 & 25 & 12 & 59,5 & 63 & 27 \\
\hline CC 1 & 26,8786127 & 20,2312139 & 15,0289017 & 58,0924855 & 64,7398844 & 2,5 \\
\hline CC 2 & 26,7857143 & 16,9642857 & 12,797619 & 60,4166667 & 70,2380952 & 5 \\
\hline CC 3 & 25,8566978 & 20,2492212 & 11,2149533 & 62,9283489 & 68,5358255 & 1,75 \\
\hline CC 4 & 24,522293 & 18,4713376 & 12,4203822 & 63,0573248 & 69,1082803 & 3,25 \\
\hline CC 5 & 29,6187683 & 21,7008798 & 9,09090909 & 61,2903226 & 69,2082111 & 1,25 \\
\hline CC 6 & 31,641791 & 23,880597 & 9,25373134 & 59,1044776 & 66,8656716 & 1,25 \\
\hline CC 7 & 27,7955272 & 23,0031949 & 11,1821086 & 61,0223642 & 65,8146965 & 2 \\
\hline CC 8 & 27,8637771 & 23,2198142 & 8,35913313 & 63,7770898 & 68,4210526 & 3,25 \\
\hline CC 9 & 25,4385965 & 19,2982456 & 11,9883041 & 62,5730994 & 68,7134503 & 1 \\
\hline CC 10 & 33,2288401 & 26,9592476 & 13,1661442 & 53,6050157 & 59,8746082 & 1 \\
\hline CC 11 & 33,2247557 & 27,3615635 & 10,7491857 & 56,0260586 & 61,8892508 & 1,75 \\
\hline CeT 3 & 35 & 28,6666667 & 13,3333333 & 51,6666667 & 58 & 0 \\
\hline CeT 85 & 34,2592593 & 25,9259259 & 9,25925926 & 56,4814815 & 64,8148148 & 0,5 \\
\hline CeT 102 & 29,8507463 & 22,0895522 & 11,641791 & 58,5074627 & 66,2686567 & 2 \\
\hline CeT 115 & 36,9565217 & 25,1552795 & 10,5590062 & 52,484472 & 64,2857143 & 1,75 \\
\hline CeT 128 & 30,4761905 & 21,9047619 & 10,4761905 & 59,047619 & 67,6190476 & 1,75 \\
\hline CeT 143 & 30 & 23,030303 & 14,2424242 & 55,7575758 & 62,7272727 & 2,5 \\
\hline CeT 156 & 35,0609756 & 24,3902439 & 9,14634146 & 55,7926829 & 66,4634146 & 4,5 \\
\hline CeT 159 & 32,0872274 & 23,0529595 & 11,5264798 & 56,3862928 & 65,4205607 & 3 \\
\hline
\end{tabular}


ANEXO 2:

Tablas Difracción de

Rayos $X$ 


\begin{tabular}{|c|c|c|c|c|c|c|c|c|c|c|c|c|c|}
\hline \multicolumn{2}{|c|}{ DRX } & \multicolumn{6}{|c|}{ Roca Total } & \multicolumn{6}{|c|}{ Arcillas } \\
\hline Perfil & Muestra & $\%$ Arc & $\% Q z$ & $\% \mathrm{Pg}$ & $\% \mathrm{Fk}$ & $\% \mathrm{Ca}$ & $\% \mathrm{D}$ & $\% 1$ & $\% \mathrm{Cl}$ & $\% \mathrm{~K}$ & $\% \mathrm{Sm}$ & $\% \mathrm{l} / \mathrm{Sm}$ & $\% \mathrm{Cl} / \mathrm{Sm}$ \\
\hline \multirow{13}{*}{ 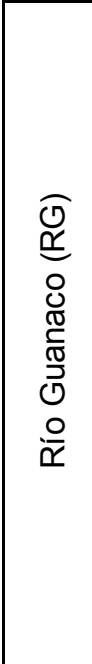 } & RG-10 & 8 & 76 & 13 & 2 & 1 & 0 & 15 & \begin{tabular}{|l|}
10 \\
\end{tabular} & 50 & 0 & 25 & 0 \\
\hline & RG-34 & 35 & 59 & 4 & 2 & 0 & 0 & 15 & 0 & 5 & 0 & 80 & 0 \\
\hline & RG-41 & 8 & 71 & 12 & 3 & 6 & 0 & 15 & 5 & 30 & 0 & 50 & 0 \\
\hline & RG-45 & 8 & 69 & 13 & 4 & 6 & 0 & 15 & 5 & 35 & 0 & 45 & 0 \\
\hline & RG-59 & 4 & 80 & 14 & 2 & 0 & 0 & 15 & 5 & 35 & 0 & 45 & 0 \\
\hline & RG-65 & 6 & 73 & 8 & 13 & 0 & 0 & 20 & 5 & 40 & 0 & 35 & 0 \\
\hline & RG-66 & 8 & 59 & 23 & 4 & 5 & 1 & 5 & 5 & 25 & 0 & 65 & 0 \\
\hline & RG-67 & 18 & 71 & 7 & 3 & 0 & 1 & 5 & 20 & 0 & 0 & 80 & 0 \\
\hline & RG-77 & 8 & 63 & 22 & 5 & 2 & 0 & 25 & 0 & 20 & 0 & 55 & 0 \\
\hline & RG-93 & 4 & 75 & 17 & 2 & 1 & 1 & 15 & 0 & 35 & 0 & 50 & 0 \\
\hline & RG-101 & 5 & 71 & 12 & 2 & 10 & 0 & 15 & 0 & 85 & 0 & 0 & 0 \\
\hline & RG-107 & 9 & 81 & 8 & 2 & 0 & 0 & 15 & 10 & 10 & 0 & 65 & 0 \\
\hline & RG-127 & 9 & 73 & 18 & 0 & 0 & 0 & 5 & 0 & 55 & 30 & 10 & 0 \\
\hline \multirow{21}{*}{ 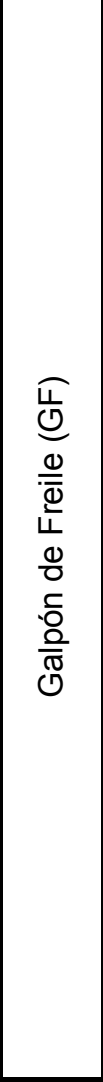 } & GFr 2 & 4 & 85 & 9 & 2 & 0 & 0 & 15 & 5 & 70 & 0 & 5 & 5 \\
\hline & GFr 10 & 5 & 75 & 8 & 5 & 5 & 2 & 15 & 5 & 70 & 0 & 5 & 5 \\
\hline & GFr 19 & 6 & 78 & 11 & 2 & 0 & 3 & 25 & 5 & 50 & 0 & 15 & 5 \\
\hline & GFr 23 & 5 & 83 & 4 & 4 & 2 & 2 & 20 & 5 & 65 & 0 & 5 & 5 \\
\hline & GFr 31 & 10 & 76 & 8 & 4 & 2 & 0 & 50 & 5 & 10 & 0 & 30 & 5 \\
\hline & GFr 33 & 8 & 79 & 5 & 4 & 2 & 2 & 30 & 10 & 30 & 0 & 20 & 10 \\
\hline & GFr 34 & 4 & 86 & 7 & 3 & 0 & 0 & 45 & 15 & 15 & 0 & 15 & 10 \\
\hline & GFr 35 & 9 & 79 & 9 & 2 & 0 & 1 & 35 & 10 & 40 & 0 & 10 & 5 \\
\hline & GFr 48 & 3 & 83 & 9 & 4 & 0 & 1 & 20 & 5 & 60 & 0 & 10 & 5 \\
\hline & GFr 63 & 10 & 74 & 8 & 7 & 0 & 1 & 30 & 5 & 50 & 0 & 10 & 5 \\
\hline & GFr 91 & 8 & 74 & 13 & 4 & 0 & 1 & 25 & 10 & 50 & 0 & 10 & 5 \\
\hline & GFr 129 & 13 & 75 & 8 & 3 & 0 & 1 & 35 & 10 & 25 & 5 & 20 & 5 \\
\hline & GFr 185 & 7 & 78 & 12 & 3 & 0 & 0 & 30 & 10 & 30 & 5 & 20 & 5 \\
\hline & GFr 187 & 20 & 68 & 6 & 4 & 0 & 2 & 30 & 15 & 5 & 10 & 30 & 10 \\
\hline & GFr 282 & 9 & 82 & 7 & 2 & 0 & 0 & 30 & 5 & 25 & 0 & 20 & 20 \\
\hline & GFr 309 & 6 & 79 & 13 & 2 & 0 & 0 & 35 & 0 & 25 & 10 & 15 & 15 \\
\hline & GFr 310 & 14 & 75 & 8 & 3 & 0 & 0 & 45 & 0 & 10 & 10 & 35 & 0 \\
\hline & GFr 346b & 2 & 88 & 7 & 3 & 0 & 0 & 60 & 0 & 40 & 0 & 0 & 0 \\
\hline & GFr 360 & 5 & 84 & 8 & 3 & 0 & 0 & 35 & 15 & 15 & 0 & 5 & 30 \\
\hline & GFr 385 & 5 & 88 & 4 & 3 & 0 & 0 & 35 & 0 & 30 & 5 & 20 & 10 \\
\hline & GFr 398 & 9 & 77 & 8 & 6 & 0 & 0 & 25 & 20 & 25 & 5 & 10 & 15 \\
\hline \multirow{11}{*}{ 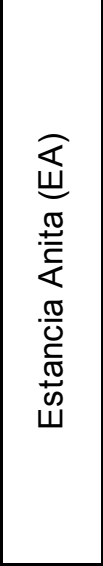 } & Ea-A 2 & 12 & 72 & 10 & 5 & 0 & 1 & 50 & 0 & 25 & 0 & 25 & 0 \\
\hline & Ea-A 37 & 4 & 89 & 6 & 1 & 0 & 0 & 30 & 0 & 45 & 0 & 25 & 0 \\
\hline & Ea-A 44 & 6 & 73 & 13 & 8 & 0 & 0 & 40 & 10 & 35 & 0 & 10 & 5 \\
\hline & Ea-A 81 & 5 & 82 & 10 & 3 & 0 & 0 & 30 & 10 & 50 & 0 & 10 & 0 \\
\hline & Ea-A 87 & 9 & 70 & 15 & 6 & 0 & 0 & 60 & 5 & 10 & 0 & 25 & 0 \\
\hline & Ea-A 96 & 23 & 66 & 8 & 3 & 0 & 0 & 35 & 0 & 5 & 0 & 60 & 0 \\
\hline & Ea-A 98 & 6 & 74 & 15 & 5 & 0 & 0 & 25 & 15 & 35 & 0 & 15 & 10 \\
\hline & Ea-A 110 & 5 & 72 & 15 & 6 & 0 & 2 & 30 & 20 & 30 & 0 & 10 & 10 \\
\hline & Ea-A 118 & 4 & 83 & 10 & 3 & 0 & 0 & 40 & 10 & 15 & 0 & 25 & 10 \\
\hline & Ea-A 130 & 4 & 82 & 9 & 4 & 0 & 1 & 40 & 10 & 20 & 5 & 15 & 10 \\
\hline & Ea-A 147 & 3 & 79 & 15 & 3 & 0 & 0 & 60 & 0 & 5 & 5 & 30 & 0 \\
\hline
\end{tabular}




\begin{tabular}{|c|c|c|c|c|c|c|c|c|c|c|c|c|c|}
\hline \multicolumn{2}{|r|}{$\mathrm{DRX}$} & \multicolumn{6}{|c|}{ Roca Total } & \multicolumn{6}{|c|}{ Arcillas } \\
\hline Perfil & Muestra & $\%$ Arc & $\% Q z$ & $\% \mathrm{Pg}$ & $\% \mathrm{Fk}$ & $\% \mathrm{Ca}$ & $\% \mathrm{D}$ & $\%$ & $\% \mathrm{Cl}$ & $\% \mathrm{~K}$ & $\% \mathrm{Sm}$ & $\% \mathrm{l} / \mathrm{Sm}$ & $\% \mathrm{Cl} / \mathrm{Sm}$ \\
\hline \multirow{5}{*}{ 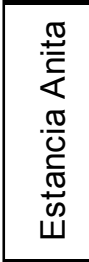 } & Ea-A 149d & 2 & 88 & 6 & 4 & 0 & 0 & 60 & 0 & 10 & 0 & 30 & 0 \\
\hline & Ea-A 157a & 7 & 84 & 6 & 3 & 0 & 0 & 40 & 20 & 5 & 0 & 20 & 15 \\
\hline & Ea-A 157d & 30 & 50 & 6 & 2 & 11 & 1 & 35 & 0 & 10 & 20 & 35 & 0 \\
\hline & Ea-A 175 & 15 & 77 & 5 & 3 & 0 & 0 & 35 & 0 & 5 & 10 & 35 & 15 \\
\hline & Ea-A 178 & 5 & 88 & 6 & 1 & 0 & 0 & 35 & 0 & 50 & 0 & 15 & 5 \\
\hline \multirow{14}{*}{ 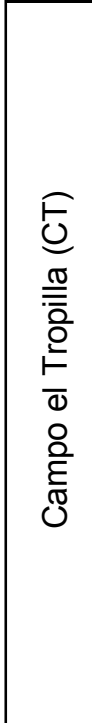 } & CeT-3 & 5 & 70 & 5 & 5 & 15 & 0 & 15 & 5 & 40 & 0 & 35 & 5 \\
\hline & CeT-21 & 10 & 30 & 10 & 5 & 45 & 0 & 30 & 5 & 25 & 5 & 25 & 5 \\
\hline & СeT-60 & 5 & 80 & 10 & 5 & 0 & 0 & 25 & 5 & 5 & 0 & 45 & 20 \\
\hline & СeT-85 & 2 & 88 & 8 & 2 & 0 & 0 & 10 & 0 & 0 & 0 & 90 & 0 \\
\hline & CeT-102 & 2 & 80 & 15 & 3 & 0 & 0 & 20 & 10 & 10 & 0 & 50 & 10 \\
\hline & CeT-105 & 3 & 84 & 10 & 3 & 0 & 0 & 25 & 5 & 5 & 0 & 60 & 5 \\
\hline & CeT-108 & 2 & 89 & 6 & 3 & 0 & 0 & 15 & 0 & 5 & 20 & 40 & 20 \\
\hline & СeT-128 & 3 & 92 & 4 & 1 & 0 & 0 & 20 & 0 & 10 & 0 & 65 & 5 \\
\hline & CeT-131 & 24 & 67 & 5 & 4 & 0 & 0 & 5 & 0 & 10 & 20 & 65 & 0 \\
\hline & CeT-143 & 6 & 75 & 14 & 5 & 0 & 0 & 50 & 0 & 5 & 0 & 45 & 0 \\
\hline & CeT-150 & 18 & 71 & 7 & 4 & 0 & 0 & 20 & 0 & 5 & 0 & 75 & 0 \\
\hline & СeT-156 & 5 & 76 & 9 & 10 & 0 & 0 & 20 & 0 & 5 & 0 & 60 & 15 \\
\hline & CeT-159 & 4 & 84 & 9 & 3 & 0 & 0 & 15 & 10 & 30 & 0 & 35 & 10 \\
\hline & CeT-170 & 4 & 82 & 11 & 3 & 0 & 0 & 15 & 5 & 25 & 5 & 30 & 25 \\
\hline \multirow{18}{*}{$\begin{array}{l}\widehat{0} \\
0 \\
0 \\
\Phi \\
\frac{\pi}{\pi} \\
\frac{\pi}{\pi} \\
0 \\
0 \\
0 \\
\frac{0}{0} \\
0\end{array}$} & CC-1 & 5 & 82 & 7 & 5 & 1 & 0 & 10 & 5 & 85 & 0 & 0 & 0 \\
\hline & $\mathrm{CC}-2$ & 4 & 87 & 7 & 2 & 0 & 0 & 5 & 5 & 90 & 0 & 0 & 0 \\
\hline & CC-3 & 5 & 86 & 7 & 2 & 0 & 0 & 10 & 5 & 85 & 0 & 0 & 0 \\
\hline & CC-4 & 7 & 80 & 8 & 4 & 0 & 1 & 15 & 10 & 60 & 0 & 15 & 0 \\
\hline & CC-5 & 5 & 84 & 6 & 3 & 1 & 1 & 10 & 5 & 85 & 0 & 0 & 0 \\
\hline & CC-6a & 2 & 89 & 5 & 3 & 1 & 0 & 15 & 5 & 75 & 0 & 5 & 0 \\
\hline & CC-7 & 4 & 84 & 8 & 4 & 0 & 0 & 30 & 5 & 60 & 0 & 5 & 0 \\
\hline & CC-8 & 1 & 94 & 3 & 2 & 0 & 0 & 10 & 0 & 85 & 0 & 5 & 0 \\
\hline & CC-9 & 5 & 85 & 5 & 5 & 0 & 0 & 5 & 0 & 85 & 0 & 10 & 0 \\
\hline & CC-10 & 1 & 93 & 3 & 2 & 1 & 0 & 5 & 0 & 95 & 0 & 0 & 0 \\
\hline & CC-11 & 4 & 84 & 4 & 2 & 6 & 0 & 5 & 0 & 90 & 0 & 5 & 0 \\
\hline & CC-Ca 2 & 16 & 75 & 5 & 2 & 2 & 0 & 25 & 0 & 20 & 20 & 35 & 0 \\
\hline & CC-Ca 13 & 27 & 62 & 6 & 5 & 0 & 0 & 15 & 0 & 20 & 30 & 35 & 0 \\
\hline & CC-Ca 25 & 9 & 85 & 2 & 2 & 2 & 0 & 40 & 0 & 30 & 10 & 20 & 0 \\
\hline & CC-Ca 30 & 1 & 95 & 3 & 1 & 0 & 0 & 0 & 0 & 90 & 0 & 10 & 0 \\
\hline & CC-Ca 50 & 16 & 76 & 2 & 2 & 2 & 0 & 30 & 0 & 30 & 20 & 20 & 0 \\
\hline & CC-Ca 58 & 38 & 56 & 4 & 2 & 0 & 0 & 15 & 0 & 10 & 60 & 20 & 0 \\
\hline & CC-Ca 64 & 31 & 63 & 2 & 2 & 2 & 0 & 20 & 0 & 15 & 30 & 35 & 0 \\
\hline
\end{tabular}

